Mínimos-quadrados e aproximação de superfície de pontos: novas perspectivas e aplicações 

Data de Depósito:

Assinatura:

\title{
Mínimos-quadrados e aproximação de superfície de pontos: novas perspectivas e aplicações
}

\author{
João Paulo Gois
}

Orientador: Prof. Dr. Antonio Castelo Filho

Tese apresentada ao Instituto de Ciências Matemáticas e de Computação - ICMC-USP, como parte dos requisitos para obtenção do título de Doutor em Ciências - Ciências de Computação e Matemática Computacional.

USP - São Carlos

Março de 2008

Esta tese foi financiada pela FAPESP (proc. $\mathrm{n}^{\circ}$ 04/10947-6) 

Aos meus pais e a minha avó Cida 



\section{Agradecimentos}

À FAPESP, ao DAAD, à Universidade de Stuttgart e ao ICMC-USP. Ao professor Castelo, amigo e orientador.

Aos professores Luis Gustavo Nonato, Thomas Ertl e Marcelo Siqueira.

Ao professor Gustavo Buscaglia, pelo imenso apoio no final dessa jornada e pela oportunidade de realização de um pós-doutorado.

Aos demais professores e aos amigos do LCAD.

Aos amigos e co-autores de trabalhos: Valdecir, Tiago, Anderson e Eduardo.

Aos amigos do Vis-Group, Universidade de Stuttgart-Alemanha.

Aos alunos e professores do IMPA, PUC-Rio e UFRGS, pelas discussões enriquecedoras.

Aos meus pais, irmãs, sobrinhos e minha avó Cida.

À minha noiva Aline e à família dela.

À Deus, acima de tudo. 



\section{Resumo}

Métodos de representação de superfícies a partir de pontos não-organizados se mantêm como uma das principais vertentes científicas que aquecem o estado-da-arte em Computação Gráfica e, significativamente, estão sendo reconhecidos como uma ferramenta interessante para definição de interfaces móveis no contexto de simulações numéricas de escoamento de fluidos. Não é difícil encontrar motivos para tais fatos: pelo lado da computação gráfica, por exemplo, a manipulação de conjuntos de pontos massivos com geometrias complexas e sujeitos a informações ruidosas ainda abre margem para novas metodologias. Já no âmbito da mecânica dos fluidos, onde os dados não são originados de scanners tridimensionais, mas sim de interfaces entre fluidos imiscíveis, mecanismos de representação de superfícies a partir de pontos nãoorganizados podem apresentar características computacionais e propriedades geométricas que os tornem atrativos para aplicações em simulação de fenômenos físicos.

O objetivo principal dessa tese de doutorado foi, portanto, o desenvolvimento de técnicas de representação de superfícies a partir de pontos não-organizados, que sejam capazes de suprir restrições de importantes trabalhos prévios. Nesse sentido, primeiramente focalizamos a elaboração de técnicas baseadas em formulações de mínimos-quadrados-móveis e de uma técnica robusta de partição da unidade implícita adaptativa em duas vias.

Além de mecanismos de representação de superfícies a partir de pontos nãoorganizados, também propusemos um método promissor para representação de interfaces em simulação numérica de escoamento de fluidos multifásicos. Para isso, embasamo-nos numa abordagem Lagrangeana (livre-de-malhas), fundamentada no método dos mínimos-quadrados-móveis algébricos e apresentamos diversos resultados numéricos, estudos de convergências e comparações que evidenciam o potencial dessa metodologia para simulações numéricas de fenômenos físicos.

Apesar de a contribuição principal deste trabalho ser o desenvolvimento de métodos para representação de superfícies a partir de pontos não-organizados, a experiência que adquirimos no desenvolvimento dessas técnicas nos conduziu à elaboração de mecanismos para representação de dados volumétricos não-organizados. Por conta disso, apresentamos dois mecanismos de representação a partir de dados volumétricos não-organizados com o intuito de serem aplicáveis a informações oriundas de malhas contendo células arbitrárias, isto é, propusemos a definição de um método de rendering unificado. 



\begin{abstract}
Surface reconstruction from unorganized points has been one of the most promising scientific research areas in Computer Graphics. In addition, it has been used successfully for the definition of fluid interface in numerical simulation of fluid flow. There are several reasons to that fact: for instance, considering Computer Graphics, we have the handling of out-of-core data from complicated geometries and subject to noisy information that brings out opportunities for the development of new techniques. Further, considering Numerical Fluid Mechanics, where the input data does not come from tridimensional scanners, but from fluid interfaces, schemes that define the surface from unorganized points can offer geometrical and computational properties useful to numerical fluid flow simulation.

The main goal of this project was the development of novel techniques for reconstructing surfaces from unorganized points with the capability to overcome the main drawbacks of important previous work. To that end, first we focused on the development of techniques based on moving-least-squares and on a robust twofold partition of unity Implicits.

Added to the development of surface reconstruction from unorganized points, we proposed a novel scheme for defining fluid flow interfaces. We approach a meshless Lagrangian based on algebraic moving-least-squares surfaces. In addition, we presented several numerical results, convergence tests and comparisons, which state the power of the method to numerical simulation of physical phenomena.

Although our main contributions were focused on surface reconstruction from points, we proposed methods to function reconstruction from unorganized volumetric data. Thus, we present two schemes to represent volumetric data from arbitrary meshes, i.e., a unified rendering scheme.
\end{abstract}





\section{CONTEÚDO}

Conteúdo

Lista de Figuras iii

Lista de Tabelas $\quad$ xii

1 Introdução 1

1.1 Definição do Problema . . . . . . . . . . . . . . . . . 1

1.2 Objetivos Alcançados . . . . . . . . . . . . . . . . 7

1.3 Organização da Tese . . . . . . . . . . . . . . . . . . 12

1.4 O Termo "Robustez" . . . . . . . . . . . . . . . . . . . . . . . . . 14

2 Contextualização $\quad 17$

2.1 Superfícies por Pontos Não-Organizados-Classificação . . . . . . . . . . . 17

2.2 Métodos de Esculpimento . . . . . . . . . . . . . . . . . 19

2.3 Métodos Incrementais . . . . . . . . . . . . . . . . . . . 21

2.4 Modelos Deformáveis . . . . . . . . . . . . . . . . . . . . . . 22

2.5 Métodos de Projeção de Pontos (Point Set Surfaces) . . . . . . . . . . . . . . 24

2.6 Métodos Implícitos . . . . . . . . . . . . . . . . . . . 36

3 Representação por Pontos Não-Organizados: Abordagens Preliminares $\quad 45$

3.1 Projeção de Pontos Guiada por Curvaturas . . . . . . . . . . . . . . . . . . 47

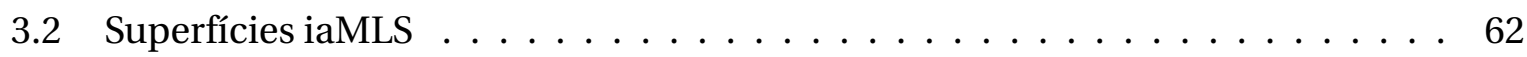

3.3 Conclusão . . . . . . . . . . . . . . . . . . . 77

4 Partição da Unidade Implícita em Duas Vias 79

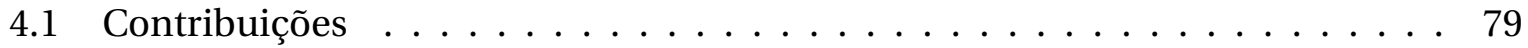

4.2 Extração de Iso-Superfícies . . . . . . . . . . . . . . . . . . . 83

4.3 Definições... . . . . . . . . . . . . . . . . . . . 84

4.4 Reconstrução Adaptativa em Duas Vias ．. . . . . . . . . . . . . . . . . . 90

4.5 Extensões do Método . . . . . . . . . . . . . . . . . . . . . . . 100

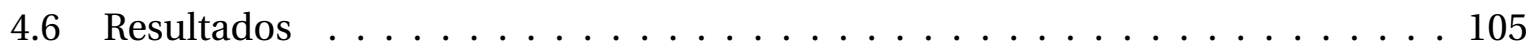

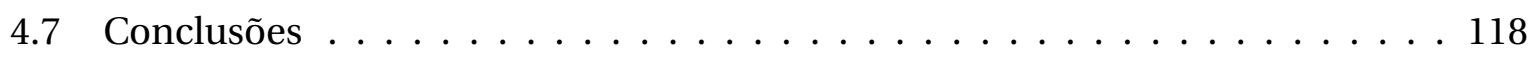


5 Acompanhamento de Fronteira com Superfície MLS 123

5.1 Contribuições . . . . . . . . . . . . . . . . . . . 123

5.2 Representações de Interfaces Móveis . . . . . . . . . . . . . . . . . . . . . 124

5.3 Superfícies AMLS Definidas Implicitamente . . . . . . . . . . . . . . . . 128

5.4 Superfícies AMLS Robustas . . . . . . . . . . . . . . . . . . . . . 146

5.5 Acompanhamento de Fronteiras com RAMLS . . . . . . . . . . . . . . . . . 153

5.6 Resultados Numéricos . . . . . . . . . . . . . . . . . . . 162

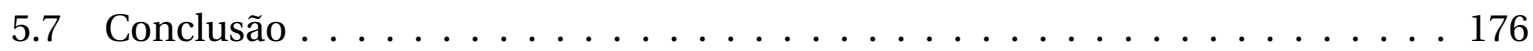

6 Representação de Dados Volumétricos Não-Organizados 181

6.1 Rendering de Dados Volumétricos . . . . . . . . . . . . . . . . . 181

6.2 Aproximação de Funções a partir de Dados Volumétricos . . . . . . . . . . . . . 185

6.3 Aproximação Robusta para Dados Volumétricos . . . . . . . . . . . . . . . 187

6.4 Reconstrução de Dados Volumétricos por iaMLS Anisotrópico . . . . . . . . . . 201

6.5 Conclusão . . . . . . . . . . . . . . . . . . . . . . . . . . 209

7 Conclusão $\quad \mathbf{2 1 5}$

7.1 Desafios Futuros . . . . . . . . . . . . . . . . . 217

$\begin{array}{ll}\text { Referências Bibliográficas } & 223\end{array}$ 


\section{LisTa DE Figuras}

1.1 Exemplo de objeto com características afiadas: União de um cone com um blobby. As características afiadas são determinadas pelo ápice e base do cone e as duas curvas definidas pelas interseções do cone com o blobby. . . . . . . . . . .

1.2 Exemplo de scanners tridimensionais sendo utilizados na estátua de Davi de Michelangelo (a)-(b) e de Lucy (c): Projeto Michelangelo Digital da Universidade de Stanford $[133,132] \ldots \ldots \ldots \ldots \ldots$. . . . . . . . . . . . . . 3

1.3 Contra-exemplos da condição de reconstrução: exemplos de objetos que não são homeomorfos (esquerda) e de objetos que não são geometricamente semelhantes, apesar de serem topologicamente equivalentes (direita) . . . . . . . . . . .

1.4 Exemplo de simulação numérica de um escoamento de fluidos multifásicos do trabalho de Sousa et al. [194] . . . . . . . . . . . . . . . . . . . . . . .

1.5 Exemplo de simulação numérica de escoamento de um fluido com superfície

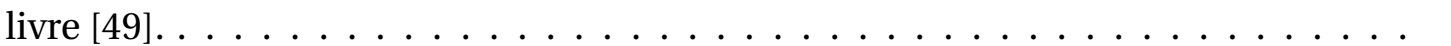

2.1 Triangulação de Delaunay de um conjunto de pontos da Enterprise (a), e o esculpimento da triangulação de Delaunay (b) com o intuito de obter a representação do objeto original. . . . . . . . . . . . . . . . . . . . . 19

2.2 Descrição do processo de estimativa das curvaturas da superfície e da malha, proposta por Huang e Menq [108]: Em (a) tem-se a malha original; em (b) a curva $d$ representa a aproximação da curvatura por mínimos-quadrados baseado nos pontos da vizinhança da aresta $e$, ao passo que $c$ define a estimativa da curvatura para a aresta $e$; em (c) o remalhamento local torna ambas aproximações das

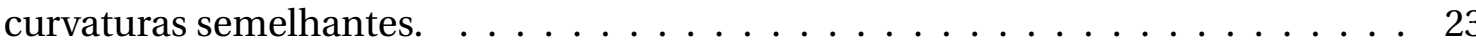

2.3 Resultado do pós-processamento proposto por Huang e Menq [108] em (b), aplicado à malha inicial em (a) . . . . . . . . . . . . . . . . . . . . . . . . 23

2.4 Alexa et al. ilustram o resultado esperado pela reamostragem de pontos dada pelo operador de projeção $[8] \ldots \ldots \ldots \ldots$. . . . . . . . . . . . . 26

2.5 (a) Situação inicial do esquema de projeção: dado $\mathbf{p}$ a ser projetado, devemos encontrar o plano (aproximadamente) tangente $H$ próximo a p. (b) Interpretação geométrica do ponto $\mathbf{q}=\mathbf{p}+t \mathbf{n} \ldots \ldots \ldots \ldots \ldots \ldots$

2.6 Diferentes valores de $\alpha_{1}$ e $\alpha_{2}$ para a Função-Peso 2.6: (a) $\alpha_{1}=1$ e $\alpha_{2}=2$, (b) $\alpha_{1}=1$ e $\alpha_{2}=10$, (c) $\alpha_{1}=5$ e $\alpha_{2}=4$ e (d) a função que utilizamos, com $\alpha_{1}=1$ e $\alpha_{2}=4$. . 
2.7 (a) Aproximação polinomial local. (b) A altura dos pontos $\mathbf{p}_{i}$ em relação a $H$. . . 30

2.8 Esquema de geração de pontos na superfície MLS, proposto por Amenta e Kil [16]. 32

2.9 Comparação entre a técnica de Alexa et al. [9] (esquerda) e a técnica de Fleishman et al. [80] (direita). A segunda abordagem é capaz de modelar características afiadas. . . . . . . . . . . . . . . . . . . . . . . 34

2.10 Exemplo apresentado por Lipman et al. [138], que exemplifica a projeção de pontos na superfície pelo LOP. . . . . . . . . . . . . . . . 36

2.11 Exemplos de densidade variada de pontos com que o trabalho de Tobor et al. [205] é capaz de lidar eficientemente. . . . . . . . . . . . . . . . . . . . . . .

3.1 Resultado gerado pelo algoritmo de traçado-de-raios para nuvens de pontos, que implementamos na GPU $[204] . \ldots \ldots \ldots \ldots$. . . . . . . . . . 46

3.2 Estimando as curvaturas direcionais sobre o plano tangente aproximado em p. . . 52

3.3 Resultados do método de Huang e Menq [108]: uma pequena perturbação na posição do ponto pode produzir consideravelmente diferentes curvaturas e direções (representadas pelas setas) . . . . . . . . . . . . . . . . . . . 54

3.4 Exemplos de gráficos da função do tipo "M". Da esquerda para a direita: $\Delta=2 \mathrm{e}$ $\varsigma=1, \Delta=1$ e $\varsigma=1$, e $\Delta=1$ e $\varsigma=2 \ldots \ldots \ldots \ldots \ldots \ldots$

3.5 Ilustração do esquema de projeção baseado nas direções e curvaturas principais. 57

3.6 Esquema bidimensional de interseção entre um raio e a superfície. Os pontos em azul representam a interseção do gráfico com o raio: (a) situação inicial - nuvem de pontos com as esferas cobrindo toda a superfície e um raio que intersecta a primeira esfera definindo a primeira estimativa de interseção da superfície; (b) calcula-se a aproximação polinomial local e projeta-se o ponto de interseção no gráfico da aproximação local. Em seguida, verifica-se se o erro é maior que um $\epsilon$. Em caso afirmativo, caminha-se para a próxima esfera e repete-se o processo(c); (d) novamente calcula-se a aproximação polinomial e verifica-se se a distância do ponto projetado ao ponto sobre o gráfico da função é menor que um $\epsilon$ e, nesse caso, a interseção é definida pelo ponto em cinza. . . . . . . . . . . . . . .

3.7 Aproximações polinomiais obtidas pelas direções e curvaturas (da esquerda para a direita) sem pesos, com a Gaussiana e com a função do tipo "M". Note que ambas a não utilização de pesos e a função Gaussiana produzem resultados semelhantes, porém incorretos. . . . . . . . . . . . . . . 
3.8 Imagem de uma superfície aproximada para o conjunto Rocker Arm (40 mil pontos), obtida pelo método de traçado-de-raios de Adamson e Alexa [2] (esquerda) e o método guiado por curvaturas (direita): é possível notar qualitativamente que ambos resultados são semelhantes, porém nossa abordagem utiliza bases de polinônios reduzidos. . . . . . . . . . . . . . . . . . . 60

3.9 Rendering pelo método guiado por curvaturas: Stanford Bunny (30 mil pontos). . 61

3.10 Rendering pelo método guiado por curvaturas: Cavalo (45 mil pontos). . . . . . . 62

3.11 Rendering pelo método guiado por curvaturas: Formiga (660 mil pontos). . . . . . 63

3.12 Rendering pelo método guiado por curvaturas: Stanford Dragon (500 mil pontos) - Proposta de capa dos anais do Sibgrapi-2006 [191]. . . . . . . . . . . . . . . 64

3.13 Exemplo de uma superfície iaMLS (Dragão de Stanford) . . . . . . . . . . . . . 65

3.14 Gráficos de valores das funções para um conjunto de pontos regularmente espaçados. Da esquerda para a direita de cima para baixo: iaMLS após 5 iterações, iaMLS após 20 iterações, função de Adamson e Alexa [3] e de Kolluri [119]. As curvas brancas mostram o nível zero da função enquanto o mapa de cores define os demais valores da função, variando do vermelho (valores baixos da função) para o azul (valores altos da função) . . . . . . . . . . . . . . . . . 72

3.15 Gráficos de valores das funções para um conjunto de pontos irregularmente espaçados. Da esquerda para a direita e de cima para baixo: iaMLS após 5 iterações, iaMLS após 20 iterações, função de Adamson e Alexa [3] e de Kolluri [3]. As curvas brancas mostram o nível zero da função, enquanto o mapa de cores define os demais valores da função, variando do vermelho (valores baixos da função) para o azul (valores altos da função). . . . . . . . . . . . . . . . . 73

3.16 Imagens das superfícies, obtidas com o método de Adamson e Alexa (topo), Kolluri (meio) e iaMLS (base). . . . . . . . . . . . . . . . . . . . . .

3.17 Efeito do número de iterações e do parâmetro $\epsilon$ na aproximação. Da esquerda para a direita: 3,4 e 5 iterações. De cima para baixo: $\epsilon=0.4, \epsilon=0.8, \epsilon=1.22$, $\epsilon=2.0$. É possível notar que, quando o número de iterações aumenta, maiores detalhes do objeto são obtidos. . . . . . . . . . . . . . . . . .

4.1 Reconstrução da estátua de Lucy, de Stanford (16 milhões de pontos), inserida em um cenário tridimensional estilo barroco (modelado com o Blender [39]). Imagem da contracapa dos anais do Sibgrapi-2007 [192] . . . . . . . . . . . . . 
4.2 Adaptatividade em duas vias: A estátua da Lucy de Stanford de 16 milhões de pontos e com malha de 7 milhões de triângulos. À esquerda, a escala de cores representa o grau máximo do polinômio das aproximações locais na superfície. Em todo o domínio, o número de polinômios corresponde a: 946601, 144956, 38236 e 26862 de grau 1 a 4, respectivamente. À direita apresentamos a profundidade da triangulação $J_{1}^{a}$, que na superfície variou de nível 6 a 10 . . . . . .

4.3 Ilustração bidimensional do domínio $\Omega$ sendo coberto por um conjunto de círculos que definem o suporte das funções-peso $\omega_{i}$. Também nessa figura, apresentamos o comportamento da octree restrita da triangulação $J_{1}^{a}$ durante a aproximação da função. . . . . . . . . . . . . . . . . . . . 8

4.4 As curvas em preto, com extremos representados pelos pontos pretos, representam as aproximações locais que definem a aproximação global (em amarelo na Figura 4.3 ) pela PUI. . . . . . . . . . . . . . . . . .

4.5 A triangulação $J_{1}^{a}$ : à esquerda, um exemplo bidimensional da triangulação adaptativa e, à direita, exemplos de operações de pivotamento. . . . . . . . . . . . .

4.6 Ilustração do critério de recobrimento do domínio: aumentar o grau do polinômio arbitrariamente pode causar soluções locais errôneas e, portanto, a função global pode ser comprometida: na esquerda, apesar da solução ser mais precisa para o conjunto de pontos, a oscilação no polinômio local faz com que sinais no bloco da $J_{1}^{a}$ sejam mal calculados. Já na direita, a aproximação não é tão precisa quanto na esquerda, porém os sinais da função são adequadamente calculados. . 92

4.7 Exemplo de situação em que a taxa $\tau$ pode alcançar seu valor máximo: a projeção da esfera no plano gera um círculo inscrito no bounding-box dos pontos projetados no plano. . . . . . . . . . . . . . . . . . . 94

4.8 Com a utilização da média dos vetores normais em vez de uma aproximação por mínimos-quadrados, podemos evitar problemas de mal-definição da aproximação local para regiões com pouco ou nenhum ponto: em (a), temos uma situação em que o plano é obtido por mínimos-quadrados, cuja superfície é localmente aproximada de forma equivocada, dividindo-se em duas regiões. Tal fato pode comprometer a função final. Já em (b), temos um plano obtido pela média das normais e com origem no centro de massa dos pontos. Nesse caso, detalhes podem ser perdidos, mas isso não compromete a aproximação global. . . . . . . .

4.9 (a) Determinação de dois ramos da superfície: (b) o método de Ohtake opta em aproximar uma quádrica completa, ao passo que (c) nosso método, simplesmente divide o bloco da triangulação $J_{1}^{a}$ e realiza uma aproximação em cada bloco. 97

4.10 Pseudo-código do algoritmo de partição da unidade implícita adaptativo em duas vias. . . . . . . . . . . . . . . . . . . . . . . . . . 99 
4.11 Interface desenvolvida que permite edição da função: em (a), os blocos vermelhos representam os blocos da triangulação $J_{1}^{a}$, selecionados para realizar a edição da função; em (b), pode-se notar alteração no objeto pela edição da função. 104

4.12 Ilustração da deformação do bloco da triangulação $J_{1}^{a}$ : a técnica de deslocamento de vértice é capaz de criar elementos com tamanhos mais uniformes. Os círculos em cor rosa representam as regiões em que o deslocamento dos vértices é permitido. . . . . . . . . . . . . . . . . 106

4.13 Edição da Função: (a)-(b) apresentam o método de Ohtake et al. com seus parâmetros padrões e com os sugeridos por nós, respectivamente; (c), a reconstrução usando nosso método sem o critério de recobrimento do domínio; (d), a reconstrução utilizando o critério de recobrimento do domínio; (e), a seleção de imperfeições pelo usuário; (f), a função editada elimina as imperfeições. . . . . . 107

4.14 Comparações realizadas por Kazhdan et al. [115]. (a) Power Crust [14], (b) Robust Cocone [62], (c) Fast RBF [44], (d) PUI [158], (e) Método de Hoppe et al. [107], (f) Volumetric Range Image Processing - VRIP [56], (g) FFT [114] e (h) reconstrução de superfícies pela Equação de Poisson [115] . . . . . . . . . . . . . . . . . . . 108

4.15 Melhoramento de um modelo por edição da função: (a) modelo sem aproximações de alto grau, (b) blocos selecionados para edição da função e (c) resultado final. . . . . . . . . . . . . . . . . . . . . . . . 110

4.16 Ilustração da detecção de características afiadas de nossa técnica (modelo do Fank Disk): em amarelo, faces detectadas como sharp edges; e, em vermelho, como sharp corners. . . . . . . . . . . . . . . . . . . . . . . 111

4.17 Capacidade de modelar características afiadas (método de Ohtake et al.): parte frontal do modelo Filigree (514 mil pontos) . . . . . . . . . . . . . . . . . . . 112

4.18 Capacidade de modelar características afiadas (nosso método): parte frontal do modelo Filigree (514 mil pontos). . . . . . . . . . . . . . . . . . 113

4.19 Capacidade de modelar características afiadas (método de Ohtake et al.): parte traseira do modelo Filigree (514 mil pontos). . . . . . . . . . . . . . . . . . . . 114

4.20 Capacidade de modelar características afiadas (nosso método): parte traseira do modelo Filigree (514 mil pontos) . . . . . . . . . . . . . . . . . . 115

4.21 Comparação da malha original produzida pela triangulação $J_{1}^{a}$ (esquerda) com a malha obtida pelo deslocamento de vértices (direita) . . . . . . . . . . . . 116

4.22 Comparação da malha produzida pela triangulação $J_{1}^{a}$ (topo) sem o processo de deslocamento de vértices, contra a malha em que se aplica tal procedimento (base).117

4.23 Reconstrução do Dragão Chinês, à esquerda, sem o melhoramento de malha e à direita, com o melhoramento de malha: É possível notar, apesar da melhoria da malha (Figura 4.22), a geometria dos modelos permanecem semelhantes. . . . . . 118 
4.24 Comparação da malha produzida pela triangulação $J_{1}^{a}$ (topo) sem o processo de deslocamento de vértices contra a malha em que se aplica tal procedimento (base).119

4.25 Uma operação de diferença entre dois modelos encontrada no artigo de Ohtake et al. [158]. Destacamos algumas regiões onde a superfície está mal definida. . . . 120

4.26 Uma operação de CSG (diferença) envolvendo o modelo Netuno e um cilindro. . . 121

5.1 Simulação de ondas utilizando a abordagem LS: a topologia e a geometria são tratadas por esta abordagem de forma natural. . . . . . . . . . . . . . . . 126

5.2 Exemplos das funções implícitas $F$ por AMLS (azul) e exemplos da superfície aproximada $\mathscr{S}$ (preto) do conjunto de pontos (quadrados pretos). (a) Pontos perturbados aleatoriamente em uma reta; (b) pontos perturbados aleatoriamente em uma quina. . . . . . . . . . . . . . . . . . . . . . . . . . 134

5.3 O conjunto zero gerado por $F$ (laranja) é o mesmo gerado por $-F \ldots \ldots$. . . . . 135

5.4 Em (a) apresentamos o conjunto de pontos $\mathscr{P}_{h}$, correspondente a $h=1.5$ no caso da elipse, e a curva AMLS $\mathscr{S}_{h}$ baseada em círculos. Em (b), apresentamos os gráficos de convergência de $d\left(\Sigma, \mathscr{S}_{h}\right)$ (denotado por erro geométrico), de $E_{N}\left(\Sigma, \mathscr{S}_{h}\right)$ (denotado por erro das normais) e $E_{C}\left(\Sigma, \mathscr{S}_{h}\right)$ (denotado por erro de

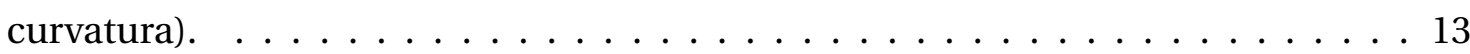

5.5 Em (a), apresentamos o conjunto de pontos $\mathscr{P}_{h}$, correspondente a $h=1.5$ no caso da elipse e a curva AMLS $\mathscr{S}_{h}$ baseada em retas. Em (b), apresentamos os gráficos de $d\left(\Sigma, \mathscr{S}_{h}\right)$ (denotado por erro geométrico) e $E_{N}\left(\Sigma, \mathscr{S}_{h}\right)$ (denotado por erro das normais). . . . . . . . . . . . . . . . . . . . . . 141

5.6 Em (a), temos o elipsóide gerado pela superfície AMLS, baseada em esferas para um conjunto de 265 pontos a uma distância média de $h=0.75$. Em (b), temos os gráficos de convergência de $d\left(\Sigma, \mathscr{S}_{h}\right)$ (denotado por erro geométrico), de $E_{N}\left(\Sigma, \mathscr{S}_{h}\right)$ (denotado por erro das normais) e de $E_{C}\left(\Sigma, \mathscr{S}_{h}\right)$ (denotado por erro de curvatura) . . . . . . . . . . . . . . . . . . . . . . . . . . . . 144

5.7 Em (a), temos o elipsóide gerado pela superfície AMLS, baseada em planos para um conjunto de 265 pontos a uma distância média de $h=0.75$. Em (b), temos os gráficos de convergência de $d\left(\Sigma, \mathscr{S}_{h}\right)$ (denotado por erro geométrico) e de $E_{N}\left(\Sigma, \mathscr{S}_{h}\right)$ (denotado por erro das normais). . . . . . . . . . . . . . 145

5.8 Aproximações do caso 3/4-esfera com a superfície AMLS baseada em conjuntos com (a) 1030, (b) 2031 e (c) 4748 pontos, respectivamente. Os artefatos no topo mostram que a função implícita falhou no momento de reconstruir, mesmo para conjuntos de dados refinados. . . . . . . . . . . . . . . . . . . . . . . . 147 
5.9 Aproximação da elipse pela curva RAMLS: (a) Conjunto de pontos $\mathscr{P}_{h}$ correspondente a $h=1.5$ junto com a curva resultante pelo RAMLS baseado em círculos; (b) Gráficos de convergência de $d\left(\Sigma, \mathscr{S}_{h}\right)$ (denotado por erro geométrico), $E_{N}\left(\Sigma, \mathscr{S}_{h}\right)$ (denotado por erro das normais), e $E_{C}\left(\Sigma, \mathscr{S}_{h}\right)$ (denotado por erro de curvatura). 152

5.10 Aproximação do elipsóide 3D com a superfície RAMLS: (a) conjunto de pontos $\mathscr{P}_{h}$ correspondente a $h=0.75$, junto com a superfície RAMLS baseada em esferas; (b) gráficos de convergência de $d\left(\Sigma, \mathscr{S}_{h}\right)$ (denotado por erro geométrico), de $E_{N}\left(\Sigma, \mathscr{S}_{h}\right)$ (denotado por erro das normais), e de $E_{C}\left(\Sigma, \mathscr{S}_{h}\right)$ (denotado por erro de curvatura) . . . . . . . . . . . . . . . . . . . . . . . 154

5.11 Exemplo do comportamento da curvatura exata (a) e dada pela aproximação por esferas (b) para o conjunto de pontos com $h=1 / 128$. . . . . . . . . . . . . . 155

5.12 Aproximação do caso 3/4-esfera com a superfície RAMLS em conjuntos com (a) 1030, (b) 2031 e (c) 4748 pontos, respectivamente. . . . . . . . . . . . . . . . . . 155

5.13 Reconstrução RAMLS de pontos perturbados a partir de (a), uma reta, e a partir de (b), uma quina: comparação com a Figura 5.2. . . . . . . . . . . . . . . . . 156

5.14 Conjunto de raios $\left(R_{1 h}, R_{2 h}\right)$ que quando intersectados com a superfície atualizada RAMLS $\mathscr{S}_{h}(t+\Delta t)$, definem o novo conjunto de pontos $\mathscr{Q}_{h}(t+\Delta t)$. . . . 160

5.15 Interseções raio-esferas: observemos que três interseções produzem o mesmo zero sobre a superfície. Nesse caso, consideramos apenas a busca pelo zero da função na primeira esfera. . . . . . . . . . . . . . . . . . . . . . . . . . 162

5.16 Pontos muito próximos: quando pontos (amarelo) são gerados por interseções de raios (verde) com a superfície a uma distância menor $0.5 h$, consideramos apenas um deles.

5.17 Resultados do método PLS [72]: em (a), temos a distribuição de pontos próximos ao contorno, e em (b), a solução obtida (em preto) após uma volta completa. . . . 166

5.18 Rotação do disco de Zalesak: resultados após uma volta: (a) modelo original, (b) $\mathrm{h}=1 / 64$, (c) $h=1 / 128$, (d) $h=1 / 256$, e (e) $h=1 / 512 \ldots \ldots \ldots \ldots 6$

5.19 Rotação da esfera de Zalesak com $h=1 / 256$ (19000 pontos em média) e nos passos de tempo $t=0,79,157,236,314,393,471,550$ e 628 unidades de tempo (da esquerda para a direita e de cima para baixo). . . . . . . . . . . . . 168

5.20 Solução exata (preto) e RAMLS (azul), $h=1 / 256$ (esquerda) e $h=1 / 512$ (direita) com $\Delta t=0.01$, em que (a) e (b) estão em 1, (c) e (d) estão em 3, e (e) e (f) estão em 5 unidades de tempo, respectivamente. . . . . . . . . . . . . . . 170

5.21 Solução exata (preto) e AMLS utilizando aproximações por retas (azul): é possível notarmos que, ao contrário do método baseado em círculos, o baseado em retas não é capaz de lidar naturalmente com duas regiões próximas da curva. Veja que a "cauda da interface" foi mal calculada, comprometendo a qualidade da interface.171 
5.22 Grade computacional com espaçamento 1/128 e $t=3$ unidades de tempo: em (a), temos o método LSL [104], com 1160 partículas no seu estado inicial e, em (b), [72] temos o PLS com 15040 partículas em seu estado inicial, no qual, em vermelho, temos a solução por LS, em verde, a solução exata, e em azul, a solução por PLS. No primeiro caso, o número de partículas necessárias em $t=3$ foi de 55914

5.23 Solução exata (preto) e as obtidas numericamente a partir de grades computacionais com resoluções $h=1 / 64$ (verde), $h=1 / 128$ (laranja), $h=1 / 256$, (azul) $h=1 / 512$ (rosa). . . . . . . . . . . . . . . . . . . . . . 172

5.24 Evolução do número de pontos em $\mathscr{Q}_{h}(t)$ ao longo dos passos no tempo, na simulação do único vórtice modulado no tempo. . . . . . . . . . . . . . . . . . . 173

5.25 Simulação do único vórtice modulado no tempo: número de partículas geradas pelo LSL [104] no tempo para uma grade computacional com espaçamento 1/128. 173

5.26 Em (a) e (b), temos os resultados de LSL [104] para grades computacionais com espaçamento de 1/128 e 1/1000 para diversas configurações do método; em (c), apresentamos soluções por LS [72] para grades computacionais com espaçamento de 1/64 (desapareceu), 1/128 (vermelho) e 1/256 (azul),e a solução exata (preto); em (d), apresentamos os resultados para o PLS (as cores para as soluções são as mesmas definidas na Figura 5.22-(b)), em que o número de partículas no estado inicial corresponde a 3376, 15040 e 59072 para as grades computacionais com espaçamentos $1 / 64,1 / 128$ e 1/256, respectivamente. . . . . 174

5.27 Torção tridimensional ( $h=1 / 512)$ obtida numericamente em diferentes instantes: o número de pontos em cada um dos conjuntos era (da esquerda para direita, de cima para baixo): 65000, 69314, 109728, 187571, 277021, 193238, 114898,

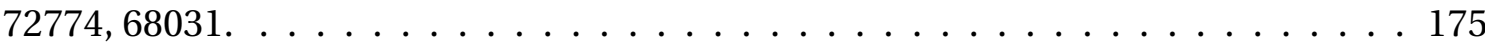

5.28 A interface à direita da parte de baixo na Figura 5.27 em outro ponto de vista. Pode ser visto um pequeno artefato na solução. . . . . . . . . . . . . . . . . . . . . 176

5.29 Torção 3D do método LSL [104] e PLS [72]: temos, em (a) LSL, grade computacional com espaçamento de 1/100 (número de partículas mínimo é de 14054 e máximo de 30739); em (b), a solução pelo LS (espaçamento da grade 1/100), e, em (c), a solução pelo PLS, também com espaçamento da grade 1/100. . . . . . . . 177

6.1 Wireframe do Space Shuttle Launch Vehicle definido por uma malha multibloco. A aproximação dos dados volumétricos armazenados em malhas desse tipo não é trivial para a tarefa de rendering. . . . . . . . . . . . . . . . . . . . . 182 
6.2 Fatia 82 do volume de dados Engine (topo-esquerda). Enquanto a aproximação por mínimos-quadrados-móveis suaviza a solução (topo-direita), a aproximação robusta preserva detalhes (base-esquerda). A aproximação de Sheperad (basedireita) também é apresentada para fins comparativos. . . . . . . . . . . . . . 197

6.3 Aproximação (polinômio de grau 2) de dados volumétricos para uma fatia da malha curvilinear do Combustion Chamber: (a) Gauss com pivotamento, (b) gradientes conjugados, (c) QR, (d) SVD e (e) polinômios ortogonais. O ruído representa os pontos de avaliação da função onde ocorreram instabilidades, acarretarando uma aproximação pobre. Em (f) temos o resultado da interpolação linear sobre a malha original. . . . . . . . . . . . . . . . . . . 198

6.4 Rendering volumétrico e de iso-superfícies de diferentes volumes de dados: (a) Bucky Ball, grade cartesiana com $32^{3}$ voxels; (b) Heat Sink, malha não-estruturada com 121668 tetraedros; (c) Combustion Chamber (grade curvilinear) $27 \times 33 \times 25$. 199

6.5 Rendering volumétrico e de iso-superfícies de diferentes volumes de dados: (a) Pingüim, malha com refinamento adaptativo contendo 115378 vértices e 106348 células (no topo apresentamos o wireframe da malha); (b) Ônibus Espacial com foguetes, malha por multiblocos com sobreposição de grades curvilinear, 9 malhas com 172139, 130060, 338653, 16951, 21846,15137, 36756, 8700 e 56206

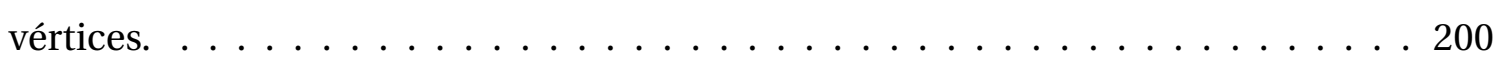

6.6 Conjunto de dados Oxygen Post: wireframe (topo) e o rendering resultante utilizando pesos esféricos (meio) e elipsoidais (base) . . . . . . . . . . . . . . 202

6.7 Comparação visual do rendering da iso-superfície (ray-casting) da Função 6.18, em (a): em (b), aproximação pela spline cúbica de Catmull-Rom; em (c), interpolação linear e; em (d), iaMLS. . . . . . . . . . . . . . . . . . . . . 208

6.8 Conjunto de dados Blunt Fin $(40 \times 32 \times 32$ células): (a) wireframe do modelo; (b) rendering volumétrico. . . . . . . . . . . . . . . . . . . 210

6.9 Rendering volumétrico dos conjuntos de dados: à esquerda, Combustion Chamber $(57 \times 33 \times 25$ células $)$ e, a direita, Oxygen Post $(38 \times 76 \times 38$ células $) . \ldots . . .211$

6.10 Rendering de iso-superfície do conjunto Bucky Ball ( $32^{3}$ células) . . . . . . . . . . 211

7.1 Resultado preliminar do agrupamento de pontos baseado no trabalho de CohenSteiner et al. [55]. . . . . . . . . . . . . . . . . . . . . 222 



\section{LISTA DE TABELAS}

3.1 Medida de desempenho (em segundos), utilizando o método de traçado-deraios, para o método de Adamson e Alexa, Kolluri e o iaMLS. O desempenho é proporcional ao número de raios que intersecta a superfície. . . . . . . . . . . . . 74

5.1 Erro na rotação de corpo rígido do elipsóide em torno do eixo $x_{3}$ - uma volta

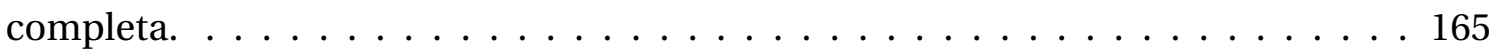

5.2 Disco de Zalesak: Método RAMLS. . . . . . . . . . . . . . . . . . . . . . . 167

5.3 Testes numéricos do único vórtice modulado com o tempo pelo RAMLS: $T=8$ unidades de tempo. . . . . . . . . . . . . . . . . . . . . . . . . . 173

6.1 Tempo de processamento (em milissegundos) para uma única avaliação da aproximação da função com Polinômios ortogonais (PO), gradientes conjugados (GC), Gauss com pivotamento (GP), QR e SVD. . . . . . . . . . . . . . . . . . . 201

6.2 Erro médio e máximo para funções-testes em malhas tetraedrais. . . . . . . . . . . 207

6.3 Tempo de rendering da imagem (em segundos) . . . . . . . . . . . . . . . . . 209 



\section{1 \\ Introdução}

Apresentamos no presente capítulo aspectos fundamentais que caracterizam a importância do problema de representação de superfícies a partir de pontos não-organizados, tanto para a computação gráfica quanto para outras áreas relacionadas à matemática aplicada. Descrevemos os principais desafios motivadores e também a evolução dos métodos ao longo do tempo. Além disso, realizamos uma discussão a respeito do que se espera atualmente de um método de representação a partir de nuvens de pontos. Em seguida, sumarizamos as principais contribuições desta tese de doutorado e finalizamos apresentando sua organização, descrevendo o conteúdo de cada capítulo.

\subsection{Definição do Problema}

O desenvolvimento de abordagens para a representação geométrica de superfícies com topologia e geometria arbitrária a partir de pontos não-organizados (ou nuvens de pontos) intensificou-se em meados da década de oitenta a partir do trabalho de Boissonnat [34]. Contudo, ainda hoje se mantém como um atraente foco de pesquisa em computação gráfica e modelagem geométrica.

Atualmente, a representação e a modelagem de objetos tridimensionais estão presentes em diversas áreas: a inferência de topografia de sítios históricos e arqueológicos, a indústria de entretenimento (cinema e jogos), a engenharia reversa e as áreas médicas são exemplos 
em que a complexidade dos problemas envolvendo representação tridimensional é crescente e conseqüentemente exige investimentos.

Nesse sentido, os problemas requerem processamento de entrada de dados com ordem superior a dezenas de milhões de pontos, contendo ruído e também originados de geometrias que possuam “características afiadas", que são superfícies de classe $C^{0}$ (características afiadas também são denominadas sharp features - Figura 1.1). No último caso, muitos métodos falham ou por não conseguirem definir uma forma para a característica afiada ou por suavizarem a característica.

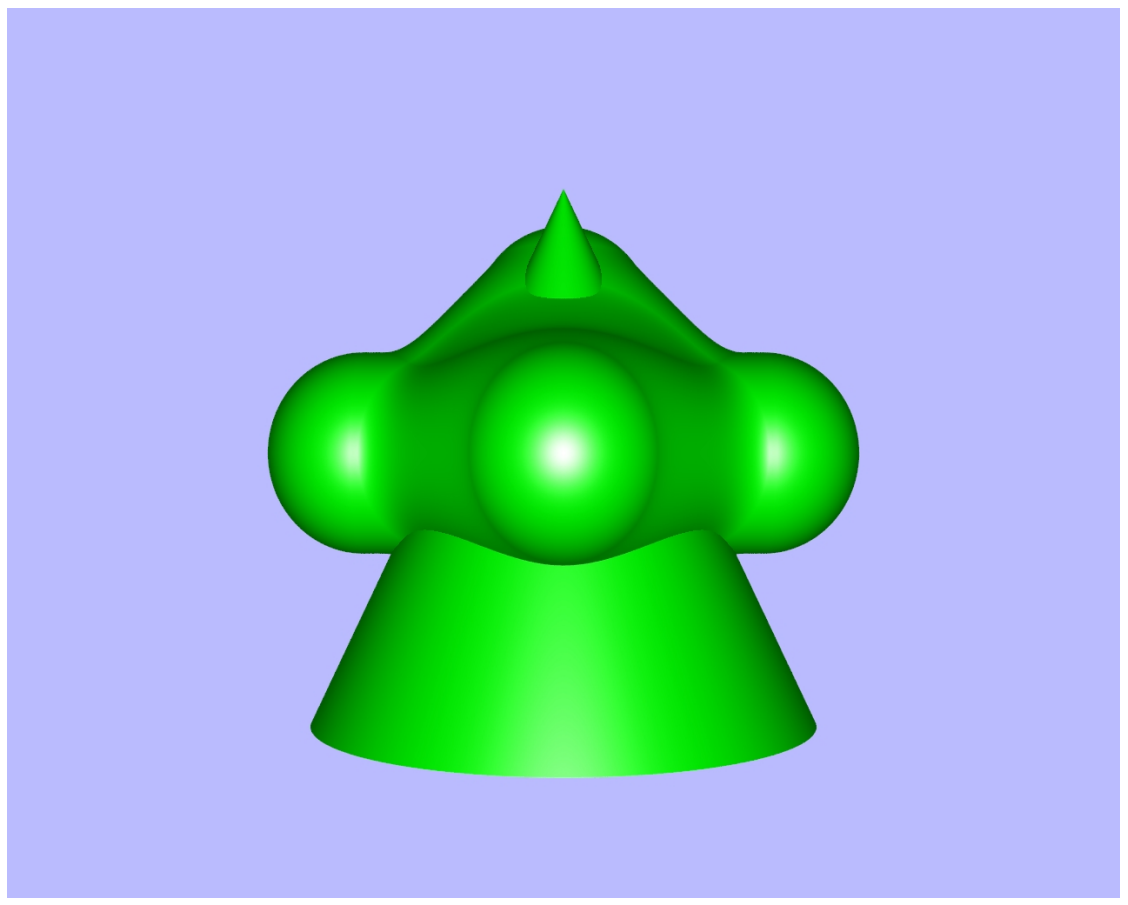

Figura 1.1: Exemplo de objeto com características afiadas: União de um cone com um blobby. As características afiadas são determinadas pelo ápice e base do cone e as duas curvas definidas pelas interseções do cone com o blobby.

Um aspecto que enriquece o desenvolvimento de métodos de representação por nuvens de pontos é o caráter interdisciplinar. Isto é, para a definição de métodos de representação por nuvens de pontos foram propostas abordagens que fazem uso do conhecimento de diversas áreas: estatística [80], geometria computacional [12, 18, 27, 88, 89, 60], programação linear [5], métodos de aproximações locais (mínimos-quadrados) [117, 9, 107, 158], métodos de aproximação global (funções de bases radiais e funções indicadoras) [153, 44, 159, 115], 
equações diferenciais parciais $[36,222,223,115]$, teoria de Morse discreta (versão de Forman) [40], entre outras.

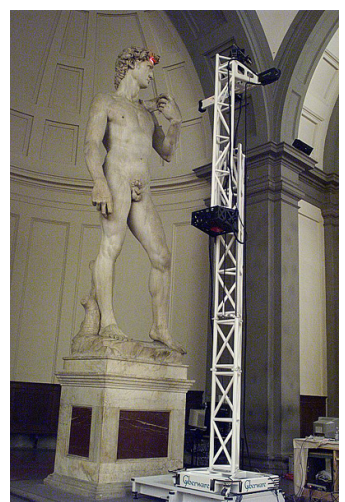

(a)

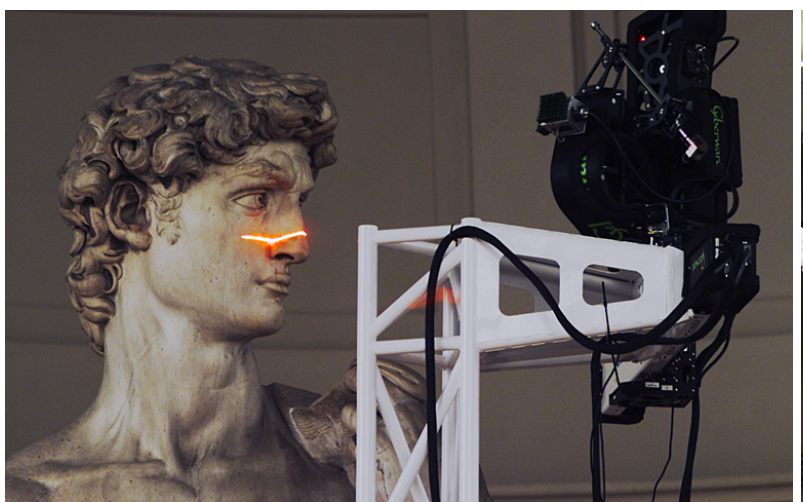

(b)

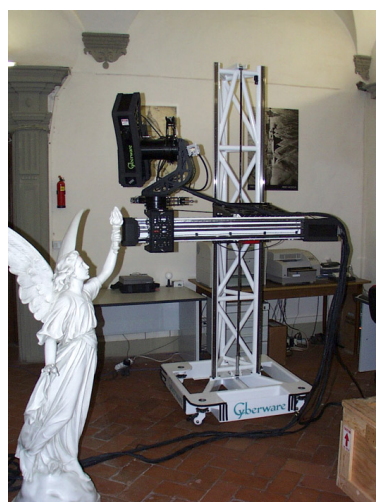

(c)

Figura 1.2: Exemplo de scanners tridimensionais sendo utilizados na estátua de Davi de Michelangelo (a)-(b) e de Lucy (c): Projeto Michelangelo Digital da Universidade de Stanford $[133,132]$.

Ademais, outros dois aspectos significantes justificam os aprimoramentos e as propostas de novos métodos de representação por pontos não-organizados. O primeiro é o fato de que a origem dos dados não se restringe aos providos pelos scanners tridimensionais de pontos (Figura 1.2), que pode ser notado por quase todos os trabalhos na literatura; o segundo está relacionado ao fato de que tais métodos sejam capazes de gerar soluções com propriedades "matematicamente enriquecidas", que extrapolam a capacidade de um método em satisfazer a condição de reconstrução:

Definição 1 (Condição de Reconstrução) Dada a superfície original $\Sigma$ e a reconstruída $\mathscr{S}$, ambas em $\mathbb{R}^{3}$, a condição de reconstrução consiste na existência de um homeomorfismo $f$ : $\Sigma \rightarrow \mathscr{S}$, assegurando que $\Sigma$ e $\mathscr{S}$ sejam topologicamente equivalentes, que satisfaça $(\Sigma, \mathscr{S})<$ $\varepsilon$ para uma métrica d e para $\varepsilon$ suficientemente pequeno, garantindo que $\Sigma$ e $\mathscr{S}$ também sejam geometricamente semelhantes (Figura 1.3).

Para exemplificar o primeiro argumento referente à não-restrição dos dados gerados pelos scanners, existem aplicações em que os conjuntos de dados são gerados pela interface entre dois fluidos por simulações numéricas de escoamento de fluidos multifásicos (Figura 

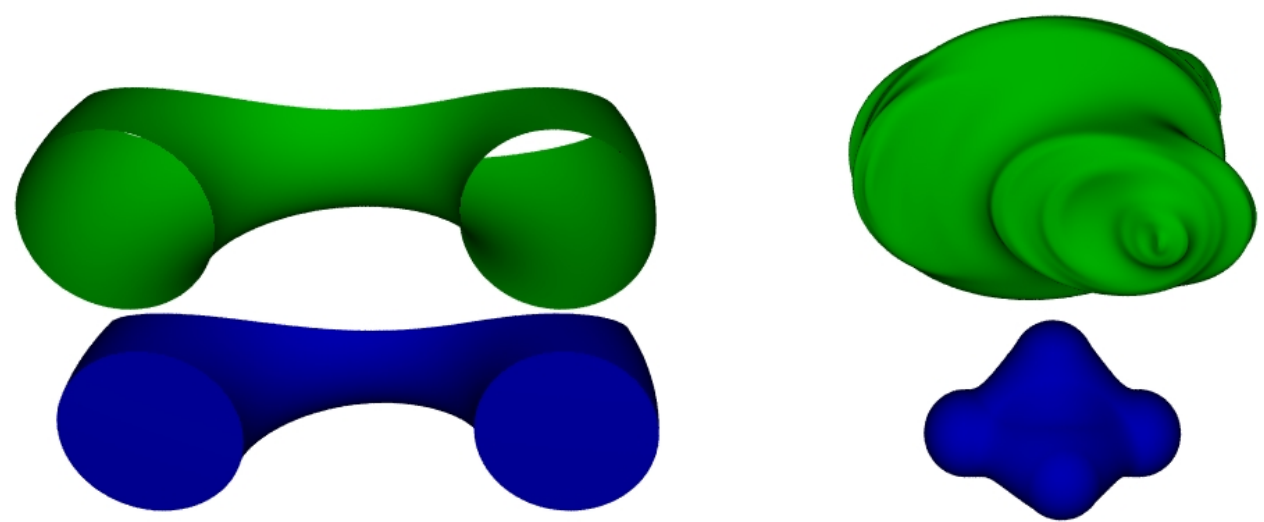

Figura 1.3: Contra-exemplos da condição de reconstrução: exemplos de objetos que não são homeomorfos (esquerda) e de objetos que não são geometricamente semelhantes, apesar de serem topologicamente equivalentes (direita).

1.4), ou com superfícies livres (Figura 1.5) [207, 94]. Para esses tipos de dados, a superfície inicial é definida pelo contato de dois tipos de fluidos (por exemplo, ar e água) e vai sendo alterada conforme evolui com o tempo.
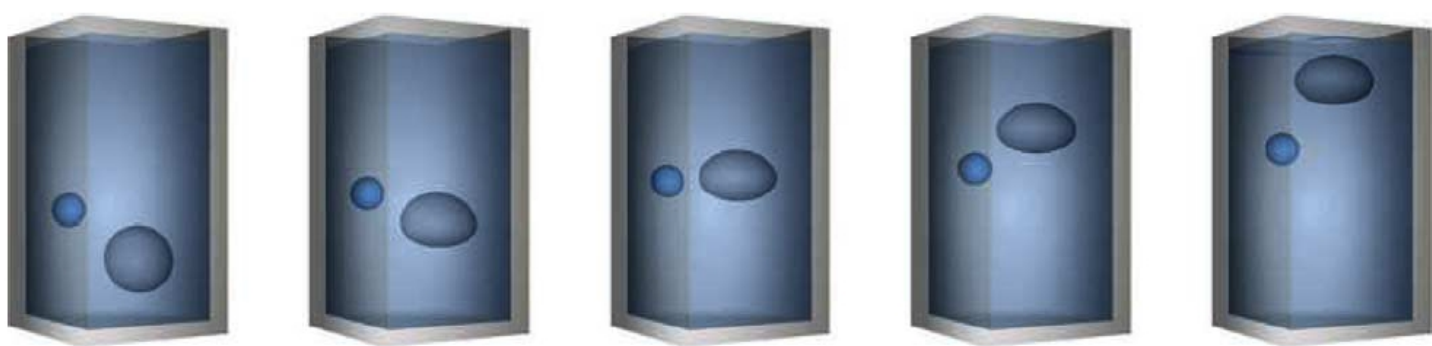

Figura 1.4: Exemplo de simulação numérica de um escoamento de fluidos multifásicos do trabalho de Sousa et al. [194].

O segundo argumento relacionado à capacidade de tais métodos em gerarem soluções com propriedades matematicamente enriquecidas, surge principalmente das necessidades de aplicações das técnicas de representação por nuvens de pontos. As primeiras soluções propostas, em geral, costumavam gerar como saída uma "sopa de polígonos" [203, 70, 175, 186]. Atualmente, as aplicações dos modelos gerados ultrapassam a necessidade puramente geométrica e topológica. Elas exigem que os modelos gerados, além de aproximar fielmente a geometria e a topologia, também aproximem outras informações da superfície de forma 
satisfatória. As duas mais comuns são os vetores normais e as curvaturas. Além dessas, outras propriedades (por exemplo, alta ordem de convergência) podem ser requeridas conforme a aplicação.
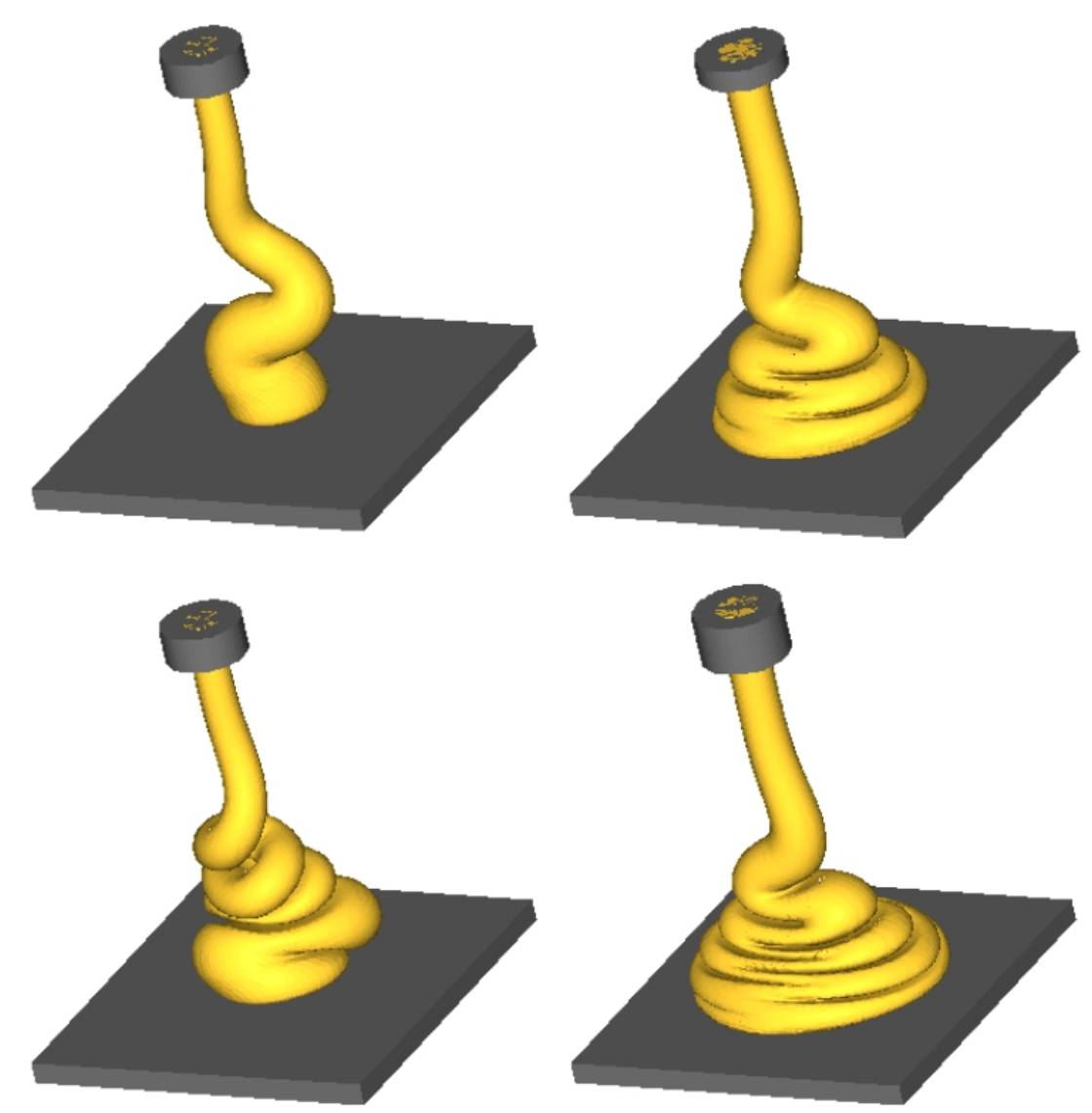

Figura 1.5: Exemplo de simulação numérica de escoamento de um fluido com superfície livre [49].

Quando o método é capaz de estimar satisfatoriamente essas propriedades, ele se torna atraente para ser aplicado em outras áreas do conhecimento (por exemplo, na área médica e nas engenharias) além, obviamente, da computação gráfica. O argumento previamente apresentado retorna novamente à discussão do caráter interdisciplinar dos métodos de representação por nuvens de pontos, mas, nesse momento, voltado às necessidades relacionadas a aplicações, e não aos mecanismos teóricos em que as técnicas são elaboradas, como exposto anteriormente.

No entanto, podemos enriquecer essa discussão e argumentar que, não só por questões 
de interdisciplinaridade, as técnicas de representação fazem jus à intensa pesquisa. A própria computação gráfica busca abordagens viáveis à elaboração de mecanismos de rendering [213, 3], modelagem CSG [97, 224], armazenamento e compactação [37], implementações em modernas placas gráficas (Graphics Processing Unit - GPU) [204] e capacidade de lidar com dados massivos maiores que a capacidade atual de memória RAM dos computadores pessoais (dados out-of-core [36]).

Portanto, dada a ampla quantidade de aplicações e de possibilidades de soluções propostas para representação por pontos não-organizados, buscamos, neste projeto, primeiramente identificar quais métodos (ou classes de métodos) são capazes de suprir a maioria das seguintes características:

- Custo computacional: consiste na elaboração de técnicas nas quais a ordem de complexidade assintótica de tempo e memória sejam aceitáveis.

- Simplicidade: diz respeito ao desenvolvimento de métodos que sejam simples de compreender e codificar. Inevitavelmente, uma técnica simples propicia melhor entendimento de suas propriedades, recebe grande atenção da comunidade científica e até mesmo torna mais fácil o seu aprimoramento e otimização. Além disso, técnicas providas por meio de simples mecanismos abrem a possibilidade de serem implementadas em arquiteturas mais restritas, entre elas em GPUs.

- Habilidade em lidar com diversos tipos de nuvens de pontos: refere-se à capacidade do método em tratar desde dados mal-amostrados e esparsos até dados com ordem de milhões de pontos de forma eficiente. Dados ruidosos e objetos com geometrias complexas (contendo bordos, características afiadas, múltiplas componentes conexas, auto-interseção) também são desafios de um método de representação.

- Capacidade de gerar informações matematicamente enriquecidas: consiste na abordagem que gere não apenas objetos que satisfaçam a condição de reconstrução, mas que também aproxime satisfatoriamente outras propriedades matemáticas do objeto, 
entre elas os vetores normais e as curvaturas. Tais características tornam o método aplicável a outras áreas do conhecimento.

Portanto, torna-se evidente que existem diversos motivos para o desenvolvimento de técnicas de representação por nuvens de pontos, tanto para a computação gráfica quanto para áreas que também carecem de mecanismos de representação de modelos tridimensionais.

Atualmente, diversas abordagens de representação por pontos não-organizados, que solucionam os problemas previamente descritos, são baseadas em métodos de mínimosquadrados-móveis (moving-least-squares-MLS) $[9,8,17,16]$ e partição da unidade implícita (PUI) $[221,51,205,160,38]$. Em ambas, embora haja uma sutil diferença que será discutida em momento oportuno, os ingredientes básicos são aproximações locais e funções-peso. Nesse momento, queremos evidenciar que a qualidade global dos resultados gerados tanto por MLS quanto por PUI depende certamente do poder das aproximações locais utilizadas por esses métodos. Veremos na seção seguinte que partes das contribuições apresentadas na presente tese estão focadas em questões relacionadas às aproximações locais.

\subsection{Objetivos Alcançados}

\subsubsection{Partição da Unidade Implícita em Duas Vias}

A primeira contribuição refere-se ao desenvolvimento de um método de representação de superfícies a partir de pontos não-organizados, baseado em partição da unidade implícita (PUI). Diferente de abordagens anteriores, propusemos, com esse método, um conjunto de soluções capazes de produzir resultados geometricamente satisfatórios sem a necessidade de criação de uma técnica que fosse computacionalmente custosa ou matematicamente sobrecarregada de cálculos. Uma das contribuições de nosso estudo está no uso de polinômios ortogonais segundo o produto interno induzido pelas equações normais, para a realização das aproximações locais por mínimos-quadrados. Tal conjunto de polinômios 
tem como propriedade computacional interessante o fato de permitir aumentar o grau da aproximação polinomial a partir da base de polinômios previamente calculados. Para isso, utilizamos o método de Bartels e Jezioranski que generaliza a recorrência de três termos para polinômios de várias variáveis [23]. Isso significa que, ao contrário de outros métodos de PUI, eficientemente recalculamos as aproximações locais antes de realizarmos uma subdivisão do espaço. Entretanto, como o uso de aproximações de alto grau arbitrariamente não garante confiabilidade, introduzimos o conceito de "espaço de cobrimento".

Além da contribuição em relação ao uso dos polinômios ortogonais no contexto de mínimos-quadrados, nosso método utiliza-se de uma triangulação adaptativa, definida algebricamente, que se encarrega de duas tarefas importantes: a decomposição espacial e a poligonalização, que no caso, ainda tem a propriedade de ser adaptativa. No entanto, como a subdivisão espacial que utilizamos é baseada em tetraedros, a malha gerada pela poligonalização pode apresentar triângulos com baixa qualidade. Esse problema pôde ser contornado por um processo de melhoramento de malhas que desloca apropriadamente vértices da triangulação algébrico-adaptativa. Nossa técnica ainda é capaz de lidar com características afiadas e dados ruidosos. Por fim, exploramos a propriedade de particionamento do domínio a fim de propor um mecanismo intuitivo para edição interativa da função implícita, que permite tanto melhorar as aproximações locais quanto corrigir imperfeições na superfície reconstruída.

\subsubsection{Acompanhamento de Fronteiras com Superfícies MLS}

O segundo método que desenvolvemos é uma contribuição, embora concebida para mecânica dos fluidos computacional, naturalmente de grande valia para a computação gráfica. A partir de mecanismos da computação gráfica, desenvolvemos um novo método Lagrangeano livre-de-malhas (meshless) de "acompanhamento de fronteiras" (fronttracking) para o transporte de interfaces no tempo. Contudo, precisamos aprimorar ferramentas da computação gráfica para serem viáveis no contexto da mecânica dos fluidos 
computacional. Especificamente, a interface é representada implicitamente por mínimosquadrados-móveis algébricos (algebraic moving-least-squares - AMLS) a partir de pontos não-organizados [97]. Ao contrário de técnicas Lagrangeanas baseadas em malhas, destacamos como aspecto importante do nosso método o fato de que apenas um conjunto de partículas é transportado, não havendo, assim, o problema da conectividade de malhas que é agravado em superfícies que se alteram com o tempo. As posições dos pontos da superfície podem, portanto, ser atualizadas sem levar em consideração a qualidade da malha da superfície. Nossa contribuição também se enquadra ao âmbito da computação gráfica, pois possui vantagens em relação ao AMLS proposto por Guennebaud e Gross [97]: aumento na robustez, eficiência computacional e a ausência de parâmetros de penalidade que tornam o processo semi-automático e pouco intuitivo. Por isso, denominamos nosso método de AMLS Robusto (ou Robust AMLS - RAMLS). Também apresentamos um algoritmo Lagrangeano para o transporte de partículas, que é baseado no princípio dos algoritmos de iluminação global traçadores-de-raios (ray-tracers). Mostramos a eficiência da técnica por meio de diversos testes e comparações que tanto mostram a precisão do RAMLS quanto a sua capacidade de representar superfícies em movimento.

\subsubsection{Métodos que Buscam a Redução de Cálculos Matriciais}

Motivados pelo desenvolvimento de abordagens computacionalmente eficientes, no sentido de reduzir a ordem das matrizes referentes ao método de mínimos-quadrados sem comprometer a qualidade das soluções, expusemos duas outras técnicas de representação de superfícies por nuvens de pontos.

Com o intuito de elaborar um mecanismo de representação por nuvens de pontos capaz de alcançar resultados precisos, porém sem o uso de cálculos matriciais, investigamos uma teoria recente e, até onde sabemos, não explorada em computação gráfica, denominada "mínimos-quadrados-móveis aproximados" (Approximate Moving-Least-Squares - aMLS) [74, 76, 77, 144, 145]. Apesar de o nome parecer estranho, os métodos numéricos baseados 
nesses princípios são computacionalmente interessantes, pois possuem a propriedade de serem livres da solução de sistemas lineares e poderem alcançar alta ordem na aproximação. Assim, o custo computacional tende a ser baixo para uma aproximação de alta ordem. O nome "aproximados" se deve ao fato de que essas técnicas permitem que o erro seja controlado de forma a ser tão pequeno que inexista a possibilidade de representá-lo pelos tipos numéricos disponíveis em um sistema operacional, para que a qualidade na aproximação não seja comprometida. Contudo, essa propriedade é garantida apenas para pontos regularmente espaçados. Por outro lado, recentemente foi proposta uma extensão desse método para dados irregularmente espaçados que a relaciona com funções de bases radiais por meio de uma versão iterativa do aMLS, denominada aMLS iterado (iterate aMLS - iaMLS) [77]. Tal resultado é tentador para aplicações em computação gráfica. Com isso, utilizando os princípios dessas teorias, propusemos um método para representação por nuvens de pontos que é promissor pela capacidade de atenuação de características do objeto reconstruído.

Todavia, ao contrário do método original, que é suportado matematicamente por provas, a nossa abordagem não apresenta resultados teóricos a respeito de sua eficiência. De fato, a falta de resultados teóricos não nos desmotivou, pois a qualidade dos resultados obtidos foi satisfatória. Assim, acreditamos que inauguramos um caminho no estudo desses mecanismos para representação por nuvens de pontos.

Por fim, ainda no âmbito de redução de cálculos matriciais, sugerimos um último método de representação por nuvens de pontos baseado em aproximações locais por curvaturas e direções principais obtidas pelo teorema de Euler, da geometria diferencial. Nessa abordagem, ao invés de utilizarmos as tradicionais aproximações locais por mínimosquadrados que fazem uso de bases polinomiais canônicas, optamos por um esquema de mínimos-quadrados com respeito a curvaturas e direções principais que permite definir uma aproximação local de segundo grau em uma vizinhança da superfície. 


\subsubsection{Reconstrução de Dados Volumétricos Não-Organizados}

Além das contribuições anteriores, também trabalhamos no desenvolvimento de mecanismos de reconstrução de dados volumétricos não-organizados (volumetric scattered data) para a definição de um mecanismo de rendering unificado: informações contidas em malhas de diferentes topologias. No primeiro método de representação de dados volumétricos, utilizamos novamente bases de polinômios ortogonais segundo o produto interno induzido pelas equações normais em conjunto com filtros bilaterais. Apresentamos resultados baseados em dados originados de diferentes tipos de malhas. Também comparamos o custo computacional e a qualidade dos resultados, quando utilizamos tais polinômios ortogonais em relação a outras formas de se obter uma solução pelo método dos mínimosquadrados (por exemplo, pelo método QR ou decomposição em valores singulares [30]). A segunda contribuição que apresentamos novamente faz uso do iaMLS para reconstrução de dados volumétricos não-organizados. Contudo, ao contrário do iaMLS original, o nosso esquema está definido em um domínio anisotrópico para suportar dados originados de diferentes tipos de malhas. Dessa forma, nossa abordagem também não é suportada matematicamente, pois o nosso processo iterativo não possui convergência garantida para uma solução ótima (como no trabalho original, em que os autores provaram que a solução iterativa converge para uma solução de função de base radial). Entretanto, novamente os resultados foram satisfatórios.

\subsubsection{Contribuições por Áreas}

Por fim, a partir do ponto de vista das áreas em que trabalhamos, as contribuições foram as seguintes:

- No âmbito da computação gráfica, desenvolvemos métodos de partição da unidade implícita, estudamos e comparamos os métodos a partir de mínimos-quadradosmóveis e mínimos-quadrados-móveis algébricos. Também evidenciamos, ainda, um método de mínimos-quadrados-algébricos que utiliza informações de vetores 
normais, mas é livre de parâmetros de penalidade. Apresentamos melhoramento de malhas a partir de extração de iso-superfícies adaptativas, um esquema de atenuação de características baseado no princípio iterativo do iaMLS e um método de representação por nuvens de pontos que faz uso de curvaturas e direções principais. Também expusemos esquemas de modelagem interativa de objetos definidos por função implícita.

- No âmbito da mecânica dos fluidos computacional, especificamente, no da simulação numérica de escoamentos multifásicos, introduzimos o conceito de superfícies MLS para representação de interfaces móveis. Além disso, apresentamos um método livre de malhas e computacionalmente eficiente.

- No âmbito de aplicações computacionais de metodologias da teoria da aproximação, fizemos uso do iaMLS, do MLS, de filtros bilaterais, do AMLS e também desenvolvemos o RAMLS. Realizamos diversas comparações entre os métodos e apresentamos diversos exemplos.

- Finalmente, no âmbito de rendering de dados volumétricos, trabalhamos no desenvolvimento de mecanismos que são independentes do tipo de malha e que têm aptidão para serem eficientemente implementados em placas gráficas modernas.

\subsection{Organização da Tese}

No Capítulo 2, contextualizamos o tema central desta pesquisa, "representação de superfícies por nuvens de pontos", por meio de um levantamento bibliográfico, partindo das primeiras técnicas de representação de superfície por nuvens de pontos até o estadoda-arte. Aproveitamos para destacar as principais características de cada método e alguns conceitos e definições que serão posteriormente utilizados. Optamos por apresentar técnicas que estão intrinsecamente relacionadas às nossas propostas, conforme a necessidade de discussão no decorrer do texto. Além disso, levantamentos bibliográficos específicos a cada tema foram elaborados nos demais capítulos: aproximações de curvaturas, no Capítulo 
3; métodos de extração de iso-superfícies, no Capítulo 4; representação de interfaces e esquemas numéricos para simulação numérica de fluidos multifásicos, no Capítulo 5; e aproximação de dados volumétricos não-organizados no Capítulo 6.

As duas primeiras contribuições da tese se encontram no Capítulo 3. Elas envolvem o problema da representação por nuvens de pontos baseando-se nas técnicas de mínimosquadrados-móveis. O principal objetivo dessas técnicas foi oferecer representações de superfície por meio das quais fosse aliviado o custo computacional sem comprometer a qualidade dos modelos reconstruídos. Dessa forma, as abordagens foram baseadas, primeiro na minimização de curvaturas e direções principais; e segundo em iaMLS. Optamos por deixar tais contribuições em um mesmo capítulo, pois foram motivadas a partir do mesmo objetivo. Apresentamos as diversas questões em aberto que, apesar de não termos investigado até o presente momento, geraram grande potencial para continuarmos a desenvolver extensões. Além disso, apesar de não formarem as principais contribuições, os resultados que obtivemos foram satisfatórios e as técnicas investigadas foram de grande valia para adquirir experiência para o desenvolvimento das nossas principais contribuições (Capítulos 4 e 5).

Reservamos ao Capítulo 4, a descrição do método baseado em partição da unidade implícita. Primeiramente, apresentamos a estrutura de dados algébrica que utilizamos para a decomposição e poligonalização da superfície e para a representação. Em seguida, mostramos diversos exemplos e comparações teóricas e práticas com trabalhos anteriores. Também apresentamos um conjunto de extensões da técnica que exploram as propriedades da partição da unidade implícita e da estrutura algébrica que utilizamos.

Dedicamos o Capítulo 5 ao nosso método Lagrangeano de representação de interfaces de fluidos móveis para a simulação numérica de escoamentos multifásicos. Apresentamos a definição do RAMLS e o comparamos com as técnicas de AMLS, propostas por Guennebaud e Gross [97]. Além disso, propusemos o nosso algoritmo de acompanhamento de fronteira que é livre de malhas e baseado no transporte e na re-geração dos pontos. Finalizamos esse capítulo com diversos exemplos e comparações envolvendo técnicas do estado-da-arte em 
representação de interfaces de superfícies livres. Certamente, os resultados alcançados e os trabalhos futuros definiram um método promissor para a representação de interfaces móveis que abrirá margem para trabalhos futuros.

O Capítulo 6 abordou métodos de representação de dados volumétricos não-organizados. Nele, dois procedimentos foram apresentados. O primeiro foi baseado em iaMLS, definido em um espaço anisotrópico e se mostrou adequado para implementações em placas gráficas modernas (GPU). O segundo foi baseado em aproximações robustas definidas com filtros bilaterais e bases de polinômios ortogonais de três variáveis para mínimosquadrados-móveis. Apresentamos diversos detalhes das técnicas e também a construção de base de polinômios ortogonais em três variáveis, acompanhada dos principais resultados que asseguraram eficiência no custo computacional. No Capítulo 4, utilizamos a mesma construção de polinômios, só que em duas variáveis. Portanto, essa explicação também é pertinente para o nosso método de partição da unidade implícita.

Finalizamos esta tese no Capítulo 7, apresentando as conclusões gerais a respeito dos métodos de representação por nuvens de pontos que desenvolvemos. Descrevemos também possíveis direções para a continuidade dos nossos trabalhos, bem como as relações a serem exploradas entre eles.

\subsection{O Termo "Robustez"}

Cabe evidenciarmos que utilizamos o termo"robustez" em várias ocasiões no decorrer desta tese, mas contendo significados distintos.

Em nosso método de acompanhamento de fronteira com superfícies MLS, propusemos o Robust AMLS - RAMLS, no sentido de que o método é capaz de definir a superfície sem ser susceptível aos problemas de orientação, que previne a propagação de erros. Isto é, robusta, nesse aspecto, é a abordagem capaz de representar a superfície sem estar facilmente exposta a casos particulares que levam a falhas. Tal fato é importante no contexto de simulação numérica de escoamento de fluidos, pois um erro devido à falta de robustez pode ser propagado e amplificado durante o processo de simulação numérica, podendo 
comprometer toda a simulação. Dessa forma, é preferível que a abordagem seja mais robusta ao custo da perda de precisão.

O termo robusto também é usado no âmbito da representação de superfícies a partir de pontos não-organizados, em dois contextos: primeiro para referenciar os métodos que são capazes de lidar com dados ruidosos e representar características afiadas dos modelos [80]; segundo para definir o nosso método de PUI, em que propusemos um conjunto de soluções que permitem gerar resultados menos susceptíveis a falhas de aproximações locais.

Já para a representação de dados volumétricos, utilizamos o termo robusto no sentido de que o esquema é capaz de capturar detalhes dos dados volumétricos. 


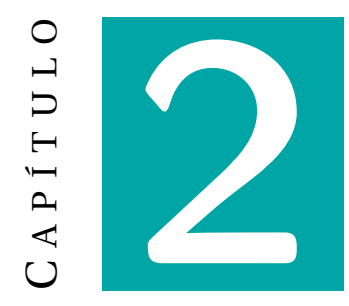

\section{Contextualização}

O objetivo desse capítulo é contextualizar o leitor sobre as metodologias computacionais e matemáticas que inspiraram o desenvolvimento dos métodos de representação de superfícies a partir de pontos não-organizados, da presente tese. Para isso, iniciamos com um levantamento bibliográfico dos métodos de representação por nuvens de pontos, por meio do qual apresentaremos maiores detalhes referentes às classes de métodos nas quais nossas abordagens se enquadram. Além do levantamento bibliográfico, a contextualização é acompanhada de definições e características pertinentes das técnicas de representação por nuvens de pontos.

\subsection{Superfícies por Pontos Não-Organizados - Classificação}

É possível classificar de diversas maneiras os métodos de representação por nuvens de pontos $[88,89,107,115,108,222]$. Entretanto, propusemos a seguinte divisão, como uma versão mais completa de todas as anteriores:

- Métodos baseados em esculpimento: tais técnicas partem, em geral, da triangulação de Delaunay do conjunto de pontos e a partir dessa, com base em heurísticas definidas por propriedades da triangulação de Delaunay, selecionam um subconjunto de simplexos para definir uma representação da superfície. Por muito tempo, reinaram como as técnicas mais populares de reconstrução de superfícies a partir de pontos não- 
organizados. Atualmente essas abordagens vêm perdendo espaço devido a uma série de deficiências, entre elas a dependência da triangulação de Delaunay, problemas de instabilidade numérica e ineficiência em lidar com dados ruidosos.

- Métodos baseados em algoritmos incrementais: são os métodos que criam elemento a elemento por caminharem pela superfície. São abordagens, em geral, extremamente algorítmicas e susceptíveis a falhas na geração dos modelos, pois necessitam de heurísticas e tabelas de casos para definir os mecanismos de criação dos triângulos.

- Métodos baseados em modelos deformáveis: essas técnicas definem um modelo (malha) inicial que, por meio de deformações, busca se adequar ao modelo final. As duas abordagens mais eficientes desses mecanismos são aquelas baseadas em funções de conjunto de nível (métodos de level-set), em que o conjunto de nível zero da função é "transportado" à forma final do objeto, e as baseadas em deformações de campos de forças e remalhamento das malhas superficiais.

- Métodos baseados em operadores de projeção de pontos (point set surfaces - PSS): essas abordagens, originalmente propostas para serem livre de malhas, permitem definir não apenas algum tipo de representação celular ou simplicial, mas também uma representação matemática da superfície a partir de operadores de projeção de pontos sobre a superfície. Essa classe de técnica vem recebendo significativa atenção nos últimos anos devido à simplicidade de sua definição e à eficiência. Uma de nossas contribuições faz uso desse tipo de abordagem.

- Métodos baseados em abordagens implícitas: Como os métodos de projeção de pontos, as técnicas baseadas em funções implícitas também definem a superfície por meio de uma representação matemática que permite realizar diversas aplicações comuns em computação gráfica, de forma eficiente. Entre elas, operações CSG e iluminação pelo método de traçado-de-raios (ray-tracing). Dedicaremos uma maior atenção na descrição e nos comentários sobre esses métodos, no presente capítulo. 
Nas seguintes seções, apresentaremos uma breve descrição das técnicas de esculpimento, incrementais e das técnicas baseadas em modelos deformáveis. Quanto aos métodos baseados em projeção de pontos e funções implícitas, ofereceremos maiores detalhes devido aos métodos que sugerimos pertencerem a essas classes.

\subsection{Métodos de Esculpimento}

O princípio básico das abordagens de esculpimento consiste em obter primeiramente a triangulação de Delaunay do conjunto de pontos e, em seguida, por meio de heurísticas (denominadas de esculpimento), remover um conjunto de simplexos, de forma que o subconjunto restante represente o objeto original. Esses trabalhos foram bem difundidos e produziram diversas coletâneas que apresentam discussões na literatura [66, 88, 89]. A Figura 2.1 ilustra um exemplo de execução da técnica de esculpimento: dada a triangulação de Delaunay de um conjunto de pontos (a), selecionam-se aqueles simplexos que melhor representam o objeto original por meio de alguma heurística baseada em propriedades da triangulação de Delaunay (b).

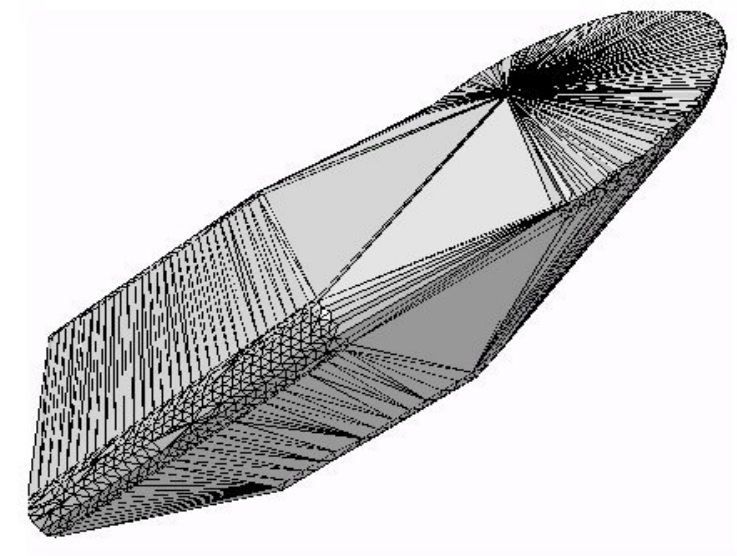

(a)

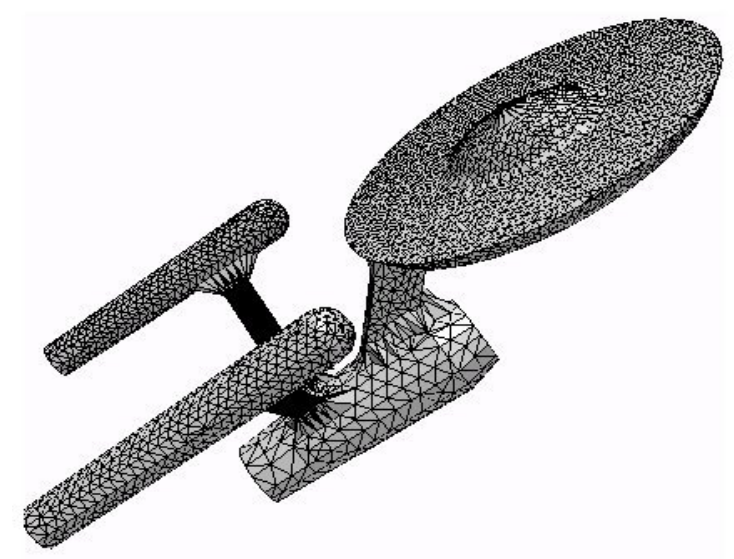

(b)

Figura 2.1: Triangulação de Delaunay de um conjunto de pontos da Enterprise (a), e o esculpimento da triangulação de Delaunay (b) com o intuito de obter a representação do objeto original.

Diversas heurísticas de remoção de simplexos foram propostas [34, 175, 70, 68, 18, 40, 19, 
5, 86]. Algumas heurísticas dependem de parâmetros, que devem ser definidos pelo usuário, que podem, por um lado dar liberdade na escolha do resultado final, mas por outro, tornar a técnica semi-automática.

Uma das técnicas de esculpimento mais conhecidas é o $\alpha$-shapes [70], cuja heurística consiste basicamente na remoção de todos os tetraedros da triangulação de Delaunay que possuem um circunraio menor que $\alpha$. A Figura 2.1 foi obtida segundo essa técnica, no qual, em (a), $\alpha$ é atribuído com o valor do maior circunraio da triangulação, e, em (b), com um $\alpha$ $40 \%$ menor que o maior circunraio, definindo a aproximação ótima para a nuvem de pontos (fato que é possível verificar empiricamente).

Amenta et al. definiram uma segunda geração de métodos de esculpimento $[11,13,15$, 146]. Nessa geração, os mecanismos de decisão para um simplexo pertencer à superfície são baseados em relações na triangulação de Delaunay com seu dual - diagrama de Voronoi, e o eixo medial. Para essas abordagens, Amenta et al. provaram, a partir de determinadas condições de amostragens, que alguns de seus métodos são capazes de gerar reconstruções homeomorfas e geometricamente próximas aos objetos originais. O primeiro método proposto foi batizado de Crust [12, 11]. Amenta et al. também elaboraram outro método, que utiliza relações entre a triangulação de Delaunay e o power diagrama [67], denominado Power Crust [15, 14]. Nesse, o esculpimento é definido no power diagrama construído em um subconjunto de vértices do diagrama de Voronoi da nuvem de pontos. Por um lado, o custo computacional do Power Crust é superior ao do Crust. Por outro, os resultados gerados são melhores.

A principal desvantagem dessas abordagens em relação às outras técnicas de esculpimento é definitivamente o custo computacional em relação à memória e ao tempo de processamento, pois necessitam do processamento de duas triangulações de Delaunay e o cálculo dos duais dos tetraedros da triangulação.

Com o intuito de aliviar a carga computacional, Amenta et al. propuseram um método denominado Cocone [13], uma versão do Crust que utiliza apenas uma triangulação de Delaunay. Além disso, as demonstrações das garantias teóricas foram simplificadas para 
esta versão.

Outras variantes dessas abordagens foram propostas [61, 62, 120]. O livro de Dey [60] contém uma descrição dessa família de algoritmos que satisfaz a Garantia de Reconstrução (Definição 1, página 3). Extensões destas abordagens com o intuito de lidar com dados ruidosos também foram propostas [146, 62].

No entanto, a principal deficiência computacional de todas as abordagens baseadas em esculpimento é o cálculo da triangulação de Delaunay. Primeiro pelo custo computacional e segundo pela instabilidade numérica tradicionais dessa triangulação para pontos definidos em superfícies [52].

\subsection{Métodos Incrementais}

O princípio dos métodos incrementais é: dada uma aresta inicial (ou um conjunto de arestas iniciais), a que denominamos fronteira de avanço, construída pela conexão de dois pontos da nuvem, definem-se triângulos (como se estivessem "caminhando" pela superfície do objeto) de maneira iterativa até que a superfície toda seja gerada. Os métodos incrementais também são conhecidos como métodos de avanço de fronteira.

Bernardini et al. [29] apresentaram um método incremental denominado Ball-Pivotting Algorithm (BPA). Este método é conceitualmente simples. Consideremos uma nuvem de pontos suficientemente densa e uma bola de raio $\rho$ que não seja capaz de "atravessar" a superfície sem tocar nos pontos da nuvem.

O processo se inicia "colocando" essa bola em contato com três pontos da nuvem, definindo um triângulo inicial. Mantendo-se a bola em contato com dois desses pontos, rota-se a bola (pivoting) até tocar outro ponto. O "pivotamento" se dá ao redor de cada aresta da fronteira atual, e, a cada tripla de pontos tocados pelo processo de pivotamento da bola, um novo triângulo é definido.

A saída desse algoritmo é um subconjunto do $\alpha$-shape [70]. Conseqüentemente, uma de suas principais vantagens é gerar uma saída que é um subconjunto da triangulação de Delaunay, obtida sem a necessidade do cálculo da triangulação. Uma extensão deste 
trabalho foi proposta por Mederos et al. [149], que utilizaram o BPA em uma técnica de multirresolução para nuvens de pontos baseada em mínimos-quadrados-móveis.

Outro método incremental foi apresentado por Huang e Menq [108]. Os autores propuseram um método cuja saída não é necessariamente uma malha que seja um subconjunto da triangulação de Delaunay. Diversos critérios geométricos são utilizados na etapa de geração da superfície reconstruída. No entanto, esses critérios não são suficientes para a geração de uma superfície razoavelmente satisfatória, e os autores apresentam uma interessante etapa de pós-processamento para suavizar as malhas obtidas.

Os autores relacionam conceitos de Geometria Diferencial para estimar a curvatura da superfície, tanto por meio das arestas quanto dos vértices da malha superficial. A Figura 2.2 ilustra a estimativa da curvatura direcional da superfície [108] para um ponto (obtida por mínimos-quadrados) em uma direção e a curvatura para uma aresta (obtida pelo ângulo definido entre as duas faces triangulares que compartilham a aresta). Em 2.2-a) está a configuração original da malha. Em 2.2-b), têm-se as estimativas da curvatura da aresta $e$, dada no ponto de mínimo local da curva $c$, e da superfície, dada pelo ponto de máximo local da curva $d$. Em 2.2-c), a malha é reestruturada localmente para que as curvaturas fiquem próximas. A Figura 2.3 apresenta o resultado final do remalhamento da superfície, utilizando tal critério de pós-processamento.

Utilizamos este esquema de cálculo de curvaturas e direções principais por meio de mínimos-quadrados para definirmos o nosso primeiro método, que é baseado em projeção de pontos. Portanto, voltaremos a discutir este processo no Capítulo 3.

\subsection{Modelos Deformáveis}

Sharf et al. [185] propuseram uma abordagem interessante de modelos deformáveis. Ela se baseia em colocar uma malha superficial triangular em uma esfera no interior da nuvem de pontos do objeto para, então, realizar o transporte dos vértices da malha na direção normal da superfície e aplicar remalhamentos à medida que os elementos da malha perdem qualidade. A definição do método, apesar de simples, requer diversos detalhes de 


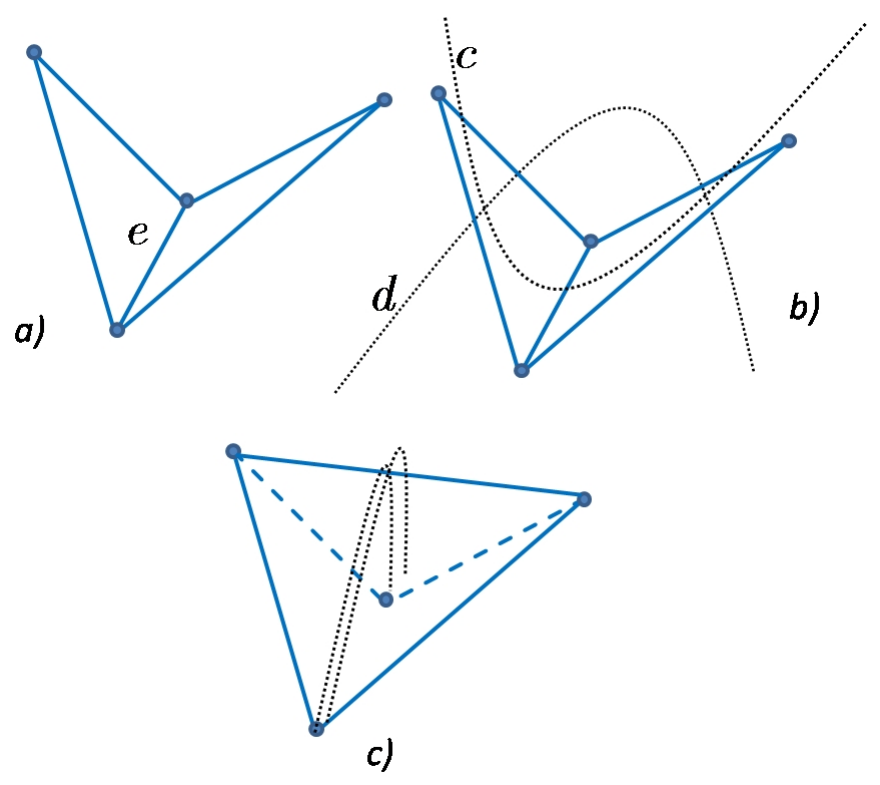

Figura 2.2: Descrição do processo de estimativa das curvaturas da superfície e da malha, proposta por Huang e Menq [108]: Em (a) tem-se a malha original; em (b) a curva $d$ representa a aproximação da curvatura por mínimos-quadrados baseado nos pontos da vizinhança da aresta $e$, ao passo que $c$ define a estimativa da curvatura para a aresta $e$; em (c) o remalhamento local torna ambas aproximações das curvaturas semelhantes.

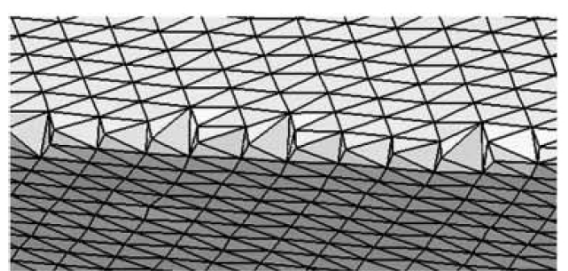

(a)

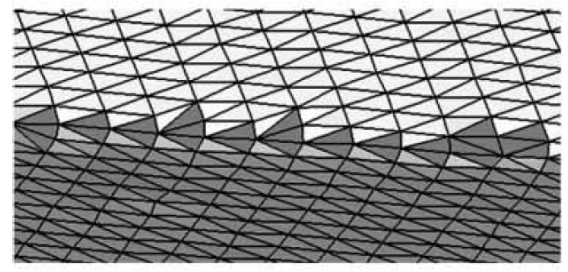

(b)

Figura 2.3: Resultado do pós-processamento proposto por Huang e Menq [108] em (b), aplicado à malha inicial em (a). 
implementação com o intuito de produzir uma abordagem robusta. Portanto, os autores sugerem mecanismos para que o método seja capaz de lidar com regiões mal-amostradas, para que a saída do método seja uma superfície topologicamente equivalente à superfície do objeto original, bem como para que a malha resultante apresente elementos de qualidade. Uma limitação dessa abordagem é a necessidade de uma grade computacional (grid) para representar a função distância, utilizada para guiar o movimento dos vértices da malha na direção normal, podendo gerar um custo computacional elevado. Além disso, caso ambas (a grade computacional e a malha) sejam finas, os autores argumentam que o método está sujeito a instabilidades numéricas [185].

Outros métodos deformáveis são aqueles baseados em funções de conjunto de nível (métodos de level-set) [222, 223], comuns em representação de interfaces em simulação numérica de escoamentos de fluidos [183, 161, 72, 42]. Uma das principais vantagens na utilização de técnicas baseadas em conjuntos de nível é a capacidade de lidar com dados incompletos e com alterações topológicas de forma eficiente. O método de Zhao et al. é baseado em princípios de geometria diferencial e em equações diferenciais parciais. A idéia geral é semelhante àquelas utilizadas em mecânica dos fluidos: dada uma superfície implícita inicial, esta é deformada por meio da solução numérica de uma equação diferencial parcial convectiva, seguindo a direção gradiente.

Segundo os autores, o método é capaz de lidar com dados ruidosos e não-uniformes. No entanto, o custo computacional para resolver numericamente as equações diferenciais envolvidas nessas abordagens é diretamente proporcional à resolução da grade computacional em que a equação diferencial é discretizada. Nesse método, mesmo para grades grosseiras, o custo computacional é alto.

\subsection{Métodos de Projeção de Pontos (Point Set Surfaces)}

Até o momento, as técnicas que descrevemos são formuladas a partir mecanismos que visam representar o modelo geométrico final por meio de uma malha poligonal. Nesta seção, apresentamos esquemas de representação de superfícies que foram inicialmente 
propostos com o intuito de serem representações livres-de-malhas (meshless). Tais técnicas são popularmente conhecidas como Point Set Surfaces (PSS) e point-based surfaces.

A definição matemática da superfície por esses métodos é baseada em aplicações locais em sistemas de coordenadas locais, inspirada pela geometria diferencial [43]. O sistema de coordenadas e as aplicações são obtidos por métodos de minimização local [173, $117,177]$, dentre os quais, o mais popular é o método de mínimos-quadrados $[30,110]$. A representação final dos modelos está fundamentada na definição de mecanismos de reamostragem (local) de pontos sobre os gráficos de tais aplicações locais, de forma a cobrir completamente a superfície no espaço da imagem. A Figura 2.4 [8] apresenta um modelo no qual a reamostragem varia na direção vertical com o intuito justamente de ilustrar a idéia de reamostragem de pontos na superfície.

A idéia de gerar uma representação puramente baseada em pontos não é recente [134]. No entanto, essas representações estão sendo desenvolvidas não apenas para visualização, mas também para suportarem diversas tarefas, como, por exemplo, o rendering $[65,213,2,3$, 8], a reamostragem de pontos [8, 9, 166], as funções de morphing, modelos elásticos [154], as operações booleanas [167] e as representação por multiescala [168]. Além dessas aplicações, também têm sido propostos métodos para eliminação de ruídos de nuvens de pontos, que fazem uso das idéias de projeção de pontos [150,179] e também métodos para a geração de malhas triangulares superficiais a partir de PSS [180, 149].

Alexa et al. [8, 9] propuseram o primeiro método computacional de projeção de pontos baseado em mínimos-quadrados-móveis (moving-least-squares - MLS) [125, 130], no qual os autores denominam os resultados por superfícies MLS. Levin [131] argumenta também que o acrônimo pode ser oriundo de Moving-Local-System ou de MeshLess-Surface.

Observação 1 É importante enfatizar a simplicidade na definição de uma superfície MLS: Cada ponto a ser projetado na superfície possui um sistema de coordenadas locais próprio, isto é, não são necessárias parametrizações em regiões homeomorfas a um disco aberto sobre a superficie. Dessa forma, problemas comuns de parametrizações por partes são evitados; 


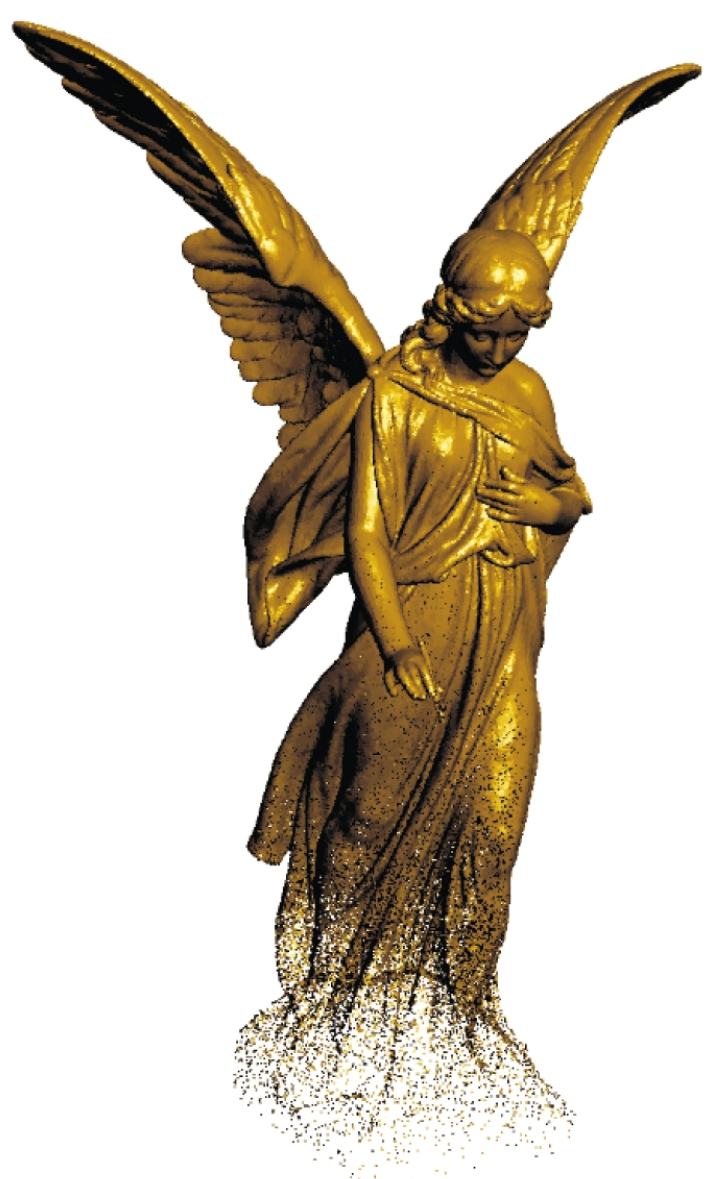

Figura 2.4: Alexa et al. ilustram o resultado esperado pela reamostragem de pontos dada pelo operador de projeção [8].

entre eles, dependência de parametrização, distorções nas parametrizações e, principalmente, problemas de continuidade ao longo dos bordos das parametrizações.

A seguir, detalhamos o esquema de definição da superfície MLS, proposto por Alexa et al. [8, 9]. Também apresentamos as características computacionais do método.

Consideremos uma superfície $\mathscr{S}$ em $\mathbb{R}^{3}$ e $\mathscr{P}=\left\{\mathbf{p}_{i} \in \mathbb{R}^{3}\right\}_{i \in I \subsetneq \mathbb{N}}$, um conjunto finito de pontos sobre ou em uma vizinhança próxima de $\mathscr{S}$ e um ponto p que queremos projetar sobre a superfície. A primeira etapa do mecanismo de projeção é a definição de um plano $H$ que aproxime o plano tangente de $\mathscr{S}$ próximo a p. A Figura 2.5-(a) apresenta um exemplo bidimensional em que as linhas tracejadas definem a interpretação de possíveis projeções de p em possíveis aproximações $H$, dadas em linhas pontilhadas. As linhas contínuas 
determinam o plano $H$ ótimo e a direção da projeção de p em $H$.

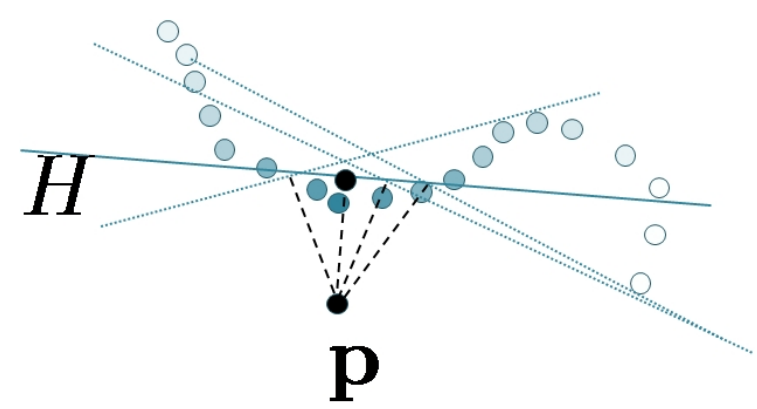

(a)

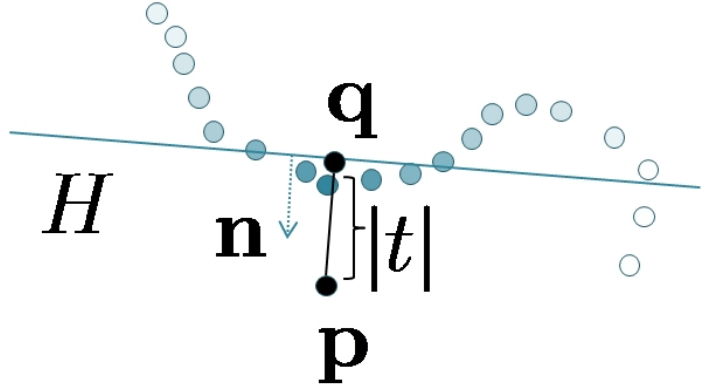

(b)

Figura 2.5: (a) Situação inicial do esquema de projeção: dado p a ser projetado, devemos encontrar o plano (aproximadamente) tangente $H$ próximo a p. (b) Interpretação geométrica do ponto $\mathbf{q}=\mathbf{p}+t \mathbf{n}$.

Consideremos o plano $H=\left\{\mathbf{x} \in \mathbb{R}^{3}:<\mathbf{x}, \mathbf{n}>-D=0\right\}$, em que $\mathbf{n}$ é o vetor ortonormal a $H$, $D$ o deslocamento do plano $H$ da origem e $<$, >, o produto interno canônico em $\mathbb{R}^{3}$. Dessa forma, podemos reescrever a equação do plano por:

$$
H=\left\{\mathbf{x} \in \mathbb{R}^{3}:<\mathbf{x}, \mathbf{n}>-<\mathbf{q}, \mathbf{n}>=0\right\},
$$

em que q é a projeção de $\mathbf{p}$ em $H$. Em seguida, reescrevemos o ponto q em função do vetor normal $\mathbf{n}$ e a distância $t$ de $\mathbf{p}$ ao plano $H$, isto é $\mathbf{q}=\mathbf{p}+t \mathbf{n}$ (Figura 2.5-(b)).

Com isso, para determinarmos o plano $H$, dado o conjunto de pontos vizinhos e o ponto $\mathbf{p}$, precisamos calcular o vetor normal $\mathbf{n}$ e o ponto do plano $\mathbf{q}=\mathbf{p}+t \mathbf{n}$ pela minimização no sentido de mínimos-quadrados, isto é, encontrar os parâmetros n e q que minimizem a equação:

$$
G(\mathbf{n}, \mathbf{q})=\sum_{\mathbf{p}_{i} \in \mathscr{P}}\left(<\mathbf{n}(\mathbf{p}), \mathbf{p}_{i}>-<\mathbf{n}(\mathbf{p}), \mathbf{q}>\right)^{2} \omega_{i}(\mathbf{q}),
$$

em que $\omega_{i}(\mathbf{q})$ são pesos definidos em função de $\mathbf{q}$ dados por uma função-peso:

Definição 2 (Função-peso) Dado um parâmetro de suavidade $\Delta$ e um ponto $\mathbf{p}_{i} \in \mathscr{P}, a$ função-peso $\omega_{i}: \mathbb{R}^{3} \rightarrow \mathbb{R}^{+}$é definida como: 


$$
\omega_{i}(\mathbf{q})=\theta\left(\frac{\left\|\mathbf{p}_{i}-\mathbf{q}\right\|}{\Delta}\right)
$$

em que $\theta: \mathbb{R}^{+} \rightarrow \mathbb{R}^{+}$é uma função de localização contínua monoticamente decrescente, que atinge seu valor máximo em $\theta(0)$ e satisfaz $\theta(t \rightarrow \infty)=0$.

Observação 2 A função-peso dita uma importante regra na minimização: quanto mais próximo um ponto $\mathbf{p}_{i}$ estiver de $\mathbf{q}$, mais influente $\mathbf{p}_{i}$ será na minimização. O parâmetro $\Delta$ define o fator de suavidade na solução. Isto significa que quanto maior for o valor de $\Delta$, pontos mais distantes serão mais influentes na solução. Em geral, o parâmetro $\Delta$ é definido como um múltiplo do espaçamento médio $h$ entre os pontos $\mathbf{p}_{i}$.

Alguns exemplos de função de localização são a função inversa da distância

$$
\theta(t)=\frac{1}{\left(t^{2}+\epsilon\right)}, \operatorname{com} \epsilon>0
$$

a função gaussiana

$$
\theta(t)=e^{-t^{2}}
$$

e a função com suporte compacto

$$
\theta(t)=\left\{\begin{array}{ll}
\left(1-t^{2 \alpha_{1}}\right)^{\alpha_{2}} & \text { para } t<1 \\
0 & \text { caso contrário }
\end{array},\right.
$$

em que diferentes valores de $\alpha_{1}, \alpha_{2} \in \mathbb{N}^{*}$ produzem diferentes funções (Figura 2.6). Em nossos métodos, presentes nos Capítulos 4 e 5, utilizamos a Função 2.6, definindo $\alpha_{1}=1$ e $\alpha_{2}=4$.

Retornando ao método de minimização de Alexa et al. [9], notemos que a minimização da Equação 2.2 depende da posição em que o ponto p está definido, no qual os pesos dependem da posição de q. Dessa forma, voltando à Equação 2.2 e substituindo o valor de q, temos: 


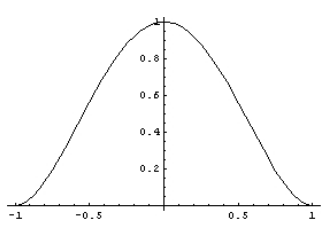

(a)

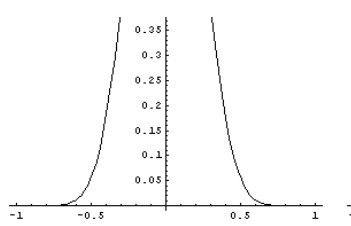

(b)

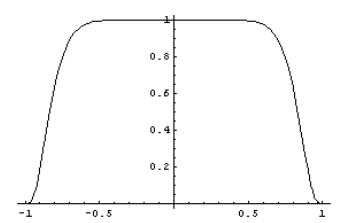

(c)

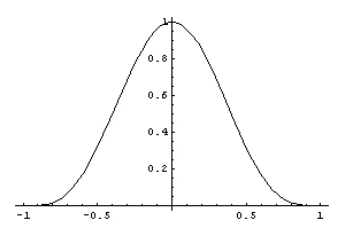

(d)

Figura 2.6: Diferentes valores de $\alpha_{1}$ e $\alpha_{2}$ para a Função-Peso 2.6: (a) $\alpha_{1}=1$ e $\alpha_{2}=2$, (b) $\alpha_{1}=1$ e $\alpha_{2}=10$, (c) $\alpha_{1}=5$ e $\alpha_{2}=4$ e (d) a função que utilizamos, com $\alpha_{1}=1$ e $\alpha_{2}=4$.

$$
G(\mathbf{n}, t)=\sum_{\mathbf{p}_{i} \in \mathscr{P}}<\mathbf{n}, \mathbf{p}_{i}-\mathbf{p}-t \mathbf{n}>^{2} \theta\left(\frac{\left\|\mathbf{p}_{i}-\mathbf{p}-t \mathbf{n}\right\|}{\Delta}\right) .
$$

Minimizar 2.7 é um problema de mínimos-quadrados-móveis, pois, conforme "movemos" o ponto p livremente obtemos uma nova minimização. Isto é, a minimização depende da posição de p. Mais detalhes de superfícies MLS podem ser encontradas no Capítulo 5, quando descrevemos o nosso método de captura de fronteira com mínimos-quadradosmóveis.

Notemos que a minimização (2.7) é não-linear, devido ao produto interno à função $\theta$ depender das incógnitas n e $t$. Como observado por Alexa e colaboradores, a Equação 2.7, em geral, possui mais que um mínimo local. Por esse fato, os autores assumem a escolha do mínimo local de $G$ utilizando um processo iterativo, que apresentaremos após a definição da superfície MLS (Definição 3, Página 30).

Depois de realizada a minimização, definimos o operador $\perp(\mathbf{p})=\mathbf{q}=\mathbf{p}+t \mathbf{n}$, que define a projeção de p sobre o plano $H$ onde (n, $t$ ) são os argumentos mínimos locais de $G$ (2.7).

Tendo definido a projeção do ponto sobre o plano, executamos a segunda etapa do operador de projeção, que consiste na definição de um sistema de coordenadas locais construído a partir do vetor $\mathbf{n}$ e do ponto q, origem do sistema de coordenadas. Essa etapa, portanto, corresponde ao cálculo da aplicação local (polinômio de duas variáveis) $\pi_{\mathbf{p}}$ que aproximará a superfície localmente. A Figura 2.7-(a) apresenta um exemplo bidimensional.

Consideremos os pontos $\mathbf{p}_{i}$ pertencentes à nuvem de pontos e $\mathbf{q}_{i}$ à projeção de $\mathbf{p}_{i}$ em $H$ (Figura 2.7-(b)). Para a aproximação polinomial, definimos a função altura $f$ dos pontos $\mathbf{p}_{i}$ a $H$, que é dada pela expressão: 


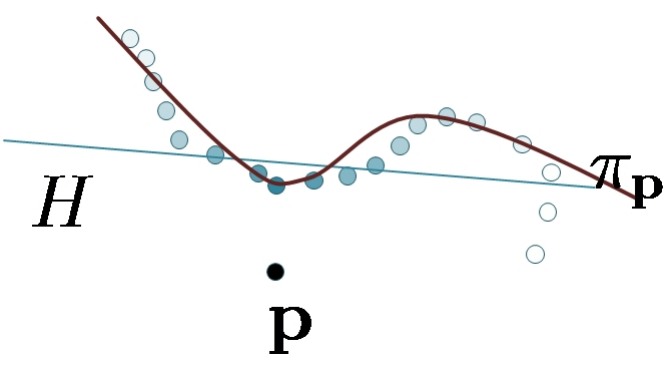

(a)

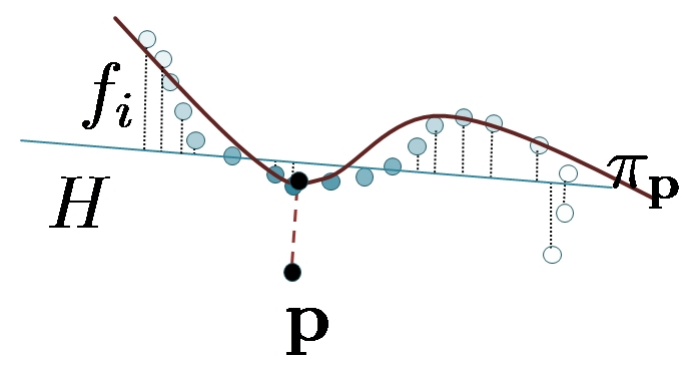

(b)

Figura 2.7: (a) Aproximação polinomial local. (b) A altura dos pontos $\mathbf{p}_{i}$ em relação a $H$.

$$
f_{i}=f\left(\mathbf{p}_{i}\right)=\mathbf{n} \cdot\left(\mathbf{p}_{i}-\mathbf{q}\right)
$$

A partir da função altura, os coeficientes $\beta(\mathbf{q})=\left(\beta_{1}(\mathbf{q}), \cdots, \beta_{m}(\mathbf{q})\right)$ do polinômio são determinados pela minimização de

$$
K(\beta(\mathbf{q}))=\sum_{\mathbf{p}_{i} \in \mathscr{P}}\left(\pi_{\mathbf{p}}\left(x_{i}, y_{i}\right)-f_{i}\right)^{2} \theta\left(\left\|\mathbf{p}_{i}-\mathbf{q}\right\|\right)
$$

Os pontos $\left(x_{i}, y_{i}\right)$ são as representações das projeções dos pontos $\mathbf{p}_{i}$ no sistema de coordenadas locais definido pelo plano $H$. Notemos que os pesos, nesse caso, já são conhecidos, pois encontramos o ponto q na etapa anterior. Dessa forma, a minimização é obtida por mínimos-quadrados-ponderados (weighted-least-squares) [30].

A projeção $\mathscr{P}$ de p sobre uma superfície localmente aproximada $\mathscr{S}(\mathbf{p})$ é definida por:

$$
\mathscr{P}(\mathbf{p})=\mathbf{q}+\pi_{\mathbf{p}}(0,0) \mathbf{n}=\mathbf{q}+\left(t+\pi_{\mathbf{p}}(0,0)\right) \mathbf{n} .
$$

O ponto q está no sistema de coordenadas canônicas em $\mathbb{R}^{3}$ e $(0,0)$ é a origem do sistema de coordenadas locais. Portanto, após a definição da Projeção 2.10, a superfície MLS, segundo Alexa et al. [9], é definida por:

Definição 3 (Superfície MLS [9]) A superfície MLS é definida pelo conjunto de pontos $\mathcal{V}=$ $\{\mathbf{p}: \mathscr{P}(\mathbf{p})=\mathbf{p}\}$. 
Para minimizar a Equação 2.7, Alexa et al. propuseram um método iterativo. O processo se inicia escolhendo $t=0$ para, primeiramente, aproximar o vetor normal $\mathbf{n}$ de $H$. Dessa forma, os valores que a função-peso assume são fixos, isto é,

$$
\theta\left(\frac{\left\|\mathbf{p}_{i}-\mathbf{p}-t \mathbf{n}\right\|}{\Delta}\right)=\theta\left(\frac{\left\|\mathbf{p}_{i}-\mathbf{p}-0 \mathbf{n}\right\|}{\Delta}\right)=\theta\left(\frac{\left\|\mathbf{p}_{i}-\mathbf{p}\right\|}{\Delta}\right)
$$

Portanto, a Equação 2.7 se torna:

$$
J(\mathbf{n}(\mathbf{p}))=\sum_{p_{i} \in \mathscr{P}}<\mathbf{n}, \mathbf{p}_{i}-\mathbf{p}>^{2} \theta\left(\frac{\left\|\mathbf{p}_{i}-\mathbf{p}\right\|}{\Delta}\right) .
$$

No entanto, para não obtermos a solução trivial (vetor normal igual ao vetor nulo), impusemos a restrição $\|\mathbf{n}\|=1$, por meio da qual a minimização de $J$ se torna [2]:

$$
\min _{\|\mathbf{n}\|=1} \mathbf{n}^{t} \mathbf{B n}
$$

em que $\mathbf{n}$ é determinado, aplicando os multiplicadores de Lagrange, pelo problema de autovalor:

$$
\mathbf{B n}=\lambda \mathbf{n},
$$

em que o problema de minimização 2.11 se resume, então, em definir o autovetor (satisfazendo a normalização $\|\mathbf{n}\|=1$ ) associado ao menor autovalor da matriz de co-variância ponderada $\mathbf{B}_{3 \times 3}$, onde cada entrada da matriz é definida por:

$$
B_{j k}=\sum_{\mathbf{p}_{i} \in P}\left(\mathbf{p}_{i j}-\mathbf{p}_{j}\right)\left(\mathbf{p}_{i k}-\mathbf{p}_{k}\right) \omega_{i}\left(\mathbf{p}_{i}\right),
$$

em que as coordenadas dos pontos são dadas pelo segundo índice de $\mathbf{p}_{i}$.

Agora, os dois seguintes procedimentos são iterados alternadamente até que os parâmetros não se alterem segundo um erro previamente definido:

1. Minimize $t$ no intervalo [ $-\Delta / 2, \Delta / 2]$ (problema de minimização não-linear em uma dimensão [172]); 
2. Minimize q sobre o atual plano $H(\mathbf{n}, t)$, utilizando o método dos gradientes conjugados [9]. O novo valor para $\mathbf{q}=\mathbf{p}+t \mathbf{n}$ gera os novos valores para o $\operatorname{par}(\mathbf{n}, t)$.

O último par (n, $t$ ) define o plano $H$. Então, realiza-se a segunda etapa do procedimento, que é o cálculo da aproximação polinomial $\pi_{\mathbf{p}}$. O procedimento de projeção, então, é concluído, projetando $\mathbf{p}$ no gráfico da função de $\pi_{\mathbf{p}}$.

Amenta e Kil [16] propuseram também uma abordagem iterativa para realizar a minimização que define o plano $H$ (Figura 2.8). A cada iteração, encontra-se o vetor normal $\mathbf{n}\left(\mathbf{x}_{i}\right)$, em que $\mathbf{x}_{i}$ é o ponto a ser projetado, e define-se a reta passando por $\mathbf{x}_{i}$, na direção de $\mathbf{n}\left(\mathbf{x}_{i}\right)$. Encontra-se $t$ (com $\mathbf{n}\left(\mathbf{x}_{i}\right)$ fixo) que é mínimo local da Equação 2.7 mais próximo de $\mathbf{x}_{i}$ sobre a reta. Esse mínimo local define o próximo $\mathbf{x}_{i+1}$ e o processo é repetido até que o módulo do valor de $t$ não seja superior limitante predefinido pelo usuário. Os autores ainda provam que o procedimento de projeção proposto gera pontos na superfície MLS, caso o processo iterativo convirja [16].

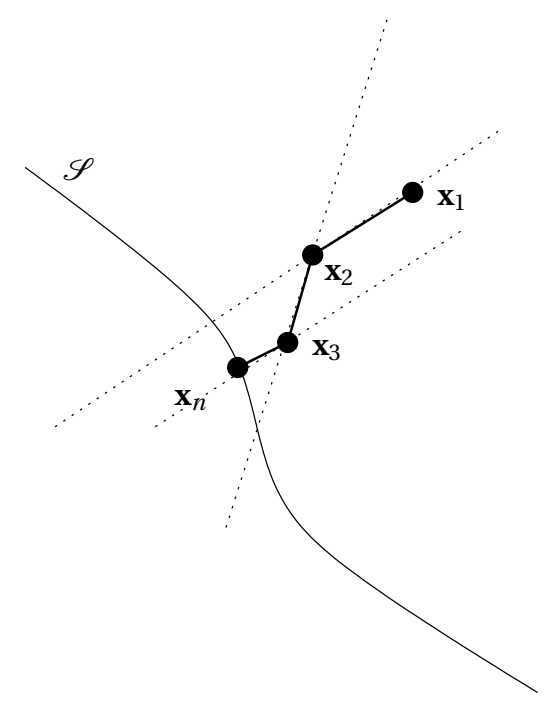

Figura 2.8: Esquema de geração de pontos na superfície MLS, proposto por Amenta e Kil [16].

Observação 3 Note que os pesos do método dos mínimos-quadrados-móveis ditam uma severa restrição à posição do ponto $\mathbf{p}$ a ser projetado: $\mathbf{p}$ deve estar próximo à superfície, pois 
à medida que $\mathbf{p}$ se afasta da superfície, os pesos rapidamente tendem a zero implicando a instabilidade do processo de minimização. Portanto a eficiência do método está garantida apenas numa vizinhança próxima da superfície [17].

Pauly et al. [167] apresentam ainda uma outra variante que não faz uso de minimizações não-lineares para definição do plano $H$. Tal abordagem está presente no software com código-fonte livre PointShop3D [224].

O mecanismo de Pauly et al. para definição do plano $H$ opera da seguinte forma: dado o ponto $\mathbf{p}$ a ser projetado, o processo se inicia com uma estimativa inicial para a projeção, digamos $\mathbf{x}_{1}$ (por exemplo, o centro de massa ponderado dos pontos ou o ponto mais próximo a $\mathbf{p})$. Então, usamos $\mathbf{x}_{1}$ para associar pesos $\theta\left(\left\|\mathbf{p}_{i}-\mathbf{x}_{1}\right\|\right)$ aos pontos $\mathbf{p}_{i}$ da nuvem de pontos, definindo, pelo método dos mínimos-quadrados ponderados, o plano $H_{\mathbf{x}_{1}}$. Em seguida, pé projetado sobre $H_{\mathbf{x}_{1}}$, dando uma nova estimativa para a projeção $\mathbf{x}_{2}$ e o processo é repetido. Este processo é computacionalmente mais simples que o proposto anteriormente, pois não necessita de uma minimização não-linear.

Observação 4 As abordagens de Alexa et al. [9] e Pauly et al. [167] são sutilmente distintas entre si em relação ao processo de "colocar" o ponto p na superfície. No entanto, Amenta e Kil [16] afirmam que ambas não produzem de fato pontos sobre a superfície MLS.

Amenta e Kil [16] ainda apresentam definições distintas das apresentadas previamente de superfície MLS. Além disso, mostraram relações com outras definições de superfícies já conhecidas na literatura (elas são as superfícies extremas [151] e os conjuntos de Jacobi [69]). Outro trabalho interessante dos autores, que complementa esta discussão, estuda o domínio e o comportamento das superfícies MLS [17].

Diversas extensões dos métodos anteriores têm sido propostas. Entretanto, aquelas que possuem grande impacto são as que definem mecanismos de modelagem de características afiadas [80, 98, 1, 167, 219, 173].

Fleishman et al. [80] propuseram uma extensão do método de Alexa et al. [9], que, além de ser capaz de modelar características afiadas, evita que pontos discrepantes (outliers) 
sejam utilizados no cálculo da superfície. A Figura 2.9 compara a técnica de Alexa et al. [9] com a técnica de Fleishman.
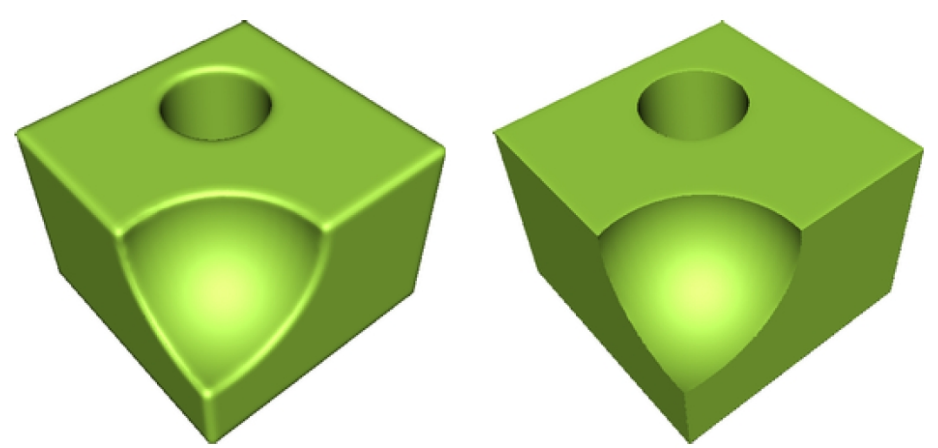

Figura 2.9: Comparação entre a técnica de Alexa et al. [9] (esquerda) e a técnica de Fleishman et al. [80] (direita). A segunda abordagem é capaz de modelar características afiadas.

Dado um ponto $\mathbf{x}$ a ser projetado sobre a superfície, o método calcula um conjunto de superfícies suaves da vizinhança de $\mathbf{x}$. Estas superfícies suaves são calculadas uma a uma utilizando-se um procedimento estatístico incremental. Para a obtenção destas superfícies, um ponto por vez da nuvem é classificado a uma das superfícies suaves. Note que um ponto pode, ao máximo, participar do cálculo de uma das superfícies. Esses pontos só são adicionados se satisfizerem os critérios estatísticos de qualidade das aproximações [80]. Uma vez que o conjunto de pontos de cada uma das superfícies esteja definido (inclusive livre de ruídos), superfícies locais são calculadas. Após a etapa de definição das superfícies, $\mathbf{x}$ é projetado conforme as possíveis configurações de vizinhanças, conforme a proposta de Pauly et al. [167]. Para isso, as superfícies devem estar propriamente orientadas. Conseqüentemente, vetores normais orientados são necessários. Apesar do elevado custo computacional, os resultados apresentados por Fleishman et al. [80] são satisfatórios, mesmo aqueles na presença de conjuntos ruidosos e com pontos discrepantes.

Existem ainda outras técnicas de PSS que também fazem uso de operações booleanas [98, 1, 167, 219] para modelar características afiadas. No entanto, ao contrário dos métodos anteriores, o trabalho de Reuter et al. [173] não faz uso de operações booleanas para definir características afiadas. O método substitui a aproximação polinomial do método 
de Alexa et al. [9], pelo Enriched Reproducing Kernel Particle Approximation (ERKPA), que considera, além de termos polinomiais, funções enriquecidas que descrevem, de alguma forma, descontinuidades nas derivadas. As principais deficiências dessa abordagem, no nosso entendimento, são: a forma não-automática para definir o domínio das funções enriquecidas, isto é, o usuário deve fornecer as descontinuidades do objeto, e a necessidade de investigar as propriedades das funções enriquecidas para assegurar que o sistema linear provido do esquema de minimização possua solução única. Além disso, os autores também argumentam que a qualidade dos vetores normais não é garantida e, portanto, com o intuito de produzir bons efeitos visuais, os autores geram o modelo utilizando a técnica de poligonalização proposta por Bloomenthal et al. [33].

Lipman et al. $[137,138]$ apresentaram recentemente duas interessantes técnicas de projeção. O primeiro trabalho [137] também segue a linha de redefinir a segunda etapa do método de Alexa et al. [9]. Os autores propuseram um eficiente esquema de detecção de características afiadas, baseado em aproximações locais de derivadas para pontos nãoorganizados, que são calculadas a partir da própria deficiência do método MLS [9], as quais tendem a suavizar as características do objeto [136]. Os autores também argumentam que a técnica deles é de duas ordens de magnitude mais rápida que o método de Fleishman et al. [80]. No entanto, uma deficiência desta abordagem é a incapacidade de modelar características afiadas que definem vértices.

O segundo trabalho de Lipman et al. [138] é um operador denominado Projeção Localmente Ótima (Locally Optimal Projection - LOP) [138]. Se a superfície é de classe $C^{2}$, LOP possui convergência de ordem $O\left(h^{2}\right)$, em que $h$ é o espaçamento médio entre os pontos. Uma característica atraente do método é a capacidade de lidar naturalmente com superfícies com bordo (Figura 2.10), o que não ocorre para os métodos previamente citados. Além disso, como pode ser observado na Figura 2.10, o método não apenas projeta pontos sobre a superfície, mas também contém um mecanismo de repulsão que evita aglomerações de pontos em determinadas regiões. Outra vantagem é que a técnica também é eficiente na presença de ruídos e pontos discrepantes. 


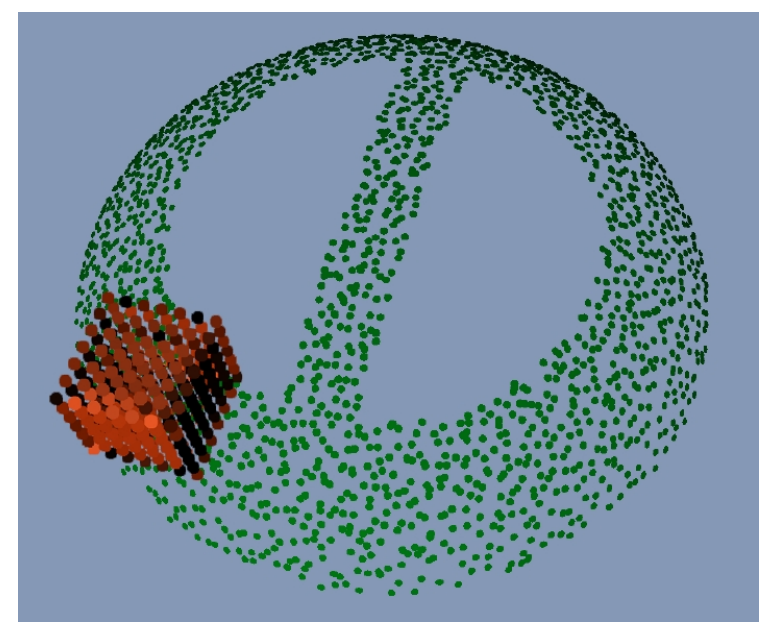

(a)

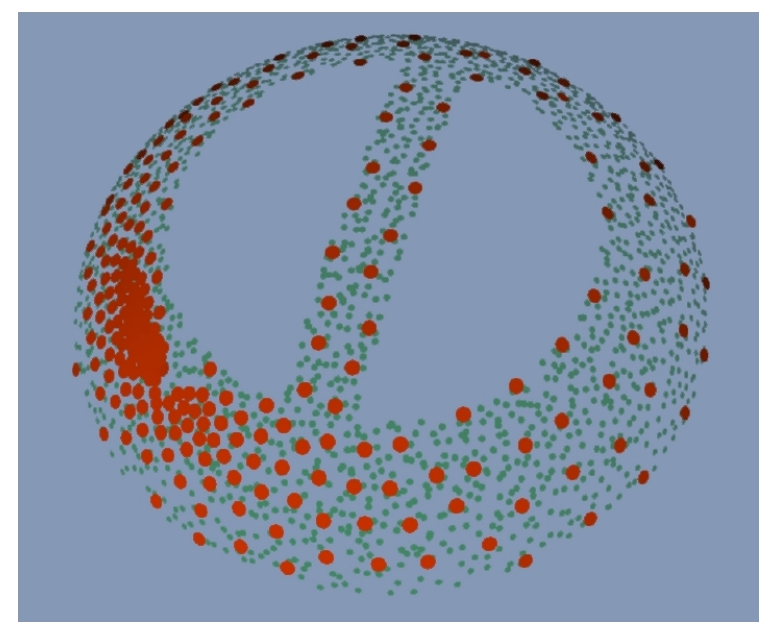

(c)

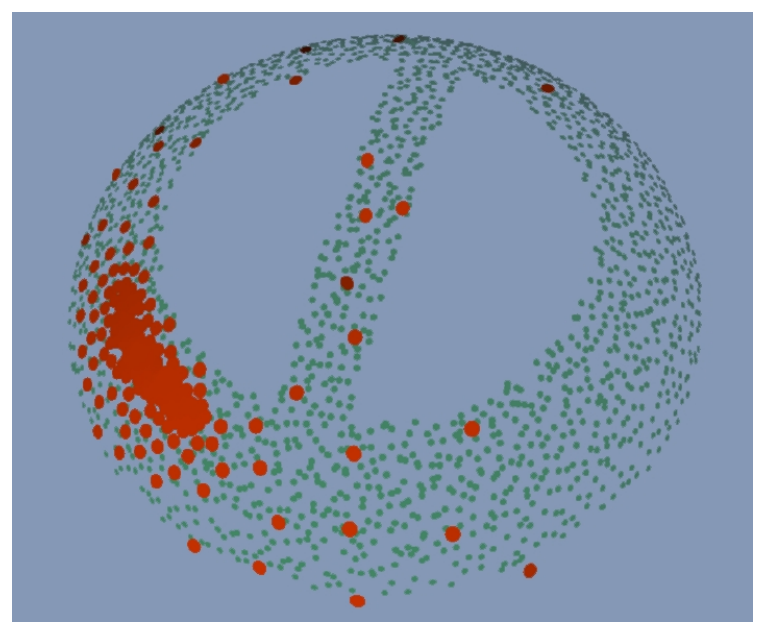

(b)

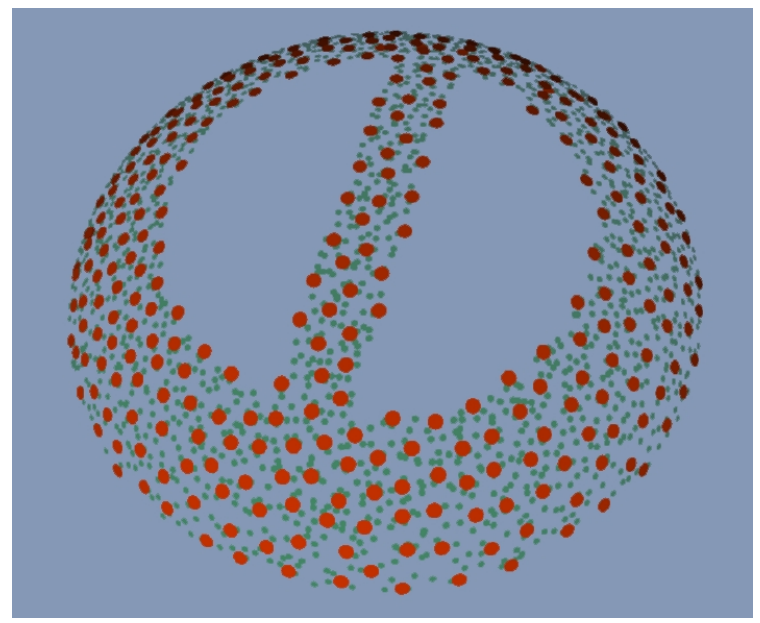

(d)

Figura 2.10: Exemplo apresentado por Lipman et al. [138], que exemplifica a projeção de pontos na superfície pelo LOP.

LOP é baseado em um método de iteração de ponto-fixo, por meio do qual a superfície aproximada é definida pelos pontos fixos da tal iteração. O método é construído a partir de mecanismos estatísticos, que são tradicionalmente aplicados a pontos não-organizados e multidimensionais para a geração de conjuntos representativos de pontos (as citações desta técnica, segundo Lipman, datam do início do século XX [138]).

\subsection{Métodos Implícitos}

Os métodos implícitos partem de um conjunto de pontos não-organizados para definir 
uma função (com sinal) $f: \mathbb{R}^{3} \rightarrow \mathbb{R}$, de forma que um conjunto de nível, em geral o conjunto $\left\{\mathbf{x} \in \mathbb{R}^{3}: f(\mathbf{x})=0\right\}$, aproxime a superfície. Portanto, a partir dessa função, a representação da superfície pode ser obtida diretamente por um método de traçado-de-raios, ou por meio de um método de poligonalização de superfícies. No Capítulo 4, apresentaremos resultados de nossa técnica de partição da unidade implícita por ambas as formas. Nessa seção, veremos que existem diversas formas de se definir uma função implícita baseada em nuvens de pontos. Aquelas que apresentam um número maior de trabalhos são as embasadas em funções de bases radiais (radial basis function-RBF), em mínimos-quadrados-móveis implícitos ou em partição da unidade implícita. Antes de iniciarmos a descrição dos trabalhos, é importante mencionar um dos trabalhos pioneiros, proposto por Hoppe et al. [107], que inspirou diversos métodos baseados em função implícita.

Nesse trabalho [107], dado o ponto $\mathbf{x}$, a função $f$ é definida por

$$
f(\mathbf{x})=<\mathbf{x}-\mathbf{c}(\mathbf{x}), \mathbf{n}(\mathbf{x})>
$$

em que $\mathbf{c}(\mathbf{x})$ é o centro de massa e $\mathbf{n}(\mathbf{x})$ é uma aproximação do vetor normal calculado a partir da matriz de co-variância. Como a estimativa do vetor normal pela matriz de co-variância não garante a consistência da orientação do vetor, os autores, nesse mesmo trabalho, propuseram um esquema de orientação dos vetores normais, baseado na árvoregeradora-mínima-euclidiana.

Adamson e Alexa [2] definiram uma função implícita baseada em mínimos-quadradosmóveis com a inclusão de funções-peso para o cálculo do centro de massa e do vetor na função definida por Hoppe et al., isto é, os pontos $\mathbf{p}_{i}$ mais próximos do ponto $\mathbf{x}$, em que se pretende avaliar a função, fornecem maior influência no cálculo. Assim, o centro de massa passa a ser dado por:

$$
\mathbf{c}(\mathbf{x})=\frac{1}{\sum_{\mathbf{p}_{i} \in \mathscr{P}} \omega_{i}(\mathbf{x})} \sum_{\mathbf{p}_{i} \in \mathscr{P}} \mathbf{p}_{i} \omega_{i}(\mathbf{x}),
$$

e a aproximação do vetor normal é calculada pela matriz de co-variância ponderada, dada 
na Equação 2.14. Note que o problema dos vetores normais não orientados se mantém para este caso e, portanto, mecanismos de orientação dos vetores normais são necessários.

Se considerarmos como entrada não somente o conjunto de pontos $\mathbf{p}_{i}$, mas também o conjunto de suas respectivas normais orientadas $\mathscr{N}=\left\{\mathbf{n}_{i}\right\}$, então a estimativa oriunda pela matriz de co-variância pode ser substituída pela média ponderada das normais:

$$
\mathbf{n}(\mathbf{x})=\frac{1}{\left\|\sum_{\mathbf{n}_{i} \in \mathscr{N}} \mathbf{n}_{i} \omega_{i}(\mathbf{x})\right\|} \sum_{\mathbf{n}_{i} \in \mathscr{N}} \mathbf{n}_{i} \omega_{i}(\mathbf{x}) .
$$

Adamson e Alexa discutem as diferenças na utilização de ambas as abordagens de aproximação do vetor normal [7].

Kolluri [119] apresentou uma função MLS implícita que possui garantias de reconstrução de uma superfície isomorfa à superfície original respeitando condições de amostragem e distribuição dos vetores normais. A função implícita desse trabalho é definida por:

$$
I(\mathbf{x})=\frac{\sum_{\mathbf{p}_{i} \in \mathscr{P}} W_{i}(\mathbf{x})\left(\mathbf{x}-\mathbf{p}_{i}\right) \cdot \mathbf{n}_{i}}{\sum_{\mathbf{p}_{i} \in \mathscr{P}} W_{i}(\mathbf{x})}
$$

em que $W_{i}(\mathbf{x})=e^{\frac{-\left\|\mathbf{x}-\mathbf{p}_{i}\right\|^{2}}{r^{2}}} / \operatorname{card}\left(\mathbf{p}_{i}\right)$, sendo $\operatorname{card}\left(\mathbf{p}_{i}\right)$ o número de pontos dentro da bola de raio $r$, centrada em $\mathbf{p}_{i}$. Essa função implícita é semelhante à utilizada por Chen et al. [186] cuja entrada consiste em um conjunto de triângulos em vez de pontos (sopa de polígonos).

A função implícita proposta por Dey e Sun [63], que é uma modificação da função de Kolluri [119], possibilita provar garantias sobre amostragens com densidade de pontos variável. O fator $h$ da função gaussiana, utilizada na formulação implícita, varia, nesse caso, em função do local feature size $[63,12]$ da amostragem. No entanto, a deficiência desse método é a dependência da triangulação de Delaunay para estimar o fator $h$. Por outro lado, o método também apresenta resultados satisfatórios mesmo na presença de ruídos.

As funções implícitas apresentadas anteriormente são baseadas em aproximações locais por planos. Recentemente, Guennebaud e Gross apresentaram outra função implícita baseada em mínimos-quadrados-móveis cuja minimização é realizada por esferas algébricas [97]. Discutiremos esse método no Capítulo 5, pois ele está relacionado com nossa 
técnica de acompanhamento de fronteiras com mínimos-quadrados-móveis.

Também foram propostos trabalhos que fazem uso da triangulação de Delaunay e de suas relações com outras definições geométricas ( $\alpha$-shapes, diagrama de Voronoi) para se definir uma função implícita [21, 28, 35]. No entanto, essas abordagens possuem algumas das deficiências dos métodos de esculpimento e, portanto, não fazem parte dos métodos pertinentes aos nossos estudos.

O uso de funções de bases radiais - RBF - (funções simétricas em relação à vizinhança radial de um ponto) [44] também tem sido explorado para definição de métodos de representação implícita por nuvens de pontos. Carr et al. [44] propuseram a seguinte função:

$$
f(\mathbf{x})=\sum_{i=1}^{m} \lambda_{i} \phi\left(\left\|\mathbf{x}-\mathbf{c}_{i}\right\|\right)+P(\mathbf{x})
$$

em que $P=\left\{p_{1}, \cdots, p_{l}\right\}$ define uma base de polinômios de baixo grau (em geral definido pelo polinômio constante e pelos lineares) que se encarrega de representar regiões planas do objeto e $\mathbf{c}_{i}$ são os centros das funções radiais $\phi$, que são definidas, por exemplo por Carr et al. [44], por $\phi(t)=|t|$.

Duas condições são necessárias para a definição da Função 2.19. A primeira é, a partir do conjunto de centros radiais $\mathbf{c}_{i}$, fornecer os valores (interpolantes) $f_{i}=f\left(\mathbf{c}_{i}\right)$. A segunda é definir polinômios $q \in P$, satisfazendo a condição $\sum_{i=1}^{m} \lambda_{i} q\left(\mathbf{x}_{i}\right)=0$. Essas duas condições permitem a definição de um sistema linear cuja solução é definida pelas incógnitas $\lambda_{i}$ e pelos coeficientes do polinômio definido por $P$ :

$$
\left(\begin{array}{ll}
A & P \\
P^{t} & 0
\end{array}\right)\left(\begin{array}{l}
\lambda \\
c
\end{array}\right)=\left(\begin{array}{l}
f \\
0
\end{array}\right),
$$

em que $A_{i j}=\phi\left(\left\|\mathbf{x}_{i}-\mathbf{x}_{j}\right\|\right), P_{i, j}=p_{j}\left(\mathbf{x}_{i}\right), f=\left(f_{1}, \cdots, f_{m}\right)$ e $c=\left(c_{1}, \cdots, c_{l}\right)$ são os coeficientes dos polinômios.

É importante mencionar que, para os pontos $\mathbf{x}_{i}$ que estão na superfície, $f\left(\mathbf{x}_{i}\right)=0$. Isto significa que é necessário considerar também pontos fora (off-set) da superfície para não se obter a solução trivial $\lambda_{i}=0$ para todo $i$. Carr et al. [44] sugerem definir pontos off-set da 
seguinte forma: a partir de cada centro $\mathbf{c}_{i}$ da superfície, define-se outro centro caminhandose na direção do vetor normal.

A qualidade da solução depende da quantidade de pontos off-sets, da posição dos centros radiais e da função radial escolhida. Por um lado, esses métodos oferecem diversas vantagens, entre elas o fato de que métodos baseados em RBF conseguem lidar com dados ruidosos e incompletos. Por outro, o custo computacional é ditado pela solução do Sistema Linear 2.20, que ainda tende a ser mal-condicionado.

Com o intuito de aliviar o custo computacional do sistema linear, Morse et al. [153] propuseram o uso de funções radiais com suporte compacto, que diminuem o custo computacional. Porém, o método tende a se tornar ineficiente para dados incompletos. Além disso, ainda existe a questão da escolha dos centros radiais. Reuter et al. [174] propuseram um método baseado em RBF cuja principal contribuição está no esquema de rendering baseado em pontos. Dihn et al. [64] aplicam bases radiais, mas utilizando pesos elípticos (funções de bases elipsoidais). Nesse trabalho, os autores argumentam que a definição apropriada das direções dos pesos permite capturar melhor características afiadas.

Kazhdan [114] propôs um método implícito para extrair a iso-superfície reconstruída a partir de uma função indicadora (função binária que assume 1 no interior do objeto e 0 fora) definida em uma discretização regular (no caso o autor utiliza uma grade computacional regular). Para isso, Kazhdan define a função indicadora pelos coeficientes da Transformada de Fourier. Na prática, dever-se-iam calcular os coeficientes de Fourier por meio da integração da função em relação aos expoentes complexos no interior do modelo. Entretanto, utilizando o Teorema de Stokes, que expressa a integral de uma função definida no interior de uma região como uma integral de superfície, representa-se apenas com informações das posições dos pontos não-organizados e suas respectivas normais. Portanto, como a entrada do método é o conjunto de pontos equipados com seus vetores normais, toda a informação necessária para os cálculos dos coeficientes de Fourier está disponível. O método é capaz de lidar com dados ruidosos, mas a dependência da grade computacional regular no espaço tridimensional torna o método caro em termos de memória e tempo de processamento. 
Kazhdan et al. [115] reformularam o método anterior para um problema de Poisson. A entrada desse método também é um conjunto de pontos com suas normais orientadas e a idéia também parte da definição de uma função indicadora. Os autores mostram que o vetor gradiente da função corresponde a um campo de vetores formados por uma integral sobre a superfície, que pode ser aproximada por uma soma sobre os pontos orientados. Isto é, dada a função indicadora $f$ e o campo de vetores $v$, para se obter uma solução de mínimosquadrados da equação:

$$
\nabla f=v
$$

aplica-se operador divergente em ambos os lados:

$$
\nabla \cdot \nabla f=\nabla \cdot v
$$

que define a equação de Poisson. Nessa abordagem, os autores verificam que é possível utilizar uma octree em vez da grade computacional regular. No entanto, para a solução numérica oriunda da Equação 2.22, é necessária a solução de um sistema linear e, dessa forma, a memória e o custo computacional também tornam-se altos. Para contornar esse problema, Bolitho et al. [36] propuseram uma versão desse método em que a criação do sistema linear, a sua solução e a extração da iso-superfície são acessadas eficiente e diretamente a partir do disco rígido, gerando assim um método eficiente, pelo qual tais informações possam ser maiores que a capacidade da memória RAM (out-of-core). É importante mencionar que, em geral, nas demais técnicas, a função é definida de forma que o isovalor 0 represente a superfície reconstruída, ao passo que, para esses trabalhos $[114,115,36]$, os autores discutem esquemas apropriados para a seleção do isovalor.

A idéia de utilizar Equação de Poisson e função indicadora não é nova. Torres e Brackbill [207] também representaram superfícies por pontos não-organizados, utilizando tais conceitos. Tal método foi desenvolvido para representar interfaces de fluidos em simulação numérica de escoamento de fluidos multifásicos. 
O último conjunto de métodos de representação de superfícies por funções implícitas consiste naqueles baseados em Partição da Unidade Implícita (PUI). A primeira abordagem nesse sentido foi proposta por Ohtake et al. [158]. A técnica, em linhas gerais, opera em subdividir o domínio, utilizando uma octree, em criar multiníveis de aproximações e em realizar blendings dessas aproximações de modo a definir uma função implícita global. A função global de Ohtake et al. é definida ao mesmo tempo em que a superfície é extraída por um poligonalizador de iso-superfícies [33] ou é obtida por métodos de traçado-de-raios [102] (método on-the-fly). Isto é, a função apenas é definida nas regiões onde é necessário aproximar a função.

No Capítulo 4, apresentaremos nossa abordagem baseada em PUI e realizaremos comparações numéricas e teóricas com a técnica de Ohtake. Desse modo, deixaremos para definir a PUI e apresentar os detalhes da técnica de Ohtake de forma comparativa naquele momento.

No entanto, com o intuito de dar continuidade ao levantamento bibliográfico, adiantamos que diversas abordagens foram propostas posteriormente para tentar contornar as principais deficiências do método de Ohtake: as heurísticas que o método utiliza para definir as aproximações locais são susceptíveis a aproximações equivocadas e sensíveis aos dados ruidosos. Portanto, a qualidade da função global pode ser comprometida pela operação de blending entre funções vizinhas que podem ter sido mal-calculadas.

Melhoramentos em PUI têm sido desenvolvidos para contornar a deficiência na imprecisão das aproximações locais e para lidar com dados ruidosos. No entanto, em todas essas abordagens, o custo computacional tende a aumentar significativamente, uma das principais vantagens do trabalho original de Ohtake et al. [158].

Ohtake et al. [160] propuseram um método que é capaz de produzir modelos com alta qualidade, mesmo na presença de ruídos. O método é definido pela combinação de funções de bases radiais e PUI. Entretanto, o custo computacional é alto devido ao fato de o método necessitar de regressão rígida [103], bem como de métodos de otimização para definir as posições ótimas para os centros das funções radiais. 
Mederos et al. [147, 148] definiram o problema de PUI pelo método de penalidade, conhecido como gradient-one-fitting [31], que é um método de mínimos-quadrados sem restrições para aproximações por quádricas. Essa técnica não apenas utiliza a posição dos pontos, mas também seus vetores normais para formular a minimização (no Capítulo 5, apresentaremos o nosso método de MLS baseado em esferas algébricas [97], que também faz uso do método de mínimos-quadrados, o qual utiliza tanto os pontos quanto as normais, só que livre de penalidades). A idéia de utilizar também as normais na minimização, segundo os autores, ajuda a evitar descontinuidades no conjunto de dados e a sensibilidade a pequenas perturbações nas amostras. Por outro lado, os principais problemas são a escolha de parâmetros ótimos e a necessidade de usar regressão rígida para resolver o sistema de equações, em que a matriz pode não apresentar posto máximo.

Recentemente, Chen e Lai [51] apresentaram um método de PUI em que as funções locais também são construídas utilizando RBF. Por meio da fórmula de complemento de Schur [163], esse método permite a inserção iterativa de novas funções radiais sem a necessidade do recálculo de todo o sistema linear. Entretanto, apesar do uso de tal fórmula, o método ainda é computacionalmente caro. Uma proposta similar foi apresentada por Xia et al. [221], mas a seleção dos centros das funções radiais é realizada utilizando mecanismos populares no contexto de redes neurais.

Tobor et al. [205] também fazem uso de RBF para definir uma PUI. O método é baseado em uma decomposição espacial (árvore), construída de baixo para cima (bottom-up) em que os nós intermediários da árvore contêm pontos obtidos por um processo de afinamento (thinning) aplicado na nuvem de pontos. Essa estrutura, combinada com o esquema de aproximações locais, possibilita ao método lidar com diferentes níveis-de-detalhe e também com densidade variada de pontos (Figura 2.11). Todavia, alguns problemas são herdados dos métodos de RBF, tais como a necessidade de se definirem pontos extras (off-set) e o custo computacional elevado. 

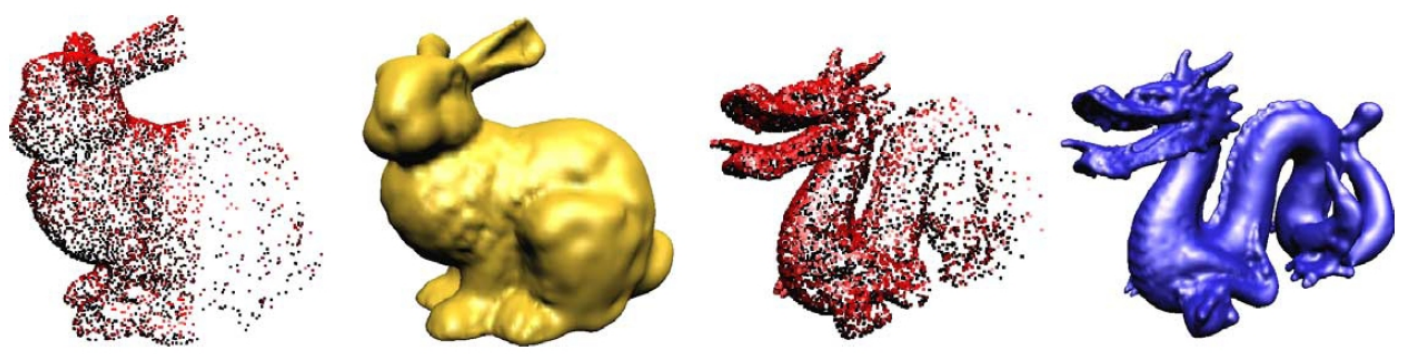

Figura 2.11: Exemplos de densidade variada de pontos com que o trabalho de Tobor et al. [205] é capaz de lidar eficientemente. 


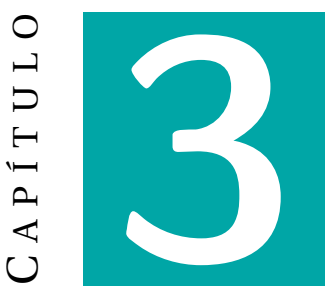

\section{Representação por Pontos Não-organizados: Abordagens Preliminares}

Neste capítulo, apresentamos dois métodos preliminares para representação de superfícies por pontos não-organizados. A primeira técnica é baseada em um operador de projeção no qual os polinômios locais são definidos por meio das curvaturas e direções principais estimadas a partir de mínimos-quadrados. Já a segunda abordagem faz uso de uma heurística inspirada em um método recente da Teoria da Aproximação, o iaMLS [77].

A motivação para as abordagens presentes nesta seção surgiu primeiramente para o desenvolvimento de técnicas que fossem adequadas para implementações em placas gráficas modernas - GPU. Como apontado por nossos parceiros da Universidade de Stuttgart - Alemanha ${ }^{1}$, os desafios para implementação de um método de representação baseado em pontos em uma GPU são diversos, tendo como principais:

1. O número de passagens pela GPU (render passes);

2. A definição de um mecanismo eficiente de busca por vizinhos;

\footnotetext{
${ }^{1}$ http://www.vis.uni-stuttgart.de/eng/
} 
3. Métodos de aproximação numérica que possam ser definidos eficientemente em matrizes (texturas) de tamanho até $4 \times 4$.

Notemos que, se quisermos uma aproximação de alta ordem, as aproximações locais devem ser constituídas de bases polinomiais de alto grau, e conseqüentemente uma única matriz de ordem 4 se torna inviável. A primeira saída, quando adaptamos o método de Adamson e Alexa [2] para GPU [204], foi selecionarmos uma base de polinômios não completa para a aproximação polinomial local da segunda etapa do operador de projeção. Por exemplo, para o resultado presente na Figura 3.1, selecionamos como base $\left\{x^{2}, y^{2}, x y, 1\right\}$, que pode comprometer a qualidade da solução em regiões planas do objeto.

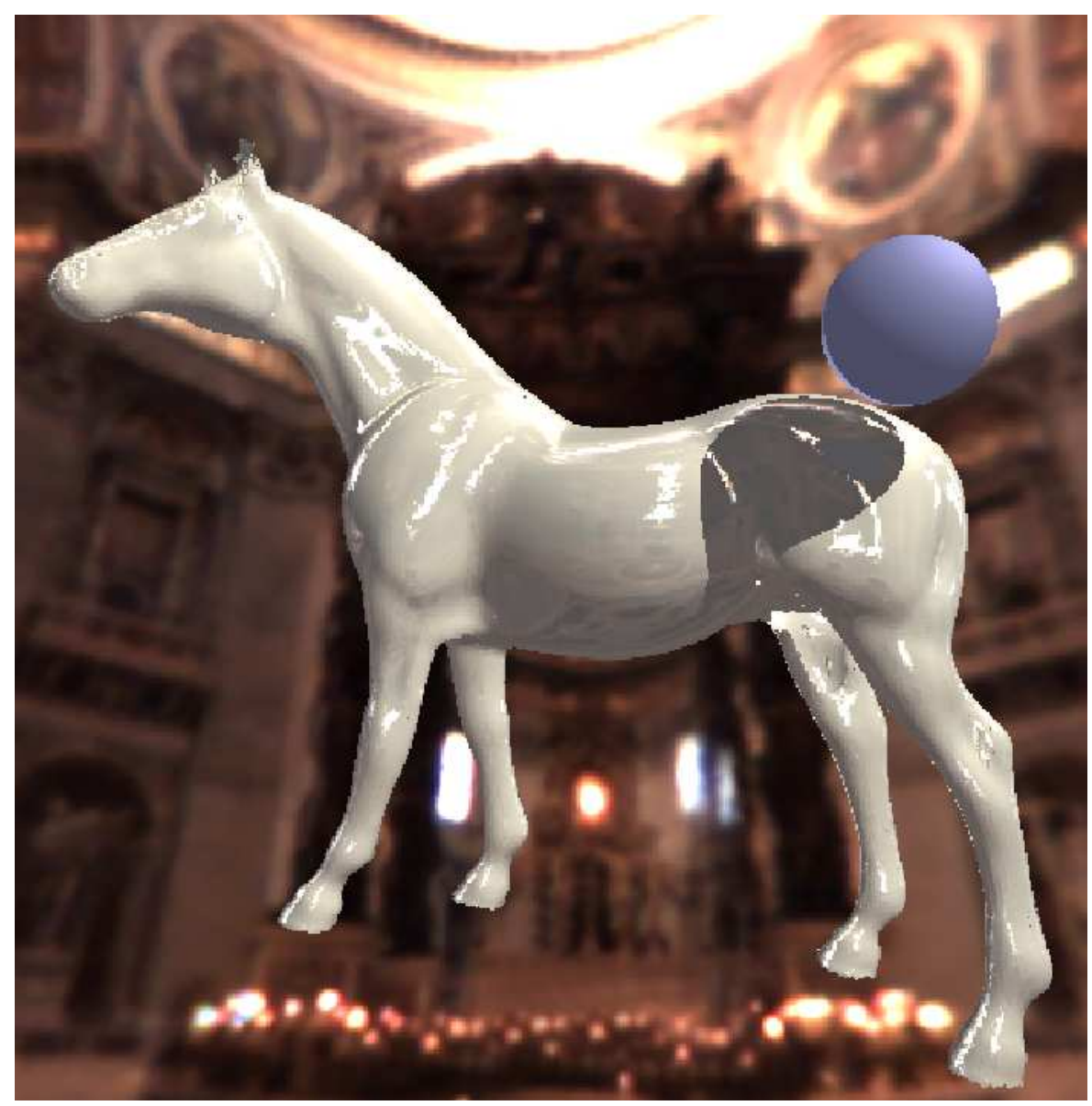

Figura 3.1: Resultado gerado pelo algoritmo de traçado-de-raios para nuvens de pontos, que implementamos na GPU [204].

Dessa forma, entre os desafios descritos acima, o nosso foco está relacionado ao âmbito 
numérico, no qual tivemos necessidade de pesquisar mecanismos que satisfizessem o último requisito. Como conseqüência, surgiu a busca por métodos de aproximação que utilizassem sistemas lineares definidos por matrizes de ordem menor ou igual a quatro [91], ou até mesmo métodos livres de sistemas lineares que fossem capazes de gerar soluções mais precisas $[75,23]$.

Por isso, nesta seção, apresentamos dois métodos de representação que buscam reduzir ou eliminar os cálculos matriciais, porém tentando manter os resultados satisfatórios.

\subsection{Projeção de Pontos Guiada por Curvaturas}

Aqui, apresentamos a técnica de projeção de pontos [9] que desenvolvemos [91]. Ela difere das anteriores, pois utiliza um polinômio reduzido definido pelas curvaturas e direções principais para realizar a aproximação polinomial local e por uma equação de difusão anisotrópica, que assegura a precisão da superfície reconstruída.

O fato de definir a aproximação como um polinômio quadrático não-completo tem por finalidade a redução do custo computacional da interseção entre o gráfico do polinômio e os raios das técnicas de traçado-de-raios para superfícies MLS [3]. Dessa forma, para fazer o rendering das superfícies definidas por nosso esquema de projeção, usamos o algoritmo de PSS de Adamson e Alexa [3]. Descrevemos como o cálculo da interseção deve ser modificado para enquadrar nosso esquema de projeção e para usar o método de traçado-de-raios com o intuito de demonstrar a qualidade das aproximações obtidas. Também comparamos nossos resultados com a técnica de Adamson e Alexa [3].

\subsubsection{Trabalhos Relacionados com Estimativas de Curvatura}

Curvaturas e direções principais em objetos definidos por grades computacionais regulares e malhas poligonais têm sido extensivamente estudadas, tanto no âmbito qualitativo quanto no quantitativo. Maltred e Daniel [141] apresentaram uma coletânea de técnicas clássicas de estimativas de curvaturas e uma classificação baseada nos requisitos e restrições 
dos métodos. Embora existam muitos métodos para se estimar curvaturas e direções principais, quase todos eles necessitam de uma malha (regular ou não). Apenas recentemente a eficiência dos métodos para estimar informações de curvaturas diretamente a partir de pontos não-organizados foi apresentada [6, 206, 108].

Tong e Tang [206] apresentaram um esquema para gerar estimativas robustas de curvatura, baseado em tensores adaptativos de curvatura por meio do tensor voting. Além disso, eles apresentaram uma comparação analítica com métodos eficientes em relação a entradas (nuvens de pontos ou malhas), seus requisitos (informações geométricas) e suas saídas (quantitativa ou qualitativa).

Huang e Menq [108], como comentado na Seção 2.3, definiram um estimador de curvaturas, utilizando mínimos-quadrados pelo o teorema de Euler, da geometria diferencial. Embora o método tenha sido proposto para remalhamento de malhas superficiais, esse também se fez adequado para nuvens de pontos. Derivamos nosso método a partir desse trabalho, pelo fato de podermos facilmente adaptá-lo para incluir funções pesos, que é uma importante condição para garantir a qualidade dos modelos gerados por PSS.

\subsubsection{Mínimos-Quadrados e as Equações Normais}

Consideremos um conjunto finito de pontos $\mathscr{P}=\left\{\mathbf{p}_{i}=\left(x_{i}, y_{i}, z_{i}\right): \mathbf{p}_{i} \in \mathbb{R}^{3}\right\}$. Nosso objetivo é construir uma função $f$ que melhor aproxima $\mathscr{P}$ com respeito à minimização das distâncias ao quadrado de $z_{i}$ a $f\left(x_{i}, y_{i}\right)$. Para isso, consideremos o seguinte sistema incompatível (sistema em que o número de equações é maior que o número de incógnitas):

$$
\mathbf{B c}=\mathbf{Z} \Longleftrightarrow\left(\begin{array}{c}
b\left(\overline{p_{1}}\right) \\
b\left(\overline{p_{2}}\right) \\
\vdots \\
b\left(\overline{p_{n}}\right)
\end{array}\right)\left(\begin{array}{c}
c_{1} \\
\vdots \\
c_{m}
\end{array}\right)=\left(\begin{array}{c}
z_{1} \\
z_{2} \\
\vdots \\
z_{n}
\end{array}\right),
$$

em que $b\left(\overline{\mathbf{p}_{i}}\right)$ é a aplicação de $\overline{\mathbf{p}_{i}}=\left(x_{i}, y_{i}\right)$ na base de funções $b$ e $\left\{c_{i}\right\}$ são os coeficientes da aproximação polinomial determinada em função de $z_{i}$. Por exemplo, se queremos 
aproximar $\mathscr{P}$ por um plano, escolhemos $b=(1, x, y)$. Por outro lado, se queremos aproximar $\mathscr{P}$ por um polinômio completo de grau 2, escolhemos $b=\left(1, x, x^{2}, y, y^{2}, x y\right)$.

Mínimos-quadrados-ponderados são formulados utilizando pesos que determinam quais pontos têm mais influência na solução. Para isso, uma matriz de pesos é multiplicada em ambos os lados do Sistema 3.1 para "forçar" alguns pontos a terem mais influência. Dessa forma, consideremos a seguinte matriz definida sobre $\mathscr{P}$ :

$$
\mathbf{W}=\left(\begin{array}{cccc}
\omega_{1} & 0 & \cdots & 0 \\
0 & \omega_{2} & \cdots & 0 \\
\vdots & \vdots & \cdots & \vdots \\
0 & 0 & \cdots & \omega_{n}
\end{array}\right)
$$

em que $w$ é a função-peso, por exemplo a gaussiana. Assim, pontos próximos ao ponto $\mathbf{p}$ oferecem maior influência na solução. Então, o Sistema 3.1 se torna:

$$
\mathbf{W B c}=\mathbf{W Z} .
$$

Simplificando a notação, definimos $\mathbf{W B}=\mathbf{A}$ e $\mathbf{W Z}=\mathbf{b}$. Então, o que queremos encontrar é o vetor c, de forma que minimizaremos:

$$
\|\mathbf{A c}-\mathbf{b}\|^{2}
$$

Como $\|u\|^{2}=<u, u>=u^{T} u$, temos que:

$$
(\mathbf{A c}-\mathbf{b})^{T}(\mathbf{A c}-\mathbf{b})=(\mathbf{A c})^{T}(\mathbf{A c})-\mathbf{b}^{T} \mathbf{A c}-(\mathbf{A c})^{T} \mathbf{b}+\mathbf{b}^{t} \mathbf{b} .
$$

Como $\mathbf{b}^{T} \mathbf{A c}=(\mathbf{A c})^{T} \mathbf{b}$, para encontrarmos o mínimo da Equação 3.5, derivam em relação a c e a igualamos a zero, isto é:

$$
\frac{d}{d \mathbf{c}}\left[(\mathbf{A c})^{T}(\mathbf{A c})-2(\mathbf{A c})^{T} \mathbf{b}+\mathbf{b}^{t} \mathbf{b}\right]=2 \mathbf{A}^{T} \mathbf{A c}-2 \mathbf{A}^{T} \mathbf{b}=0
$$

Portanto, o vetor c, que minimiza a Equação 3.4, é solução da equação normal: 


$$
\mathbf{A}^{T} \mathbf{A c}=\mathbf{A}^{T} \mathbf{b} .
$$

cuja matriz $\left(\mathbf{A}^{T} \mathbf{A}\right)^{-1} \mathbf{A}^{T}$ é chamada de pseudo-inversa de $\mathbf{A}$.

Tradicionalmente, três abordagens numéricas são empregadas para a minimização da Equação 3.4 [30]. A primeira é realizada pelo Sistema 3.7, utilizando esquemas baseados na fatoração de Gauss da matriz $\mathbf{A}^{T} \mathbf{A}$. No entanto, esse método, apesar de simples, é viável apenas se $\mathbf{A}^{T} \mathbf{A}$ tem posto completo e é bem-condicionada.

O segundo método numérico tradicional aplica a decomposição QR diretamente na matriz A, isto é, decompõe a matriz $\mathbf{A}_{m \times n}=\mathbf{Q}_{m \times n} \mathbf{R}_{n \times n}$, no qual $\mathbf{Q}$ é ortogonal e $\mathbf{R}$ triangular superior. Nesse caso, a solução do sistema se torna $\mathbf{R c}=\mathbf{Q b}$.

A terceira forma de minimização, computacionalmente a mais custosa, porém útil para matrizes significantemente mal-condicionadas, é obtida pelo método da decomposição em valores singulares (singular value decomposition - SVD). Nesse mecanismo, aplica-se uma decomposição $\mathbf{A}_{m \times n}=\mathbf{U}_{m \times m} \Sigma_{m \times n} \mathbf{V}_{n \times n}^{*}$, em que $\mathbf{U}$ e $\mathbf{V}^{*}$ são matrizes unitárias e $\Sigma$ é a matriz diagonal com valores singulares. Nesse caso, temos $\mathbf{c}=\mathbf{V} \Sigma^{+} \mathbf{U}^{*} \mathbf{b}$, em que cada entrada de $\Sigma^{+}$é o valor inverso de cada entrada correspondente em $\Sigma$. Porém, as entradas nulas se mantêm inalteradas. Note que, para os valores singulares muito próximos de zero, as inversões podem adicionar ruídos na solução. Nessa situação, com o intuito de oferecer uma solução mais exata, atribui-se zero a todos os valores singulares abaixo de um limite, ignorando-os antes do cálculo da pseudo-inversa $\mathbf{V} \Sigma^{+} \mathbf{U}^{*}$. Maiores detalhes a respeito desses esquemas são apresentados por Björk [30].

Apresentamos na próxima seção o esquema de mínimos-quadrados, definido a partir do teorema de Euler também pelas equações normais.

\subsubsection{Cálculo das Curvaturas e das Direções Principais}

As curvaturas direcionais em um ponto p sobre uma superfície suave $\mathscr{S}$ são definidas em termos das curvaturas de curvas suaves sobre $\mathscr{S}$, contendo p. As curvaturas direcionais, 
mínima e máxima, calculadas a partir de tais curvas são chamadas de curvaturas principais e suas respectivas direções são chamadas de direções principais. Um resultado importante atesta que as direções principais em um ponto qualquer da superfície $\mathscr{S}$ sempre são ortogonais [43].

O teorema de Euler, da geometria diferencial, atesta que cada curvatura direcional em $\mathbf{p} \in \mathscr{S}$ pode ser descrita pelas suas curvaturas e direções principais [43]. Formalmente, definimos direções e curvaturas principais em $\mathbf{p} \operatorname{como} v_{1}^{\mathbf{p}}$ e $v_{2}^{\mathbf{p}}$, e $\kappa_{1}^{\mathbf{p}}$ e $\kappa_{2}^{\mathbf{p}}$ respectivamente. $\mathrm{O}$ teorema de Euler nos diz que a curvatura em p na direção $\mu$ é dada por:

$$
\kappa^{\mathbf{p}}(\mu)=\kappa_{1}^{\mathbf{p}} \cos ^{2}(\alpha)+\kappa_{2}^{\mathbf{p}} \operatorname{sen}^{2}(\alpha)
$$

em que $\mu=\cos (\alpha) v_{1}^{\mathbf{p}}+\operatorname{sen}(\alpha) v_{2}^{\mathbf{p}}$.

Consideremos uma aproximação para o plano tangente $\mathscr{T}$ em p, no qual definimos um sistema de coordenadas local $\left\{t_{1}, t_{2}\right\}$ com origem em $\mathbf{p}$ (Figura 3.2). Calculamos as projeções $\tilde{\mathbf{p}}_{i}$ sobre $\mathscr{T}$ dos vizinhos $\mathbf{p}_{i}$ de $\mathbf{p}$, definindo as direções $v^{i}$. Ordenando tais direções no sentido horário, obtemos os ângulos $\theta_{i}$ de $t_{1}$ a $\tilde{\mathbf{p}}_{i}$. Denotemos também por $\beta_{i}$ o ângulo no sentido horário da direção principal $v_{1}^{\mathbf{p}}$ a $v^{i}$.

Portanto, aproximamos a curvatura direcional por:

$$
k^{\mathbf{p}}\left(v^{i}\right):=\frac{2<\mathbf{n}_{\mathbf{p}}, \varrho^{i}>}{<\varrho^{i}, \varrho^{i}>}
$$

em que $\mathbf{n}_{\mathbf{p}}$ é o vetor normal em $\mathbf{p}$ e $\varrho^{i}=\mathbf{p}_{i}-\mathbf{p}$ para $\mathbf{p}_{i}$ na vizinhança de $\mathbf{p}$. Essa curvatura discreta direcional tem sido utilizada em diversos outros trabalhos para estimativa de curvatura [108, 126, 202, 206].

O seguinte sistema incompatível não-linear é obtido a partir do teorema de Euler e das estimativas de curvaturas direcionais 3.9: 


$$
\left(\begin{array}{cc}
\cos ^{2}\left(\beta_{1}\right) & \operatorname{sen}^{2}\left(\beta_{1}\right) \\
\cos ^{2}\left(\lambda_{2}\right) & \operatorname{sen}^{2}\left(\lambda_{2}\right) \\
\vdots & \vdots \\
\cos ^{2}\left(\lambda_{m}\right) & \operatorname{sen}^{2}\left(\lambda_{m}\right)
\end{array}\right)\left(\begin{array}{c}
\kappa_{1}^{\mathbf{p}} \\
\kappa_{2}^{\mathbf{p}}
\end{array}\right)=\left(\begin{array}{c}
\kappa^{\mathbf{p}}\left(v^{1}\right) \\
\kappa^{\mathbf{p}}\left(v^{2}\right) \\
\vdots \\
\kappa^{\mathbf{p}}\left(v^{m}\right)
\end{array}\right)
$$

em que $\lambda_{i}=\beta_{1}+\delta \beta_{i}$ e $\delta \beta_{i}=\beta_{i}-\beta_{1}=\theta_{i}-\theta_{1}$.

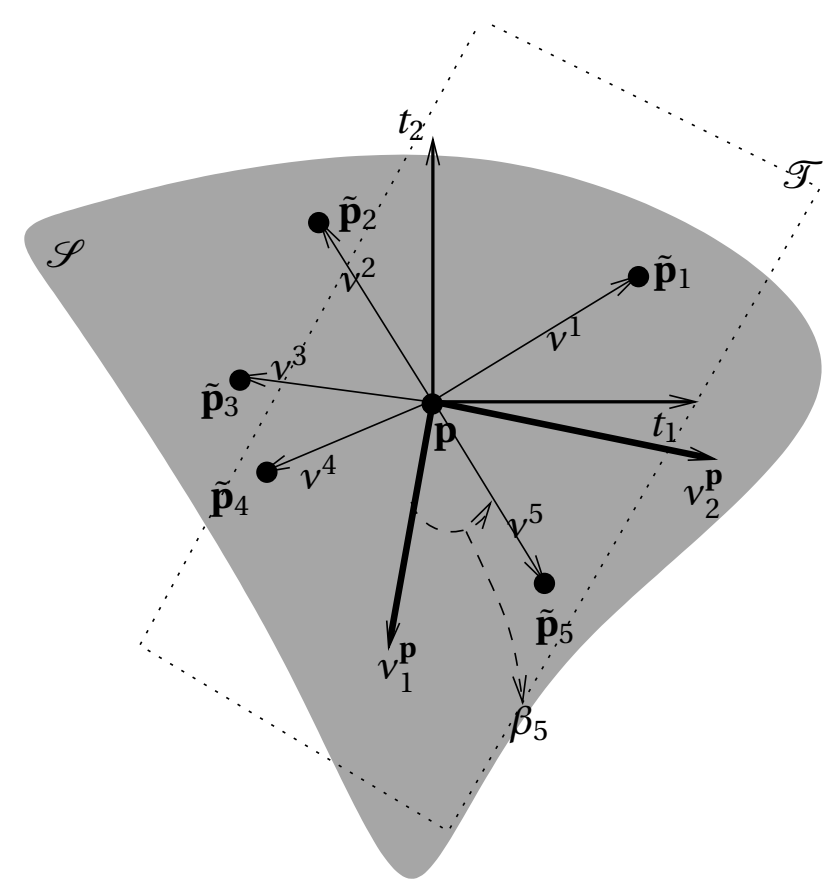

Figura 3.2: Estimando as curvaturas direcionais sobre o plano tangente aproximado em $\mathbf{p}$.

Huang e Menq [108] propuseram uma linearização para tal sistema. Para isso, definiram $\gamma_{1}=\frac{\kappa_{1}^{p}+\kappa_{2}^{p}}{2}, \gamma_{2}=-\cos \left(2 \beta_{1}\right)\left(k_{2}^{p}-k_{1}^{p}\right)$ e $\gamma_{3}=\operatorname{sen}\left(2 \beta_{1}\right)\left(k_{2}^{p}-k_{1}^{p}\right)$, produzindo o seguinte sistema linear incompatível:

$$
\left(\begin{array}{ccc}
1 & 1 & 0 \\
1 & \cos \left(2 \delta \beta_{2}\right) & \operatorname{sen}\left(2 \delta \beta_{2}\right) \\
\vdots & \vdots & \vdots \\
1 & \cos \left(2 \delta \beta_{m}\right) & \operatorname{sen}\left(2 \delta \beta_{m}\right)
\end{array}\right)\left(\begin{array}{c}
\gamma_{1} \\
\gamma_{2} \\
\gamma_{3}
\end{array}\right)=\left(\begin{array}{c}
\kappa^{p}\left(v^{1}\right) \\
\kappa^{p}\left(v^{2}\right) \\
\vdots \\
\kappa^{p}\left(v^{m}\right)
\end{array}\right)
$$

Portanto, as equações normais a partir do Sistema 3.11 são: 


$$
\left(\begin{array}{ccc}
m & \sum_{i=1}^{m} c_{i} & \sum_{i=1}^{m} s_{i} \\
\sum_{i=1}^{m} c_{i} & \sum_{i=1}^{m}\left(c_{i}\right)^{2} & \sum_{i=1}^{m} c_{i} s_{i} \\
\sum_{i=1}^{m} s_{i} & \sum_{i=1}^{m} c_{i} s_{i} & \sum_{i=1}^{m}\left(s_{i}\right)^{2}
\end{array}\right)\left(\begin{array}{l}
\gamma_{1} \\
\gamma_{2} \\
\gamma_{3}
\end{array}\right)=\left(\begin{array}{c}
\sum_{i=1}^{m} \hat{\kappa}_{i} \\
\sum_{i=1}^{m} \hat{\kappa}_{i} c_{i} \\
\sum_{i=1}^{m} \hat{\kappa}_{i} s_{i}
\end{array}\right)
$$

nas quais $c_{i}=\cos \left(2 \delta \beta_{i}\right), s_{i}=\operatorname{sen}\left(2 \delta \beta_{i}\right)$ e $\hat{\kappa}_{i}=\kappa^{p}\left(v^{i}\right)$. Dessa forma, as direções e curvaturas principais são obtidas diretamente a partir de $\gamma_{i}, 1 \leq i \leq 3$.

Embora Huang e Menq aleguem que o método é robusto para dados ruidosos, apenas obtivemos robustez após adicionar um tipo de peso particular. Para esse fim, definimos os pesos $\mathbf{w}_{i}=\left(\mathbf{w}\left(\left\|\mathbf{p}_{i}-\mathbf{p}\right\|\right)\right)^{2}$, em que w é uma função peso do tipo "M". Para o nosso problema, utilizamos:

$$
\mathbf{w}(t)=t^{2 \varsigma} e^{-\frac{t^{2}}{\Delta^{2}}}
$$

em que $\varsigma \in \mathbb{N}^{*}$ e $\Delta$ é o fator de suavidade, como no trabalho de Alexa et al. [9]. Mais adiante, veremos como a alteração desses parâmetros mudam a função-peso do tipo "M". Assim, modificamos as equações normais para:

$$
\left(\begin{array}{ccc}
\sum_{i=1}^{m} \mathbf{w}_{i} & \sum_{i=1}^{m} \mathbf{w}_{i} c_{i} & \sum_{i=1}^{m} \mathbf{w}_{i} s_{i} \\
\sum_{i=1}^{m} \mathbf{w}_{i} c_{i} & \sum_{i=1}^{m} \mathbf{w}_{i}\left(c_{i}\right)^{2} & \sum_{i=1}^{m} \mathbf{w}_{i} c_{i} s_{i} \\
\sum_{i=1}^{m} \mathbf{w}_{i} s_{i} & \sum_{i=1}^{m} \mathbf{w}_{i} c_{i} s_{i} & \sum_{i=1}^{m} \mathbf{w}_{i}\left(s_{i}\right)^{2}
\end{array}\right)\left(\begin{array}{l}
\gamma_{1} \\
\gamma_{2} \\
\gamma_{3}
\end{array}\right)=\left(\begin{array}{c}
\sum_{i=1}^{m} \mathbf{w}_{i} \hat{\kappa}_{i} \\
\sum_{i=1}^{m} \mathbf{w}_{i} \hat{\kappa}_{i} c_{i} \\
\sum_{i=1}^{m} \mathbf{w}_{i} \hat{\kappa}_{i} s_{i}
\end{array}\right)
$$

O uso da função do tipo "M" é fundamental para se obterem bons resultados com nosso método. Isso é devido ao fato de que as curvaturas direcionais da Equação 3.9 são dependentes da posição dos pontos e de seus vetores normais [108]. A Figura 3.3 exemplifica um caso em que uma pequena perturbação na posição do ponto p, representado por um quadrado, pode produzir um resultado muito diferente do obtido com o original método de Huang e Menq, já que o sinal da estimativa dada por 3.9 se altera, e, portanto, a aproximação local também se alterará. 
Na função do tipo "M", $x^{2 \varsigma}$ controla a influência dos pontos próximos a p na solução. Quanto maior $\varsigma$, menor é a região ao redor de p que terá significante influência na solução. A parte exponencial da função mantém o mesmo comportamento da tradicional função Gaussiana. Apresentamos gráficos dessa função na Figura 3.4 com diferentes parâmetros.

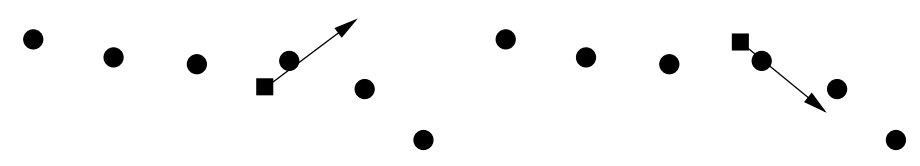

Figura 3.3: Resultados do método de Huang e Menq [108]: uma pequena perturbação na posição do ponto pode produzir consideravelmente diferentes curvaturas e direções (representadas pelas setas).

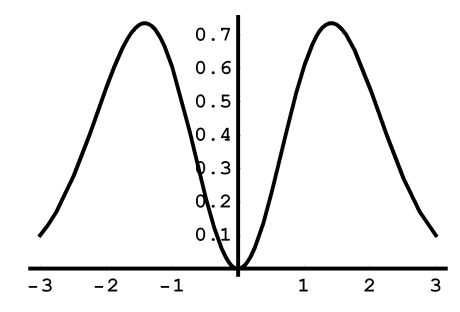

(a)

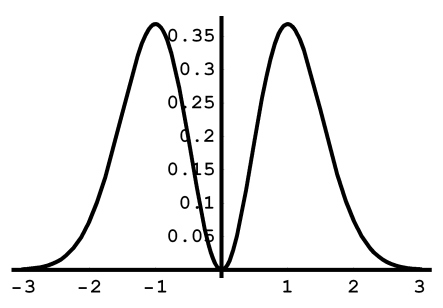

(b)

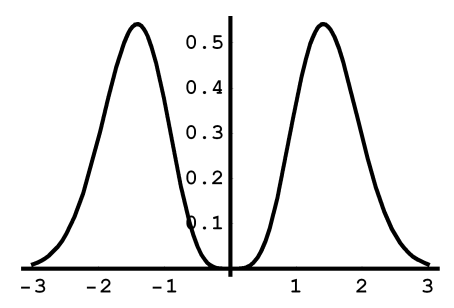

(c)

Figura 3.4: Exemplos de gráficos da função do tipo "M". Da esquerda para a direita: $\Delta=2 \mathrm{e}$ $\varsigma=1, \Delta=1$ e $\varsigma=1$, e $\Delta=1$ e $\varsigma=2$.

Ao contrário do peso Gaussiano, usualmente empregado nos trabalhos anteriores [9], a função do tipo "M" é capaz de resolver o problema descrito na Figura 3.3. Tal fato será mostrado na próxima seção, após a descrição do método de aproximação da superfície.

\subsubsection{Procedimentos de Projeção e de Rendering Baseados em Curvaturas}

Como mencionado anteriormente, os tradicionais métodos baseados em pontos [9, 167] definem a superfície aproximada por meio de pontos projetados nela, utilizando um operador de projeção. Dessa forma, a nuvem de pontos de entrada pode ser reamostrada pela projeção de um número suficientemente denso de pontos a partir de sua vizinhança 
sobre a superfície aproximada. Esse procedimento então gera uma densa amostragem que cobre completamente o objeto no espaço da imagem.

Nesta seção, descrevemos o nosso operador de projeção, derivado da teoria discutida, relacionada às estimativas de direção e curvaturas principais por meio do mínimosquadrados-ponderados. Para isso, fizemos uso de um resultado da geometria diferencial que atesta que uma superfície pode ser localmente definida (em uma vizinhança de p) por:

$$
g_{\kappa}(\xi, \eta)=\frac{1}{2}\left(\kappa_{1}^{\mathbf{p}} \xi^{2}+\kappa_{2}^{\mathbf{p}} \eta^{2}\right)
$$

em que $(\xi, \eta)$ está no sistema de coordenadas locais, definido pelas direções principais em $\mathbf{p}$. Entretanto, essa aproximação local é válida apenas para pontos sobre a superfície. Esse fato não permite definir um polinômio em um ponto próximo (mas não sobre) à superfície, como nos trabalhos prévios $[9,167]$. Objetivando evitar esse problema, usamos um esquema para mover um ponto que está relativamente próximo, mas não suficientemente próximo para garantir a qualidade na aproximação local guiada por curvaturas.

Lange e Polthier [126] adaptaram o método mesh oriented de Taubin [202] para o contexto de nuvens de pontos. Nesse trabalho, os autores usam o método de Taubin em consonância com uma equação de difusão anisotrópica para remover ruídos de nuvem de pontos sem suavizar características afiadas. Os autores fazem uso de uma equação de difusão (também conhecida como do calor) anisotrópica, que tem a vantagem de preservar características afiadas.

Consideremos a equação de difusão:

$$
\frac{\partial \mathbf{p}}{\partial t}=\gamma \Delta \mathbf{p}
$$

em que $\Delta \mathbf{p}=\left(\frac{\partial^{2} \mathbf{p}}{\partial x^{2}}+\frac{\partial^{2} \mathbf{p}}{\partial y^{2}}+\frac{\partial^{2} \mathbf{p}}{\partial z^{2}}\right)$ é o Laplaciano de $\mathbf{p}, \gamma$ é o termo de difusividade e $\mathbf{p}(t)$ é o ponto no tempo $t$ [105]. Aproximamos o Laplaciano pelo operador guarda-chuva:

$$
\tilde{\Delta} \mathbf{p}=\frac{1}{\Omega} \sum_{i=1}^{m} \omega_{i} \cdot\left(\mathbf{p}_{i}-\mathbf{p}\right),
$$


em que $\omega_{i}=\frac{1}{\left\|\mathbf{p}_{i}-\mathbf{p}\right\|^{2}}$ e $\Omega=\sum_{i=1}^{m} \omega_{i}$.

O método explícito de Euler para frente da discretização da Equação 3.16 define o tradicional método iterativo (conhecido como suavização Gaussiana) para suavização de dados:

$$
\mathbf{p}^{(n+1)}=\mathbf{p}^{(n)}+\gamma \delta t \tilde{\Delta} \mathbf{p}^{(n)}
$$

Observemos que $\gamma \delta t$ deve satisfazer as condições do tamanho do passo no tempo [105]. Lange e Polthier modificaram o operador tradicional de guarda-chuva para uma versão anisotrópica, introduzindo uma função real que oferece informações relacionadas à forma do objeto. Esse operador é capaz de mover um ponto sobre a superfície de forma precisa.

Portanto, o Laplaciano anisotrópico se torna:

$$
\tilde{\Delta}_{\Lambda} \mathbf{p}^{(n)}=\frac{1}{\Omega} \sum_{i=1}^{m} \Lambda_{i} \cdot\left(p_{i}-\mathbf{p}^{(n)}\right),
$$

em que $\Lambda_{i}$ é uma função real que depende das curvaturas direcionais (Equação 3.9) em $\mathbf{p}^{n}$. Lange e Polthier propuseram o uso de uma das duas funções para um dado limitante $\varepsilon$ :

$$
\begin{aligned}
& \Lambda_{i}=\left\{\begin{array}{cc}
1, & \text { if }\left|\kappa^{\mathbf{p}^{(n)}}\left(v^{i}\right)\right|<\varepsilon \\
0, & \text { if }\left|\mathcal{\kappa}^{\mathbf{p}^{(n)}}\left(v^{i}\right)\right| \geq \varepsilon
\end{array}\right.
\end{aligned}
$$

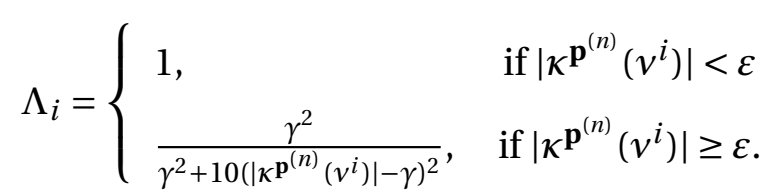

É importante mencionar que o custo computacional dessa etapa não é alto, se partimos de pontos já próximos à superfície, pois rapidamente o processo iterativo alcança o estado estacionário. Embora esse passo pareça ser desnecessário, ele é importante por assegurar uma solução satisfatória.

Após a definição do processo de minimização das direções e curvaturas principais, utilizando o teorema de Euler e a equação diferencial para movimentação de pontos, temos as ferramentas necessárias para definir o procedimento de projeção. 


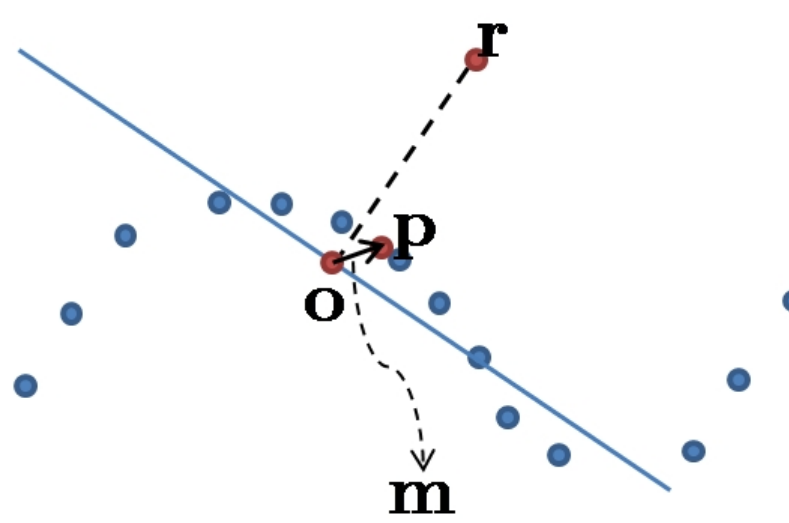

(a)

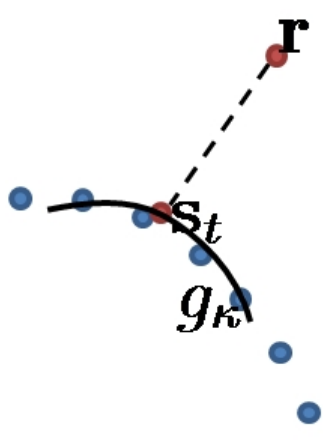

(b)

Figura 3.5: Ilustração do esquema de projeção baseado nas direções e curvaturas principais.

A projeção $\mathbf{s}$ de um ponto $\mathbf{r}$ sobre a superfície é calculada utilizando o seguinte procedimento (acompanhe pela Figura 3.5):

Passo 1. Encontre o plano aproximadamente tangente $\mathscr{H}$ com origem em o e normal 1, no qual o é o centro de massa ponderado dos vizinhos de $\mathbf{r}$ e $\mathbf{l}$ é a média ponderada das normais dos vizinhos de $\mathbf{r}$.

Passo 2. Encontre a projeção q de $\mathbf{r}$ sobre $\mathscr{H}$.

Passo 3. Calcule a normal $\mathbf{m}$ em $\mathbf{q}$.

Passo 4. Encontre o ponto $\mathbf{p}$ sobre a superfície, movendo $\mathbf{q}$ na direção de $\mathbf{m}$, usando a equação anisotrópica.

Passo 5. Calcule a normal $\mathbf{n}$, as direções principais $v_{1}^{\mathbf{p}}, v_{2}^{\mathbf{p}}$ e as curvaturas $\kappa_{1}^{\mathbf{p}}, \kappa_{2}^{\mathbf{p}}$ em $\mathbf{p}$.

Passo 6. $\operatorname{Defina}\left(v_{1}^{p}, v_{2}^{p}, \mathbf{n}\right)$ como o sistema de coordenadas locais e $g_{\kappa}(\xi, \eta)=\frac{1}{2}\left(\kappa_{1}^{\mathbf{p}} \xi^{2}+\kappa_{2}^{\mathbf{p}} \eta^{2}\right)$ como a aproximação polinomial à superfície.

Passo 7. Transforme $\mathbf{r}$ para o sistema de coordenadas locais e encontre sua projeção $\mathbf{s}_{t}$ sobre $g_{\kappa}$.

Passo 8. O ponto projetado s é o ponto $\mathbf{s}_{t}$ no sistema de coordenadas global. 
A superfície é definida como o conjunto de pontos estacionários do procedimento de projeção descrito anteriormente. Para fazer o rendering da superfície aproximada, implementamos o algoritmo de traçado-de-raios proposto por Adamson e Alexa [3], alterando apenas o procedimento de projeção. Primeiro define-se um conjunto de esferas centradas em cada um dos pontos da nuvem, de forma que a união dessas esferas englobe a superfície completamente. As esferas são usadas para encontrar a primeira estimativa da interseção i entre um raio e a superfície. Essa interseção i é, então, usada em um processo iterativo que projeta o ponto de interseção i sobre a superfície, que é definida localmente pelas curvaturas e direções principais, e, então, calcula a nova interseção i' definida entre o raio e a aproximação polinomial local. Se essa nova interseção i não pertence à atual esfera, a próxima esfera é testada. O processo pára quando a distância entre a atual interseção aproximada e sua projeção é menor do que um limitante $\epsilon$ predefinido ou quando todas as esferas que intersectam o raio foram testadas. A Figura 3.6 ilustra o procedimento, previamente descrito, de interseção de um raio com a superfície.

Uma boa estimativa das curvaturas $\left(\kappa_{1}^{\mathbf{p}}, \kappa_{2}^{\mathbf{p}}\right)$ e direções $\left(v_{1}^{\mathbf{p}}, v_{2}^{\mathbf{p}}\right)$ principais é de fundamental importância para se obter uma boa aproximação local para a superfície. Como argumentamos na seção anterior, para obtermos resultados satisfatórios tivemos que utilizar a função-peso do tipo “M”. A Figura 3.7 apresenta o efeito de introduzir pesos no Sistema 3.14. Como pode ser observado, o peso Gaussiano não aproxima bem a superfície localmente, ao passo que, a função do tipo "M" é de capaz assegurar tal fato. É importante notar que a função do tipo "M" é apenas utilizada para a estimativa das curvaturas, ao passo que a Gaussiana é utilizada para o resto do processo.

\subsubsection{Resultados}

Implementamos o método de Alexa et al. [9] para comparar com a nossa técnica. Nosso objetivo era obter resultados comparáveis pela utilização de polinômios reduzidos a partir das informações de curvatura. Portanto, usamos para o método de Alexa et al. polinômios completos de grau dois. Na Figura 3.8, apresentamos imagens com resultados de ambas as 


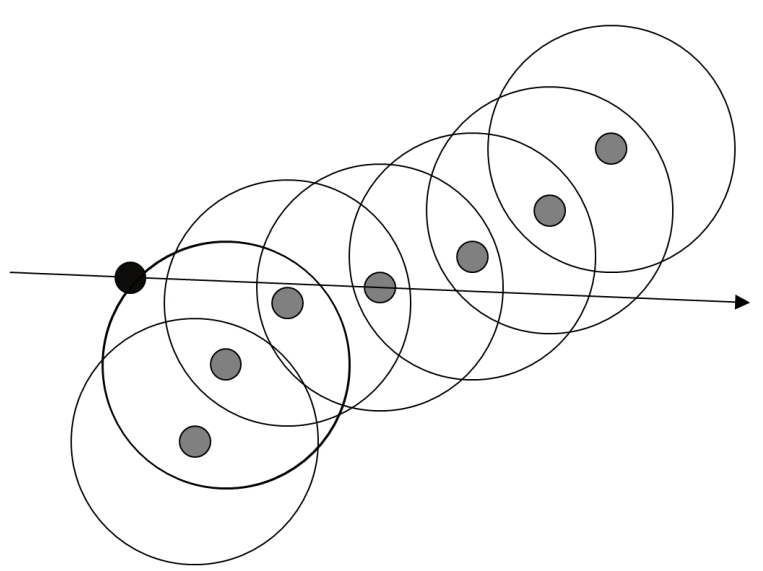

(a)

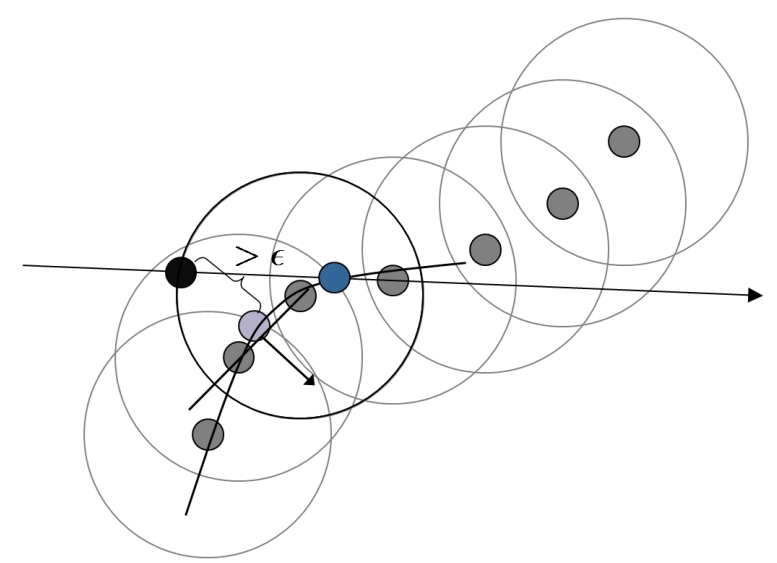

(c)

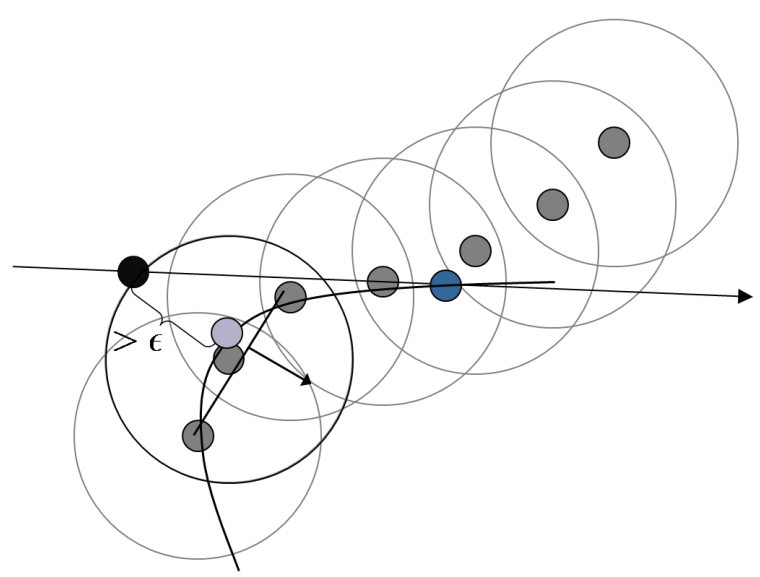

(b)

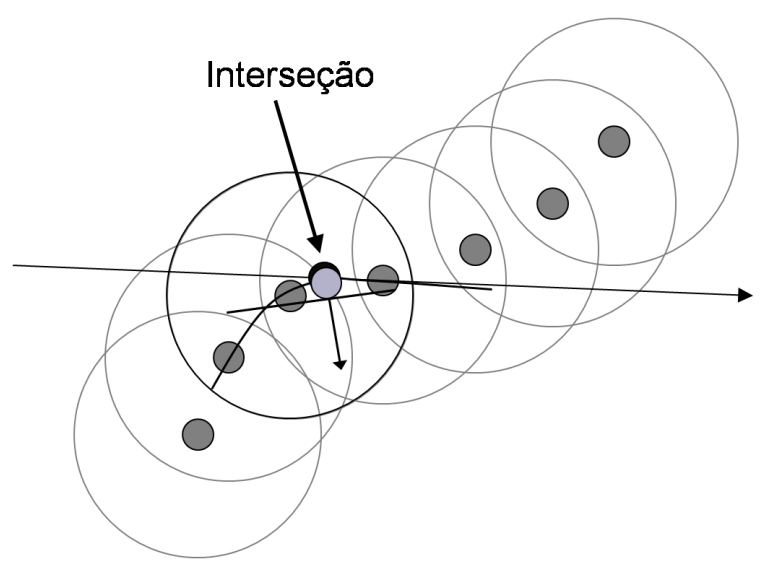

(d)

Figura 3.6: Esquema bidimensional de interseção entre um raio e a superfície. Os pontos em azul representam a interseção do gráfico com o raio: (a) situação inicial - nuvem de pontos com as esferas cobrindo toda a superfície e um raio que intersecta a primeira esfera definindo a primeira estimativa de interseção da superfície; (b) calcula-se a aproximação polinomial local e projeta-se o ponto de interseção no gráfico da aproximação local. Em seguida, verifica-se se o erro é maior que um $\epsilon$. Em caso afirmativo, caminha-se para a próxima esfera e repete-se o processo(c); (d) novamente calcula-se a aproximação polinomial e verifica-se se a distância do ponto projetado ao ponto sobre o gráfico da função é menor que um $\epsilon$ e, nesse caso, a interseção é definida pelo ponto em cinza. 


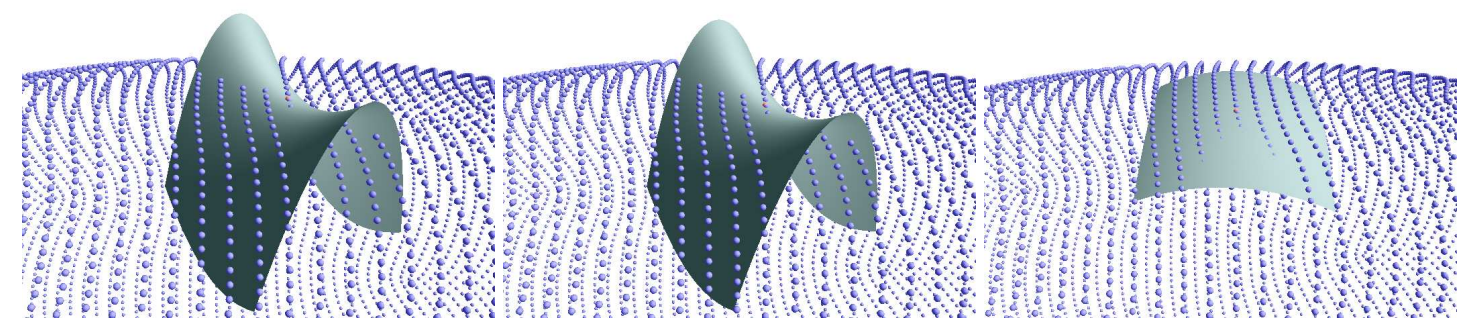

Figura 3.7: Aproximações polinomiais obtidas pelas direções e curvaturas (da esquerda para a direita) sem pesos, com a Gaussiana e com a função do tipo "M". Note que ambas a não utilização de pesos e a função Gaussiana produzem resultados semelhantes, porém incorretos.
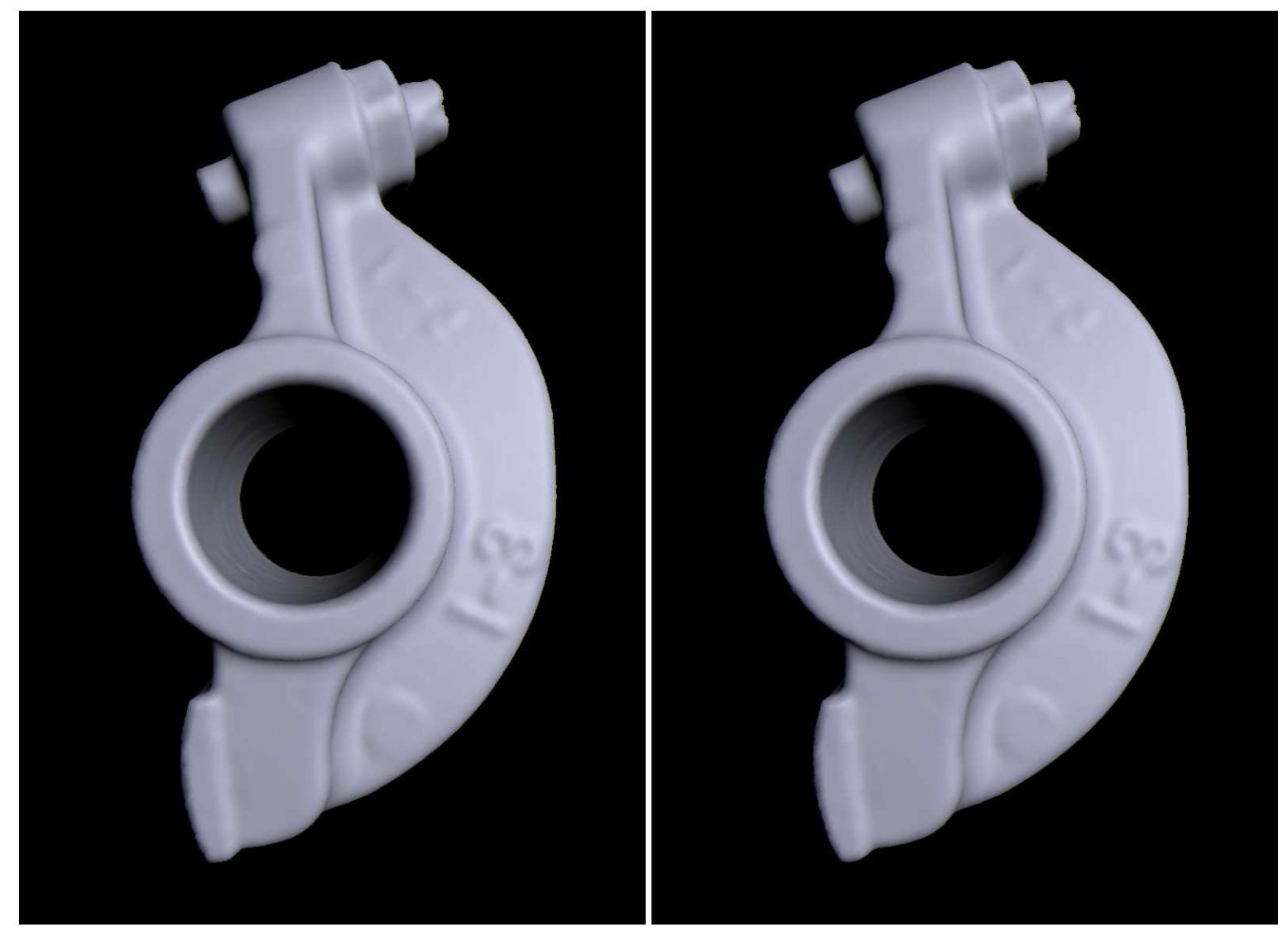

Figura 3.8: Imagem de uma superfície aproximada para o conjunto Rocker Arm (40 mil pontos), obtida pelo método de traçado-de-raios de Adamson e Alexa [2] (esquerda) e o método guiado por curvaturas (direita): é possível notar qualitativamente que ambos resultados são semelhantes, porém nossa abordagem utiliza bases de polinônios reduzidos. 


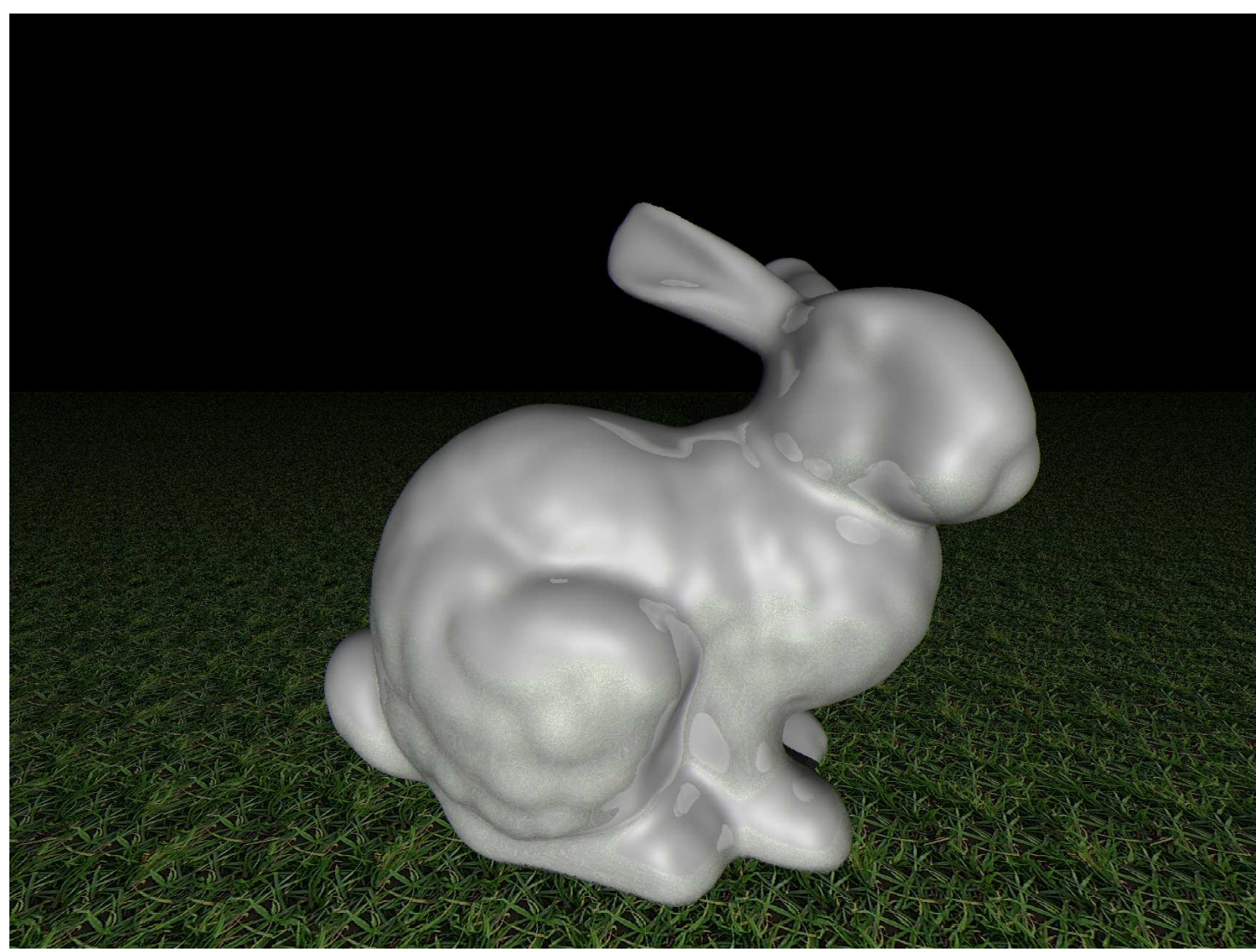

Figura 3.9: Rendering pelo método guiado por curvaturas: Stanford Bunny (30 mil pontos).

técnicas, utilizando nossa implementação do traçado-de-raios de Adamson e Alexa [3] no qual utilizamos uma $k d$-tree para acelerar o processo. Como podemos observar na figura, os resultados são qualitativamente semelhantes, entretanto nosso método, em média, 1.5 vez mais rápido. Para os testes de desempenho, os modelos foram obtidos sem efeitos de reflexão ou refração em uma porta de visão com dimensões $533 \times 400$. Cenas mais complexas utilizando nossa abordagem são apresentadas nas Figuras de 3.9 - 3.12.

A diferença no tempo de processamento é que nosso método necessita apenas resolver um sistema $3 \times 3$, que fizemos diretamente por fórmulas fechadas, embora nosso método faça uso de funções trigonométricas para construir as equações normais. Outra razão para o ganho no tempo de processamento é o uso de normais ponderadas, pelo qual evitamos estimativas do vetor normal pela análise de co-variância. Portanto, para nosso método ser vantajoso é necessário ter as normais como parte do conjunto de entradas. 


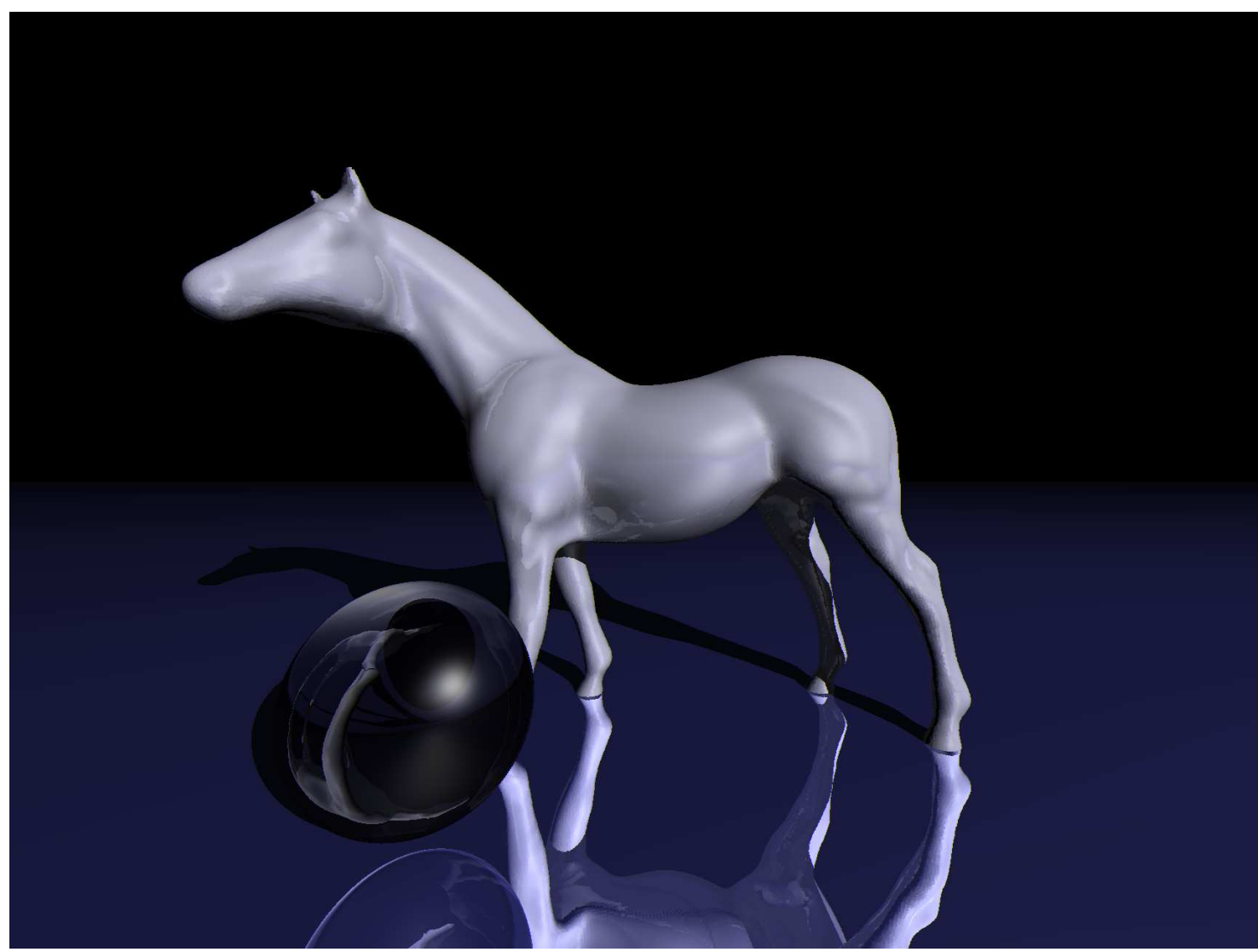

Figura 3.10: Rendering pelo método guiado por curvaturas: Cavalo (45 mil pontos).

Embora um polinômio completo de grau dois possa aproximar melhor uma grande vizinhança, quando comparado à estimativa que utilizamos, para os cálculos locais envolvidos em nosso trabalho, tal estimativa se mostrou precisa. Outra vantagem do nosso método, em termos práticos, é que descartamos para o cálculo das curvaturas e direções principais pontos cujos pesos são menores que um limitante, o que diminuiu a quantidade de cálculos, evitando avaliações de funções trigonométricas e ainda melhorando a estabilidade do método.

\subsection{Superfícies iaMLS}

O método iterativo descrito nesta seção é capaz de gerar uma família de modelos reconstruídos que capturam os detalhes do objeto original, por meio da manipulação de um parâmetro e do número de iterações. Além disso, o método ainda é livre da solução 


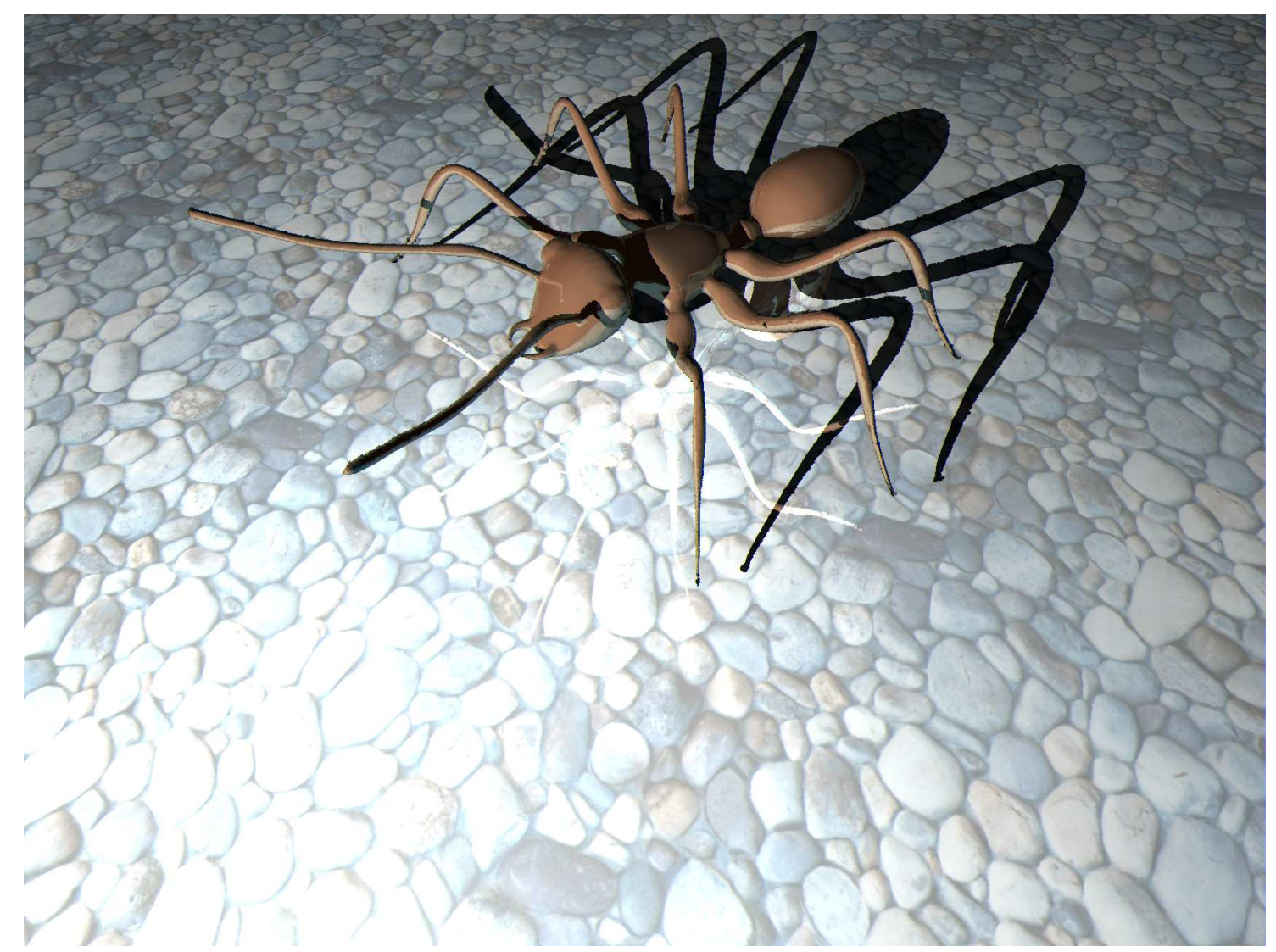

Figura 3.11: Rendering pelo método guiado por curvaturas: Formiga (660 mil pontos).

de sistemas lineares. Inspiramos nossa abordagem nos recentes resultados que conectam o método "mínimos-quadrados-móveis aproximados" com o método de funções de bases radiais, denominados "mínimos-quadrados-móveis aproximados iterados" - iaMLS [77]. Como em trabalhos prévios, fizemos uso de uma definição implícita da superfície MLS. No entanto, o processo iterativo de aproximação da superfície nos permitiu lidar eficientemente com dados irregulares. Dessa forma, utilizando a abordagem desta seção, denominamos as superfícies que geramos de superfícies iaMLS. Um exemplo da superfície reconstruída com o nosso método é apresentado na Figura 3.13.

Recentemente, Lipman et al. [138] também apresentaram um mecanismo iterativo de projeção de pontos e provaram que o mecanismo possui convergência de ordem 2. Contudo, o nosso interesse está na definição de um método baseado em MLS implícito, mas que também use uma abordagem iterativa para produção de soluções satisfatórias. Além disso, 


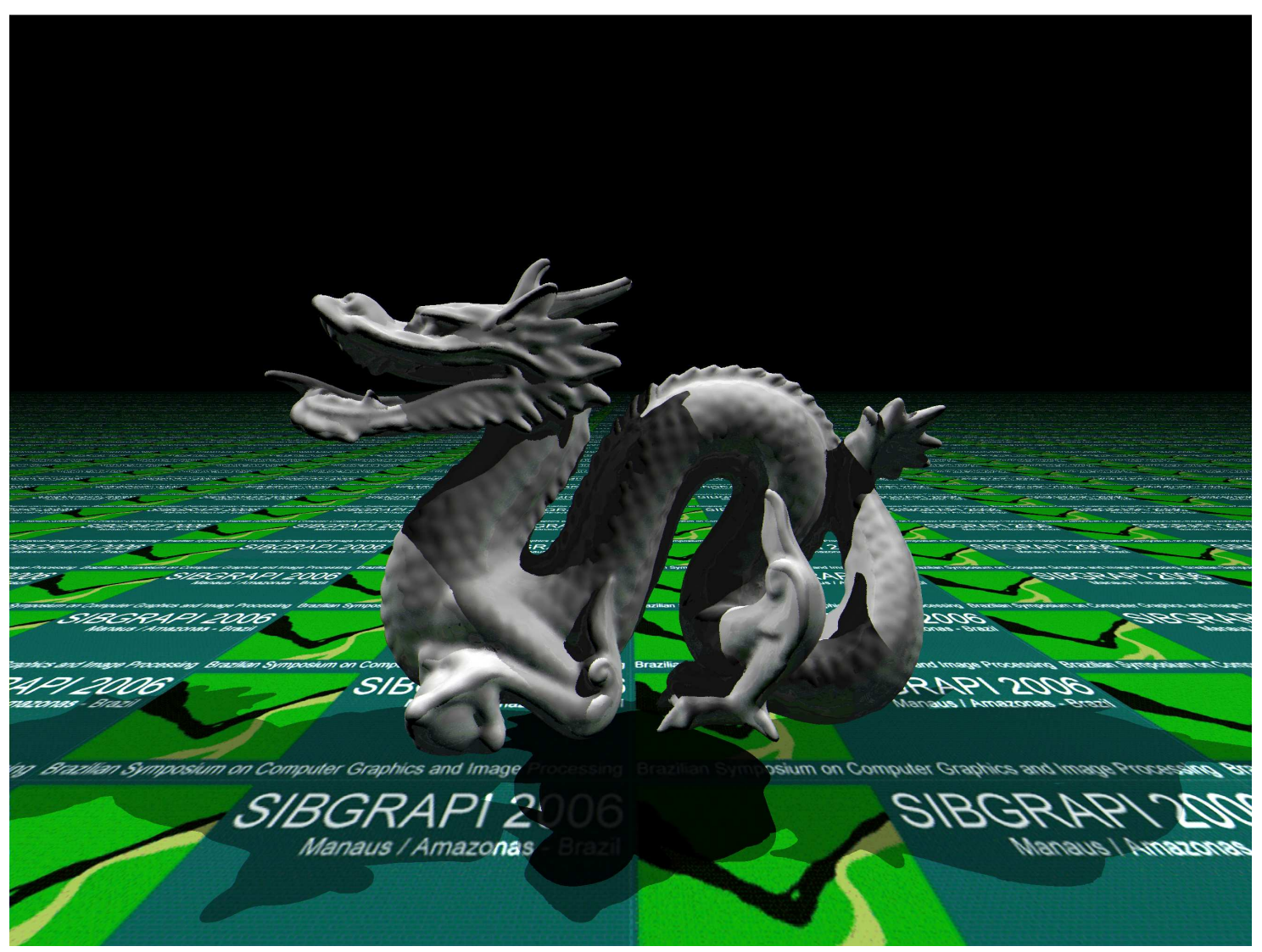

Figura 3.12: Rendering pelo método guiado por curvaturas: Stanford Dragon (500 mil pontos) - Proposta de capa dos anais do Sibgrapi-2006 [191].

a nossa técnica, ao contrário do procedimento Lipman et al., não é acompanhada de provas matemáticas que garantem que o processo iterativo é capaz de definir uma variedade. Apesar da falta de rigor matemático, acreditamos que os resultados são promissores e justificam pesquisas nessa direção.

\subsubsection{Mínimos-quadrados-móveis aproximados}

O método dos mínimos-quadrados-móveis aproximados (Approximate moving leastsquares-aMLS) [74] é um mecanismo computacionalmente eficiente e livre de sistemas lineares que habilita aproximações de alta-ordem, mas com a restrição de que o conjunto de pontos precisa ser regularmente espaçado. Por outro lado, as funções de bases radiais (RBF) são métodos interpolatórios (como argumentado por Fasshauer [77]) que garantem 


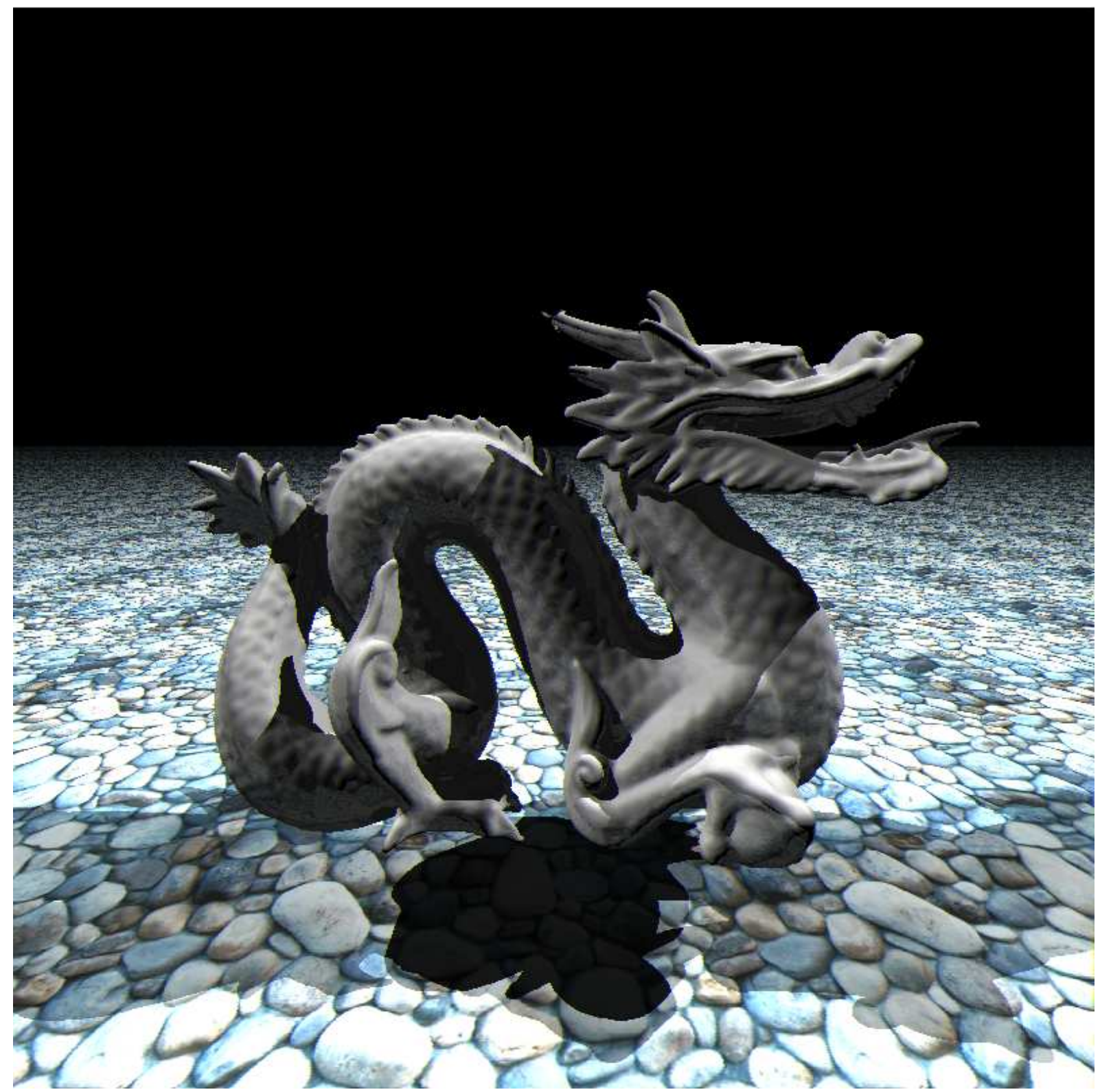

Figura 3.13: Exemplo de uma superfície iaMLS (Dragão de Stanford). 
a melhor aproximação na norma induzida do espaço das funções bases. Na prática, entretanto, instabilidades numéricas surgem durante o cálculo das interpolações por RBF, devido à natureza do sistema linear inerente das funções radiais (em geral, grande e malcondicionado) envolvidas no problema.

Recentemente, Fasshauer apresentou uma versão iterativa do aMLS, que foi denominada de aMLS iterado (iterate approximate moving-least-squares - iaMLS) [77], no qual, além de conectar as duas abordagens acima, ainda é capaz de amenizar o problema de ambas - a restrição quanto à regularidade dos pontos (aMLS) e o mal-condicionamento do sistema linear (RBF). Isto é, esse método gera uma seqüência de soluções aproximadas pelo aMLS que converge para uma solução de interpolação de funções de bases radiais. O que torna o método capaz de lidar com pontos irregularmente espaçados. Como ele é baseado em aMLS, não existe a necessidade da solução de sistemas lineares e, conseqüentemente, o problema de instabilidade numérica é melhor evitado.

Fasshauer baseou a definição do aMLS a partir dos trabalhos de Maz'ya [145], que propôs um método de interpolação de alta-ordem (denominado quasi-interpolantes), livre de sistemas de equações, com um mecanismo numericamente eficiente: a definição de um parâmetro que, quando propriamente definido, permite deixar o erro da aproximação tão pequeno de modo que os tipos numéricos de ponto flutuante do computador não sejam capazes de representar tal erro. Maz'ya desenvolveu esse mecanismo originalmente para a solução numérica de operadores diferenciais, tais como em operadores integro-diferenciais multidimensionais [181].

Fasshauer observou que tal "aproximação aproximada" poderia ser vista como a versão do MLS de Backus-Gilbert [75]. Além disso, Fasshauer apresentou métodos para eficientemente definir tal aproximação, propondo a aproximação por mínimos-quadrados-móveis aproximados. Embora esse mecanismo seja computacionalmente promissor, devido a sua simplicidade, não conhecemos aplicações dessa teoria além da apresentada por Fasshauer para compressão de dados [76, 74].

Consideremos um conjunto finito de pontos igualmente espaçados $\mathbb{X}=\left\{\mathbf{x}_{0}, \ldots, \mathbf{x}_{m}\right\} \subset \mathbb{R}^{n}$ 
e o conjunto $\mathbb{F}=\left\{f\left(\mathbf{x}_{0}\right), \ldots, f\left(\mathbf{x}_{m}\right)\right\}$ de valores de uma função $f \in C^{d}$ avaliada em $\mathbb{X}$. O MLS pela aproximação de Backus-Gilbert, segundo Fasshauer, define, em $\mathbb{X}$, a função $\mathscr{Q}_{f}$ que aproxima $f$ por:

$$
f(\mathbf{x}) \approx \mathscr{Q}_{f}(\mathbf{x})=\sum_{i=1}^{m} f\left(\mathbf{x}_{i}\right) \Psi_{i}(\mathbf{x}),
$$

em que as funções geradoras $\Psi_{i}$ satisfazem

$$
\sum_{i=1}^{m} p\left(\mathbf{x}_{i}\right) \Psi_{i}(\mathbf{x})=p(\mathbf{x}),
$$

para todo polinômio $p$ de dimensão $s$ e grau $d$, e

$$
\frac{1}{2} \sum_{i=1}^{m} \Psi_{i}^{2}(\mathbf{x}) \omega_{i}(\mathbf{x}) \rightarrow \min ,
$$

em que $\omega_{i}$ são funções-peso. A restrição 3.23 é importante, pois garante a reprodução dos polinômios de grau até $d$, e, portanto, garante ordem de aproximação $d+1$. Tal resultado foi provado por Levin [130] e Wedland [217].

Dessa forma, a partir de tal versão do MLS, Fasshauer apresentou funções $\Psi$ predefinidas que eram capazes de garantir alta ordem no sentido de controle de erro apresentado por Maz’ya. Por exemplo, Fasshauer propôs:

$$
\Psi_{i}(\mathbf{x})=\frac{\epsilon^{n}}{\pi^{n / 2}} L_{d}^{n / 2}\left(r_{i}(\mathbf{x})\right) \exp \left(-r_{i}(\mathbf{x})\right)
$$

em que $r_{i}(\mathbf{x})=\frac{\epsilon^{2}\left\|\mathbf{x}-\mathbf{x}_{i}\right\|^{2}}{h^{2}}, L_{d}^{n / 2}$ são os polinômios generalizados de Laguerre de grau $d$ [216], $h$ é o espaçamento entre os pontos, $n$ é a dimensão e $\epsilon$ é o parâmetro que controla a saturação do erro por escalar as funções-peso. As funções geradoras de ordem $O\left(h^{2}\right), O\left(h^{4}\right)$ e $O\left(h^{6}\right)$ da equação anterior são, respectivamente:

$$
\begin{gathered}
\Psi_{i}(\mathbf{x})=\frac{\epsilon^{3}}{\pi^{3 / 2}} \exp \left(-r_{i}(\mathbf{x})\right), \\
\Psi_{i}(\mathbf{x})=\frac{\epsilon^{3}}{\pi^{3 / 2}}\left(\frac{5}{2}-r_{i}(\mathbf{x})\right) \exp \left(-r_{i}(\mathbf{x})\right)
\end{gathered}
$$


$\mathrm{e}$

$$
\Psi_{i}(\mathbf{x})=\frac{\epsilon^{3}}{\pi^{3 / 2}}\left(\frac{35}{8}-\frac{7}{2} r_{i}(\mathbf{x})+\frac{1}{2} r_{i}(\mathbf{x})^{2}\right) \exp \left(-r_{i}(\mathbf{x})\right) .
$$

Utilizando tais funções $\Psi_{i}$, denominadas funções Laguerre-Gaussianas, é possível assegurar aproximação de ordem $O\left(h^{2 d+2}\right)$ para uma função de classe $C^{d}$.

Embora existam resultados teóricos desse método para dados não-regulares, não fomos capazes de notar que tais resultados são razoáveis para uma implementação computacional [145, 74]. Entretanto, recentemente, Fasshauer e Zhang [77] provaram um resultado computacionalmente interessante e eficiente (aquele que usamos no presente método). Tal resultado facilmente contorna a dificuldade dos pontos não-regulares. Especificamente, os autores apresentaram uma conexão entre RBF e aMLS pela qual atestam que é possível obter uma aproximação por RBF utilizando uma versão iterativa do aMLS - iterado aMLS (iaMLS).

Essa conexão une vantagens de ambas as abordagens: pelo lado do iaMLS, a natureza de ser livre de sistemas lineares; pelo lado de RBF, a capacidade das funções de bases radiais aproximarem funções de pontos irregularmente espaçados. A seguir, apresentaremos os resultados de tal conexão.

\section{Funções de bases radiais}

Assumindo que as funções $\Psi_{i}$ são funções radiais positivas definidas, elas podem ser utilizadas para calcularem-se interpolações $\mathscr{R}(\mathbf{x})$ por RBF:

$$
\mathscr{R}(\mathbf{x})=\sum_{i=1}^{m} c_{i} \Psi_{i}(\mathbf{x})
$$

em que

$$
\mathscr{R}\left(\mathbf{x}_{i}\right)=f\left(\mathbf{x}_{i}\right)
$$

Para se obter os coeficientes $c_{i}$, que satisfazem a Equação 3.30, o sistema simétrico:

$$
\mathbf{A c}=\mathbf{f}
$$


deve ser resolvido, sendo $\mathbf{A}=\left(\Psi_{i}\left(\mathbf{x}_{j}\right)\right)_{i, j=0}^{N}, \mathbf{c}=\left(c_{0} \cdots c_{N}\right)^{T}$ e $\mathbf{f}=\left(f\left(\mathbf{x}_{0}\right) \cdots f\left(\mathbf{x}_{N}\right)\right)^{T}$. Existe a garantia de que a matriz A é inversível. Contudo, quando consideramos aspectos numéricos, a solução nem sempre é facilmente obtida, devido a problemas de instabilidade numérica. Destacamos a importância do parâmetro $\epsilon$ nas interpolações, pois ele controla o quão "achatadas" (flatness) as funções $\Psi_{i}$ podem ser, pois quanto maior for o achatamento dessas funções $\Psi_{i}$ mais suaves serão as soluções por RBF.

\section{A conexão entre RBF e iaMLS}

Fasshauer e Zhang [77] propuseram o seguinte método iterativo, baseado na Equação 3.22, que produz o aMLS:

$$
\begin{gathered}
\mathscr{Q}_{f}(\mathbf{x})^{(0)}=\sum_{i=1}^{m} f\left(\mathbf{x}_{i}\right) \Psi_{i}(\mathbf{x}), \\
\mathscr{Q}_{f}^{(n+1)}(\mathbf{x})=\mathscr{Q}_{f}^{(n)}(\mathbf{x})+\sum_{i=1}^{m}\left[f\left(\mathbf{x}_{i}\right)-\mathscr{Q}_{f}^{(n)}\left(\mathbf{x}_{i}\right)\right] \Psi_{i}(\mathbf{x}),
\end{gathered}
$$

e o definiram como o método aMLS iterado (iaMLS). A partir das Equações 3.32 e 3.33, Fasshauer e Zhang provaram os seguintes resultados:

Teorema 1 ([77]) Considerando as definições da Seção 3.2.1, foi provado que:

$$
\|\mathbf{I}-\mathbf{A}\|_{2}<1 \Longleftrightarrow \mathscr{Q}_{f}^{(n)}(\mathbf{x}) \rightarrow \mathscr{R}(\mathbf{x}) \text { quando } n \rightarrow \infty
$$

$\mathrm{e}$

Teorema 2 ([77]) Uma conseqüência do resultando anterior é que:

$$
\max _{i=1,2, \cdots, m}\left\{\sum_{j=1}^{m}\left|\mathbf{A}_{i, j}\right|\right\}<2 \Longrightarrow \mathscr{Q}_{f}^{(n)}(\mathbf{x}) \rightarrow \mathscr{R}(\mathbf{x}) \text { quando } n \rightarrow \infty
$$

De fato, Fasshauer e Zhang apresentam exemplos de funções $\Psi$ nos quais a condição matricial dada pelo Teorema 2 pode ser facilmente obtida [77]. Fasshauer e Zhang ainda 
argumentam que, ao contrário do método de RBF, que é sensível a instabilidades numéricas para pequenas variações em $\epsilon$, o iaMLS, por produzir uma seqüência de soluções suaves que converge para a solução do RBF, é capaz de gerar resultados mais estáveis.

\subsubsection{Definição das superfícies iaMLS}

Antes de apresentarmos a definição da superfície, é importante enfatizar que nosso método, apesar de baseado no processo iterativo do aMLS, é de fato, uma heurística fundamentada na observação de que podemos refinar a solução da superfície MLS por um processo iterativo. Notemos que existe uma grande diferença no tipo de dados do iaMLS de Fasshauer e Zhang [77] que assume que os pontos estão em $\mathbb{R}^{3}$, ao passo que nossos pontos estão apenas em uma superfície (espaço de dimensão 2).

Uma solução mais direta, obviamente, seria a utilização do iaMLS no lugar da aproximação polinomial por mínimos-quadrados-ponderados da segunda etapa do operador de projeção de Alexa et al. [9]. Desse modo, acreditamos que os resultados teriam potencial para também serem satisfatórios e matematicamente corretos (a implementação de tal abordagem faz parte de um trabalho futuro). No entanto, concentramos esforços na definição de um mecanismo de uma única etapa e que fizesse uso de abordagens baseadas em funções implícitas.

Como mencionado anteriormente, as vantagens do iaMLS estão em duas direções: a primeira é a capacidade de gerar uma aproximação local de alta ordem sem a necessidade de resolver sistemas lineares, e a segunda, é a possibilidade de, por meio do controle de parâmetros, definir uma boa aproximação, mesmo na presença de dados ruidosos [78]. Fasshauer e Zhang [78] já apresentaram um método para estimar o número ótimo de iterações e o parâmetro forma $\epsilon$. O desenvolvimento de um mecanismo semelhante faz parte dos nossos planos para trabalhos futuros.

A principal vantagem da nossa abordagem é a capacidade de atenuar as características dos objetos reconstruídos por meio do controle do número de iterações e do parâmetro $\epsilon$. 
A seguir, apresentaremos a definição do nosso mecanismo iterativo para representação de superfícies, que utiliza uma função implícita MLS e o processo iterativo do iaMLS. Para isso, consideremos uma função $\digamma: \mathbb{R}^{3} \rightarrow \mathbb{R}$, cujo conjunto zero aproxima a superfície:

$$
\digamma(\mathbf{x})=\sum_{i=1}^{m} \mathscr{G}_{i} \Psi_{i}(\mathbf{x}),
$$

em que $\mathscr{G}_{i}=<\mathbf{x}_{i}-\mathbf{x}, \mathbf{n}_{i}>, \mathbf{n}_{i}$ é o vetor normal em cada ponto $\mathbf{x}_{i}$. Tal função é semelhante à proposta por Kolluri [119] com exceção da normalização.

A partir dessa função, e utilizando o processo iterativo do iaMLS, definimos:

$$
\begin{gathered}
\digamma^{(0)}(\mathbf{x})=\sum_{i=1}^{m} \mathscr{G}_{i} \Psi_{i}(\mathbf{x}) \\
\digamma^{(n+1)}(\mathbf{x})=\digamma^{(n)}(\mathbf{x})+\sum_{i=1}^{m}\left[\mathscr{G}_{i}-\digamma^{(n)}\left(\mathbf{x}_{i}\right)\right] \Psi_{i}(\mathbf{x}) .
\end{gathered}
$$

Seguindo o mesmo princípio, apresentamos uma aproximação para a direção do vetor normal em x, necessário para calcular a iluminação no algoritmo de traçado-de-raios, que também é definida por um processo iterativo:

$$
\begin{gathered}
\mathbf{n}^{(0)}(\mathbf{x})=\sum_{i=1}^{m} \mathbf{n}\left(\mathbf{x}_{i}\right) \Psi_{i}(\mathbf{x}), \\
\mathbf{n}^{(n+1)}(\mathbf{x})=\mathbf{n}^{(n)}(\mathbf{x})+\sum_{i=1}^{m}\left[\mathbf{n}_{i}-\mathbf{n}^{(n)}\left(\mathbf{x}_{i}\right)\right] \Psi_{i}(\mathbf{x}),
\end{gathered}
$$

Dessa forma, em nossas aplicações, utilizamos as funções Laguerre-Gaussianas de segunda ordem e, como veremos, os resultados foram promissores. Para manter consistência com a definição do iaMLS, utilizamos uma função $\mathscr{G}_{i}$ fixa para cada $\mathbf{x}$ durante todo o processo iterativo.

\subsubsection{Resultados}

Realizamos comparações bidimensionais e tridimensionais com a definição da superfície MLS implícita de Adamson e Alexa [3] e de Kolluri [3]. Nas Figuras 3.14 e 3.15, apresenta- 

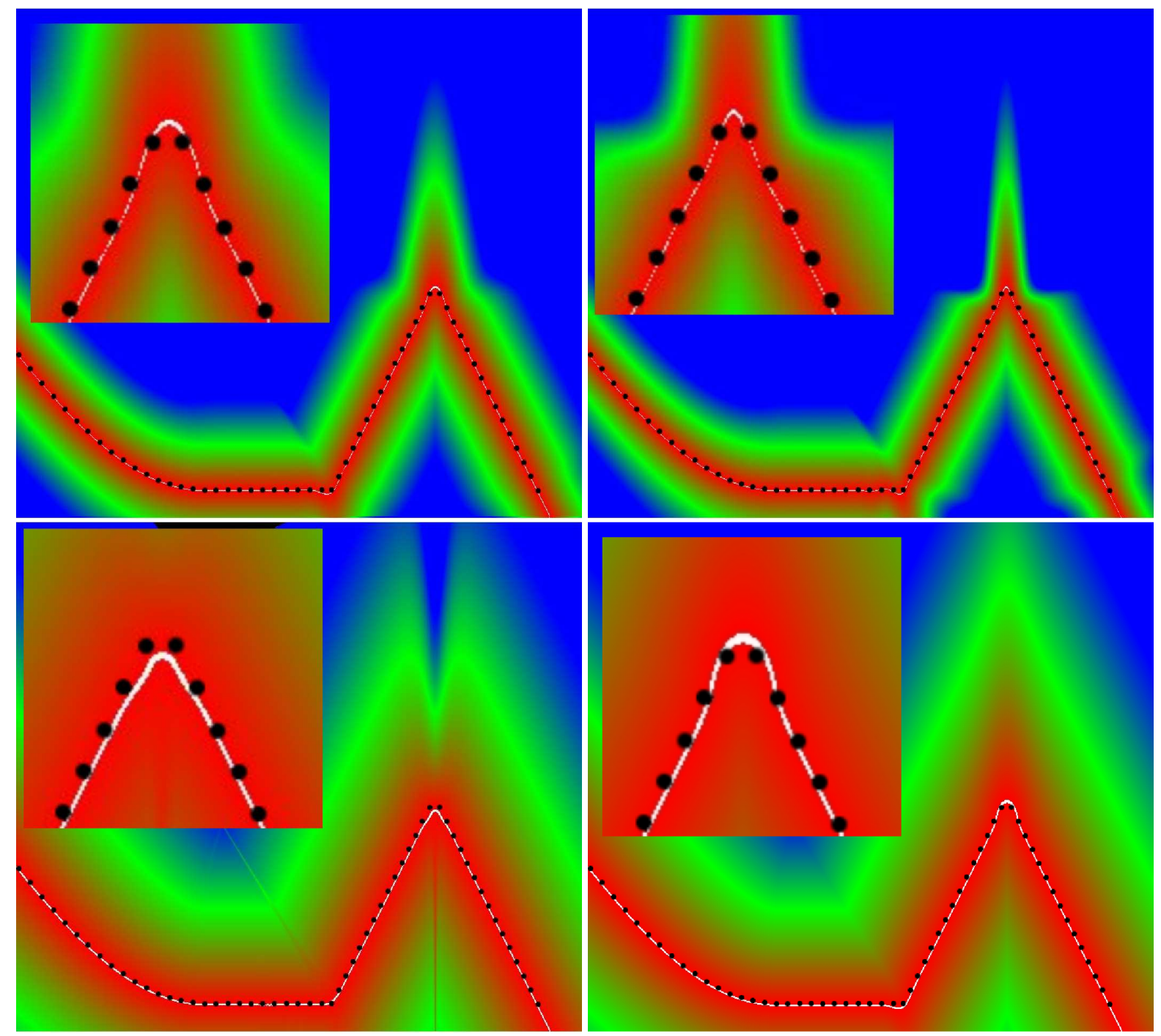

Figura 3.14: Gráficos de valores das funções para um conjunto de pontos regularmente espaçados. Da esquerda para a direita de cima para baixo: iaMLS após 5 iterações, iaMLS após 20 iterações, função de Adamson e Alexa [3] e de Kolluri [119]. As curvas brancas mostram o nível zero da função enquanto o mapa de cores define os demais valores da função, variando do vermelho (valores baixos da função) para o azul (valores altos da função). 
mos comparações com dados regularmente e irregularmente espaçados, respectivamente.

A irregularidade foi introduzida para ilustrarmos a eficiência dos métodos em cada um dos casos.

Comparamos as funções implícitas MLS de Kolluri [119] e Adamson \& Alexa [3] com o intuito de analisar o impacto do desempenho computacional necessário do processo iterativo e também para analisar qualitativamente as soluções.
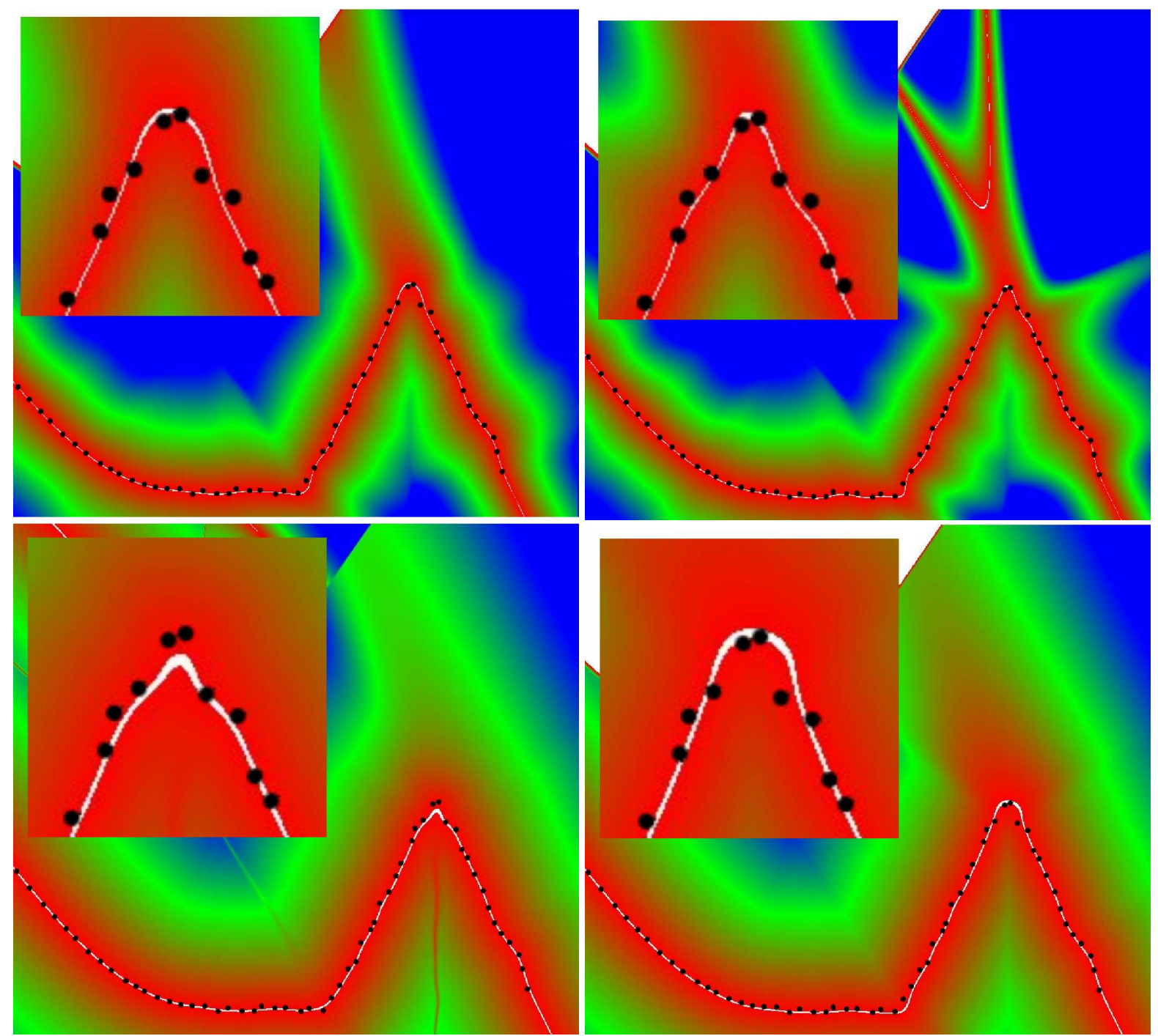

Figura 3.15: Gráficos de valores das funções para um conjunto de pontos irregularmente espaçados. Da esquerda para a direita e de cima para baixo: iaMLS após 5 iterações, iaMLS após 20 iterações, função de Adamson e Alexa [3] e de Kolluri [3]. As curvas brancas mostram o nível zero da função, enquanto o mapa de cores define os demais valores da função, variando do vermelho (valores baixos da função) para o azul (valores altos da função). 
Podemos observar, nas Figuras 3.14 e 3.15, que nosso método aproxima melhor os pontos sem realmente interpolá-los. A suavidade da aproximação, portanto, pode ser controlada pelo parâmetro $\epsilon$ e pelo número de iterações. Nos detalhes no topo-esquerda das figuras, podemos notar que com 5 iterações, a aproximação tende a interpolar os dados. Após 20 iterações, entretanto, notamos que a função se ajustou melhor aos pontos. Cessamos, então, o procedimento para evitar que dados ruidosos começassem a ser interpolados também.

Tabela 3.1: Medida de desempenho (em segundos), utilizando o método de traçado-deraios, para o método de Adamson e Alexa, Kolluri e o iaMLS. O desempenho é proporcional ao número de raios que intersecta a superfície.

\begin{tabular}{cccccc} 
& $\begin{array}{c}\text { Função de } \\
\text { Adamson e Alexa }\end{array}$ & $\begin{array}{c}\text { Função de } \\
\text { Kolluri }\end{array}$ & \multicolumn{3}{c}{ iaMLS. } \\
Modelo (pontos) & 3 iter. & 10 iter. \\
\hline Bunny (35 mil) & 30 & 29 & 103 & 107 & 126 \\
Horse (48 mil) & 50 & 52 & 183 & 283 & 389 \\
Fan Disk (103 mil) & 30 & 30 & 79 & 97 & 109 \\
Armadillo (172 mil) & 30 & 32 & 106 & 152 & 236 \\
Dragon (400 mil) & 116 & 120 & 361 & 499 & 778
\end{tabular}

Testamos a eficiência do nosso método, visualizando as imagens pelo método de traçadode-raios. Os testes foram realizados em um PC Athlon com 3.4GHz e 2GB de RAM. O desempenho foi medido em janelas-de-visão $400 \times 300$. Apresentamos novamente comparações com as abordagens de Adamson e Alexa e Kolluri. Em todos os casos, utilizamos a mesma implementação do método de traçado-de-raios, alterando apenas o método de avaliação da função. Os resultados de desempenho, em segundos, utilizando o método de traçado-deraios estão na Tabela 3.1. Claramente, devido ao processo iterativo, nosso método é mais lento em relação aos métodos comparados.

Apresentamos comparações de dois modelos clássicos na Figura 3.16. Para os três métodos, utilizamos o mesmo valor de $h$ para cada modelo. Para o nosso método, realizamos 3 iterações assumindo $\epsilon=0.8$. Pudemos observar que a superfície iaMLS aproximou melhor os conjuntos de pontos.

Objetivando mostrar o efeito dos parâmetros e o número de iterações, conduzimos testes com diferentes valores de $\epsilon$ e do número de iterações. Apresentamos os resultados na Figura 

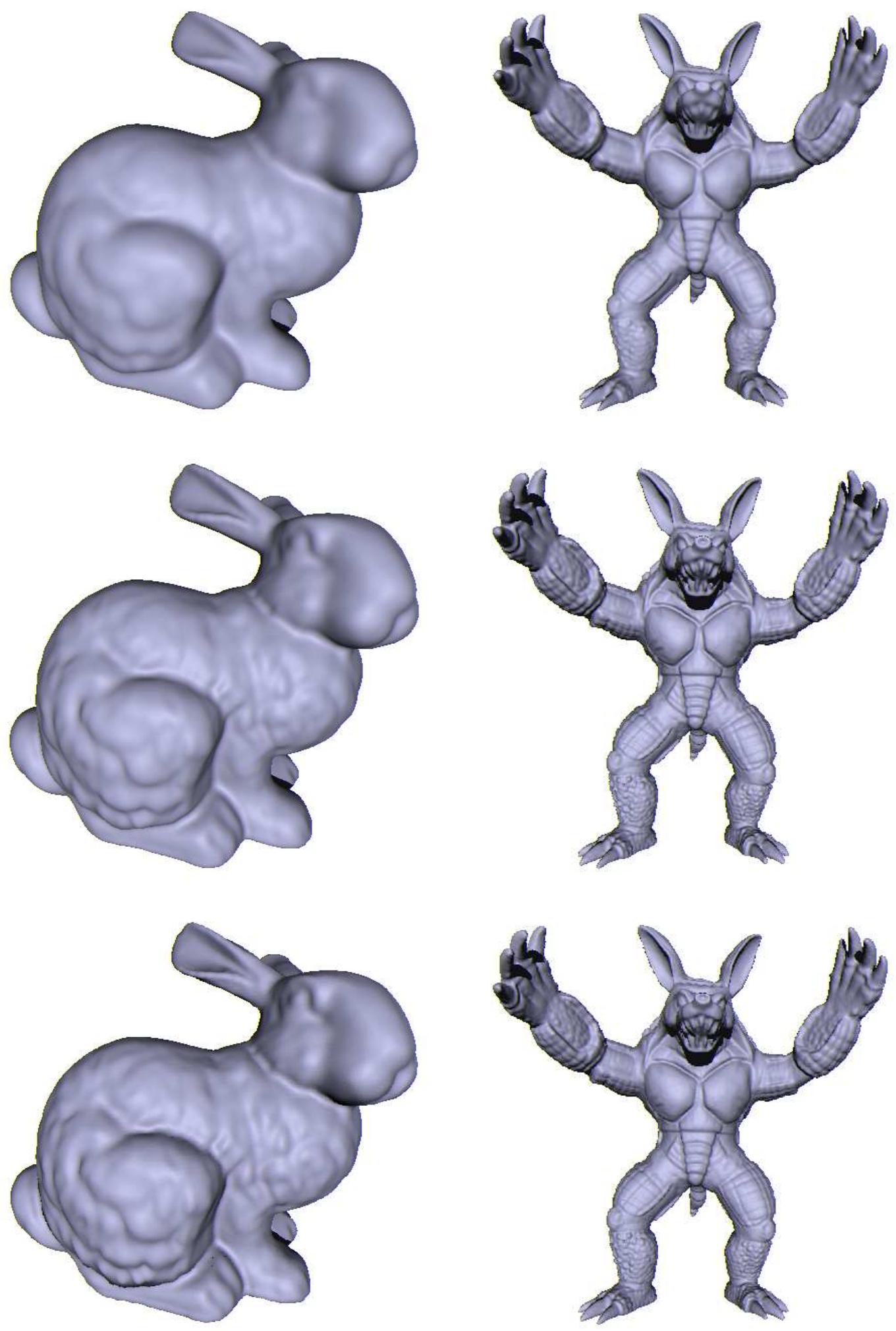

Figura 3.16: Imagens das superfícies, obtidas com o método de Adamson e Alexa (topo), Kolluri (meio) e iaMLS (base). 

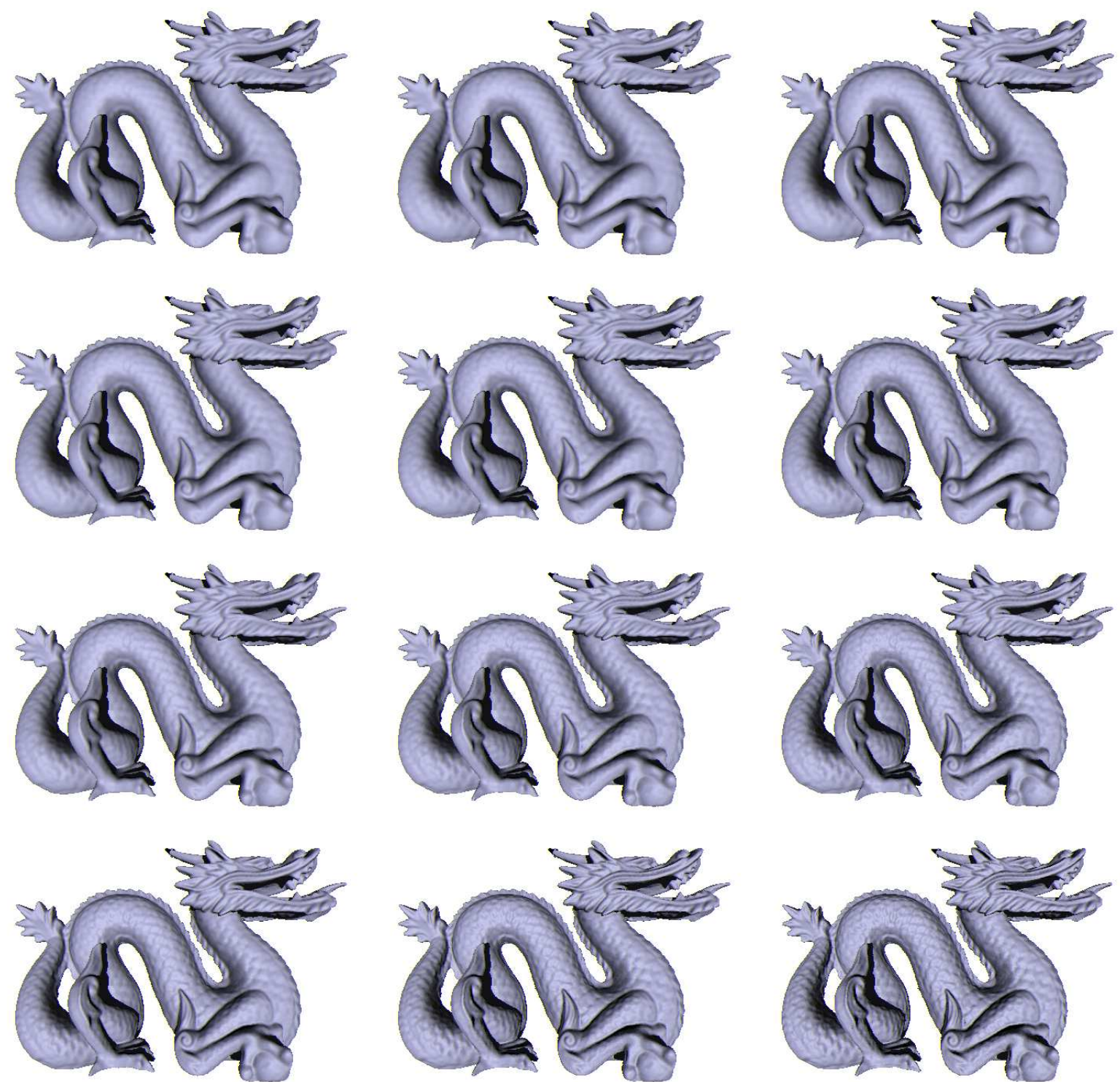

Figura 3.17: Efeito do número de iterações e do parâmetro $\epsilon$ na aproximação. Da esquerda para a direita: 3,4 e 5 iterações. De cima para baixo: $\epsilon=0.4, \epsilon=0.8, \epsilon=1.22, \epsilon=2.0$. É possível notar que, quando o número de iterações aumenta, maiores detalhes do objeto são obtidos. 
3.17. Devido ao valor de $\epsilon$ afetar a convergência do método, ambos são dependentes e precisam ser estimados de forma simultânea, como argumentado por Fasshauer e Zhang [77].

\subsection{Conclusão}

Em relação ao nosso método de aproximações guiadas por curvaturas, apesar de os resultados serem qualitativamente semelhantes ao método de Adamson e Alexa [2], a estimativa de curvaturas e direções principais pode ser útil para outras aplicações, por exemplo, para efeitos de sombras [97]. Além disso, existem poucos trabalhos na literatura que estimam curvaturas e direções principais por nuvens de pontos e nenhum trabalho anterior realiza comparações entre eles. Portanto, um estudo da eficiência computacional e questões envolvendo uma análise numérica dessas técnicas podem ser realizados de forma aprofundada.

Notamos a necessidade de fazer uma análise mais precisa do método que utilizamos, principalmente, no que se refere à avaliação da convergência do método (semelhante à que conduzimos no Capítulo 5, para curvaturas obtidas por mínimos-quadrados-móveis, utilizando esferas algébricas). Também achamos importante avaliar o impacto do desempenho do cálculo da equação de difusão e do cálculo das curvaturas principais, isto é, avaliar qual a porcentagem de custo computacional total do processo que cada etapa requer.

Pretendemos utilizar o método anisotrópico, baseado em pontos, de Adamson e Alexa [4], em razão dos pesos que podem ser definidos para cada amostra independentemente. Buscaremos explorar esse fato pela definição dos pesos baseados nas direções principais. Como as curvaturas produzem uma informação local sobre o objeto, elas podem ser usadas para auxiliar na identificação de características afiadas, como feito por Lipman et al. [137]. Por fim, tais informações de curvaturas também podem ser utilizadas por mecanismos de rendering que utilizam mais informações do que os pontos, por exemplo, os differential points [113].

Já em relação ao método baseado em iaMLS, pudemos notar pelos resultados que a 
atenuação de características do modelo é obtida por uma família de soluções resultantes do parâmetro $\epsilon$ e do número de iterações. Com isso, nosso método foi capaz de detectar detalhes dos modelos e gerar modelos mais suaves com baixo custo computacional.

É importante destacar que nossa abordagem é uma heurística inspirada no processo iterativo de Fasshauer e Zhang [77], com base no qual inferimos que é possível obter soluções mais precisas, refinando a solução inicial apropriadamente. Atualmente, buscamos meios de definir um processo iterativo que possua uma justificativa comprovada matematicamente.

Lipman et al. [138] também apresentaram um mecanismo iterativo de projeção de pontos na superfície por meio de um operador livre de parâmetros. Em nosso caso, buscamos, ainda, a elaboração de um método iterativo que, além de ser capaz de definir pontos na superfície, fosse definido por uma função implícita.

Como pôde ser notado, ainda não exploramos as propriedades e também não realizamos comparações significativas em relação às duas abordagens propostas nesse capítulo. Sabemos que, apesar de os resultados serem interessantes, fica clara a necessidade da realização de maiores comparações em relação aos parâmetros, custos computacionais e também da análise de convergência de ambos os métodos. 


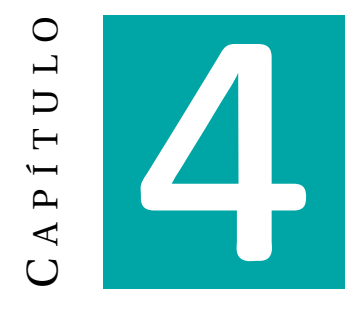

\section{Partição da Unidade Implícita em Duas Vias}

Neste capítulo, apresentamos uma técnica de Partição da Unidade Implícita (PUI), proposta para a representação de superfícies por nuvens de pontos [90]. Buscamos fornecer mecanismos que a tornassem mais robusta do que o método original, proposto por Ohtake e colaboradores [158], sem aumentar significativamente o custo computacional. Mostraremos a eficiência na utilização da triangulação $J_{1}^{a}$ para decomposição espacial e para poligonalização, bem como a utilização de bases de polinômios ortogonais, segundo o produto interno induzido pelas equações normais, cuja principal vantagem está na forma recursiva que permite refinar a solução localmente, sem adicionar um custo computacional elevado. Produzimos, assim, um método adaptativo em duas vias. Além dessa abordagem, apresentamos extensões na nossa técnica, explorando as suas propriedades. Também realizaremos comparações teóricas e empíricas com o método de Ohtake et al. [158]. A Figura 4.1 apresenta um exemplo de reconstrução obtida segundo nossa técnica de PUI.

\subsection{Contribuições}

O método de representação por nuvens de pontos, baseado em PUI, foi proposto originalmente por Ohtake et al. [158] (os autores, de fato, denominam a técnica por Multilevel Partition of Unity Implicits, pelo fato de as representações locais serem definidas pelos 


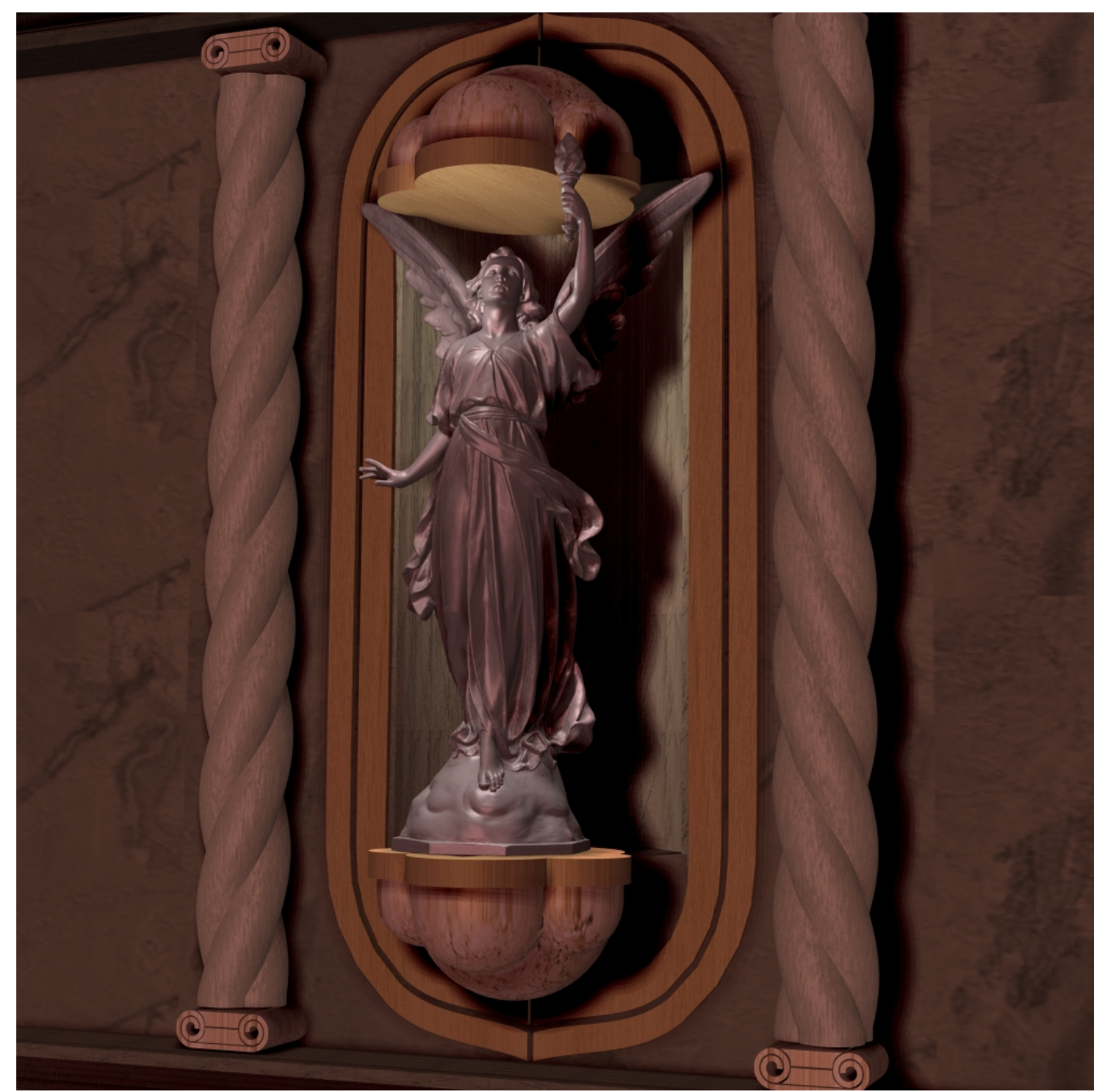

Figura 4.1: Reconstrução da estátua de Lucy, de Stanford (16 milhões de pontos), inserida em um cenário tridimensional estilo barroco (modelado com o Blender [39]). Imagem da contracapa dos anais do Sibgrapi-2007 [192].

níveis de uma octree). Tal método tornou-se popular devido à capacidade de gerar modelos em multiníveis permitindo a manipulação eficiente de entradas contendo ordem de milhões de pontos. Além disso, métodos baseados em PUI possuem grande flexibilidade para a definição dos tipos de aproximações locais e para as formas de decomposição espacial, o que torna interessante a busca por mecanismos eficientes de PUI. Um método de PUI, basicamente torna o problema de reconstrução em um problema de aproximações locais definido recursivamente, no qual tais aproximações são propriamente combinadas - por meio da partição da unidade - em uma função contínua global. Apesar da elegância e 
eficiência do método, alguns problemas ainda existem: o primeiro é a falta de robustez para definir as funções locais; é o desacoplamento entre a estrutura de decomposição espacial e a estrutura de poligonalização, evidenciando que informações com respeito a detalhes do objeto podem, tanto ser desconsideradas quanto "super-amostradas".

Dessa forma, propusemos um método de reconstrução de superfícies a partir de pontos não-organizados que combina eficientemente a triangulação adaptativa $J_{1}^{a}[47,48]$ (que é definida por uma octree restrita) com uma construção adaptativa de aproximações locais por meios de bases de polinômios ortogonais de duas variáveis para o método dos mínimosquadrados $[23,22]$. Isso nos permite aumentar o grau da aproximação polinomial em regiões em que o critério de qualidade (erro da aproximação) não é satisfeito. Nesse sentido, as principais contribuições deste trabalho são:

Extração da iso-superfície adaptativa e com garantia topológica: ao contrário dos métodos anteriores, extraímos a iso-superfície diretamente a partir da estrutura utilizada para subdividir o domínio (a triangulação $J_{1}^{a}$ ). Isso permite que a extração da iso-superfície seja beneficiada com a informação do refinamento obtido durante a aproximação da função. Além disso, como a triangulação $J_{1}^{a}$ é definida por tetraedros, o algoritmo não sofre de casos ambíguos como métodos baseados em cubos [139].

Estabilidade numérica: em geral, os métodos de solução por mínimos-quadrados são resolvidos utilizando-se a base polinomial canônica, que tende a gerar um sistema mal condicionado. Bartels e Jezioranski [23, 22] argumentam em seu trabalho que a técnica proposta por eles melhora a estabilidade do método sem a necessidade de cálculos computacionalmente custosos. Obviamente as técnicas QR com fatoração de Householder e decomposição de valores singulares (SVD) são mais estáveis, porém, o custo computacional desses métodos é mais alto.

Aproximação adaptativa das funções locais: o uso dos polinômios ortogonais nos permite eficientemente aumentar o grau dos polinômios das aproximações locais recursivamente. Por tal razão, nosso método também é adaptativo em relação às aproximações locais.

Evitando superfícies espúrias: sugerimos alguns critérios de robustez que não são com- 
putacionalmente custosos e que tornam o nosso método mais robusto do que trabalhos anteriores. Com isso, o nosso método é capaz de evitar a geração de superfícies espúrias e artefatos.

A adaptatividade em duas vias (na profundidade da partição espacial e no grau das aproximações locais) pode ser vista na Figura 4.2. Além dos melhoramentos citados previamente, elaboramos extensões para lidar com a qualidade da malha obtida pelo extrator de iso-superfícies da triangulação $J_{1}^{a}$, além de algumas extensões relacionadas à qualidade das aproximações locais.

Melhoramento de malha: a razão de aspecto dos triângulos (Equação 4.15, Página 114) gerados pelo poligonalizador de iso-superfícies, induzido pela triangulação $J_{1}^{a}$, em geral, não é satisfatória. Tal fato nos motivou à definição de um simples, porém eficiente, procedimento de deslocamento de vértices da triangulação que é capaz de melhorar consideravelmente a qualidade da malha.

Edição interativa da função implícita: na busca por robustez, o método automático de reconstrução da superfície pode causar a perda de detalhes em algumas regiões devido ao uso de um polinômio de baixo grau. Desconsiderar os critérios de robustez que propusemos não é uma boa solução para esses problemas, pois artefatos e superfícies espúrias podem aparecer na superfície. Além disso, mesmo com um bom critério de qualidade, PUIs são particularmente sensíveis a dados de entrada ruidosos (raw data). Como antes, simplesmente tornar mais severas as condições de robustez tende a gerar modelos suaves, sem assegurar que todos os problemas serão resolvidos. Portanto, apresentamos um mecanismo que permite ao usuário editar localmente a aproximação global para definir aproximações mais adequadas.

Modelagem de características afiadas: para a detecção e a aproximação local de uma característica afiada, baseada na abordagem de Ohtake et al. [158], apresentamos as alterações necessárias para adaptar esse processo em nosso algoritmo.

Observação 5 A utilização de aproximações locais pelo método de mínimos-quadrados não 


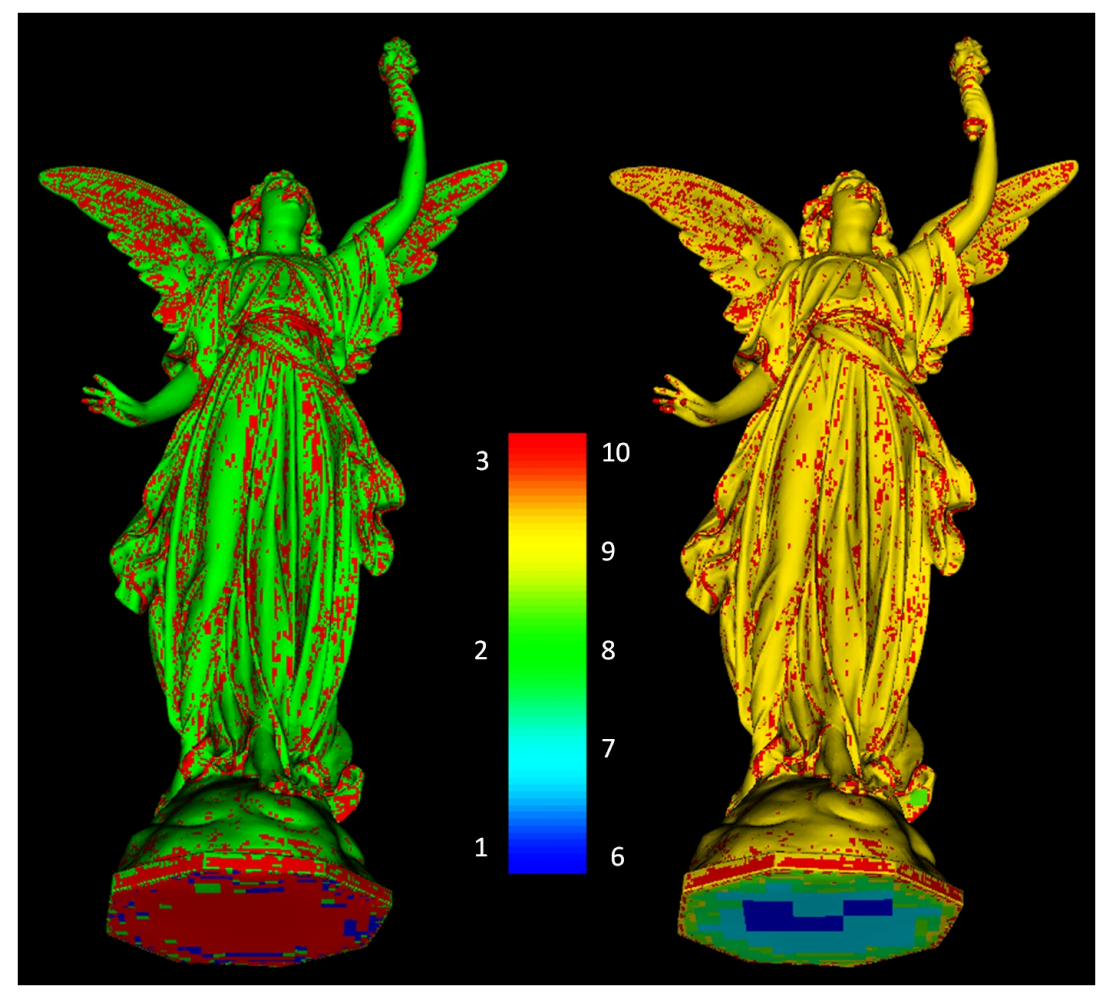

Figura 4.2: Adaptatividade em duas vias: A estátua da Lucy de Stanford de 16 milhões de pontos e com malha de 7 milhões de triângulos. À esquerda, a escala de cores representa o grau máximo do polinômio das aproximações locais na superfície. Em todo o domínio, o número de polinômios corresponde a: 946601, 144956, 38236 e 26862 de grau 1 a 4, respectivamente. À direita apresentamos a profundidade da triangulação $J_{1}^{a}$, que na superfície variou de nível 6 a 10.

é obrigatória em uma abordagem de PUI. Existem trabalhos que fazem uso de outros tipos de função, por exemplo, funções de bases-radiais [160, 51, 221]. No entanto, em nosso método, utilizamos aproximações locais por mínimos-quadrados com bases ortogonais, pois sua propriedade de construção recursiva se fez necessária.

\subsection{Extração de Iso-Superfícies}

Uma característica desejável em um poligonalizador de iso-superfícies é a adaptatividade: a superfície pode ser representada fielmente por um conjunto de polígonos cujos tamanhos sejam adequados aos detalhes das regiões. Um dos primeiros trabalhos nesse sentido, proposto por Bloomenthal, aplicou uma octree e derivou regras para conexão de blocos em níveis de refinamentos distintos [32]. Hall e Warren [99] propuseram um 
poligonalizador a partir da subdivisão recursiva de tetraedros. Recentemente, Paiva et al. [164] aplicaram uma subdivisão baseada em octree para gerar uma triangulação adaptativa por meio de malhas duais. Kazhdan et al. [116] também apresentaram um esquema para extrair iso-superfícies a partir de uma octree. Esse método faz uso de árvores binárias para assegurar uma decomposição celular livre de buracos e de uma única componente conexa (superfície watertight).

Em relação à qualidade dos triângulos, durante a extração da iso-superfície, Figueiredo et al. [58], em seu trabalho, aplicaram um mecanismo baseado em princípios físicos de sistemas de forças para obter malhas triangulares de alta qualidade. Schreiner et al. deesenvolveram recentemente uma técnica de avanço-de-fronteira para a criação de isosuperfícies a partir de dados volumétricos regulares e irregulares [182]. No entanto, o custo computacional do trabalho de Schreiner é elevado e as condições impostas à função para a correta extração são severas.

Já Castelo et al. [48] definiram uma triangulação adaptativa em dimensão arbitrária, nomeada triangulação $J_{1}^{a}$, que apresenta características extras, como: habilidade em ser definida de forma eficiente em qualquer dimensão, descrições algébricas bem definidas, que permitem economia de memória e implementação eficiente, além do fato de a triangulação possuir limites inferiores para a qualidade dos tetraedros [47].

\subsection{Definições}

Iniciamos este item definindo o método de PUI para, em seguida, apresentarmos uma breve descrição da estrutura de dados algébrica da triangulação $J_{1}^{a}$, além de suas propriedades que são usadas na adaptatividade em duas vias, de nosso método.

\subsubsection{Partição da Unidade Implícita em Multinível}

Como em outros métodos de aproximação por função implícita, os métodos de PUI são definidos como o conjunto de nível zero de uma Função $F$. O elemento primordial para 
a construção dessa função (global) $F$ em um domínio finito $\Omega$ é combinar linearmente as aproximações locais por meio de pesos. Para esse propósito, primeiramente, consideramos um conjunto de funções-peso não-negativas com suporte compacto:

$$
\Phi=\left\{\omega_{1}, \ldots, \omega_{n}\right\}
$$

satisfazendo a propriedade

$$
\sum_{i=0}^{n} \omega_{i}(\mathbf{x}) \equiv 1, \mathbf{x} \in \Omega
$$

que denominamos por partição da unidade. Também consideramos o conjunto:

$$
\mathbb{F}=\left\{f_{1}, \ldots, f_{n}\right\}
$$

de funções (com sinal) locais em $\Omega$, de forma que os conjuntos $\mathbb{F}$ e $\Phi$ definam a função global $F: \mathbb{R}^{3} \rightarrow \mathbb{R}$ por:

$$
F(\mathbf{x}) \equiv \sum_{i=0}^{n} f_{i}(\mathbf{x}) \omega_{i}(\mathbf{x}), \quad \mathbf{x} \in \Omega
$$

A partição da unidade pode ser definida a partir de um conjunto de uma função nãonegativa com, suporte compacto $\theta$ :

$$
\omega_{i}(\mathbf{x})=\frac{\theta\left(\left\|\mathbf{x}-\mathbf{c}_{i}\right\| / R_{i}\right)}{\sum_{k=1}^{n} \theta\left(\left\|\mathbf{x}-\mathbf{c}_{k}\right\| / R_{k}\right)},
$$

em que $\mathbf{c}_{i}$ e $R_{i}$ são o centro e o raio do suporte de $\omega_{i}$, respectivamente.

Dessa forma, a partir da função $F$, temos que a superfície reconstruída é definida implicitamente pelo conjunto $\mathscr{S}=\left\{\mathbf{x} \in \mathbb{R}^{3}: F(\mathbf{x})=0\right\}$.

Na Figura 4.3, ilustramos um exemplo bidimensional (de um trecho) de um domínio $\Omega$ sendo coberto com um conjunto de círculos, que no caso são os suportes das funçõespeso $\omega_{i}$, no qual o conjunto de nível zero da função $F$ (para esse trecho do domínio) é apresentado em amarelo. Ainda a Figura 4.3, que veremos em momento oportuno, ilustra o comportamento da octree restrita da triangulação $J_{1}^{a}$ durante a etapa de aproximação 
da função. Já na Figura 4.4, mostramos as aproximações locais que são combinadas para definirem a curva amarela da Figura 4.3.

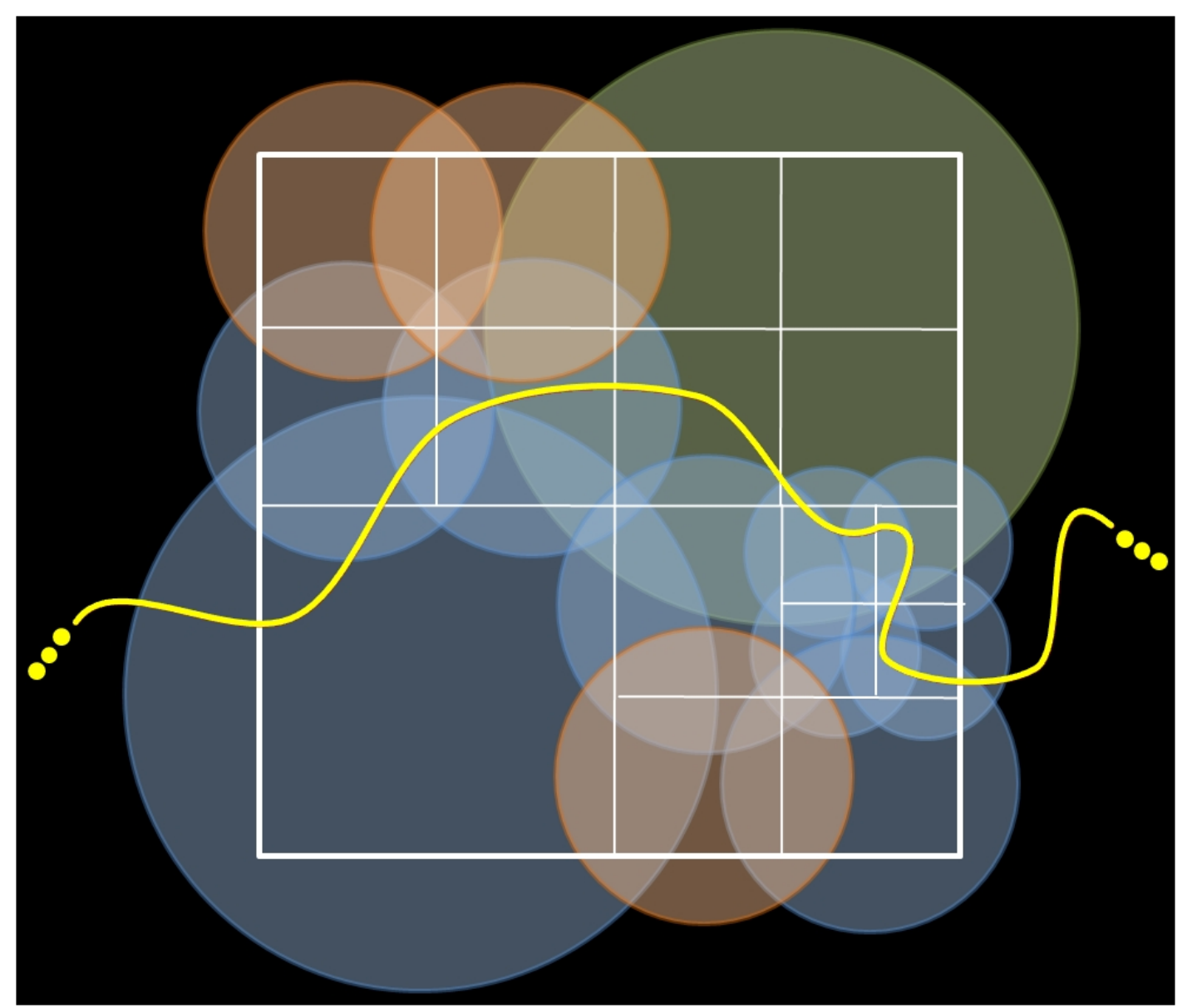

Figura 4.3: Ilustração bidimensional do domínio $\Omega$ sendo coberto por um conjunto de círculos que definem o suporte das funções-peso $\omega_{i}$. Também nessa figura, apresentamos o comportamento da octree restrita da triangulação $J_{1}^{a}$ durante a aproximação da função.

\subsubsection{A triangulação $J_{1}^{a}$}

Castelo e colaboradores [48, 47] propuseram a triangulação $J_{1}^{a}$ como uma estrutura adaptativa definida por descrições algébricas que a tornam eficiente, tanto em termos de armazenamento em memória, quanto para sua definição e implementação em qualquer dimensão. Tal descrição algébrica é baseada em dois mecanismos: o primeiro é utilizado para definir unicamente um simplexo na triangulação, e o segundo é utilizado para realizar percursos na estrutura (definição de iteradores baseados algébricos). 


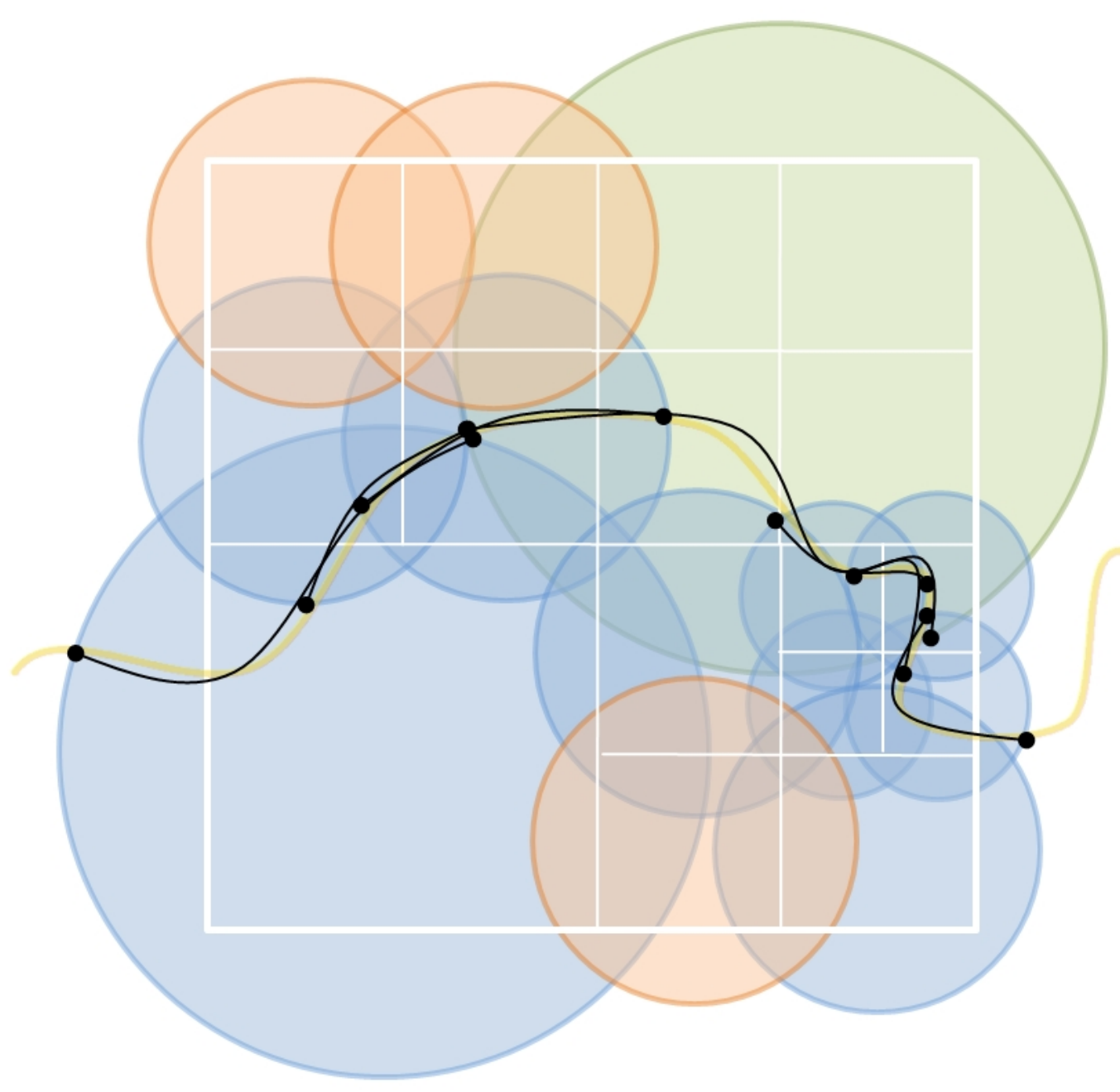

Figura 4.4: As curvas em preto, com extremos representados pelos pontos pretos, representam as aproximações locais que definem a aproximação global (em amarelo na Figura 4.3) pela PUI.

A triangulação $J_{1}^{a}$ é condicionada por uma grade computacional de "blocos" que correspondem a hipercubos $N$-dimensionais em $\mathbb{R}^{N}$. Os simplexos da triangulação $J_{1}^{a}$ são obtidos pela divisão de tais blocos, de forma que cada simplexo é codificado por uma sêxtupla:

$$
S=(g, r, \pi, s, t, h)
$$

em que as duas primeiras componentes estão relacionadas com a localização do bloco na grade computacional e as últimas quatro são utilizadas para identificar o simplexo dentro do bloco. Especificamente, o vetor $N$-dimensional $g$ oferece a localização de um bloco 
particular em um nível de refinamento $r$. A Figura 4.5 ilustra, à esquerda, um exemplo bidimensional da triangulação $J_{1}^{a}$ e, à direita, um bloco em destaque do nível de refinamento $r=0$ (0-bloco) e $g=(3,1)$. Também, na mesma figura, podemos observar blocos com nível de refinamento $r=1$ (1-bloco) ilustrado em azul escuro.

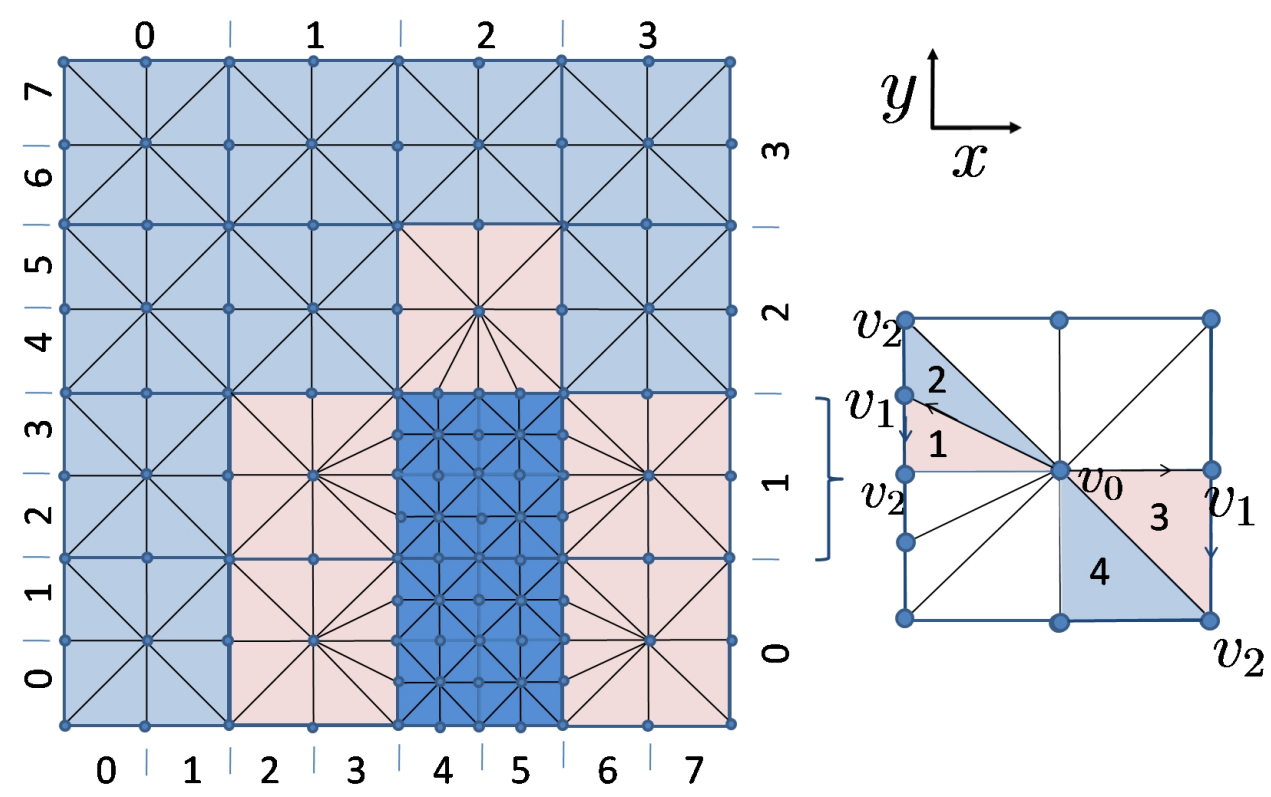

Figura 4.5: A triangulação $J_{1}^{a}$ : à esquerda, um exemplo bidimensional da triangulação adaptativa e, à direita, exemplos de operações de pivotamento.

Antes de explicarmos como os simplexos são descritos, é importante compreender que a triangulação $N$-dimensional $J_{1}^{a}$ permite o refinamento de um $i$-bloco por dividí-lo em $2^{N}(i+1)$-blocos. Também é importante notar que, com o intuito de acomodar os novos blocos criados, alguns blocos são forçados a serem refinados para que a diferença no nível de refinamento de dois blocos vizinhos não seja maior do que um. A última parte desse processo de acomodação é impor condições aos blocos cujos níveis de refinamentos diferem por mais do que um. Aquele tendo o menor $r$ é transformado em um bloco de transição. Tal bloco possui apenas uma de suas faces $k$-dimensionais refinadas $(0<k<N)$. A situação é ilustrada na Figura 4.5 em que blocos básicos (0-blocos) são coloridos em azul claro, 1blocos básicos são coloridos em azul escuro e blocos de transição são coloridos em laranja. Em particular, o bloco de transição em destaque tem apenas uma de suas arestas refinadas. 
De agora em diante, para tornar as explicações mais claras, qualquer bloco que não é de transição será denominado simplesmente por bloco básico.

A representação de um simplexo é baseada no fato que todos os simplexos dentro de um bloco compartilham um mesmo vértice $\mathbf{v}_{0}$, que é o centro de um hipercubo $N$ dimensional. Então, iniciando em $\mathbf{v}_{0}$, o próximo passo para a determinação do próximo vértice do simplexo é tomado na direção positiva ou negativa de um sistema de coordenadas predefinido. Isso produzirá $\mathbf{v}_{1}$ como sendo o centro de uma face $(N-1)$-dimensional, e continuando com o procedimento, os vértices $\mathbf{v}_{2}, \ldots, \mathbf{v}_{n}$ serão definidos como centros de faces $(N-2), \ldots, 0$-dimensionais respectivamente. Em outras palavras, simplexos podem ser simbolizados por um caminho percorrido de $\mathbf{v}_{0}$ até $\mathbf{v}_{N}$ que é codificado por $\pi$ e $s$, da Equação 4.6. O vetor $\pi$ armazena a permutação de $N$ inteiros de 1 a $N$, representando os eixos coordenados, enquanto $s$ representa a direção (positiva ou negativa) que pode ser seguida em cada eixo. Por exemplo, na Figura 4.5, o Simplexo 3 é representado por $\pi=(1,2)$ e $s=(1,-1)$, que significa que, a partir de $\mathbf{v}_{0}$, o percurso é traçado pelos eixos $\pi_{1}=1(x$, na figura), na direção positiva $\left(s_{\pi_{1}}=1\right)$, e então pelo eixo $\pi_{2}=2$ ( $y$, na figura), na direção negativa $\left(s_{\pi_{2}}=-1\right)$.

Para simplexos dentro de um bloco básico e simplexos dentro de um bloco de transição, que não atingem alguma face refinada, as informações que são fornecidas por $\pi$ e $s$ são suficientes. Entretanto, nos demais casos, necessita-se de mais informação, porque, quando uma face refinada de dimensão $k$ é alcançada, não existe apenas um centro, mas $2^{k}$ centros. Por essa razão, o escalar $h$ é usado para informar quantos passos são tomados antes de uma face refinada ser atingida, enquanto que o vetor $t$ define sinais extras para os eixos $\pi_{h+1} \ldots \pi_{N}$ que são usados para selecionar um centro de todas as possibilidades. Por exemplo, na Figura 4.5, o Simplexo 1 é representado por $\pi=(1,2), s=(-1,1), h=1$ e $t=(0,1)$ porque apenas um passo é tomado antes de alcançar a aresta refinada, e a escolha do centro para se definir $\mathbf{v}_{1}$ está na direção positiva de $\pi_{h+1}$.

A seguinte expressão formalmente descreve como compor um simplexo dentro de um hipercubo centrado na origem $(0, \ldots, 0)$, com arestas de comprimento 2 : 


$$
\left\{\begin{array}{l}
v_{0}=(0, \ldots, 0) \\
v_{i}=v_{i-1}+e_{\pi_{i}} s_{\pi_{i}}, \quad \text { for } 1 \leq i<h \\
v_{h}=v_{h-1}+e_{\pi_{h}} s_{\pi_{h}}+\frac{1}{2} \sum_{k=h+1}^{N} e_{\pi_{k}} t_{\pi_{k}} \\
v_{i}=v_{i-1}+\frac{1}{2} e_{\pi_{i}} s_{\pi_{i}}, \quad \text { for } h<i \leq N
\end{array},\right.
$$

em que $e_{j}$ é um vetor com valor 1 na posição $j$ e 0 nas posições restantes.

Além da descrição das localizações dos simplexos, a triangulação $J_{1}^{a}$ também define regras de pivotamento para realizar o percurso na triangulação, sem usar qualquer outra estrutura de dados topológica. Essas regras são completamente algébricas, pois assumem a descrição do simplexo $\sigma^{\prime}$ por uma operação de pivotamento a partir de outro simplexo $\sigma^{\prime \prime}$ em relação a algum vértice de $\sigma^{\prime \prime}$. A Figura 4.5 ilustra duas operações de pivotamento em que os Simplexos 1 e 2 são pivotados em relação aos vértices $v_{2}$ e $v_{1}$, respectivamente, gerando simplexos 3 e 4 . Todas as regras de pivotamento podem ser encontradas nos trabalhos de Castelo [48, 47].

\subsection{Reconstrução Adaptativa em Duas Vias}

Ao invés de propormos um método híbrido ou uma abordagem matematicamente carregada de cálculos [221, 160, 205], decidimos solucionar alguns dos problemas da técnica de PUI, porém procurando preservar suas vantagens: simplicidade e eficiência. Dessa forma, antes de apresentarmos o algoritmo proposto, apresentamos um conjunto de características do nosso método, que asseguram sua eficiência e robustez.

\section{Aproximações Locais e o Critério de Recobrimento do Domínio}

Dado o conjunto de pontos iniciais, a primeira tarefa que realizamos, assim como no trabalho de Ohtake [158], foi a de escalarmos os pontos para que estivessem contidos em um domínio $\Omega=[0,1]^{3}$. Dessa forma, geramos as aproximações locais $f_{i}: \mathbb{R}^{3} \rightarrow \mathbb{R}$ para cada suporte esférico das funções-peso $\omega_{i}$, que foram definidos como as circunsferas dos blocos 
aumentados por um fator maior do que um. O nosso caso padrão assume 1.5, como no método de Ohtake.

As funções $f_{i}$ de cada bloco são calculadas a partir de sistemas de coordenadas locais $(\xi, \eta, v)_{i}$ com origem nos centros $\mathbf{c}_{i}$ dos suportes. O par $(\xi, \eta)_{i}$ define o domínio (plano local) e $v_{i}$ define a imagem (direção ortogonal ao plano, determinada pelo vetor normal resultante da média ponderada dos vetores normais aos pontos $\mathbf{p}_{i}$, que pertencem ao interior do suporte). Assim, $f_{i}$ é definida como:

$$
f_{i}(\mathbf{x})=w-g_{i}(u, v)
$$

em que $(u, v, w)_{i}$ define $\mathbf{x}$ na base $(\xi, \eta, v)_{i}$. É importante mencionarmos que nosso método requer a existência de vetores normais orientados para cada ponto da amostra.

Em nosso método, as funções (polinomiais) locais são calculadas por meio de mínimosquadrados. Entretanto, em vez de utilizar uma base canônica $\left\{u^{i} v^{j}: i, j \in \mathbb{N}\right\}$, como no trabalho de Ohtake [158], utilizamos uma base de polinômios ortogonais de duas variáveis em relação ao produto interno induzido pelas equações normais (na Seção 6.3.1 apresentamos a construção de polinômios ortogonais de várias variáveis). Para se calcular tais bases, utilizamos o algoritmo de Bartels e Jezioranski [23].

Dado um conjunto de polinômios, que são ortogonais segundo o produto interno induzido pelas equações normais, $\Psi=\left\{\psi_{1}, \ldots, \psi_{l}\right\}$, a aproximação polinomial no sistema de coordenadas locais é definida por:

$$
g_{i}(u, v)=\sum_{\psi_{j} \in \Psi} \psi_{j}(u, v) \frac{\sum_{i=1}^{m} w_{i} \psi_{j}\left(u_{i}, v_{i}\right)}{\sum_{i=1}^{m} \psi_{j}\left(u_{i}, v_{i}\right) \psi_{j}\left(u_{i}, v_{i}\right)},
$$

em que $g_{i}$ é a função $g$ que define o mínimo de:

$$
\left.\sum_{\left(u_{i}, v_{i}\right)}\left(g\left(u_{i}, v_{i}\right)-w_{i}\right)\right)^{2}
$$

A principal motivação para o uso dos polinômios ortogonais segundo o produto interno induzido pelas equações normais é a sua capacidade de se gerar aproximações de alto grau 
a partir de aproximações previamente calculadas, com baixo custo computacional.

Contudo, a utilização arbitrária de bases polinomiais de alto grau nas aproximações locais acarreta o fato de que tais bases podem gerar aproximações com efeitos oscilatórios. Mesmo que a minimização seja satisfatória (apresente um erro pequeno no sentido de mínimos-quadrados), a aproximação resultante pode ser ruim dentro da região (do suporte) de interesse. Tal fato é exemplificado na Figura 4.6, em cuja esquerda, o polinômio está próximo aos pontos dentro do suporte, mas os sinais obtidos durante a avaliação da função nos vértices do bloco da triangulação $J_{1}^{a}$ não estão corretos. Portanto, dependendo da disposição dos pontos dentro do domínio, essa situação pode gerar superfícies extras ou artefatos.
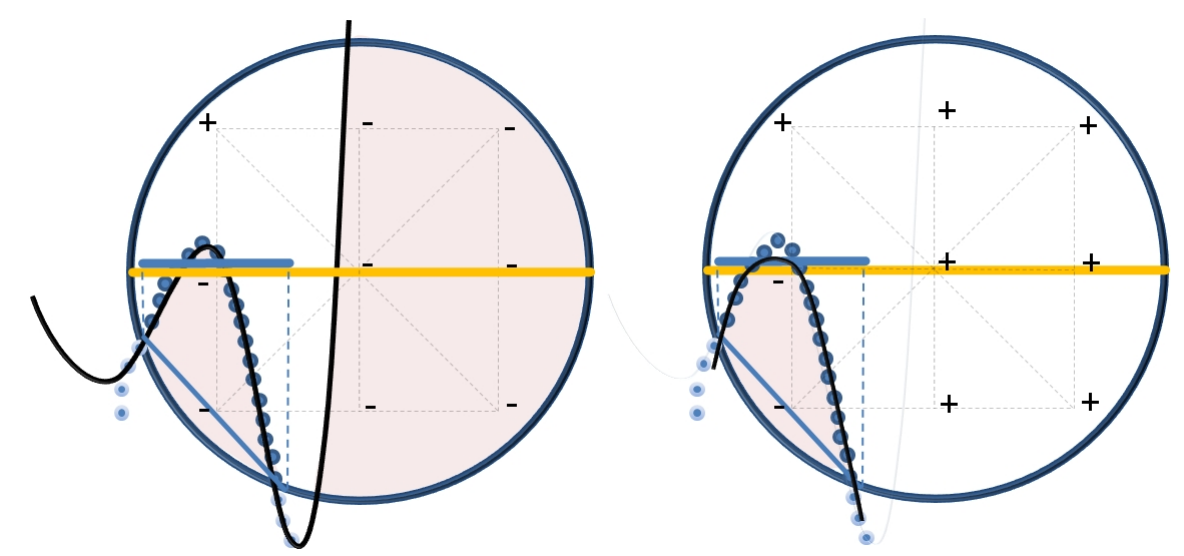

Figura 4.6: Ilustração do critério de recobrimento do domínio: aumentar o grau do polinômio arbitrariamente pode causar soluções locais errôneas e, portanto, a função global pode ser comprometida: na esquerda, apesar da solução ser mais precisa para o conjunto de pontos, a oscilação no polinômio local faz com que sinais no bloco da $J_{1}^{a}$ sejam mal calculados. Já na direita, a aproximação não é tão precisa quanto na esquerda, porém os sinais da função são adequadamente calculados.

Antes de apresentarmos uma solução, é importante notarmos que, embora polinômios de alto grau sejam capazes de aproximar de forma precisa a região entre os pontos, que a chamamos de recobrimento do domínio, eles podem oscilar em localizações em que não existam pontos para controlar a solução, como ilustrado à esquerda da Figura 4.6. Baseado nesse fato, é possível observar que, para a nossa técnica, não é apenas necessário um número mínimos de pontos para garantia da unicidade da solução pelo método dos 
mínimos-quadrados [30], mas também a distribuição dos pontos dentro do suporte. As Figuras 4.13-(c) e 4.13-(d) (Página 107) apresentam situações nas quais a aplicação do critério de recobrimento do domínio se faz necessária.

Portanto, propomos um método que fornece uma solução aproximada, não sendo computacionalmente custoso, para medir o quão bem distribuídos estão os pontos dentro do suporte. Como em nosso método, os domínios locais são planos, devemos determinar a área desses planos cobertos pelos pontos presentes no suporte. Para isso, calculamos uma taxa $(k)$ entre a área $A_{c d}$ da projeção do bounding-box dos pontos sobre o plano e a área $A_{s r}$ definida pela projeção do suporte esférico delimitado pelo bloco:

$$
\tau=A_{c d} / A_{s r}
$$

Assim, o limite superior de $\tau$ ocorre quando a projeção da esfera do suporte é inscrita na projeção do bounding-box dos pontos do suporte, que é igual a:

$$
\tau_{\max }=\frac{2 r 2 r}{\pi r^{2}}=\frac{4}{\pi} \approx 1.27
$$

A Figura 4.7 apresenta um exemplo do caso extremo em que a razão $\tau$ atinge seu máximo, pois os pontos quando projetados no plano, definem o bounding-box de forma a ter a projeção da esfera inscrita nele.

Definimos empiricamente um valor mínimo para $\tau$, conforme o grau da aproximação polinomial, isto é, 0.4 , 0.8, 0.85 são os parâmetros padrões para polinômios de grau dois, três e quatro, respectivamente.

Como mencionado anteriormente, além do critério de recobrimento, também consideramos o número mínimo de pontos que deveria ser utilizado para cada aproximação polinomial (o padrão é duas vezes o número mínimo de pontos para cada grau). As duas condições, portanto, constituem os nossos dois primeiros critérios de robustez.

Um problema imediato refere-se à existência de blocos que não possuem pontos suficientes para se realizar uma aproximação polinomial como descrita anteriormente. Para 


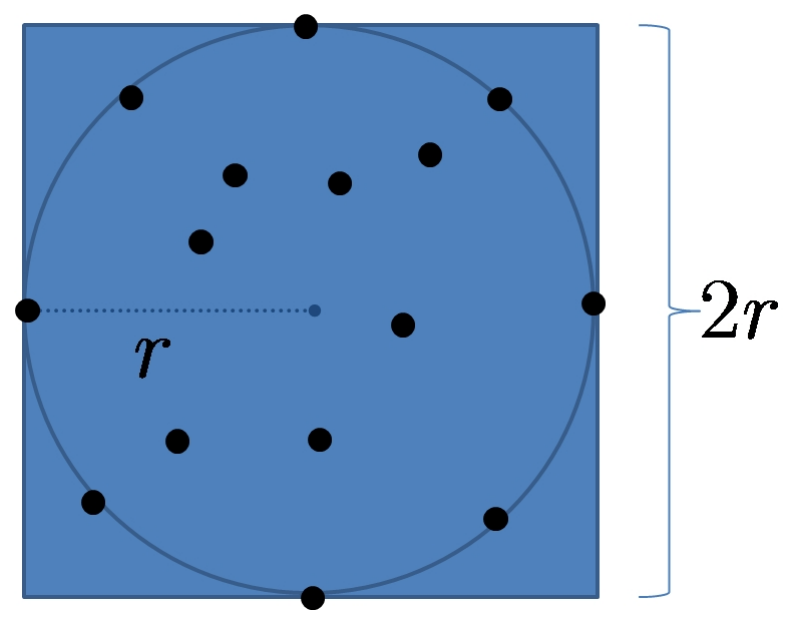

Figura 4.7: Exemplo de situação em que a taxa $\tau$ pode alcançar seu valor máximo: a projeção da esfera no plano gera um círculo inscrito no bounding-box dos pontos projetados no plano.

contornar essa dificuldade, criamos uma estratégia que se difere dos trabalhos anteriores, a saber:

- No método de Ohtake et al. [158], os autores propuseram um esquema iterativo de crescimento do suporte que para quando atinge um número mínimo de pontos (30, no caso desse trabalho, segundo proposta dos autores). A desvantagem desse procedimento é que um suporte muito grande pode influenciar uma grande região do domínio. Além disso, no caso de o centro do suporte estar distante da nuvem de pontos, esse processo iterativo que "marcha" na direção dos pontos tende a ser custoso;

- No método de Mederos et al. [147], os autores propuseram utilizar a aproximação do nó-pai, que definitivamente pode ser uma aproximação ruim.

Para resolvermos essa situação, assumimos, a princípio, que o tamanho do suporte sempre será proporcional (1.5 vezes maior) ao seu bloco da triangulação $J_{1}^{a}$, para não permitir que um suporte que possua uma aproximação de baixa qualidade influencie uma grande região do domínio. Partindo desse princípio, primeiro determinamos o ponto $\mathbf{r}$ mais próximo do centro do bloco $\mathbf{c}_{i}$, e a partir de $\mathbf{r}$, buscamos seus $p$ vizinhos mais próximos (em nosso caso, consideramos $p=20$ pontos como padrão) que definiram uma aproximação 
de um plano por mínimos-quadrados. Porém, dependendo da distribuição dos pontos, a aproximação por plano pode ser inviável.

Portanto, detectamos essa situação comparando o ângulo entre o vetor normal do plano gerado por mínimos-quadrados e a média dos vetores normais dos pontos vizinhos de $\mathbf{r}$. Se o ângulo é maior do que $\pi / 6$ (parâmetro que é definido empiricamente), a função de mínimos-quadrados é substituída pelo plano definido pelo vetor normal, que é calculado pela média dos vetores normais dos vizinhos de $\mathbf{r}$ e pela origem, dada pelo centro de massa dos vizinhos de r. Esse último teste define a terceira e última condição de robustez do nosso método. Exemplificamos tal situação na Figura 4.8-(a). O trabalho de Amenta e Kil [17] apresenta um estudo do comportamento do método de mínimos-quadrados, no qual são apresentados maiores detalhes dessa situação [17].

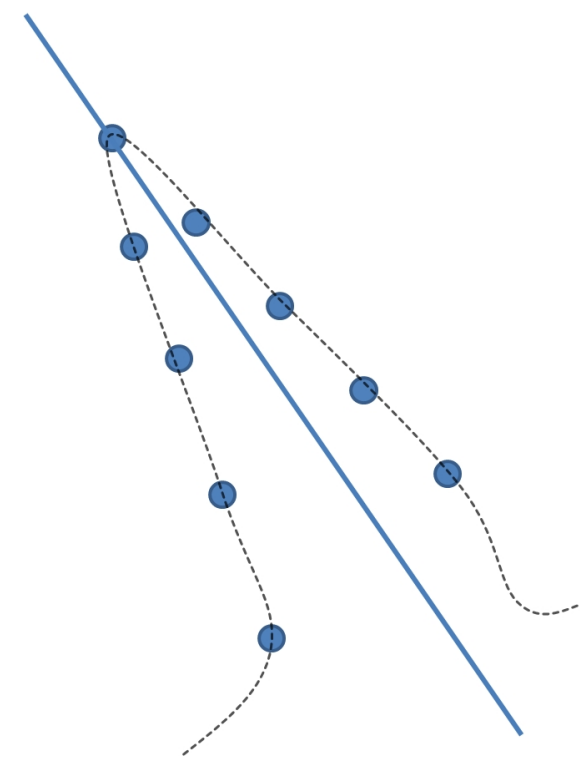

(a)

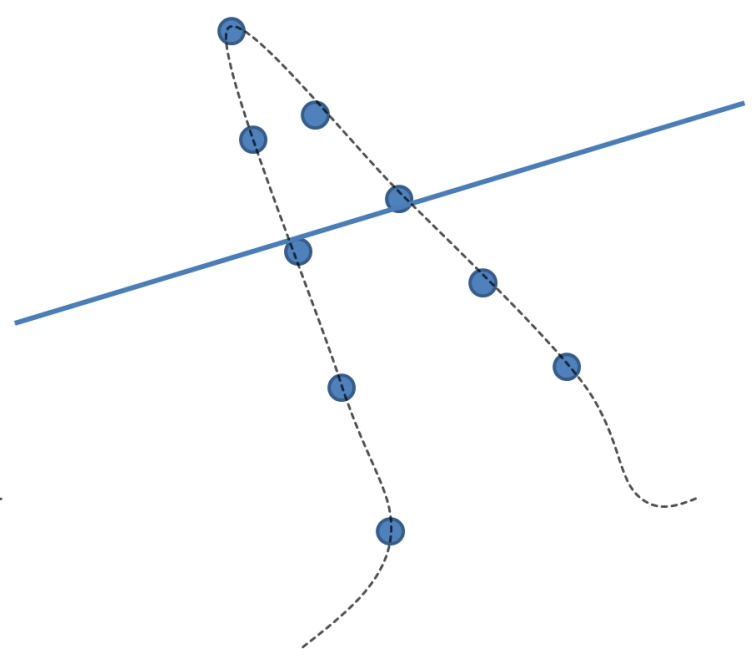

(b)

Figura 4.8: Com a utilização da média dos vetores normais em vez de uma aproximação por mínimos-quadrados, podemos evitar problemas de mal-definição da aproximação local para regiões com pouco ou nenhum ponto: em (a), temos uma situação em que o plano é obtido por mínimos-quadrados, cuja superfície é localmente aproximada de forma equivocada, dividindo-se em duas regiões. Tal fato pode comprometer a função final. Já em (b), temos um plano obtido pela média das normais e com origem no centro de massa dos pontos. Nesse caso, detalhes podem ser perdidos, mas isso não compromete a aproximação global. 


\subsubsection{O Algoritmo}

Agora que os principais conceitos do método foram discutidos, estamos aptos para a descrição do algoritmo. Primeiramente, definimos a configuração inicial da triangulação $J_{1}^{a}$, em vez de começarmos com um único bloco (que é o caso do método de Ohtake, iniciado com uma octree por um único nó raiz). Permitimos ao usuário definir uma resolução inicial, sendo que a padrão é $3 \times 3 \times 3$ blocos. A partir da configuração inicial, para cada bloco que não possui, até o momento, uma aproximação, existem três possíveis situações:

(i) O número de pontos dentro do suporte é suficiente para realizar a aproximação;

(ii) O número de pontos dentro do suporte não é suficiente para realizar, ao menos, uma aproximação de primeiro grau;

(iii) O número de pontos dentro do suporte é maior que um limitante superior.

No Caso $(i)$, realizamos um teste que verifica a variação entre vetores normais dos pontos pertencentes ao suporte, assim como realizada por Ohtake et al. [158]. Esse teste é realizado para determinar a presença de dois ramos da superfície dentro do suporte (Figura 4.9): a média das normais $\tilde{\mathbf{n}}_{i}$ é calculada e verificamos se o ângulo entre cada vetor $\mathbf{n}_{i}$ dos pontos do suporte e $\tilde{\mathbf{n}}_{i}$ é maior que $\pi / 2$. Nesse caso, o suporte provavelmente contem duas folhas. Com isso, o nosso método refina o bloco e o processo se inicia novamente a partir dos novos blocos criados.

Já o método de Ohtake opta por aproximar a região definida por uma quádrica completa. Porém, no caso em que apenas um ramo é detectado, os autores também definem um sistema de coordenadas locais e realizam uma aproximação polinomial local de segundo grau de duas variáveis.

Dando continuidade, se o teste anterior falha, realizamos uma aproximação polinomial de primeiro grau, e o grau da aproximação local é recursivamente elevado até que:

(a) o critério de erro seja satisfeito ou; 
(b) o teste de robustez não permita utilizar um polinômio de grau maior ou;

(c) o maior grau do polinômio permitido seja alcançado (no nosso caso, usamos quatro como maior grau permitido).

Se o procedimento anterior termina e a tolerância do erro é aceitável, a aproximação é armazenada no bloco. Caso contrário, o bloco é refinado, a menos que seu suporte possua um número crítico de pontos (assumimos 100 pontos). Nessa situação, a subdivisão pode ser abortada, caso as novas aproximações dos blocos aumentem o erro, ao invés de diminuírem. Notemos a importância dessa verificação, pois, novos blocos podem possuir pequenas quantidades de pontos ou até nenhum, o que não permitiria uso de polinômios de alto grau, podendo gerar aproximações que, quando combinadas, fossem piores do que uma única função definida pelo bloco-pai.

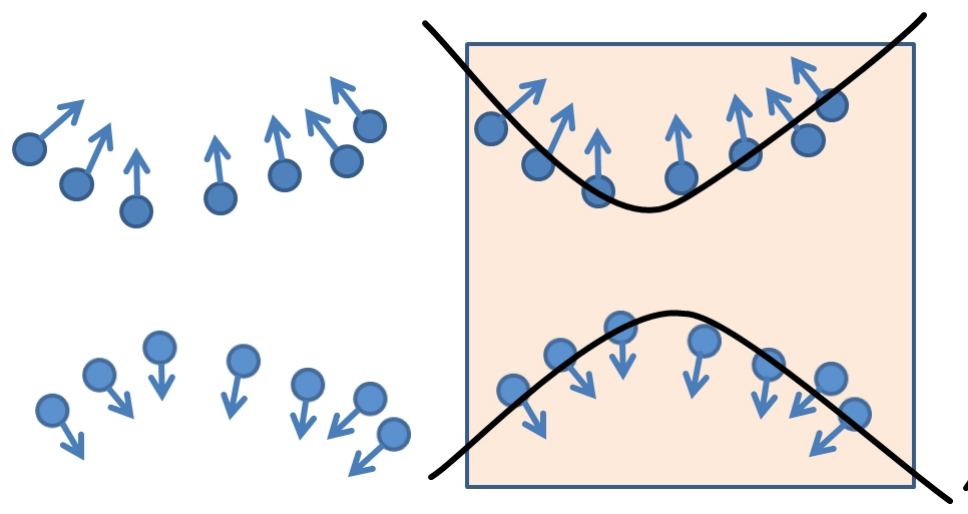

(a)

(b)

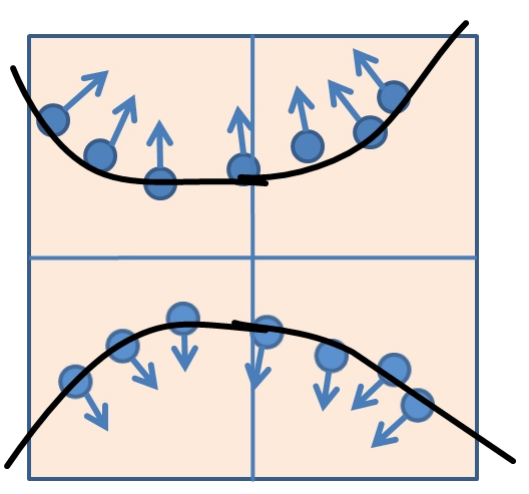

(c)

Figura 4.9: (a) Determinação de dois ramos da superfície: (b) o método de Ohtake opta em aproximar uma quádrica completa, ao passo que (c) nosso método, simplesmente divide o bloco da triangulação $J_{1}^{a}$ e realiza uma aproximação em cada bloco.

Nas duas etapas em que o refinamento é sugerido, o bloco pode já estar no refinamento máximo permitido pelo usuário, então a única opção restante para esse caso é utilizar a melhor aproximação que se pôde calcular.

É importante mencionarmos que o critério de erro que utilizamos é trivial para nossas funções e consiste basicamente em verificar se o erro relativo dos mínimos-quadrados da função aproximada é maior que um limitante. 
O Caso $(i i)$ é referente à aproximação por um plano, que foi previamente discutido (Página 94): primeiro aplicamos a busca pelo agrupamento de pontos mais próximos ao centro $\mathbf{c}_{i}$ do bloco, para, então, calcularmos a aproximação de primeiro grau adequada.

O último caso ( i i i) é uma heurística que desenvolvemos para evitar cálculos desnecessários e custosos. Consideramos um esforço desnecessário aplicar o método de mínimosquadrados para mais do que mil pontos. Portanto, nesse momento, forçamos a subdivisão do bloco, caso o máximo refinamento não tenha sido alcançado, pois, a aproximação é calculada de qualquer forma.

Destaque deve ser dado à diferença entre refinamentos de blocos causados pelas condições de aproximações locais e aqueles causados pela restrição da triangulação $J_{1}^{a}$ (explicada na Seção 4.3.2). No último caso, novas aproximações não são calculadas, caso já tenha sido definida uma aproximação para o bloco, que será a mesma para todos os blocos-filho.

A Figura 4.3 (Página 86) ilustra o caso em que nem todos os blocos-folha mantêm aproximações associadas a eles. Na figura, os círculos em azul representam os suportes dos blocos-folha que contem aproximações obtidas por terem pontos suficientes dentro de seus blocos; em laranja, os suportes dos blocos-folha que contêm aproximações, mas não possuem pontos suficientes em seus suportes; e, em verde, o suporte para um bloco nãofolha, mas que contem uma aproximação, e foi subdividido para acomodar o processo da triangulação $J_{1}^{a}$. Dessa forma, seus quatro blocos-filho possuam a mesma aproximação local que o bloco-pai.

Por fim, na Figura 4.10 apresentamos o pseudo-código do nosso algoritmo.

\section{Avaliação da Função e Poligonalização Adaptativa}

Dado um ponto $\mathbf{x}$ dentro do domínio $\Omega$, um percurso pela octree restrita da triangulação $J_{1}^{a}$ é realizado em seus blocos, com o intuito de determinar quais suportes esféricos contêm x em seu interior. Dessa forma, o valor da função $F(\mathbf{x})$ é obtido pela soma de todas as funções locais dos suportes que contêm $\mathbf{x}$, isto é: 


\section{Entradas}

- MAXPONTOS e MINPONTOS o número máximo e mínimo de pontos admitidos para realizar a aproximação

- MAXNível o maior nível de refinamento definido pelo usuário

- LIMERRO o limite de erro

2. Para todo bloco B sem aproximação

- Obtenha o conjunto de pontos $\mathrm{P}(\mathrm{B})$ no suporte de B

- Se o número de pontos em $(\mathrm{P}(\mathrm{B}))>$ MAXPONTOS e nível (B) < MAXNíveL

- Refine B e recomece o processo com os filhos de B

- $\quad$ Se quantidade $(\mathrm{P}(\mathrm{B}))<\operatorname{MINPONTOS}$

- Aproxime B com um plano usando o cluster de pontos mais próximos

- Senão

- Se existe mais do que uma folha no bloco

- Refine B e recomece o processo com os filhos de B

- Aproxime o polinômio de grau um Pol(B)

- /* g representa o grau do polinômio */

- $\mathrm{g}=1$

- Enquanto ErroPol $(B)<\operatorname{LIMERRO~e~} \mathrm{g}<4$ e robustez $(\mathrm{P}(\mathrm{B}), \mathrm{g})=0 \mathrm{~K}$

- Aumente o grau g de Pol(B)

(a)

Figura 4.10: Pseudo-código do algoritmo de partição da unidade implícita adaptativo em duas vias. 


$$
F(\mathbf{x})=\frac{\sum_{i=1}^{m} f_{i}(\mathbf{x}) \theta_{i}\left(\left\|\mathbf{x}-\mathbf{c}_{i}\right\| / R_{i}\right)}{\sum_{i=1}^{m} \theta_{i}\left(\left\|\mathbf{x}-\mathbf{c}_{i}\right\| / R_{i}\right)},
$$

em que $m$ é o número de suportes que contêm $\mathbf{x}, f_{i}(\mathbf{x}), \mathbf{c}_{i}$ e $R_{i}$ são a função local, o centro e o raio do bloco $i$ respectivamente. Para a função-peso, nesse caso, assumimos como sendo:

$$
\theta(t)=\left\{\begin{array}{ll}
\left(1-t^{2}\right)^{4} & \text { if } t<1 \\
0 & \text { caso contrário }
\end{array} .\right.
$$

O processo de poligonalização consiste em determinar o simplexo inicial cuja superfície corta seu interior. Essa tarefa é imediata e consiste em, a partir de um ponto $\mathbf{x}$ da nuvem, calcular o ponto que está próximo à superfície. Para a realização de tal tarefa, utilizamos:

$$
\mathbf{x}_{p}=\mathbf{x}-\frac{1}{\|\nabla F(\mathbf{x})\|^{2}} \nabla F(\mathbf{x}) F(\mathbf{x}),
$$

para, então, definir o simplexo inicial que contem $\mathbf{x}_{p}$. Para a definição do simplexo inicial, primeiro verificamos em qual bloco (folha) $\mathbf{x}_{p}$ está, para, em seguida, percorrermos todos os simplexos do bloco, verificando qual contem $\mathbf{x}_{p}$. Após a determinação do simplexo inicial, realizamos um percurso por todos os simplexos que intersectam a superfície, pelas regras de pivotamento da triangulação $J_{1}^{a}$, ao passo que a malha adaptativa que define a aproximação da superfície foi sendo gerada.

Notemos que o processo para encontrar o simplexo inicial é sujeito a falhas. Contudo, em todos os testes que realizamos esse procedimento nunca falhou. Com o intuito de definir uma abordagem robusta, no caso de o simplexo inicial não ser encontrado pelo procedimento anterior, realizamos uma busca que percorre todos os blocos da triangulação $J_{1}^{a}$ (“força-bruta") para determinar o simplexo inicial.

\subsection{Extensões do Método}

O método de PUI em duas vias que propusemos, até o momento, não é capaz de modelar eficientemente características afiadas, pois as aproximações locais são baseadas em funções polinomiais. Logo, como uma extensão do método, sugerimos incluir uma 
técnica de modelagem de características afiadas. Decidimos apresentar tal abordagem como uma extensão pelo fato de ser uma tarefa que fica a cargo de o usuário escolher utilizar o mecanismo de modelagem de características, pois é uma etapa que aumenta o custo computacional. As demais extensões que introduzimos, seguem o mesmo princípio de serem utilizadas apenas a partir da decisão do usuário.

A segunda extensão se refere à possibilidade de interativamente editar a função implícita localmente. Tal extensão possui diretamente duas utilidades, a primeira em reparar artefatos produzidos por funções locais e a segunda em melhorar a qualidade da aproximação escolhendo funções apropriadas.

A última extensão foi proposta para contornar o fato de que o poligonalizador da triangulação $J_{1}^{a}$ apresenta malhas cujos triângulos possuem baixa qualidade. Assim, definimos um cálculo realmente simples e eficiente em termos de memória e tempo que desloca vértices da triangulação $J_{1}^{a}$ com o intuito de melhorar a razão de aspecto dos triângulos. Os resultados das extensões do método estão apresentadas na Seção 4.6.

\section{Características Afiadas}

Detectar e modelar uma região como uma característica afiada não é um problema trivial. Contudo, a solução apresentada por Kobbelt et al. [118] é capaz de produzir bons resultados. Tal abordagem serviu de base para Ohtake et al. [158] na elaboração de seu mecanismo de detecção das características afiadas.

A idéia que suporta a definição de uma característica afiada primeiro realiza agrupamentos de pontos baseada na diferença entre seus vetores normais que são capazes de classificar o tipo de característica afiada [158]. Em seguida, realizam-se aproximações polinomiais locais para cada um desses conjuntos, cuja função em um ponto $\mathbf{x}$ é avaliada conforme sua posição em relação às aproximações locais.

Dessa maneira, dado um conjunto de pontos $P=\left\{\mathbf{p}_{1}, \ldots, \mathbf{p}_{k}\right\}$ associado com seus vetores normais $N=\left\{\mathbf{n}_{1}, \ldots, \mathbf{n}_{k}\right\}$, o teste consiste primeiro na determinação da existência de uma 
característica afiada. Para isso, dois testes são sugeridos por Kobbelt [118]. O primeiro é:

$$
\min _{i, j}\left(\mathbf{n}_{i} \cdot \mathbf{n}_{j}\right)<0.9
$$

Se a Equação 4.12 é satisfeita, a região é classificada como uma característica afiada. O segundo teste é utilizado para definir se a característica afiada define um vértice (definida pelo encontro de três ou mais superfícies - sharp corner) ou uma aresta (definida pelo encontro de duas superfícies - sharp edge). Para isso, dados os dois pontos $\left\{\mathbf{p}_{l}, \mathbf{p}_{m}\right\}$, que definem o maior ângulo entre seus vetores normais, $\left\{\mathbf{n}_{l}, \mathbf{n}_{m}\right\}$, um vetor ortogonal é calculado pelo produto vetorial entre eles, isto é, $\mathbf{n}^{*}=\frac{\mathbf{n}_{l} \times \mathbf{n}_{m}}{\left\|\mathbf{n}_{l} \times \mathbf{n}_{m}\right\|}$. Após isso, se o segundo teste:

$$
\max _{i}\left\|\mathbf{n}_{i} \cdot \mathbf{n}^{*}\right\|>0.7
$$

for verdadeiro, a região é definida como um vértice, caso contrário, se apenas a Equação 4.12 é satisfeita, a região é definida como uma aresta. Em nossa implementação, esses testes são complementados pela verificação do número de pontos - se é menor que um parâmetro definido pelo usuário (usamos 30 como padrão). Utilizamos a mesma implementação proposta por Ohtake et al. [158] para a detecção de características afiadas. Nessa, os autores propuseram a detecção e modelagem de arestas e vértices definidos pelo encontro de três ou quatro superfícies.

A adição de características afiadas à nossa técnica requer a alteração de duas partes do algoritmo explicado na Seção 4.4, já que nosso método trata esta situação diferente ao Ohtake, para os casos em que uma pequena quantidade de pontos é encontrada no suporte.

No Caso (i) (Página 96), após decidir a melhor aproximação polinomial, o teste de detecção de características afiadas é realizado e, se detectada, a característica afiada é calculada, utilizando a abordagem de Ohtake et al. [158]. Se o erro da aproximação por características afiadas é menor do que o erro dado pela aproximação polinomial, a aproximação por características afiadas é utilizada. Também alteramos o Caso (i i) (Página 96), para os blocos que originalmente apresentam algum ponto pelo menos. Testamos não 
apenas por uma aproximação de primeiro grau, mas também funções de características afiadas para os agrupamentos de pontos. Como o número de pontos é pequeno, o teste do erro não é considerado como anteriormente. Caso o teste de características afiadas seja satisfeito, a aproximação por características afiadas é definida de qualquer forma.

\section{Edição Interativa da Função Implícita}

Para a edição da função, exploramos uma das vantagens dos métodos baseados em PUI sobre outras técnicas, tais como as baseadas em MLS ou RBF: o fato de a função global ser definida por um conjunto de funções locais independentes em subdomínios implica que mudar uma dessas funções apenas afeta a função localmente. Enfim, alterar localmente a função consiste em localizar o bloco desejável e também alterar sua função associada. Encontrar tal bloco na triangulação $J_{1}^{a}$ é uma tarefa simples, pois sua estrutura consiste de uma octree restrita, descrita pelas representações algébricas. O cálculo é feito testando blocos que contêm o desejável ponto, em diferentes níveis de refinamento, até que aquele em que a função está definida seja encontrado.

Em nossa implementação, desenvolvemos uma ferramenta gráfica (Figura 4.11) que permite escolher pontos do modelo reconstruído e selecionar uma nova função para aproximar a superfície localmente a tais pontos. Temos as seguintes opções:

1. Função constante: nessa opção ou o usuário pode forçar a definição de um valor constante ou deixar que o próprio método calcule a função como uma aproximação de grau 0;

2. Funções polinomiais: aquelas definidas pelas aproximações polinomiais, variando de grau um a quatro;

3. Funções de características afiadas. 


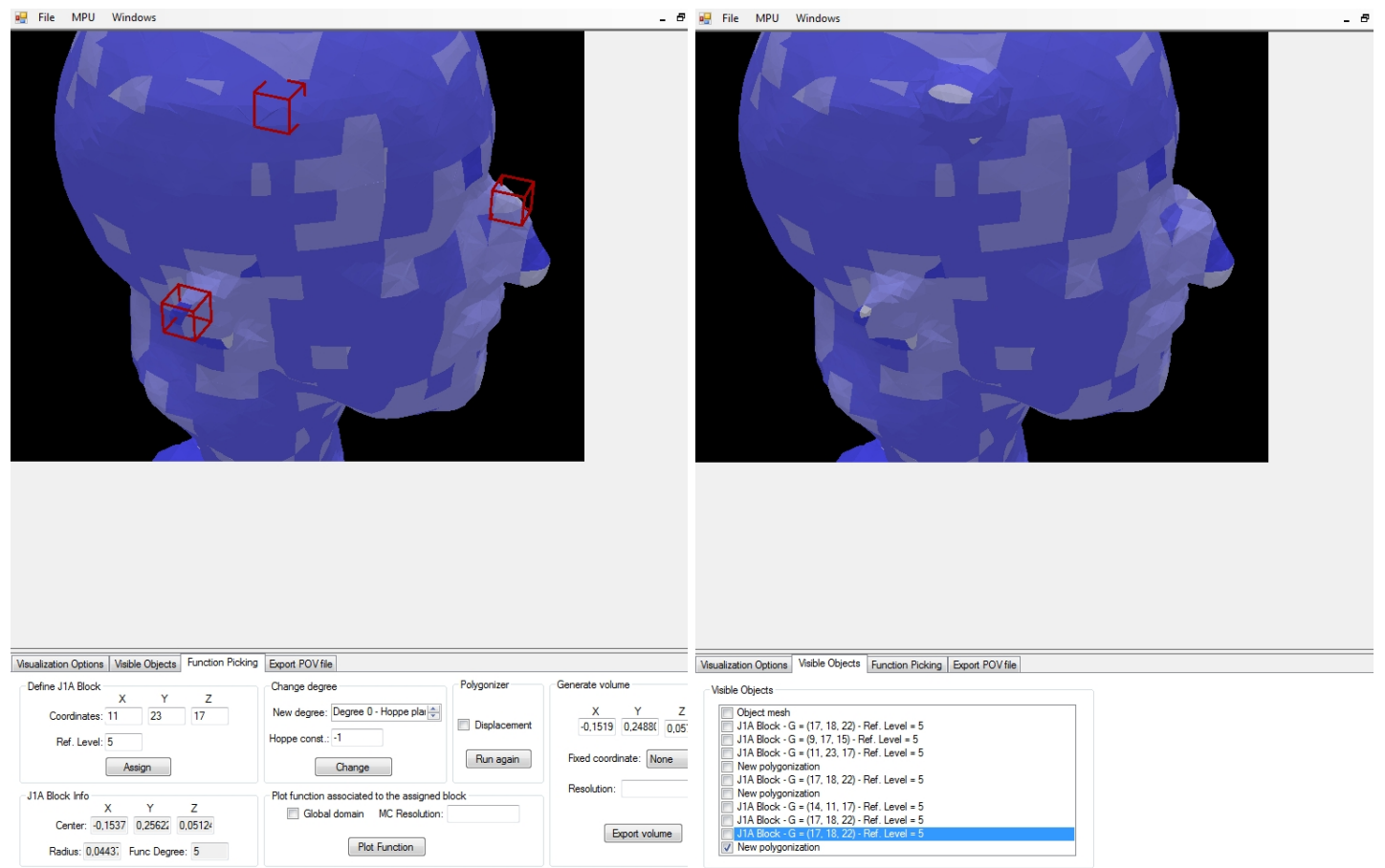

(a)

(b)

Figura 4.11: Interface desenvolvida que permite edição da função: em (a), os blocos vermelhos representam os blocos da triangulação $J_{1}^{a}$, selecionados para realizar a edição da função; em (b), pode-se notar alteração no objeto pela edição da função.

\section{Melhoramento de Malha}

Utilizamos uma técnica de deslocamento de vértices devido a sua simplicidade e, principalmente, por não inserir um custo computacional elevado em termos de memória e tempo de execução do poligonalizador. Todavia, como os graus de liberdade para movimentação dos vértices da triangulação $J_{1}^{a}$ sem invalidar a estrutura são restritos, o melhoramento também é limitado.

A idéia do método consiste em "afastar" os vértices da superfície a uma taxa inversamente proporcional ao valor da função no vértice, de forma a melhorar a razão de aspecto dos triângulos. A seguinte equação apresenta como um vértice $\mathbf{x}$ é redefinido em sua nova posição $\mathbf{x}_{n e w}$ :

$$
\mathbf{x}_{n e w}=\mathbf{x}+\left[\frac{\operatorname{sign}(F(\mathbf{x}))}{\|\nabla F\|}\left(\frac{F_{\max }-F(\mathbf{x})}{F_{\max }}\right)^{2} \frac{e(\ell)}{4} \alpha\right] \nabla F(\mathbf{x})
$$


em que sign $(F(\mathbf{x}))$ representa o sinal da função, $F_{\max }$ é uma estimativa para o máximo da função no domínio, $\ell$ é o nível de refinamento associado ao vértice, $e(\ell)$ é o tamanho da aresta do bloco da triangulação $J_{1}^{a}$ no nível de refinamento $\ell$, e $0<\alpha<1$ determina a amplitude máxima de movimento permitida sem invalidar a triangulação. A Equação 4.14 tem por finalidade movimentar um vértice na direção do gradiente, porém no sentido do sinal da função. O termo $\left(\frac{F_{\max }-F(\mathbf{x})}{F_{\max }}\right)^{2}$ normaliza o deslocamento permitido por um vértice, enquanto que o termo $\frac{e(\ell)}{4} \alpha$ define a amplitude máxima de deslocamento de um vértice da triangulação $J_{1}^{a}$.

Na Figura 4.12, ilustramos a representação do deslocamento de vértices de um bloco da triangulação $J_{1}^{a}$ em duas dimensões, em que os círculos (em rosa) representam a região máxima em que é permitida a movimentação de um vértice.

Aplicamos o procedimento de deslocamento apenas para os vértices pertencentes aos simplexos que intersectam a superfície durante a poligonalização. Tal fato implica a desnecessidade de memória extra, e o maior esforço computacional adicionado ao poligonalizador se deve ao cálculo de $F_{\max }$ e à avaliação do gradiente da função em cada deslocamento de vértice.

É importante diferenciar o nível de refinamento permitido para um bloco básico e para um bloco de transição. Para blocos básicos, o nível de refinamento associado com um vértice $\ell$ é igual ao refinamento do bloco $r$. Por outro lado, para blocos de transição, esse nível é igual a $(r+1)$ para os vértices que pertencem à face refinada e a $r$ para as demais.

\subsection{Resultados}

As imagens na Figura 4.13 foram geradas, utilizando-se o código-fonte do método de traçado-de-raios "Persistence of Vision - PovRay" [170], adaptado para suportar a função implícita e também para a função de Ohtake [158]. Na Figura 4.13, ilustramos a importância do espaço de recobrimento e também o procedimento interativo de edição da função. Para esses testes, utilizamos o Bunny de Stanford de 362 mil pontos que contem ruídos (a versão 

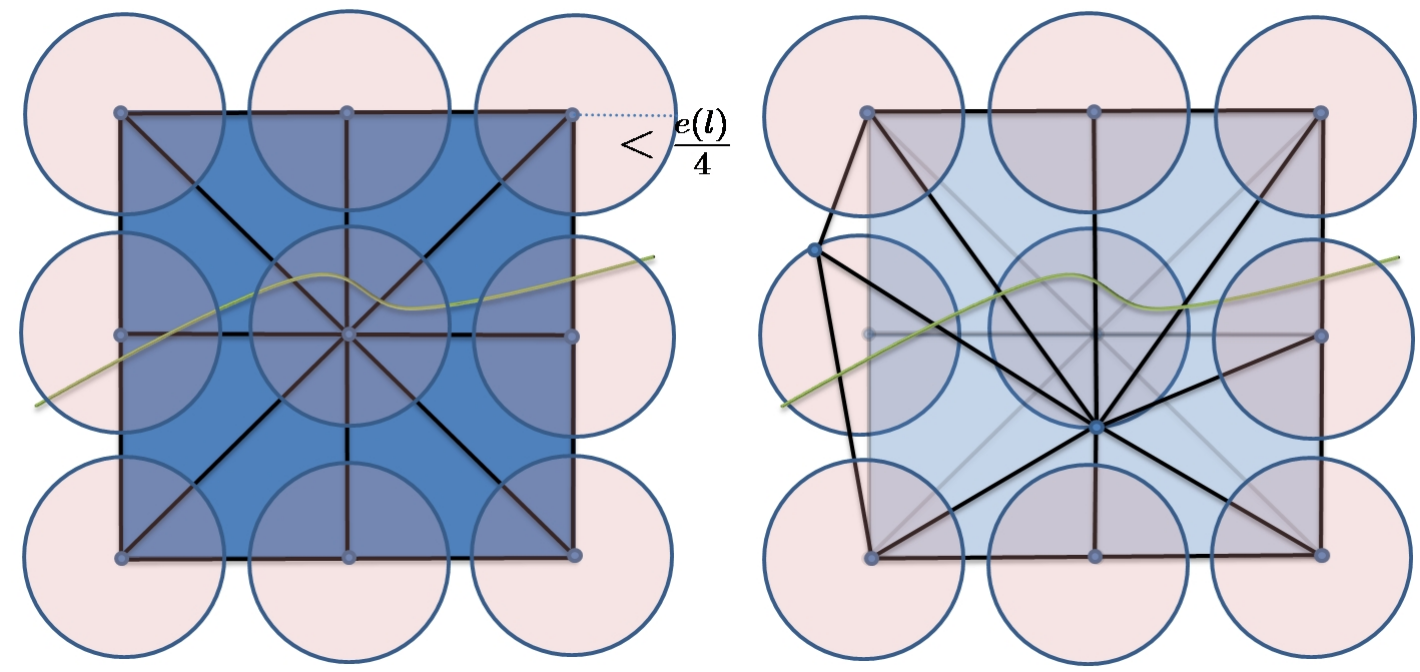

Figura 4.12: Ilustração da deformação do bloco da triangulação $J_{1}^{a}$ : a técnica de deslocamento de vértice é capaz de criar elementos com tamanhos mais uniformes. Os círculos em cor rosa representam as regiões em que o deslocamento dos vértices é permitido.

raw data do Bunny de Stanford). Em (a), o modelo foi reconstruído, utilizando-se o método de Ohtake com os parâmetros sugeridos pelo autor, mas sem habilitar a opção de modelagem de características afiadas (pois quando a habilitávamos, a quantidade de superfícies extras e artefatos aumentavam). Em (b), selecionamos um conjunto de parâmetros para o método de Ohtake semelhante aos parâmetros padrões do nosso método (resolução inicial contendo apenas um bloco, nível de refinamento máximo 9 da triangulação $J_{1}^{a}$ e tolerância do erro igual a 0.002). Novamente, desabilitamos o mecanismo de características afiadas. Em (c), usamos nossa técnica para reconstruir o mesmo modelo, porém desabilitando o critério de recobrimento. É possível notar que existe a presença de diversos artefatos sobre a superfície e algumas superfícies extras, que são praticamente quase todas eliminadas com o teste de recobrimento (Figura 4.13(d)). Em (e) iniciamos a edição da função: definimos a seleção dos blocos, para os quais atribuímos funções constantes com pequenos valores positivos (utilizamos $f_{i} \equiv 0.002$ ), com o intuito de eliminar as características indesejáveis de superfícies extras. Finalmente, na Figura 4.13-(f), apresentamos a reconstrução do Bunny de Stanford após a edição da função.

Observação 6 A utilização de funções constantes (com valores definidos pelo usuário) para 

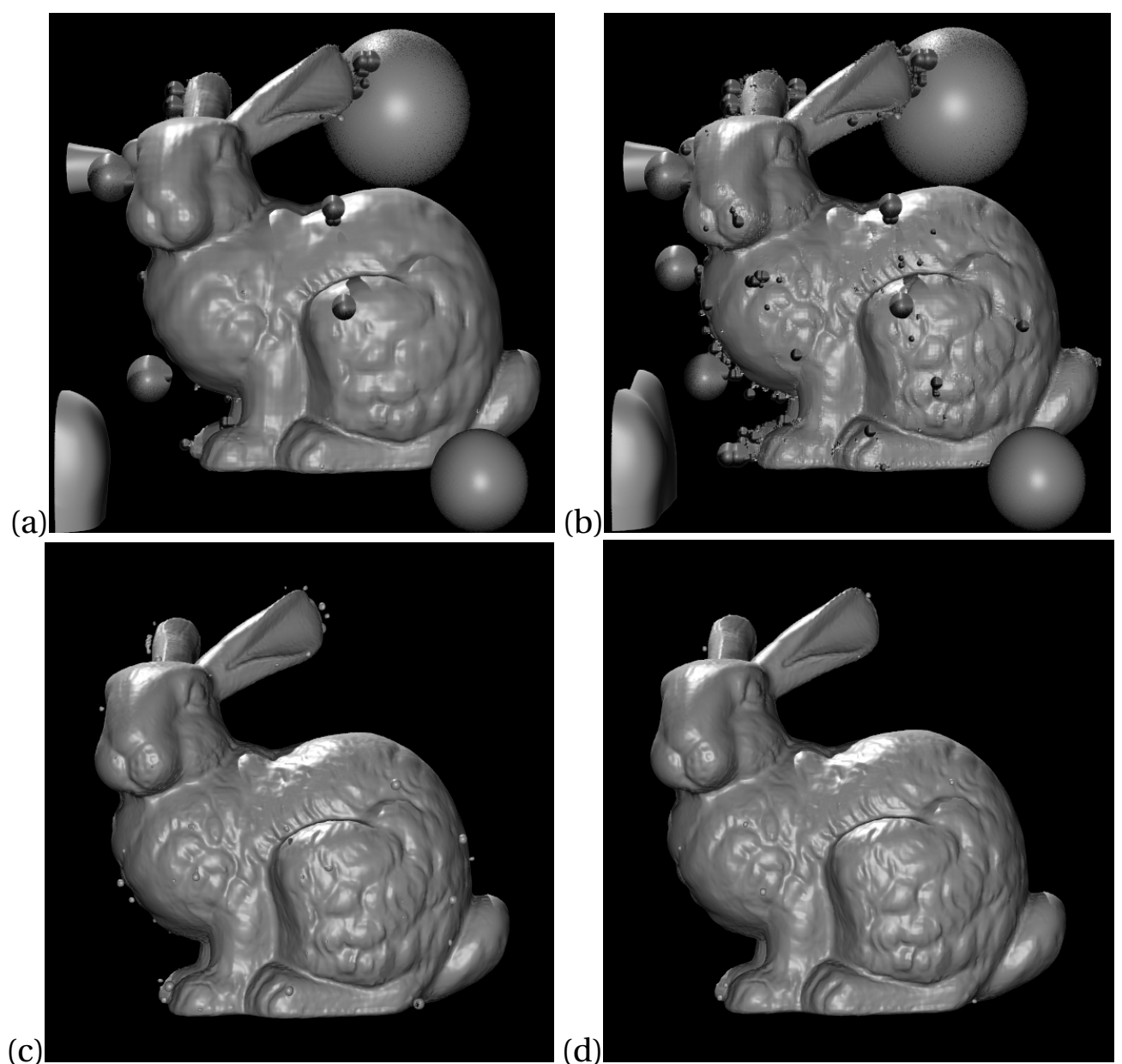

(c) (d)
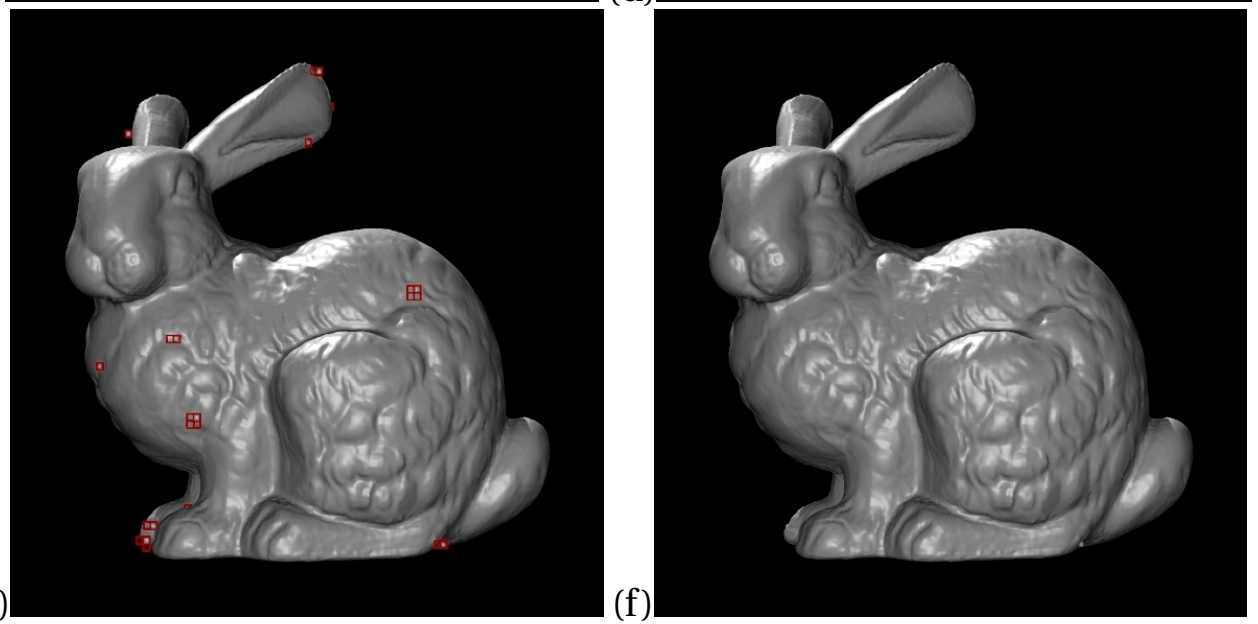

Figura 4.13: Edição da Função: (a)-(b) apresentam o método de Ohtake et al. com seus parâmetros padrões e com os sugeridos por nós, respectivamente; (c), a reconstrução usando nosso método sem o critério de recobrimento do domínio; (d), a reconstrução utilizando o critério de recobrimento do domínio; (e), a seleção de imperfeições pelo usuário; (f), a função editada elimina as imperfeições. 
(a)

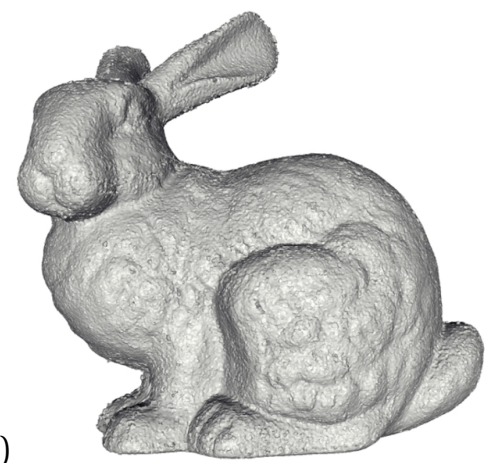

(c)

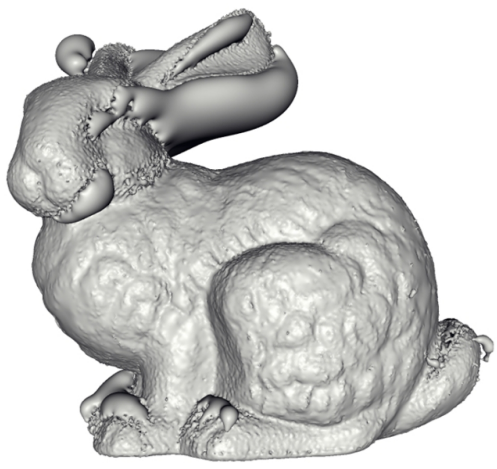

(e)

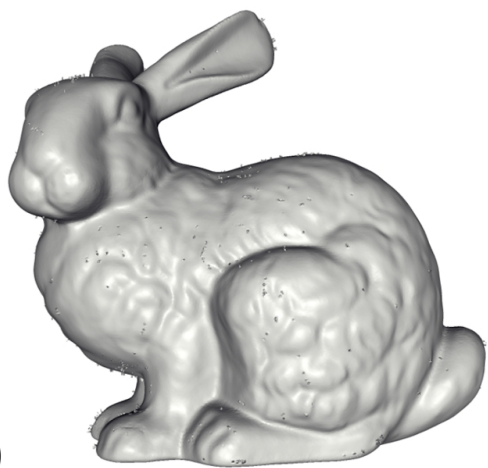

(g)

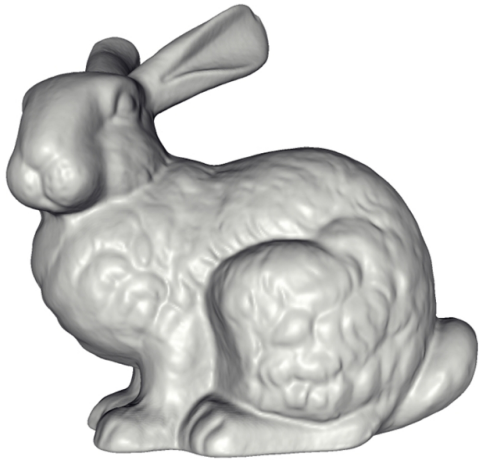

(b)

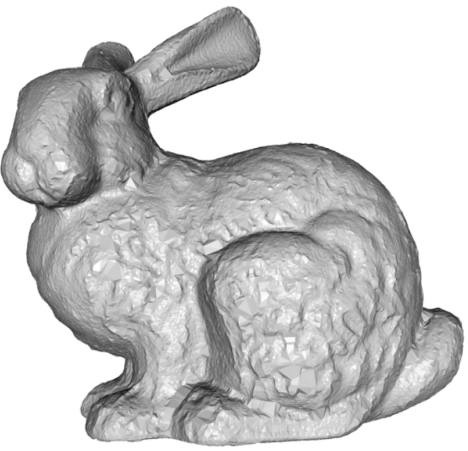

(d)

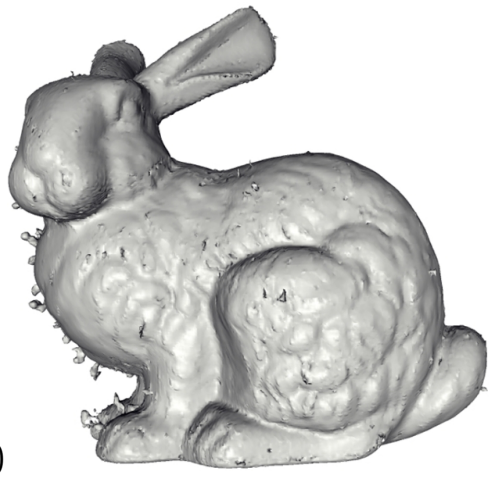

(f)

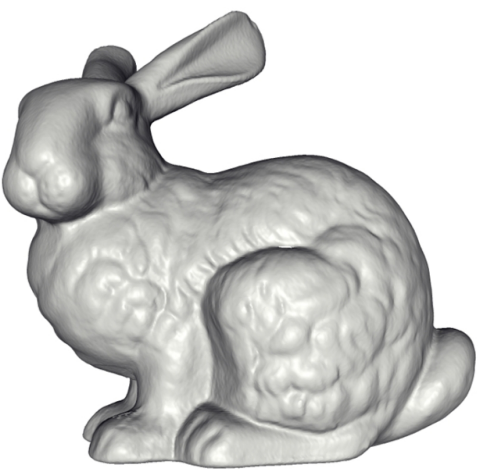

(h)

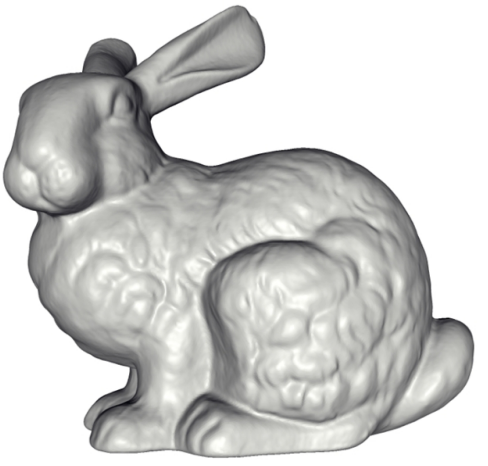

Figura 4.14: Comparações realizadas por Kazhdan et al. [115]. (a) Power Crust [14], (b) Robust Cocone [62], (c) Fast RBF [44], (d) PUI [158], (e) Método de Hoppe et al. [107], (f) Volumetric Range Image Processing - VRIP [56], (g) FFT [114] e (h) reconstrução de superfícies pela Equação de Poisson [115]. 
reparar localmente superfícies extras se mostrou suficiente. Dessa forma, a edição da função implícita para correção da superfície, nos casos que encontramos, é definitivamente intuitiva.

Também apresentamos as comparações (Figura 4.14) realizadas por Kazhdan et al. [115] do Bunny de Stanford, fundamentadas em diversos métodos de reconstrução. É importante observar que os modelos reconstruídos pelo método de Ohtake et al. apresentaram uma série de artefatos e superfícies extras em ambas versões. As duas diferenças entre o modelo da técnica de Ohtake et al., apresentadas por Kazhdan et al., e o nosso se devem ao fato de que Kazhdan utilizou características afiadas e a superfície foi obtida pelo poligonalizador de Bloomenthal [33], que percorre apenas a superfície, isto é, apenas uma componente conexa é gerada. Esse último fato, omite a maioria das superfícies extras. A situação ilustrada na Figura 4.13 mostra que o conjunto de soluções que propusemos melhora a robustez das reconstruções. De mesmo modo, sem considerar a presença de ruídos, o método foi capaz de minimizar o número de defeitos.

Ainda em relação à edição da função, apresentamos, na Figura 4.15, outro exemplo no qual funções lineares foram substituídas nas seleções destacadas, por funções de segundo grau (b). Ao contrário do exemplo anterior, aqui a função é editada com o intuito de melhorar a qualidade da função, não apenas para remoção de artefatos. A comparação entre as Figuras 4.15(a) e (c) ilustra o ganho de qualidade.

O próximo teste demonstra a capacidade do método na representação de características afiadas. O primeiro resultado que ilustramos está na Figura 4.16, nela, em amarelo, estão as faces da triangulação $J_{1}^{a}$ que foram definidas nos blocos, nos quais as funções locais são definidas como arestas e, em vermelho, como vértices.

Nas Figuras de 4.17 a 4.20 existem comparações entre nosso método, com resultados presentes nas Figuras 4.18 e 4.20, e o método de Ohtake et al. [158], com resultados presentes nas Figuras 4.17 e 4.19. Utilizamos parâmetros similares para o limitante de erro e para a profundidade máxima da árvore. Podemos evidenciar que a nossa técnica foi capaz de gerar características afiadas parecidas, porém um pouco melhores, a um custo computacional 


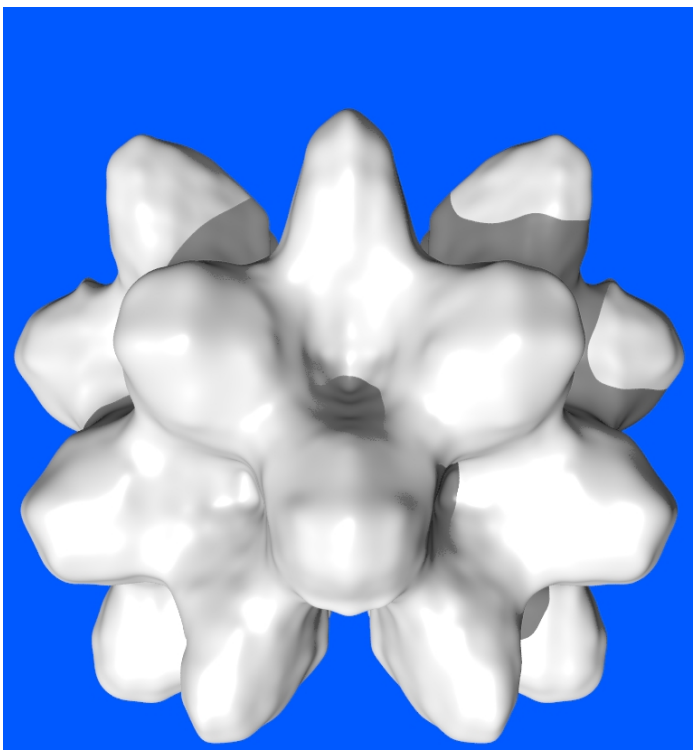

(a)

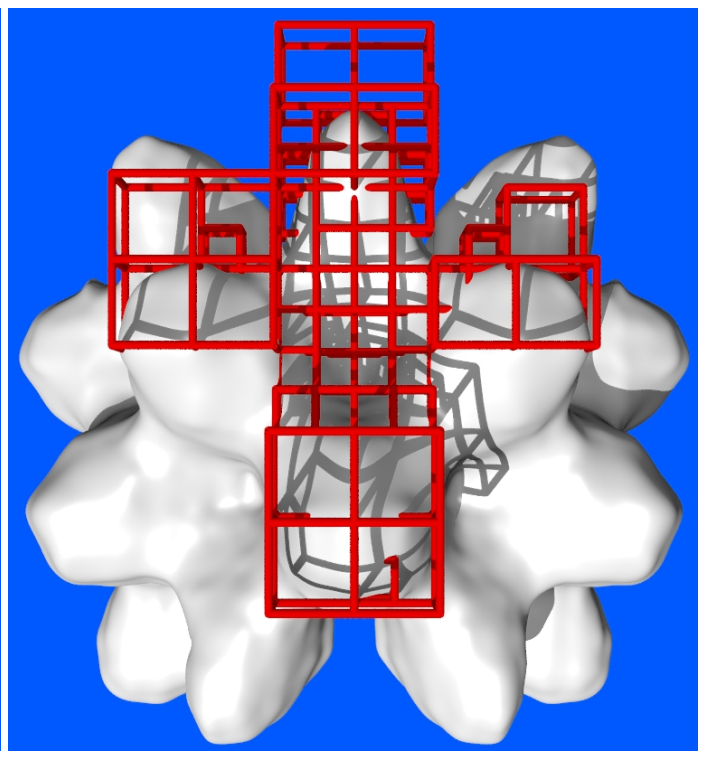

(b)

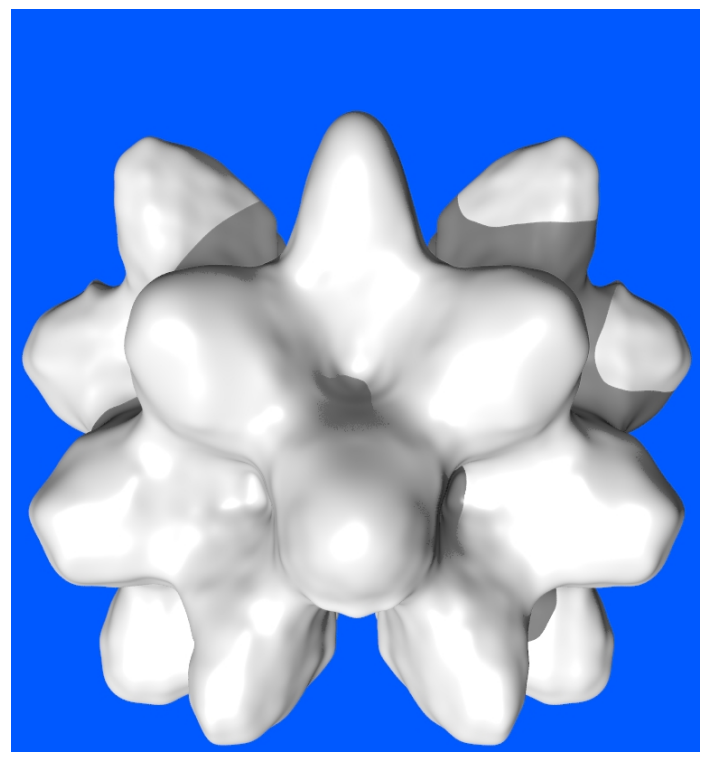

(c)

Figura 4.15: Melhoramento de um modelo por edição da função: (a) modelo sem aproximações de alto grau, (b) blocos selecionados para edição da função e (c) resultado final. 


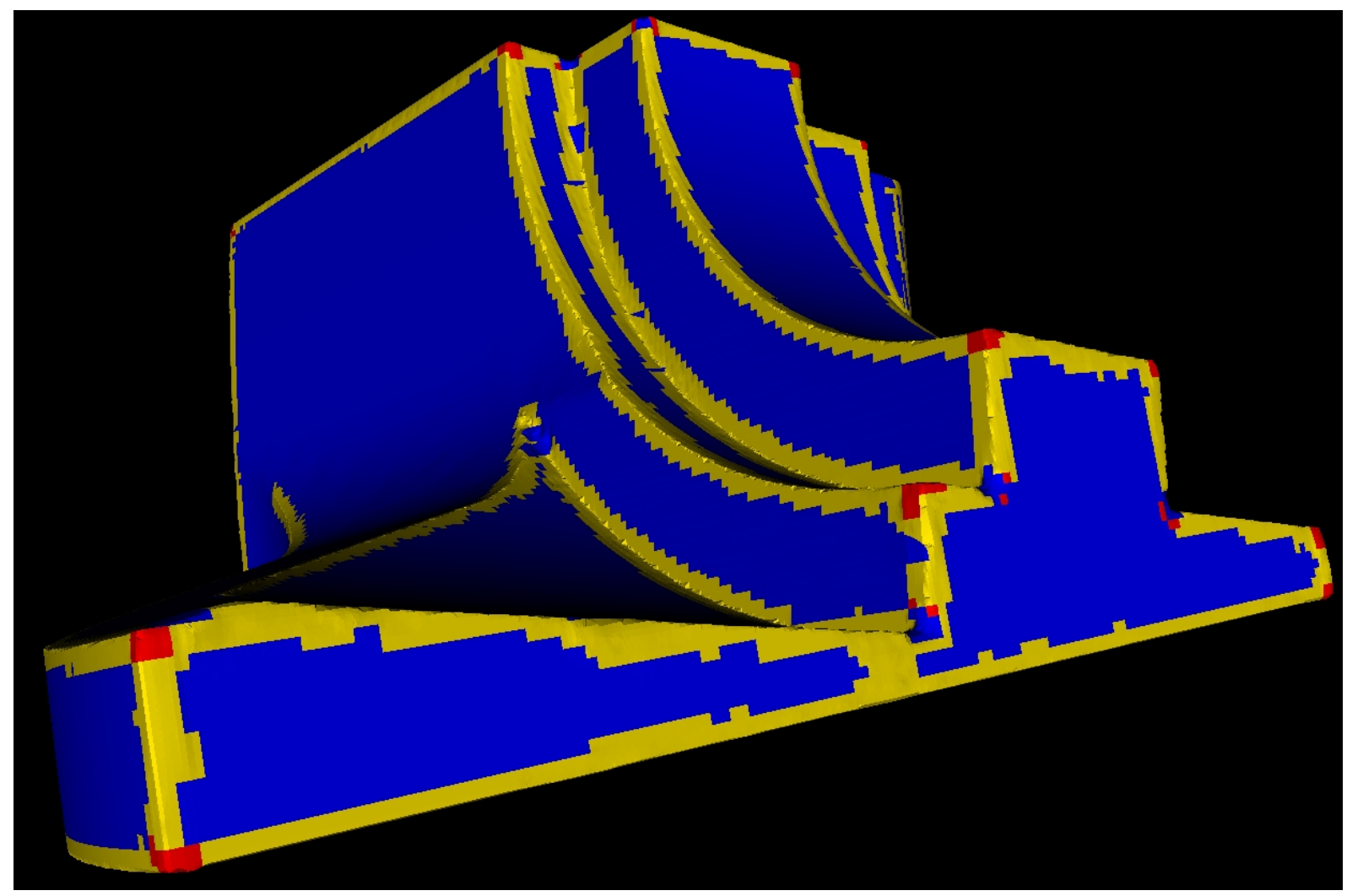

Figura 4.16: Ilustração da detecção de características afiadas de nossa técnica (modelo do Fank Disk): em amarelo, faces detectadas como sharp edges; e, em vermelho, como sharp corners.

um pouco maior. Enquanto o método de Ohtake gerou um modelo com porta-de-visão no método de traçado-de-raios $1280 \times 1024 \mathrm{em} 1527 \mathrm{~s}$, o nosso levou $1620 \mathrm{~s}$ para realizar a mesma tarefa.

A principal diferença entre os métodos se deve ao fato de a avaliação da função, em nossa técnica, ser desacoplada da etapa de aproximação da função. Isto é, a função primeiramente é definida em todo o domínio, antes de se realizar a primeira avaliação da função. Já o método de Ohtake et al., quando uma avaliação da função é solicitada, verifica se existe já uma aproximação em tal região, para, então, definir se constrói ou não a aproximação da função. Tal fato faz com que o método de Ohtake tenda a ser mais rápido para grades computacionais grosseiras e para pequenas portas-de-visão do traçado-de-raios. Mas, à medida que o número de avaliações da função é aumentado, nosso método se torna similar ao de Ohtake em termos do tempo de processamento. 


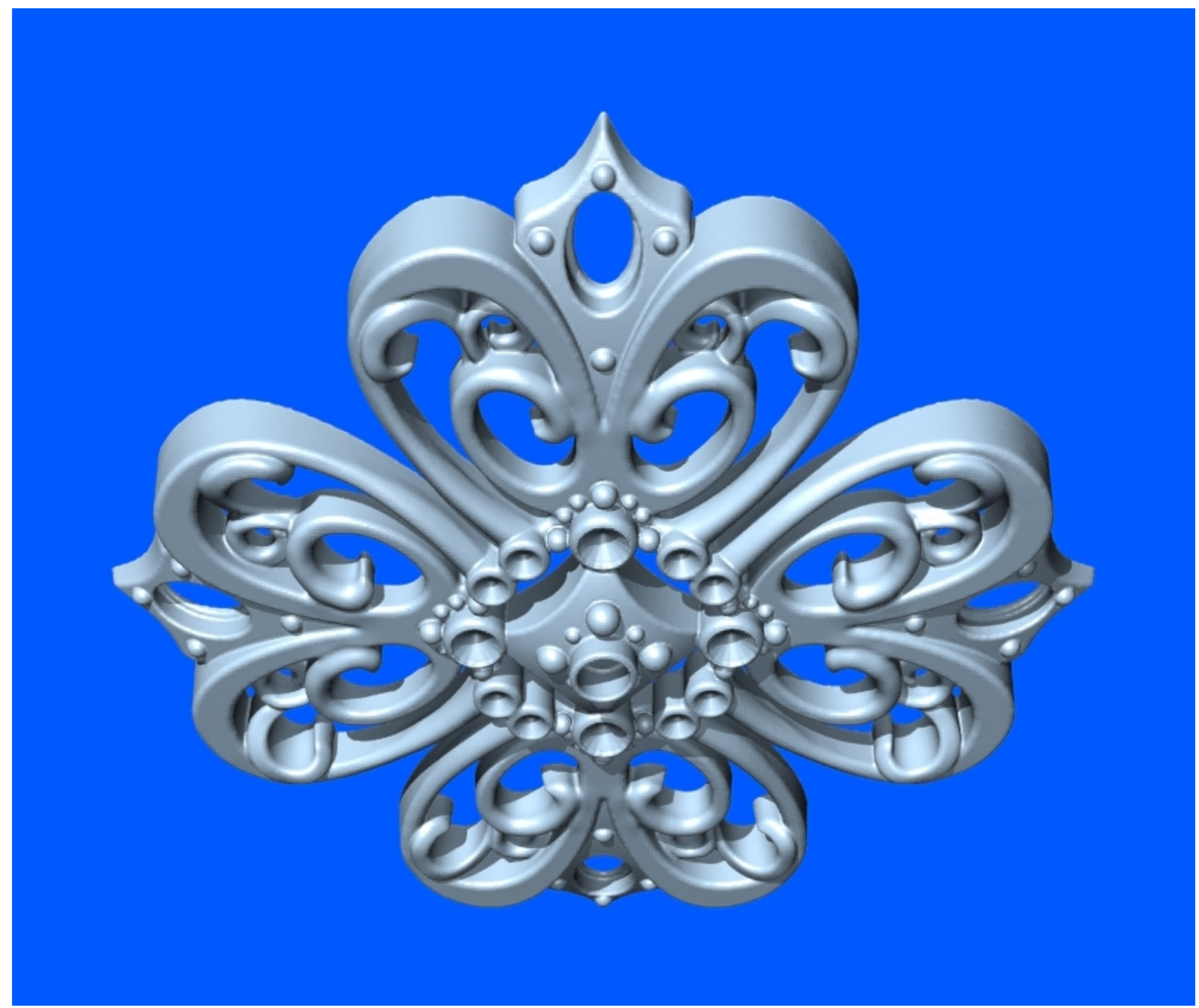

Figura 4.17: Capacidade de modelar características afiadas (método de Ohtake et al.): parte frontal do modelo Filigree (514 mil pontos).

Notamos outra diferença substancial entre os métodos relacionada ao comportamento da função implícita. O nosso método apresentou um limite superior para a magnitude do gradiente em todo o domínio, provavelmente devido aos critérios de robustez e à forma em que definimos os suportes dos domínios aplicados durante a fase de aproximação da função. Por exemplo, para o modelo do Filigree, o método de traçado-de-raios que aplicamos [170] fornece uma estimativa para a magnitude máxima do gradiente encontrada durante a fase de avaliação. Para o nosso método, o máximo fornecido foi 1.9, enquanto para o método de Ohtake foi $10^{10}$, provavelmente devido a erros numéricos.

Ilustramos o resultado obtido pelo deslocamento de malhas nas Figuras 4.21, $4.22 \mathrm{e}$ 


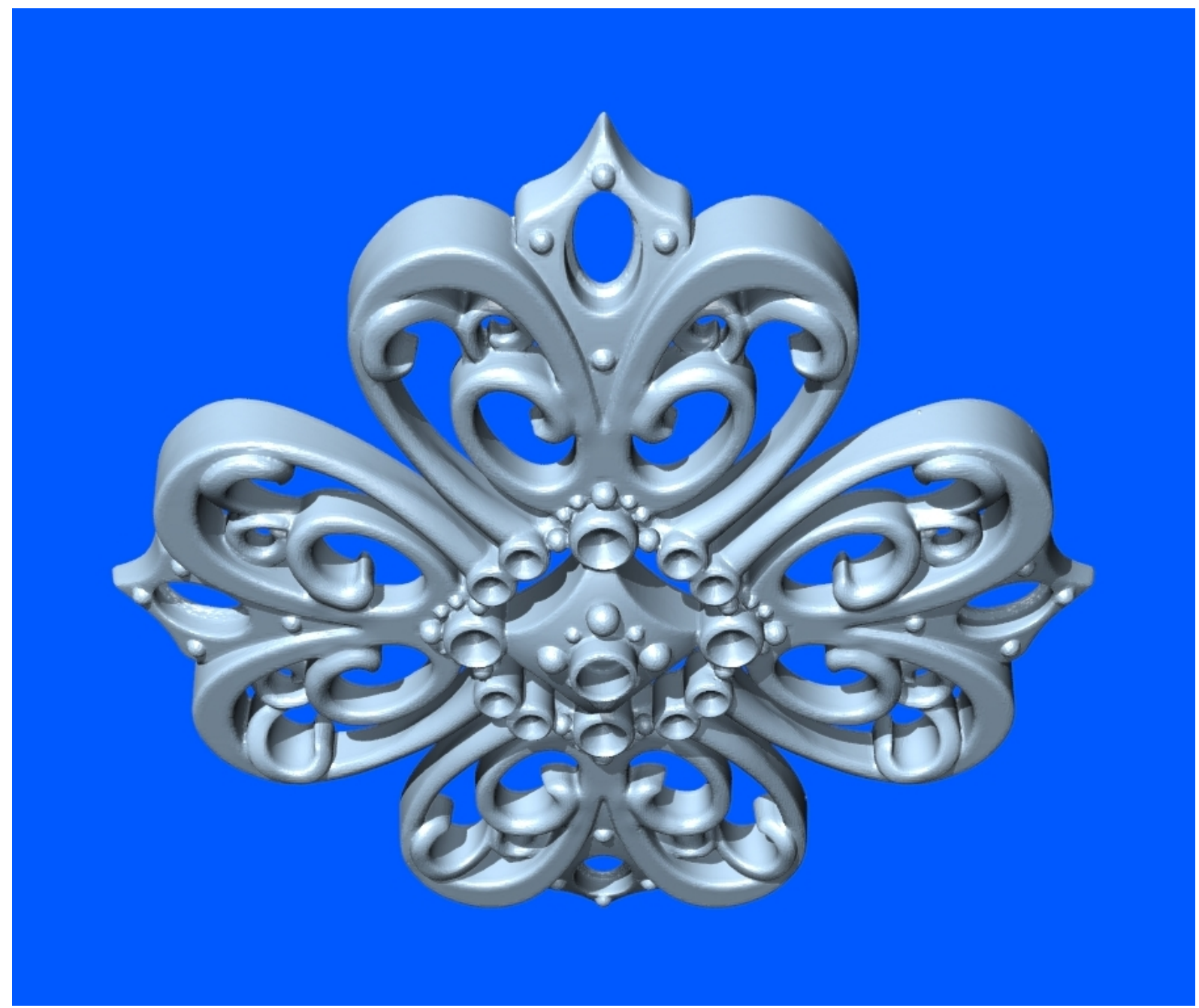

Figura 4.18: Capacidade de modelar características afiadas (nosso método): parte frontal do modelo Filigree (514 mil pontos).

4.24. Na Figura 4.21, simplesmente aplicamos a técnica de deslocamento dos vértices da triangulação $J_{1}^{a}$ em uma esfera na qual todos os blocos estão no mesmo nível de refinamento. O resultado apresentado foi satisfatório. No entanto, também reconstruímos o modelo do Dragão Chinês (665 mil pontos), utilizando o nível de refinamento variando até 7 e desabilitando a função de características afiadas. A Figura 4.22 apresenta a malha original (topo da imagem) e o modelo gerado com deslocamento de vértices (base). Na Figura 4.23, apresentamos as duas reconstruções sem o wireframe. Ambas as malhas são compostas de 535605 triângulos e o tempo para a poligonalização do modelo foi $39.433 s$ e $202.9 s$ para a versão sem e com o deslocamento de vértices, respectivamente. Tal aumento no custo 


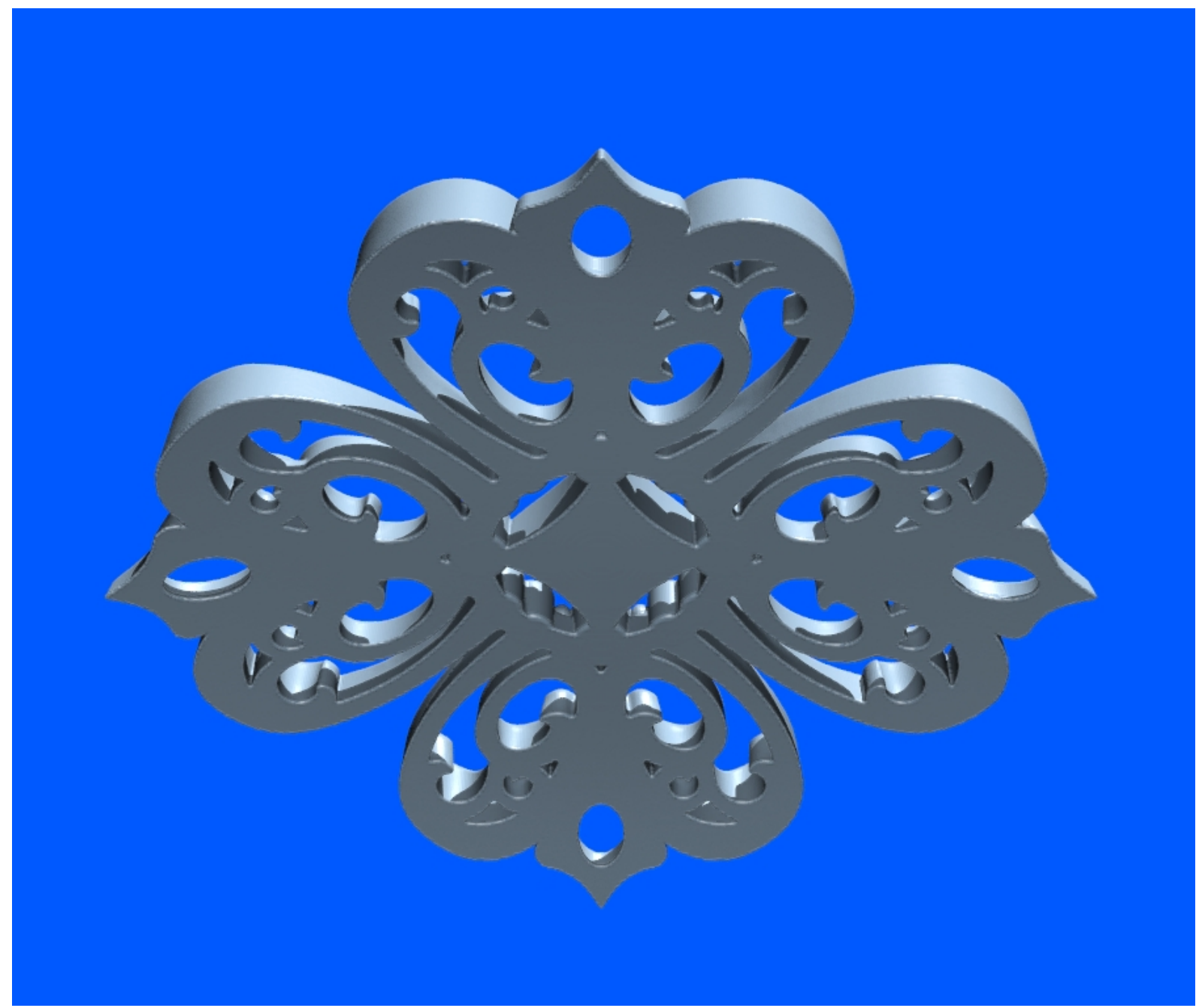

Figura 4.19: Capacidade de modelar características afiadas (método de Ohtake et al.): parte traseira do modelo Filigree (514 mil pontos).

computacional é previsível, pois são necessárias mais avaliações da função para se calcular a aproximação do gradiente (para o cálculo, utilizamos diferenças centradas, que requerem duas avaliações da função, para cada uma das componentes do vetor), embora esse custo extra seja constante e não altere a complexidade do algoritmo.

Com intuito de estimar o melhoramento dos triângulos, causado pelo deslocamento, usamos a seguinte medida de qualidade de um triângulo $\triangle$ :

$$
\alpha_{\triangle}=\frac{\sqrt{3} e_{\max } P}{12 A}
$$

em que $e_{\text {max }}$ é a maior aresta, $P$ é o perímetro e $A$ é a área do triângulo $\triangle$ (note que a melhor 


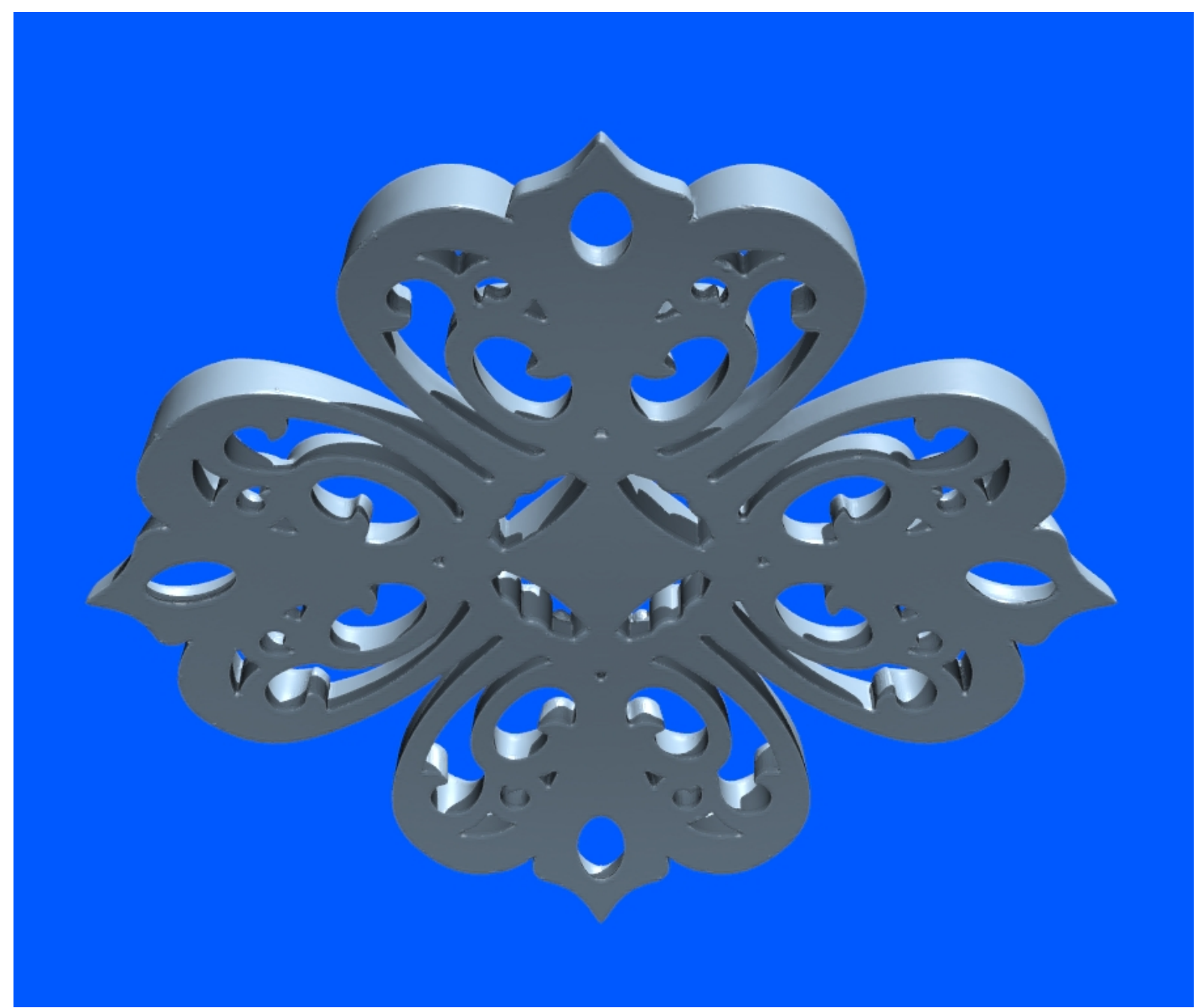

Figura 4.20: Capacidade de modelar características afiadas (nosso método): parte traseira do modelo Filigree (514 mil pontos).

razão de aspecto é obtida quando $\alpha_{\triangle}=1$, e nesse caso temos um triângulo eqüilátero).

Para a malha sem a aplicação do deslocamento, a razão de aspecto média foi 5.55 e o desvio-padrão foi 128.09. Já com o melhoramento de malha, a razão de aspecto média foi 1.68 e o desvio padrão foi 0.61 . Esse resultado confirma a eficiência da técnica, porque ela é capaz não apenas de melhorar a qualidade média dos triângulos, mas também de diminuir a variação de aspecto entre eles. Isso significa que elementos muito pequenos são recalculados e a malha por um todo apresenta uma razão de aspecto global melhor. Outro exemplo de melhoramento de malha (Dragão de Stanford) é apresentado na Figura 4.24. Nesse caso, para a malha sem melhoramento (topo), a razão de aspecto média foi 10.62 e o 


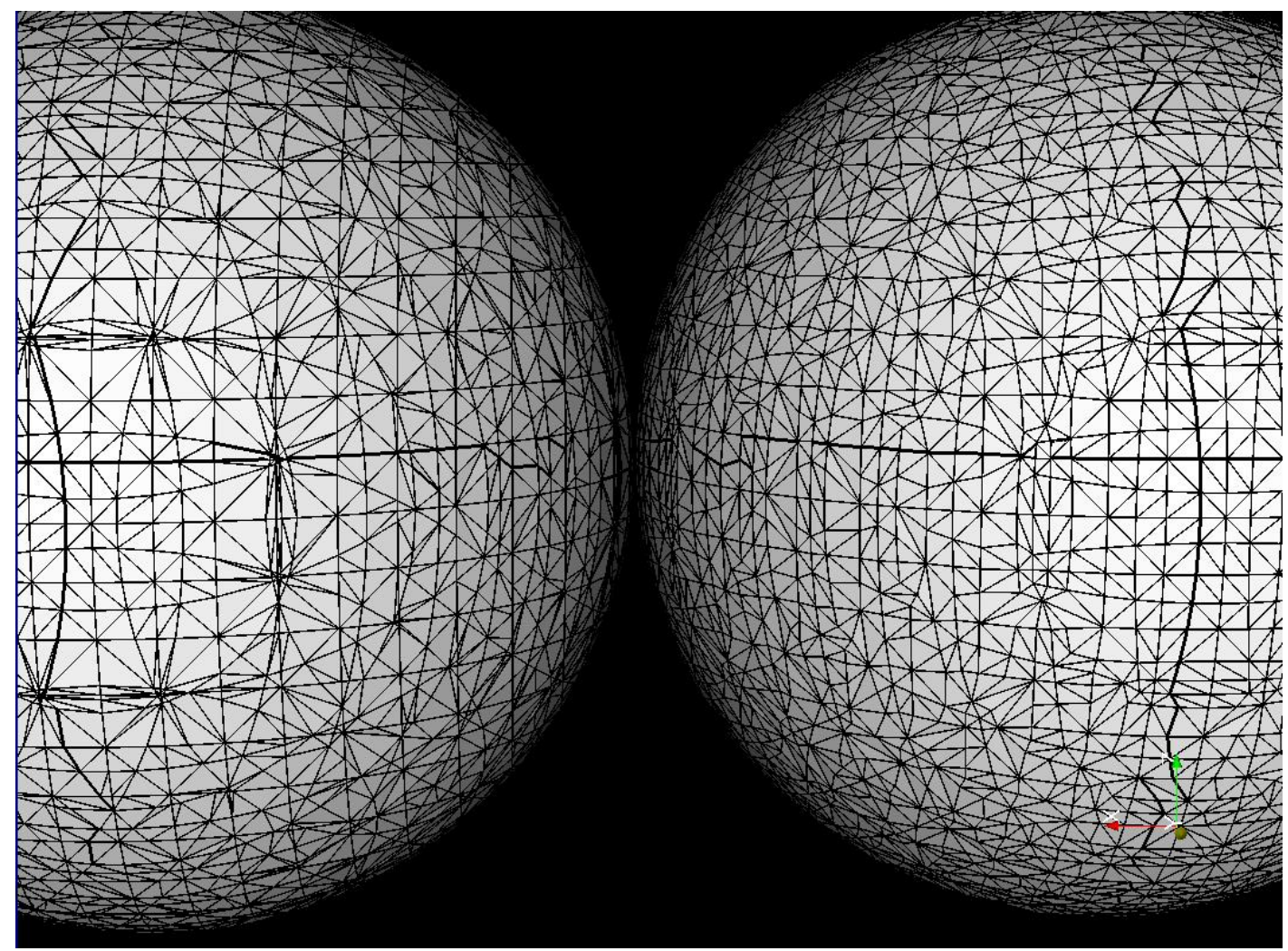

Figura 4.21: Comparação da malha original produzida pela triangulação $J_{1}^{a}$ (esquerda) com a malha obtida pelo deslocamento de vértices (direita).

desvio-padrão, 1173.16; enquanto que para a malha com melhoramento (base), a razão de aspecto média foi 1.60 e o desvio-padrão, 0.77 .

Com o intuito de ilustrar o pico de memória, para o modelo Netuno (2 milhões de pontos), representado na Figura 4.26, a memória requerida para a geração da função foi 660 MB. Quando a poligonalização da triangulação $J_{1}^{a}$ foi levada em consideração, o pico de memória passou a 850 MB.

O último exemplo, ilustrado na figura 4.26, é uma operação CSG que realizamos: a diferença entre o modelo Netuno e um cilindro, em que o rendering foi realizado pelo Povray. Como consideração final, é importante notarmos a diferença entre as características afiadas geradas pelo método de traçado-de-raios, e as características afiadas produzidas pela função de PUI que propusemos. Obviamente, o mesmo fato se aplica aos modelos apresentados por Ohtake et al. [158] (exemplo na Figura 4.25). Além disso, ainda nessa figura, destacamos 

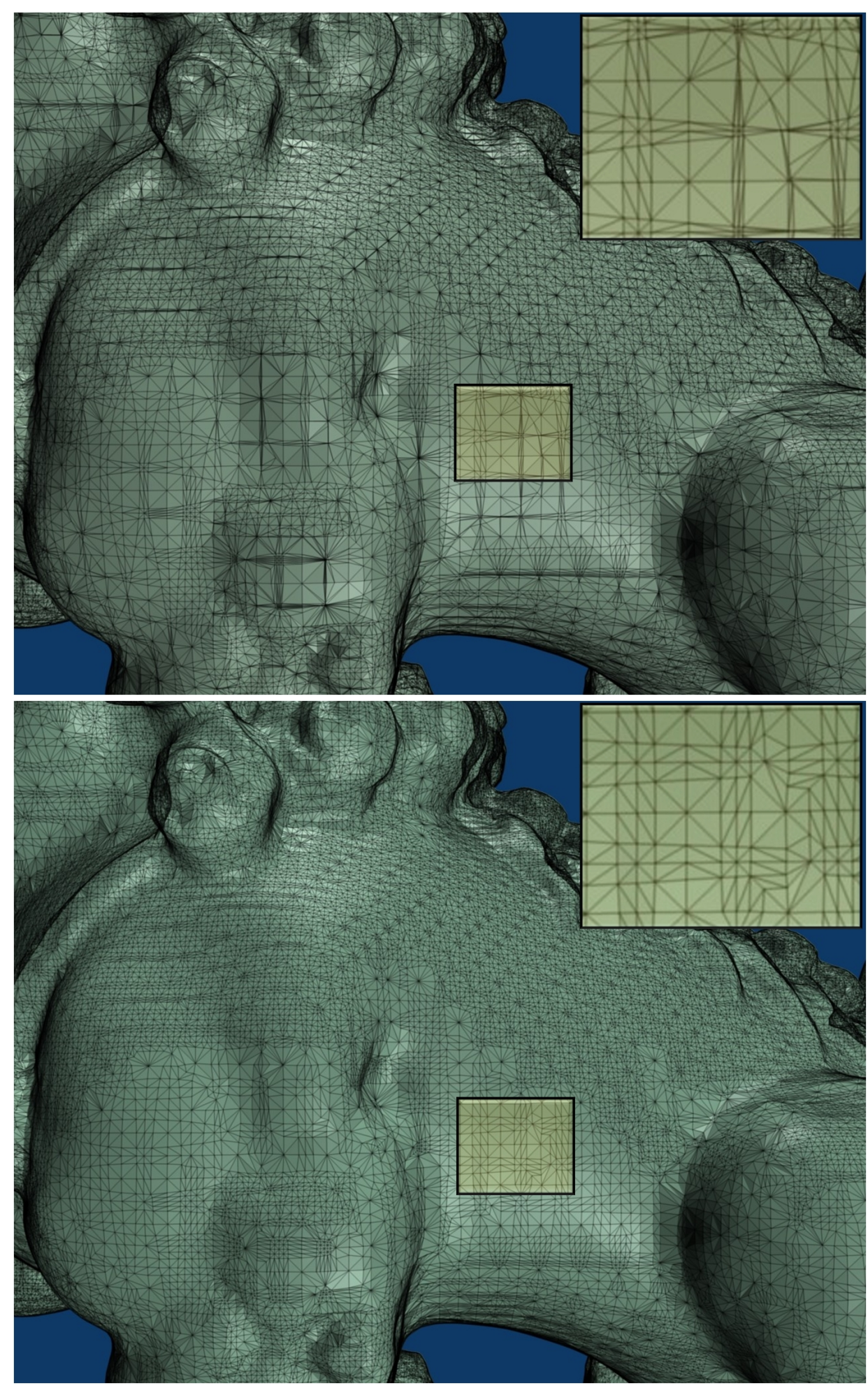

Figura 4.22: Comparação da malha produzida pela triangulação $J_{1}^{a}$ (topo) sem o processo de deslocamento de vértices, contra a malha em que se aplica tal procedimento (base). 

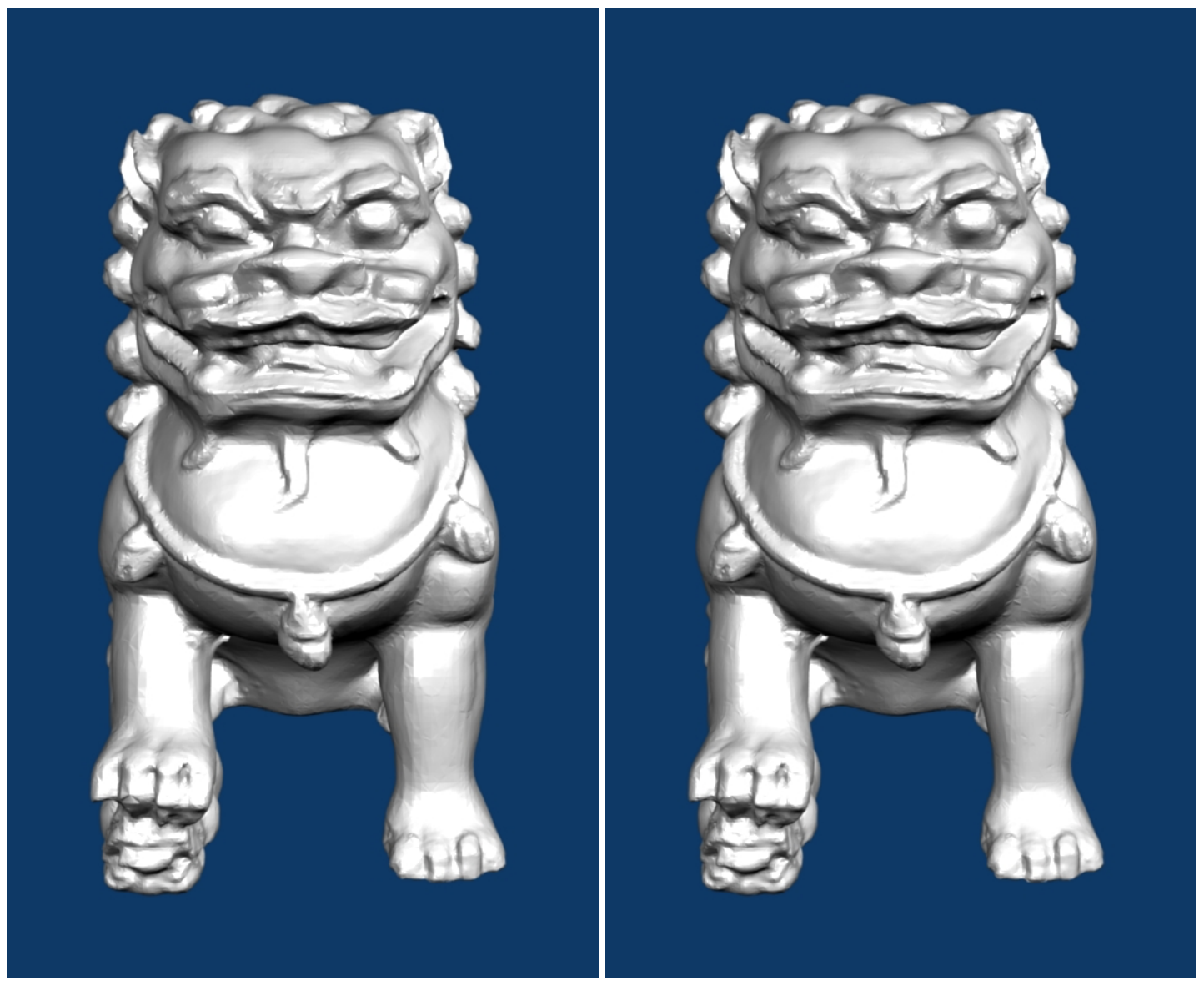

Figura 4.23: Reconstrução do Dragão Chinês, à esquerda, sem o melhoramento de malha e à direita, com o melhoramento de malha: É possível notar, apesar da melhoria da malha (Figura 4.22), a geometria dos modelos permanecem semelhantes.

regiões da superfície onde aparentemente a função foi mal calculada devido, provavelmente, à falta de robustez.

\subsection{Conclusões}

Neste capítulo, apresentamos um esquema adaptativo em duas vias, tanto em termos do refinamento do domínio, quanto no grau das aproximações locais, que são calculadas de forma eficiente. A robustez do método é obtida por melhoramentos que levam em consideração os problemas da técnica original de PUI. A triangulação $J_{1}^{a}$ foi empregada para duas tarefas: a decomposição do espaço e a poligonalização adaptativa. Também apresentamos extensões do nosso método, que incluem a habilidade de lidar com características 

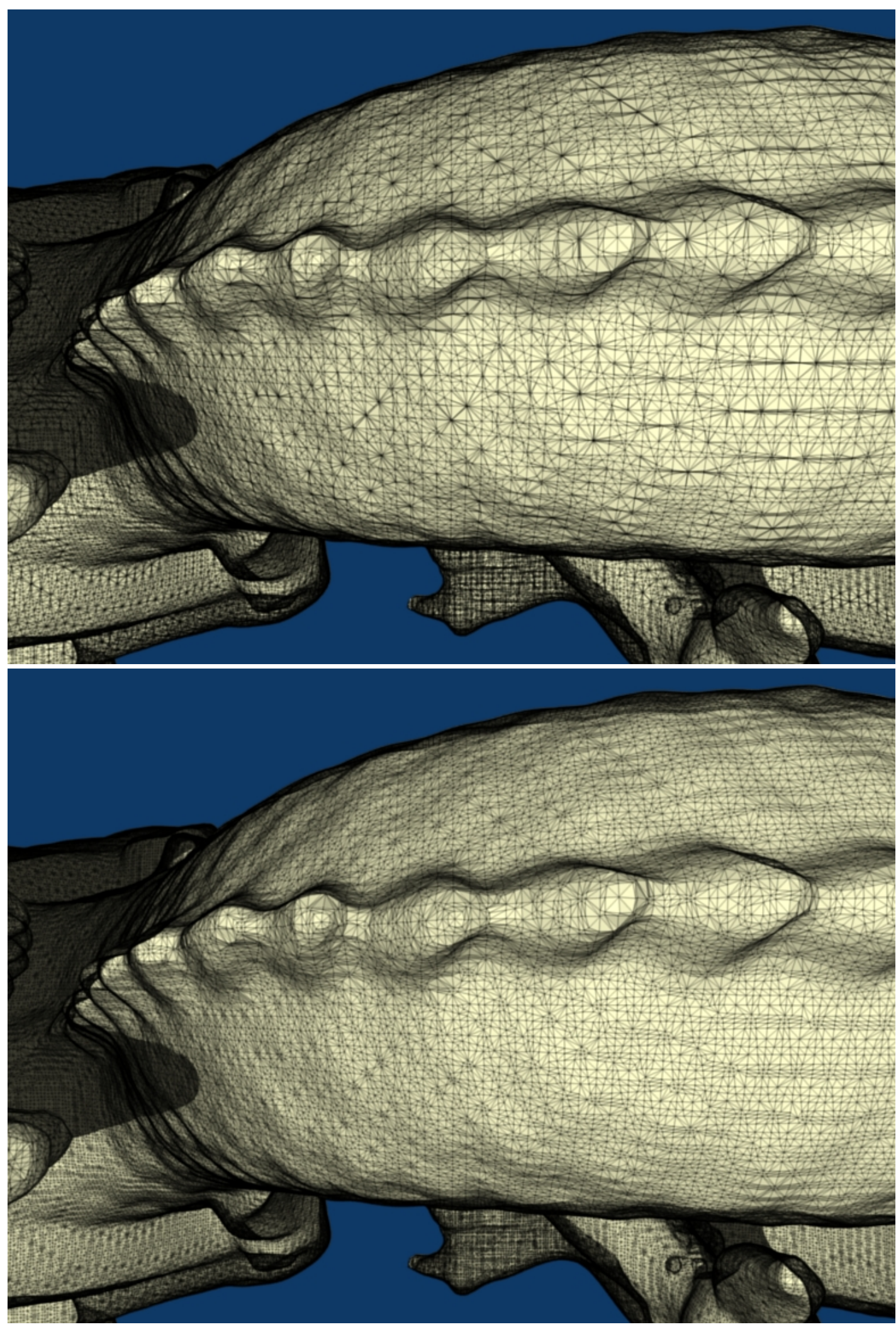

Figura 4.24: Comparação da malha produzida pela triangulação $J_{1}^{a}$ (topo) sem o processo de deslocamento de vértices contra a malha em que se aplica tal procedimento (base). 


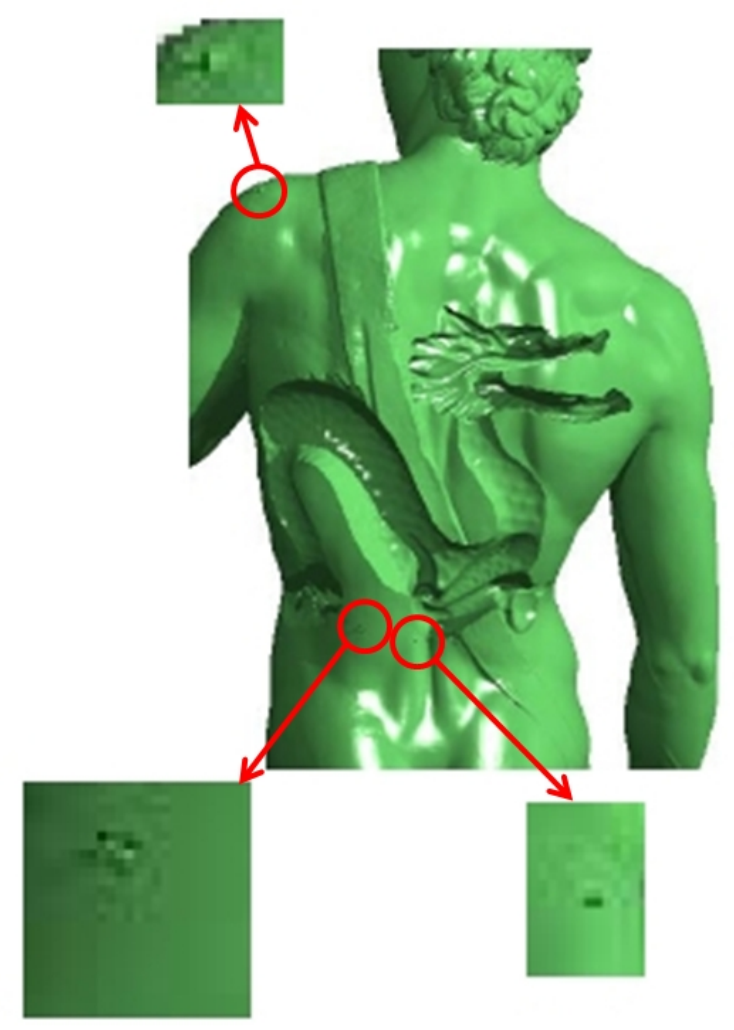

Figura 4.25: Uma operação de diferença entre dois modelos encontrada no artigo de Ohtake et al. [158]. Destacamos algumas regiões onde a superfície está mal definida.

afiadas, a edição interativa da função implícita e o melhoramento de malha. Os resultados demonstram que nosso método é capaz de obter resultados mais robustos e com um custo computacional comparável a técnicas anteriores.

Entre os trabalhos futuros, pretendemos derivar limites teóricos com respeito aos critérios de recobrimento do domínio, bem como aprimorar o esquema de edição da função, isto é, pretendemos incluir outros tipos de função e interpolação, por exemplo, RBF, abordagem proposta por Lipman et al. [137] que utiliza splines e funções trigonométricas.

Também pretendemos investigar o uso de outras estruturas de decomposição espacial no lugar da triangulação $J_{1}^{a}$, entre elas a estrutura proposta por Kazhdan et al. [116], a Regular Binary Multi-Triangulation [135], a subdivisão 4-k [212] e a adaptive tetrapuzzles [53]. O nosso objetivo é compreendê-las para, então, estudar as possibilidades de explorar suas propriedades no âmbito da reconstrução por partição da unidade implícita. Buscare- 


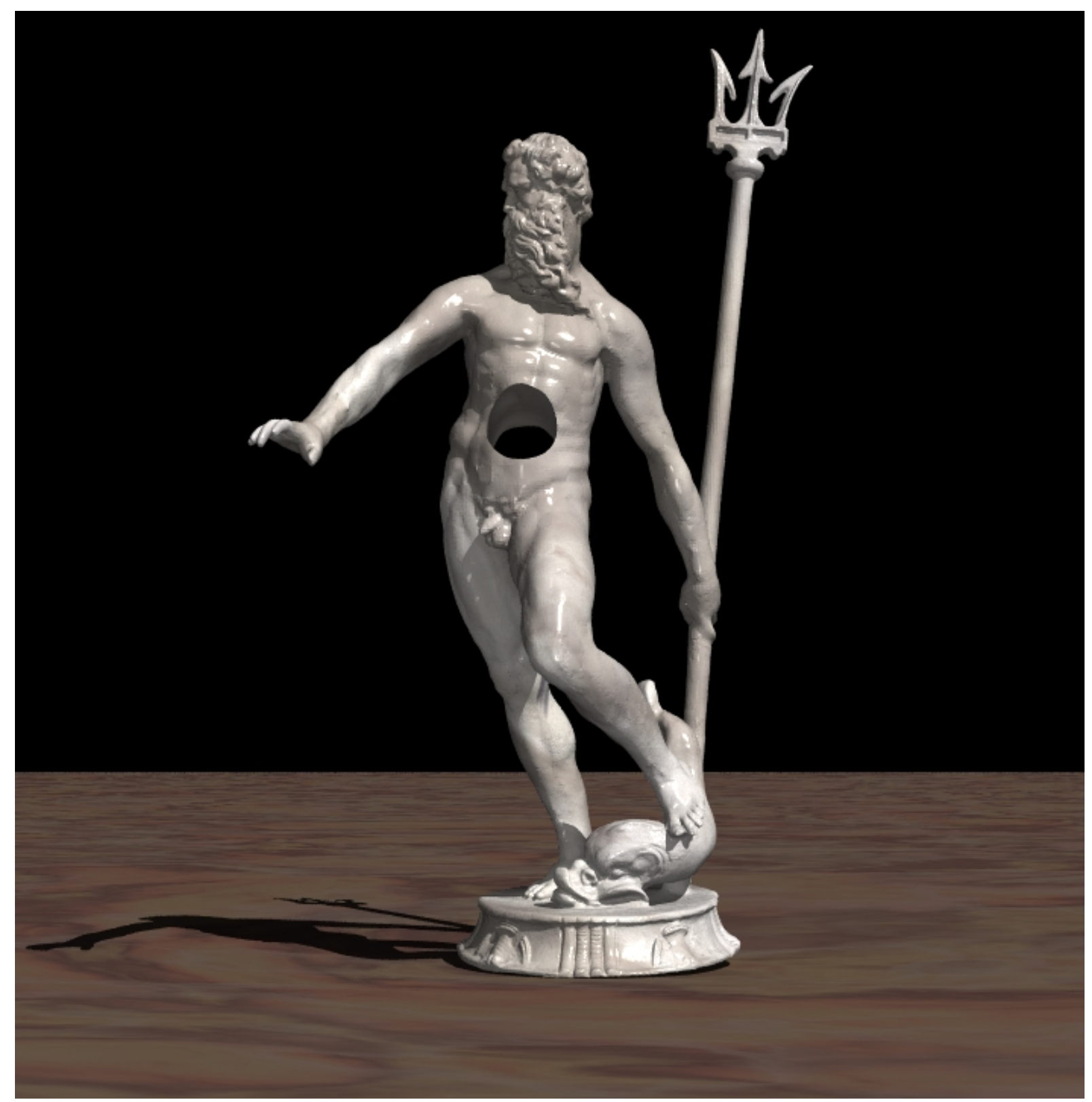

Figura 4.26: Uma operação de CSG (diferença) envolvendo o modelo Netuno e um cilindro. 
mos o estudo das propriedades de outras estruturas com o intuito de definir um método em que o poligonalizador seja acoplado com a construção da função, já que a $J_{1}^{a}$ torna tal procedimento inviável e também uma estrutura que permita gerar malhas superficiais com melhor qualidade.

Atualmente, estamos utilizando pesos com suporte esférico para realizar a partição da unidade. Como trabalho futuro, almejamos utilizar pesos cujos suportes sejam baseados no tipo de decomposição espacial, isto é, obedecendo à forma dos cubos ou dos tetraedros da triangulação $J_{1}^{a}[193]$. 


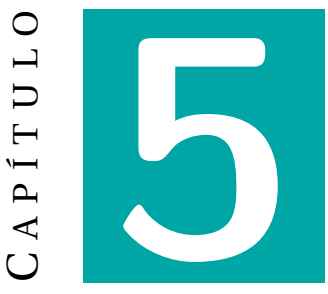

\section{Acompanhamento de Fronteira com Superfície MLS}

Neste capítulo, evidenciamos uma solução para o problema de representação de interfaces móveis que se alteram com o tempo. Utilizamos, para isso, o princípio das superfícies MLS [131], em sua versão algébrica e implícita (algebraic moving-least-squares-AMLS) [97] para a representação das interfaces por meio de um conjunto de partículas não-organizadas. Isto é, definimos um método (Lagrangeano) de acompanhamento de fronteiras (fronttracking [208]) livre-de-malhas que faz uso de superfícies MLS.

Observação 7 Seguindo o contexto de simulação numérica de escoamento de fluidos, também denominamos as superfícies por interfaces e os pontos por partículas.

\subsection{Contribuições}

A principal característica da nossa técnica é a capacidade de representação de interfaces por meio de um conjunto de partículas desconectadas. Dessa maneira, ao contrário dos métodos tradicionais de acompanhamento de fronteira [210, 208, 209, 194], as partículas são transportadas sem levar em consideração a preocupação em relação à qualidade e consistência topológica das malhas que definem a interface. 
Outro aspecto inédito do nosso trabalho está relacionado ao âmbito das superfícies MLS. Apresentamos uma nova e eficiente abordagem AMLS, que denotamos por RAMLS (Robust $A M L S$ ) para o contexto de evolução de interfaces e que possui três vantagens em relação ao método anterior [97]: $i$ ) robustez, $i$ i) eficiência computacional e $i i$ i) desnecessidade de parâmetros de penalidade definidos pelo usuário.

Definimos uma grade computacional Euleriana com espaçamento $h$ em que a advecção dos pontos faz a superfície RAMLS evoluir com o tempo. Outro detalhe pertinente à nossa técnica, diz respeito ao processo de re-geração de partículas a cada passo de tempo, realizada pela interseção da grade computacional com a superfície RAMLS evoluída, garantindo que a densidade de pontos da superfície seja sempre bem balanceada. O algoritmo de interseção é inspirado nos métodos de traçado-de-raios apropriadamente, adaptado para o presente contexto.

Diversos testes e análises demonstram a precisão do RAMLS, tanto para representação de superfícies estáticas, quanto para o método de acompanhamento de fronteiras definido a partir dele. Realizamos comparações com outras técnicas presentes na literatura baseadas em esquemas Eulerianos e híbridos (Lagrangeanos/Eulerianos), os quais nos têm encorajado para a continuidade do desenvolvimento do método proposto para aplicações em mecânica dos fluidos computacional.

\subsection{Representações de Interfaces Móveis}

A simulação numérica de fenômenos relacionados com interfaces necessita de duas tarefas distintas e independentes: a primeira, que é o nosso foco, é a representação da interface durante sua evolução (o tema deste capítulo) e a segunda é a solução das equações que governam o problema durante a variação do tempo.

Partículas não-organizadas têm sido utilizadas no âmbito de simulação numérica em duas vertentes. Na primeira, diversos métodos já foram propostos, tal como o Smoothed Particle Hydrodynamics - SPH, métodos meshless e métodos baseados em partículas (vejam, por exemplo, os trabalhos $[20,157,26,109,152,121]$ e as referências por eles citadas). Esses 
métodos usam partículas em todo o domínio, de forma que as duas tarefas anteriores estão conectadas. Contudo, a quantidade de trabalhos baseados em partículas não-organizadas para a tarefa de representação da interface separada do solver (Euleriano, por exemplo) é bem menor [207, 72, 104], mas não menos importante.

Propusemos um método para o problema de modelagem de uma interface $\mathscr{S}(t)$ que evolui com o tempo $t$, encarregada de separar dois fluidos $A$ e $B$, com a possibilidade de o fluido $B$ ser o ambiente, por exemplo, o ar. Além disso, o problema ocorre no interior de um domínio finito $\Omega$ com bordo $\partial \Omega$.

Os métodos puramente Lagrangeanos para modelagem de interfaces móveis consistem em definir um conjunto de partículas sobre a interface e movê-las conforme um campo de velocidades. Esses métodos têm se mostrado eficientes em termos de precisão numérica [124, 210, 208, 87, 194], porém, esses métodos apresentam três problemas básicos:

- A dificuldade em simular processos de rompimento e junção (merging) da superfície: é difícil lidar com mudanças topológicas;

- O problema de manter a densidade de partículas consistente com o desejável nível de discretização: regiões da superfície podem conter um número excessivo de pontos, acarretando um custo computacional desnecessário, ou podem conter, por outro lado, uma pequena quantidade, levando ao comprometimento da precisão do método. Para contornar tal problema, essas abordagens exigem métodos eficientes para criação e remoção de partículas;

- Métodos puramente Lagrangeanos exigem que as partículas estejam conectadas (dependência da malha) $[210,208,194]$.

Todos os problemas previamente citados acerca dos métodos Lagrangeanos têm feito os métodos Eulerianos - tais como o método Volume-of-Fluid (VOF) [123, 178] ou o método de conjunto de nível (Level-Set - LS) [162, 183, 197, 161, 184] ou, ainda, combinações desses [196, 199] - os preferidos para modelagem de interfaces complexas com significantes 
alterações topológicas, tais como simulação de fusão de bolhas ou quebra de ondas (Figura $\left.5.1^{1}\right)[200,198,220,45,46]$. Os métodos Eulerianos são baseados na advecção de campos escalares $\phi$ definidos em todo o domínio. No método VOF, esse campo escalar representa o conteúdo parcial do fluido $A$ em cada célula da grade computacional, ao passo que, no método de LS $\phi$, define-se implicitamente a interface como o conjunto zero de uma função.

Entretanto, apesar de os métodos Eulerianos tratarem da topologia da interface de forma natural, eles apresentam problemas de perda de massa, devido aos erros de interpolação e aos erros numéricos no transporte de $\phi$.
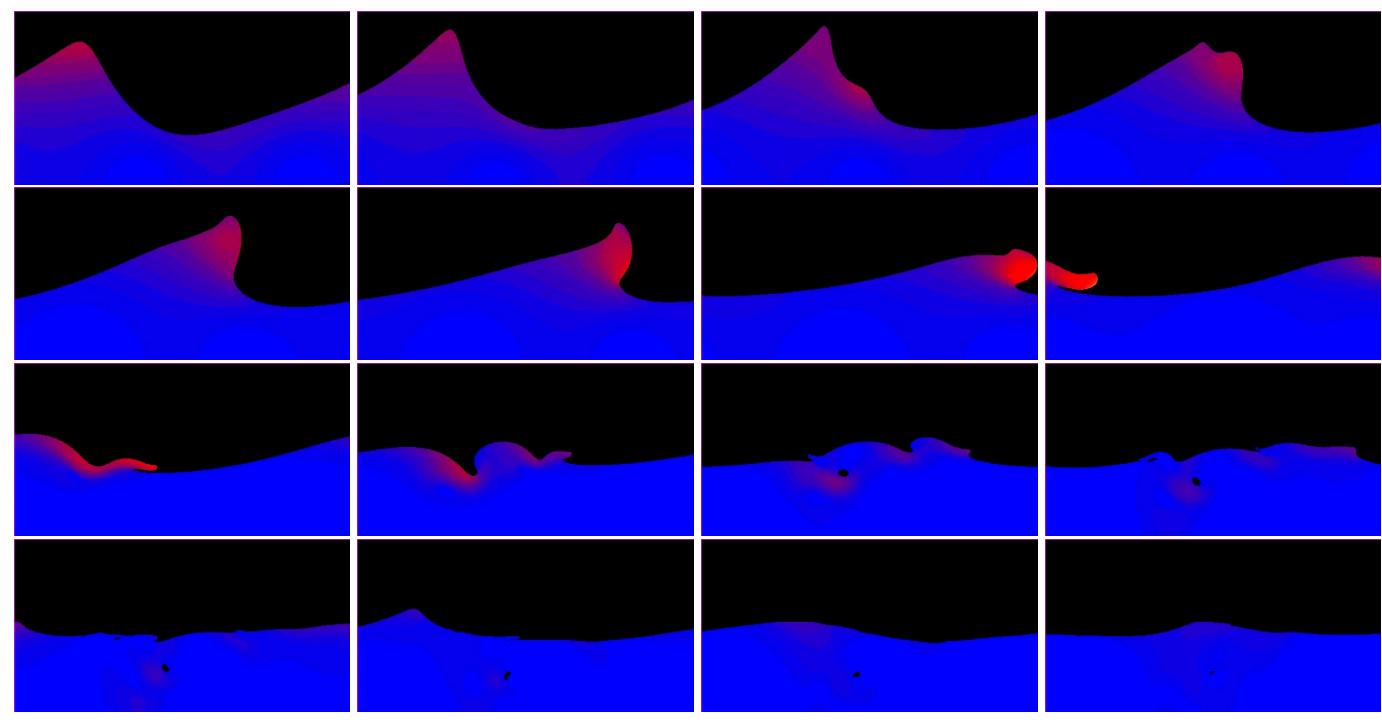

Figura 5.1: Simulação de ondas utilizando a abordagem LS: a topologia e a geometria são tratadas por esta abordagem de forma natural.

Portanto, as considerações prévias motivaram o desenvolvimento de métodos que sejam capazes de combinar a precisão das técnicas Lagrangeanas com a flexibilidade dos procedimentos Eulerianos. Alguns desenvolvimentos nessa direção estão relacionados ao nosso trabalho. Torres e Brackbill [207] desenvolveram o Point-Set Method (não devemos confundir com Point-Set Surface de Alexa et al. [9]) por meio do qual o acompanhamento de fronteira também é realizado sem a necessidade de uma malha. Tal método tem por finalidade evoluir um conjunto de partículas, conforme um campo de velocidade, para, então, construir uma função de nível $\phi$, através da Equação de Laplace em $\Omega$. Eles

\footnotetext{
${ }^{1}$ Cortesia de Gustavo C. Buscaglia: e-mail: gustavo.buscaglia@gmail.com
} 
prescrevem $\phi=1$ nas células contendo partículas e $\phi=0$ no bordo $\partial \Omega$. A função resultante $\phi$ é igual a 1 dentro de $\mathscr{S}$, identificando a região ocupada pelo fluido $A$. Um procedimento de suavização baseado em B-splines, seguido por uma etapa de correção é, então, aplicado a $\phi$ para que um conjunto de nível passe pelas partículas marcadoras. A técnica, então, regera os pontos da interface pelas projeções dos centros das células de uma grade computacional mais fina sobre o conjunto de nível $\phi$.

Enright et al. [72], por outro lado, iniciam o processo a partir de um método Euleriano de LS para melhorar a solução por meio da incorporação de informações sobre a localização da interface provida por um conjunto de partículas Lagrangeanas. Em maiores detalhes, a informação é incorporada por meio de operações de blending, da interface resultante do método Euleriano, com esferas centradas em tais partículas Lagrangeanas, que no início do passo no tempo são todas tangentes à interface. O método de Enright et al., denominado Particle Level Set (PLS), se mostrou muito eficiente em muitas aplicações [140, 161], pois a topologia da interface pode alterar naturalmente devido à parte Euleriana (método conjunto de nível) . Além disso, o PLS não necessita de solvers altamente precisos para a equação do transporte do conjunto de nível [73], pelo fato de a parte Lagrangeana do método ser capaz de corrigir as imperfeições.

Hieber e Koumoutsakos [104] propuseram uma outra abordagem que também utiliza partículas Lagrangeanas para atualizar a interface. O método, baseia-se em conjunto de nível (Lagrangian Level-Set - LSL) e faz uso de Smooth Particle Hydrodynamics (SPH).

Nossa abordagem utiliza o potencial do método de mínimos-quadrados-móveis [130] em sua versão implícita para a representação de superfícies por pontos não-organizados no contexto de modelagem de interfaces em movimento. Assim como o método Point-set de Torres e Brackbill [207], definimos uma movimentação Lagrangeana de partículas que, no início de cada passo no tempo, são colocadas na interface $\mathscr{S}(t)$. Todavia, no tempo $t+\Delta t$ não se garante que as partículas obrigatoriamente estejam na interface $\mathscr{S}(t+\Delta t)$, mas sim na superfície definida por elas, por meio da função implícita MLS, isto é, definida pelos pontos transportados. 
Essa metodologia evita o custo de resolver os sistemas lineares de Torres e Brackbill [207] para a construção de $\phi$. Ainda mais, para a representação MLS de $\mathscr{S}(t+\Delta t)$, simultaneamente realizamos a re-geração dos pontos e a construção da função de nível $\phi$, que indica a região ocupada por cada fluido. Para tal tarefa, realizamos uma técnica semelhante ao método de traçado-de-raios de Adamson e Alexa [3] para a detecção de pontos sobre $\mathscr{S}(t+\Delta t)$, definidos pelas interseções de uma grade computacional ("de raios") cartesiana tridimensional $\mathscr{T}_{h}$. O espaçamento $h$ da grade computacional $\mathscr{T}_{h}$ é o único parâmetro que governa a aproximação de $\mathscr{S}(t)$.

Isso significa que mantemos a distância entre as partículas marcadoras da ordem de $h$, e conseqüentemente, características menores que $h$ são descartadas, como nos métodos Eulerianos. Porém, o acompanhamento da superfície se mantém Lagrangeano, portanto, preciso.

Por outro lado, se comparado ao método PLS, o custo do passo Euleriano é evitado e também o número de partículas é significativamente menor, bem como são re-gerados de forma mais fácil, pois são aqueles que realmente estão sobre a superfície e não os centros de esferas tangentes.

\subsection{Superfícies AMLS Definidas Implicitamente}

\subsubsection{Definições Básicas}

Consideremos um conjunto finito de pontos $\mathscr{P}=\left\{\mathbf{p}_{1}, \ldots, \mathbf{p}_{m}\right\}$ e uma função $F \in C^{0}(U)$, em que $U \subset \mathbb{R}^{n}$, é uma vizinhança aberta de $\mathscr{P}$. Também assumamos que os pontos estão regularmente espaçados a uma distância $h$. Nosso objetivo, nesse momento, é definir uma função $F$ tal que seu nível zero é a superfície $\mathscr{S}$ que aproxima o conjunto $\mathscr{P}$.

Assim, a primeira etapa é definir, para qualquer ponto $\mathbf{x} \in U$ :

$$
F(\mathbf{x})=\sum_{k=1}^{N} \alpha_{k}(\mathbf{x}) q_{k}(\mathbf{x})
$$


em que o conjunto $\left\{q_{k}, k=1 \cdots N\right\}$ é formado por bases polinomiais, como nos capítulos anteriores. Concentramo-nos nas mesmas bases escolhidas por Guennebaud e Gross [97]:

$$
N=5, \quad q_{1}(\mathbf{x})=1, \quad q_{2}(\mathbf{x})=x_{1}, \quad q_{3}(\mathbf{x})=x_{2}, \quad q_{4}(\mathbf{x})=x_{3}, \quad q_{5}(\mathbf{x})=x_{1}^{2}+x_{2}^{2}+x_{3}^{2}
$$

Observação 8 A Equação 5.2 define uma base para uma esfera tridimensional. Embora detalhemos todo o método para essa aproximação, é natural sua modificação para o caso bidimensional, círculos, ou para aproximações de planos (em $\mathbb{R}^{3}$ ) ou retas (em $\mathbb{R}^{2}$ ). Por exemplo, nesse último caso, consideram-se apenas as bases $q_{1}, q_{2}$ e $q_{3}$. Em momentos oportunos apresentaremos exemplos de todas essas bases alternativas.

Considerando $\alpha$ uma $N$-upla de funções $\left(\alpha_{1}, \alpha_{2}, \ldots, \alpha_{N}\right)$, temos que $F$ é completamente definida por $\alpha$, dada na Equação 5.1. Indicaremos $\alpha$ como subíndice de $F$, isto é, $F_{\alpha}$, quando quisermos enfatizar a dependência de $F \operatorname{com} \alpha$. Note que cada $\alpha$, que também foi definido como função de x, também define implicitamente a superfície $\mathscr{S}_{\alpha}$, dada por:

$$
\mathscr{S}_{\alpha}=\left\{\mathbf{x} \in U \mid F_{\alpha}(\mathbf{x})=0\right\} .
$$

Na próxima seção apresentaremos o mecanismo de escolha de $\alpha(\mathbf{x})$. Essa escolha é feita de forma a superfície $\mathscr{S}_{\alpha}$ estar próxima do conjunto de pontos $\mathscr{P}=\left\{\mathbf{p}_{1}, \ldots, \mathbf{p}_{m}\right\}$ por uma esfera algébrica. Para esse propósito, adotaremos a superfície algébrica de Guennebaud e Gross [97].

\subsubsection{Mínimos-Quadrados de Esferas Algébricas}

Com o intuito de simplificar a explicação da minimização por esferas algébricas, consideramos primeiramente os $\alpha_{k}$ constantes, isto é, assumimos que os pesos são constantes e não dependem da posição de x. Nesse caso, $\mathscr{S}_{\alpha}$ é simplesmente uma esfera. Denotado por $d\left(\mathbf{p}_{i}, \mathscr{S}_{\alpha}\right)$ a distância geométrica (com sinal) de $\mathbf{p}_{i}$, a esfera e o conjunto de coeficientes $\alpha^{*}$ ótimos podem ser definidos por: 


$$
\alpha^{*}=\arg \min _{\beta \in \mathbb{R}^{N}} J(\beta), \quad \operatorname{com} \quad J(\beta)=\sum_{i=1}^{m} \omega_{i}\left|d\left(\mathbf{p}_{i}, \mathscr{S}_{\beta}\right)\right|^{2},
$$

em que $\left\{\omega_{i}, i=1, \ldots, m\right\}$ define o conjunto de pesos. No entanto, no restante desta seção, também por simplicidade, assumiremos $\omega_{i}=1$.

Infelizmente, a minimização de $J$, dada na Equação 5.4 é numericamente inconveniente [85]. Por outro lado, a aproximação algébrica define $\alpha$ como:

$$
\alpha=\arg \min _{\beta \in Q} \tilde{J}(\beta), \quad \operatorname{com} \quad \tilde{J}(\beta)=\sum_{i=1}^{m} \omega_{i}\left|F_{\beta}\left(\mathbf{p}_{i}\right)\right|^{2} .
$$

sujeito a

$$
Q=\left\{\beta \in \mathbb{R}^{N} \mid \beta_{2}^{2}+\beta_{3}^{2}+\beta_{4}^{2}-4 \beta_{1} \beta_{5}=1 .\right\}
$$

Tal restrição, proposta por Pratt [171], é razoável, pois garante que sobre a superfície $\mathscr{S}_{\beta}$, o gradiente de $F$ é igual a 1. Assim:

$$
\left\|\nabla F_{\beta}\right\|^{2}=\beta_{2}^{2}+\beta_{3}^{2}+\beta_{4}^{2}-4 \beta_{1} \beta_{5}
$$

e, portanto [201],

$$
F_{\beta}\left(\mathbf{p}_{i}\right)=d\left(\mathbf{p}_{i}, \mathscr{S}_{\beta}\right)+\mathscr{O}\left(\left|d\left(\mathbf{p}_{i}, \mathscr{S}_{\beta}\right)\right|^{2}\right) \quad \forall \beta \in Q
$$

Isso significa que, se o conjunto de pontos $\mathscr{P}$ estiver próximo a uma esfera, o processo de minimização definido pelas Equações 5.5 e 5.6 produzirá $\alpha$ tal que $\mathscr{S}_{\alpha}$ é muito próximo à esfera "ótima” $\mathscr{S}_{\alpha^{*}}$ definida pela Equação 5.4. Ademais, para qualquer $\mathbf{x}$ suficientemente próximo a $\mathscr{S}_{\alpha}$, o valor de $F_{\alpha}(\mathbf{x})$ aproximará a distância com sinal $d\left(\mathbf{x}, \mathscr{S}_{\alpha}\right)$, isto é:

$$
F_{\alpha}(\mathbf{x})=d\left(\mathbf{x}, \mathscr{S}_{\alpha}\right)+\mathscr{O}\left(\left|d\left(\mathbf{x}, \mathscr{S}_{\alpha}\right)\right|^{2}\right)
$$

A vantagem do esquema de minimização dado pelas Equações (5.5)-(5.6) se deve ao fato da desnecessidade de uma minimização não-linear. De fato, como: 


$$
F_{\beta}\left(\mathbf{p}_{i}\right)=\sum_{k=1}^{N} \beta_{k} q_{k}\left(\mathbf{p}_{i}\right),
$$

segue que

$$
\begin{aligned}
\tilde{J}(\beta) & =\sum_{i=1}^{m} \omega_{i}\left|\sum_{k=1}^{N} \beta_{k} q_{k}\left(\mathbf{p}_{i}\right)\right|^{2} \\
& =\sum_{k, \ell=1}^{N} \beta_{k} \beta_{\ell}\left(\sum_{i=1}^{m} \omega_{i} q_{k}\left(\mathbf{p}_{i}\right) q_{\ell}\left(\mathbf{p}_{i}\right)\right) \\
& =\beta^{T} \mathbf{M} \beta
\end{aligned}
$$

em que a matriz simétrica $\mathbf{M}$ é dada por:

$$
\mathbf{M}_{k \ell}=\sum_{i=1}^{m} \omega_{i} q_{k}\left(\mathbf{p}_{i}\right) q_{\ell}\left(\mathbf{p}_{i}\right),
$$

mostrando que a matriz $\mathbf{M}$ não depende de $\beta$, implicando que $\tilde{J}$ é uma forma quadrática em $\mathbb{R}^{N}$. Além disso, notemos que a restrição de $Q$ (Eq. 5.6) também é uma forma quadrática. De fato, podemos definir a única matriz simétrica $\mathbf{C}$ em que os únicos elementos não-nulos são:

$$
\mathbf{C}_{22}=\mathbf{C}_{33}=\mathbf{C}_{44}=1, \quad \mathbf{C}_{15}=\mathbf{C}_{51}=-2
$$

Reescrevendo o problema de minimização (5.5)-(5.6) na forma matricial, temos:

$$
\begin{aligned}
& \alpha=\arg \quad \min \quad \beta^{T} \mathbf{M} \beta \\
& \beta \in \mathbb{R}^{N} \\
& \beta^{T} \mathbf{C} \beta=1 \text {. }
\end{aligned}
$$

Portanto, a $N$-upla $\alpha$ é obtida, aplicando os multiplicadores de Lagrange na minimização acima, pelo seguinte problema de autovetor generalizado [93]:

$$
\mathbf{M} \alpha=\lambda \mathbf{C} \alpha,
$$


que corresponde a encontrar o autovetor $\alpha$ associado ao menor autovalor $\lambda$ (pois $\tilde{J}(\alpha)=\lambda$ ), normalizado, segundo a restrição, isto é, $\alpha^{T} \mathbf{C} \alpha=1$.

Notemos, para efeitos computacionais, que a matriz $\mathbf{C}^{-1}$ é simplesmente dada por:

$$
\mathbf{C}_{22}^{-1}=\mathbf{C}_{33}^{-1}=\mathbf{C}_{44}^{-1}=1, \quad \mathbf{C}_{15}^{-1}=\mathbf{C}_{51}^{-1}=-\frac{1}{2},
$$

e zero nas demais entradas. Portanto, o Problema 5.14 pode ser reescrito como:

$$
\mathbf{C}^{-1} \mathbf{M} \alpha=\lambda \alpha .
$$

Tal problema pode ser resolvido numericamente utilizando-se a fatoração de Schur, que é aplicável a matrizes complexas e não-simétricas, fazendo uso da biblioteca de domínio público GNU Scientific Library [96].

Portanto, a aproximação por mínimos-quadrados do conjunto de pontos $\mathscr{P}$ com pesos $\left\{\omega_{i}: i=1, \ldots, m\right\}$ é definida pelo conjunto de nível zero $\mathscr{S}_{\alpha} \operatorname{com} \alpha$ dado como anteriormente e a distância algébrica (com sinal) de um ponto $\mathbf{x}$ a $\mathscr{S}_{\alpha}$ é dada por $F_{\alpha}(\mathbf{x})$, que é uma aproximação de segunda ordem para $d\left(\mathbf{x}, \mathscr{S}_{\alpha}\right)$, se x está próximo a $\mathscr{S}_{\alpha}$.

\subsubsection{Superfícies MLS Algébricas - AMLS}

Na seção anterior, definimos formalmente a aproximação de mínimos-quadrados por esferas algébricas. No entanto, como discutido no Capítulo 2, quando adicionamos apropriadamente pesos $\left\{\omega_{i}(\mathbf{x})\right\}_{i=1, \ldots, m}$ que dependem da posição do ponto $\mathbf{x}$ no método de mínimos-quadrados, obtemos o método dos mínimos-quadrados-móveis, que é capaz de aproximar uma superfície a partir de um conjunto de pontos não-organizados dela extraídos.

Objetivando assegurar a eficiência do método, também definimos o raio de influência $\Delta$ (constante), que naturalmente define o domínio $U$ :

$$
U=\left\{\mathbf{x} \in \mathbb{R}^{n}: \text { o número de pontos } \mathbf{p} \in \mathscr{P} \text { com }\|\mathbf{x}-\mathbf{p}\|<\Delta \text { deve ser } \geq 4\right\}
$$


no qual a função implícita $F$ será calculada.

É relevante considerarmos que, no mínimo, quatro pontos estão a uma distância menor que $\Delta$, para assegurar que a matriz $\mathbf{M}$ não seja singular, implicando na não-unicidade da solução. No presente trabalho, assumimos $\Delta=3$, em que $h$ é a distância média entre os pontos ( $h$ é definido como o espaçamento da grade computacional que usaremos). Chegamos a tal escolha após vários experimentos com diferentes valores de $\Delta$.

Em resumo, para cada $\mathbf{x} \in U$, definimos o conjunto de pesos $\left\{\omega_{i}(\mathbf{x}), i=1, \ldots, m\right\}:$

$$
\omega_{i}(\mathbf{x})=\theta\left(\frac{\left\|\mathbf{x}-\mathbf{p}_{i}\right\|}{\Delta}\right)
$$

fazendo uso novamente da Equação 2.6 (Página 28):

$$
\theta(t)=\left\{\begin{array}{ll}
\left(1-t^{2}\right)^{4} & \text { para } t<1 \\
0 & \text { caso contrário }
\end{array} .\right.
$$

Agora, quando resolvemos o Problema de Autovalores Generalizados 5.14, obtivemos os coeficientes $\alpha(\mathbf{x})$ que dependem de $\mathbf{x}$, porque $\mathbf{M}$ também depende de $\mathbf{x}$, e assim, fica definido o Problema de mínimos-quadrados-móveis algébricos.

A função implícita em $\mathbf{x}$ é dada por $F(\mathbf{x})=\sum_{k=1}^{N} \alpha_{k}(\mathbf{x}) q_{k}(\mathbf{x})$, e como discutido previamente, é a distância algébrica da esfera que aproxima, no sentido dos mínimos-quadrados e com pesos $\left\{\omega_{i}(\mathbf{x}), i=1, \ldots, m\right\}$, o conjunto $\mathscr{P}$.

No entanto, a continuidade de $F$ para um conjunto de pontos arbitrários não é óbvia. $\mathrm{O}$ conjunto de nível zero de $F$,

$$
\mathscr{S}=\{\mathbf{x} \in U \mid F(\mathbf{x})=0\}
$$

que definimos como a superfície que aproxima a nuvem de pontos $\mathscr{P}$, não garante ser uma variedade de dimensão $n-1$.

Na Figura 5.2, apresentamos alguns exemplos de curvas de níveis da função $F$ e a aproximação da superfície $\mathscr{S}$, utilizando círculos algébricos. 


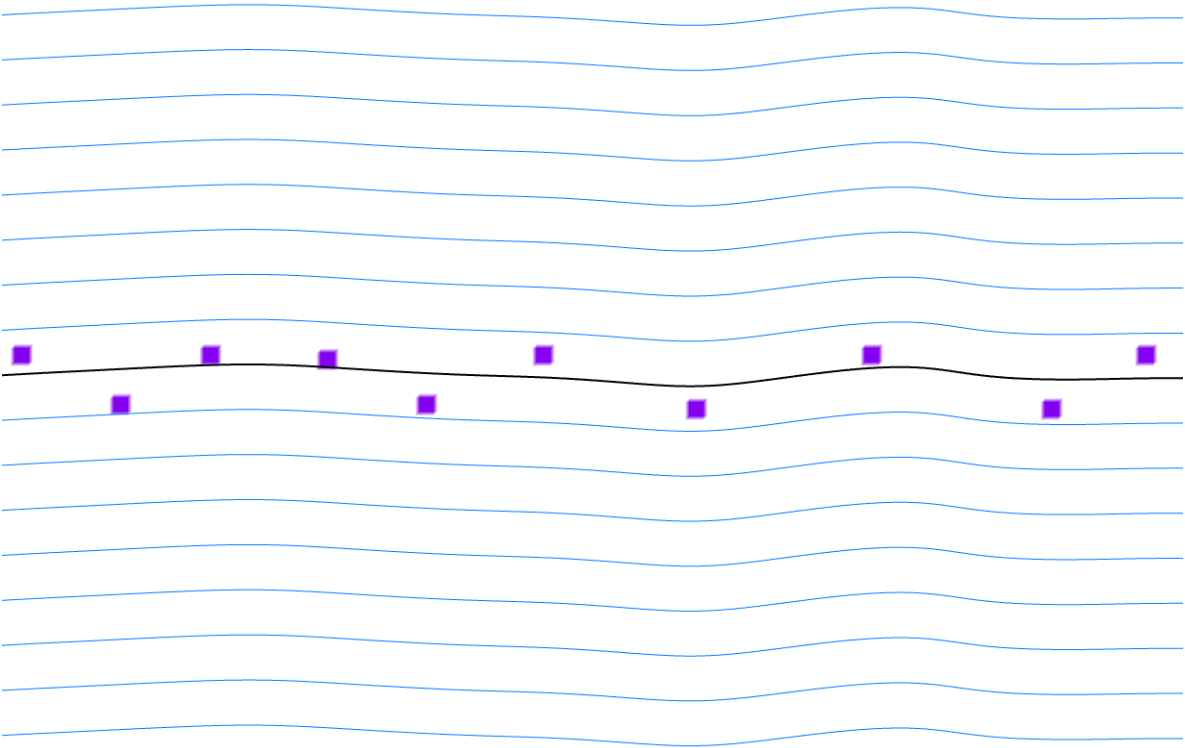

(a)

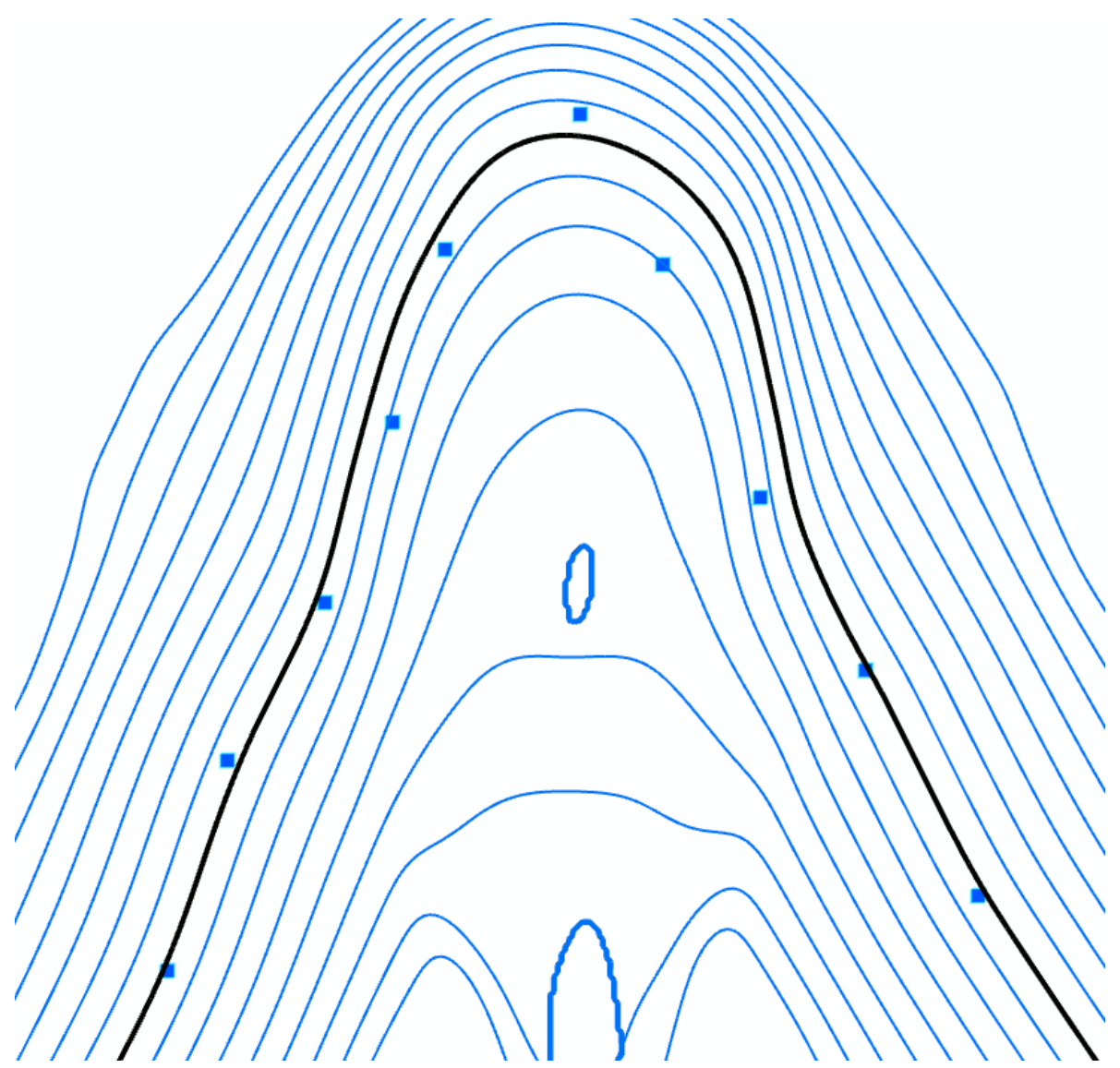

(b)

Figura 5.2: Exemplos das funções implícitas $F$ por AMLS (azul) e exemplos da superfície aproximada $\mathscr{S}$ (preto) do conjunto de pontos (quadrados pretos). (a) Pontos perturbados aleatoriamente em uma reta; (b) pontos perturbados aleatoriamente em uma quina. 


\subsubsection{A Questão dos Vetores Normais Orientados}

Um aspecto fundamental do problema de minimização previamente descrito se refere à orientação de $\alpha(\mathbf{x})$. Podemos notar que o vetor de coeficientes $\alpha(\mathbf{x})$, quando mutiplicado por -1 não afeta $\mathscr{S}_{\alpha}$, mas altera o sinal de $F(\mathbf{x})$ (Figura 5.3).

Como algoritmos de detecção de interseção da superfície $\mathscr{S}_{\alpha}$ com uma reta (em nosso caso, aplicamos o método regula-falsi [41]) levam em consideração o valor e o sinal da função, tal indeterminação do sinal da função compromete o método, pois gera interseções errôneas (no nosso caso, a reta é substituída pelo "raio" do algoritmo de traçado-de-raios).

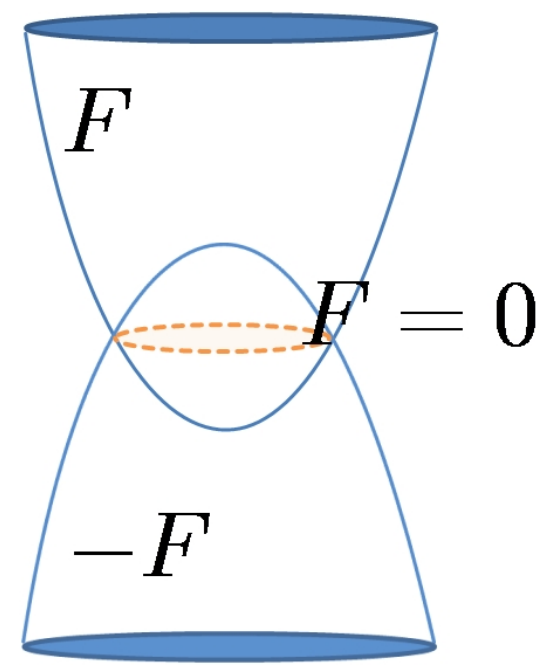

Figura 5.3: O conjunto zero gerado por $F$ (laranja) é o mesmo gerado por $-F$.

$\mathrm{Na}$ literatura, existem abordagens que orientam consistentemente vetores normais de uma nuvem de pontos por meio de propagação de informações utilizando grafos [97, 107]. No entanto, veremos que, para o nosso método de acompanhamento de fronteiras, será possível assumir que a superfície inicial possui já um conjunto de vetores normais aproximados $\left\{\tilde{\mathbf{n}}_{i}, i=1, \ldots, m\right\}$ consistentemente orientados para cada ponto de $\mathscr{P}$. Usamos esse conjunto de vetores normais aproximados apenas para definir a orientação. Por tal motivo, esses não precisam ser muito precisos. Em momento oportuno (Observação 11, Página 158), mostraremos como construímos o conjunto $\left\{\tilde{\mathbf{n}}_{i}\right\}$.

Então, definimos para um ponto $\mathbf{x}$ o gradiente do polinômio gerado como a melhor 
aproximação pelo método dos mínimos-quadrados-móveis:

$$
\mathbf{g}_{\alpha}(\mathbf{x})=\left(\alpha_{2}(\mathbf{x})+2 \alpha_{5}(\mathbf{x}) x_{1}, \alpha_{3}(\mathbf{x})+2 \alpha_{5}(\mathbf{x}) x_{2}, \alpha_{4}(\mathbf{x})+2 \alpha_{5}(\mathbf{x}) x_{3}\right)
$$

Além disso, também definimos a média ponderada por $\mathbf{x}$ dos vetores normais:

$$
\tilde{\mathbf{n}}(\mathbf{x})=\sum_{i=1}^{m} \tilde{\mathbf{n}}_{i} \omega_{i}(\mathbf{x})
$$

E assim, definimos o critério de orientação:

Definição 4 Se o ângulo entre $\mathbf{g}_{\alpha}(\mathbf{x})$ e $\tilde{\mathbf{n}}(\mathbf{x})$ é maior do que $\pi / 2$, então $\alpha(\mathbf{x})$ é substituído por $-\alpha(\mathbf{x}) ;$ caso contrário, não é alterado.

Enfatizamos que no método AMLS, especialmente na presença de características afiadas, a escolha da orientação de $\alpha(\mathbf{x})$ ainda é crítica, mesmo com a situação descrita previamente. A técnica acima apresenta resultados satisfatórios na maioria dos casos, mas, como veremos na Seção 5.3.6 (Página 143), dificuldades podem surgir nas proximidades de características afiadas.

Notemos que a média dos vetores normais $\tilde{\mathbf{n}}(\mathbf{x})$, por exemplo, poderia ser substituída pelo vetor normal aproximado $\tilde{\mathbf{n}}_{i}$ correspondente ao ponto $\mathbf{p}_{i}$, que é o ponto mais próximo de $\mathbf{x}$. No entanto, qualquer uma dessas escolhas estará sujeita a falhas, caso o conjunto de pontos seja difícil de lidar, implicando que ambos os mecanismos são apenas heurísticas sem garantia de qualidade. Ainda, é importante mencionarmos que, mesmo as abordagens de propagação de orientação de vetores normais - propostas na literatura, que não assumem vetores normais aproximados $[97,107]$ - também estão sujeitas a falhas de orientação.

\subsubsection{Estudo de Convergência do Método AMLS}

Com o intuito de investigar a eficiência do método AMLS no âmbito de transporte de interfaces móveis, nesta seção apresentamos o estudo de convergência do método AMLS, considerando todas as situações descritas na Observação 8. 
Convém reforçar que a forma em que uma superfície AMLS converge (ou falha) para um dado conjunto de dados depende da aplicação. Se a nuvem de pontos contiver dados ruidosos, serão necessários mecanismos estatísticos para se explicarem as taxas de convergência. No entanto, em nosso caso, como definimos a posição dos pontos conforme nossa técnica de acompanhamento de fronteira, assumimos que os pontos $\mathscr{P}$ estão exatamente sobre a superfície $\Sigma$. Pelo fato de conhecermos a superfície $\Sigma$, o conjunto de pontos $\mathscr{P}$, que usamos para aproximar $\Sigma$ por $\mathscr{S}$, é definido de forma a ser tão bom quanto necessário.

Assim, definimos a distância entre duas superfícies pela distância de Hausdorff:

$$
d(\Sigma, \mathscr{S})=\max \left\{\max _{\mathbf{x} \in \Sigma} \min _{\mathbf{y} \in \mathscr{S}}\|\mathbf{x}-\mathbf{y}\|, \max _{\mathbf{x} \in \mathscr{S}} \min _{\mathbf{y} \in \Sigma}\|\mathbf{x}-\mathbf{y}\|\right\} .
$$

Consideremos $\mathscr{P}_{h}$ uma família de pontos regularmente espaçados, amostrados "exatamente" a partir da superfície $\Sigma$ e parametrizados por uma distância média $h$. Consideremos também $\mathscr{S}_{h}$ a família associada de superfícies AMLS, obtidas pelo método descrito na seção anterior. A partir disso, definimos a convergência do método:

Definição 5 Se $\lim _{h \rightarrow 0} d\left(\Sigma, \mathscr{S}_{h}\right)=0$, então a taxa de convergência $r$ é:

$$
d\left(\Sigma, \mathscr{S}_{h}\right)=\mathscr{O}\left(h^{r}\right)
$$

Para realizar o estudo de convergência, utilizamos os mesmos modelos de Torres e Brackbill no estudo de convergência do Point-Set Method [207]. São eles, uma elipse para o caso bidimensional e um elipsóide para o caso tridimensional. Para determinarmos de forma satisfatória a distância entre um ponto da superfície AMLS e uma elipse (2D) e um elipsóide (3D), utilizamos o algoritmo de Hart [101].

\section{Elipse (Caso Bidimensional)}

Examinemos primeiramente a convergência para a elipse $\Sigma$, dada por:

$$
\frac{x_{1}^{2}}{9}+\frac{x_{2}^{2}}{4}=1
$$


Para isso, geramos a família de conjuntos de pontos $\mathscr{P}_{h}$ sobre a Elipse 5.23 com distâncias médias

$$
h=1.5,0.75,0.375, \ldots, 2.34 \times 10^{-2},
$$

correspondendo a $N_{h}$ pontos sobre a elipse, com

$$
N_{h}=14,27,54, \ldots, 860
$$

respectivamente. Na Figura 5.4-(a), apresentamos o conjunto de pontos para $h=1.5$, junto com a curva AMLS correspondente.

Na Figura 5.4-(b) apresentamos o erro geométrico $d\left(\Sigma, \mathscr{S}_{h}\right)$ em função de $h$. A convergência, como pode ser notado, tem ordem $\mathscr{O}\left(h^{3}\right)$. Ainda, podemos observar que, com apenas 54 pontos, a uma distância média de 0.375 , o erro máximo entre $\mathscr{S}_{h}$ e $\Sigma$ já é menor que $7.3 \times 10^{-4}$.

Antes de apresentarmos os resultados de convergência para curvatura e vetores normais, precisamos definir a função implícita para o caso bidimensional:

$$
F(\mathbf{x})=\alpha_{1}(\mathbf{x})+\alpha_{2}(\mathbf{x}) x_{1}+\alpha_{3}(\mathbf{x}) x_{2}+\alpha_{4}(\mathbf{x})\left(x_{1}^{2}+x_{2}^{2}\right) .
$$

A partir disso, para cada ponto $\mathbf{x}$ de $\mathscr{S}_{h}$, também calculamos o vetor normal e a curvatura. O vetor normal da função $\mathbf{n}_{\alpha}(\mathbf{x})$, correspondente aos coeficientes $\alpha(\mathbf{x})$, é definido como o vetor normal do melhor círculo em $\mathbf{x}$, que é dado por:

$$
\mathbf{n}_{\alpha}(\mathbf{x})=\left(\alpha_{2}(\mathbf{x})+2 \alpha_{4}(\mathbf{x}) x_{1}, \alpha_{3}(\mathbf{x})+2 \alpha_{4}(\mathbf{x}) x_{2}\right) .
$$

Dessa forma, denotando por $\mathbf{y}_{\mathbf{x}}$ o ponto em $\Sigma$ que é mais próximo a $\mathbf{x}$, definimos o erro para os vetores normais por:

$$
E_{N}\left(\Sigma, \mathscr{S}_{h}\right)=\max _{\mathbf{x} \in \mathscr{S}_{h}}\left\|\mathbf{n}_{\alpha}(\mathbf{x})-\mathbf{n}\left(\mathbf{y}_{\mathbf{x}}\right)\right\|
$$




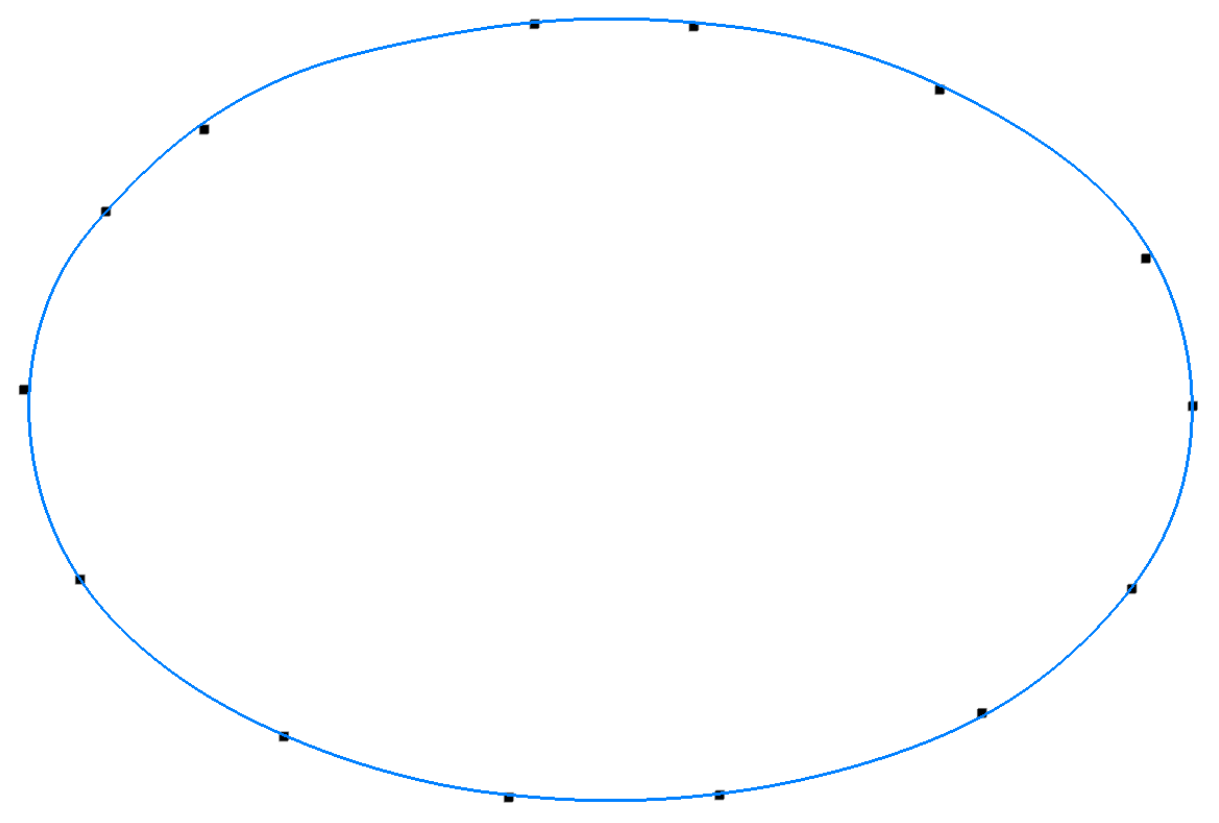

(a)

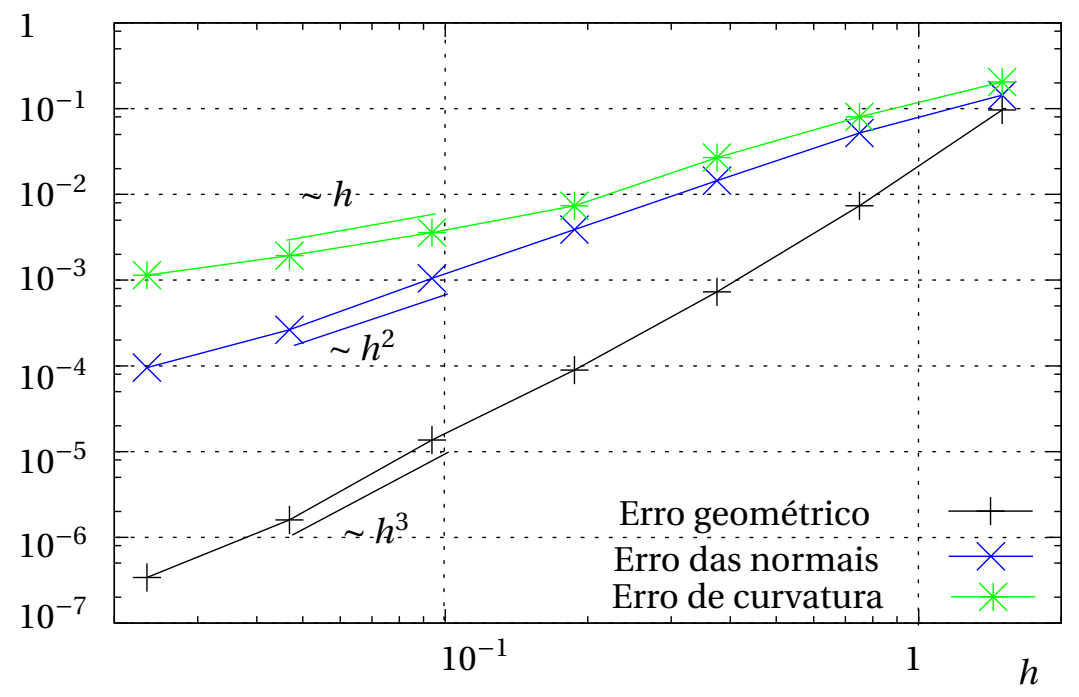

(b)

Figura 5.4: Em (a) apresentamos o conjunto de pontos $\mathscr{P}_{h}$, correspondente a $h=1.5$ no caso da elipse, e a curva AMLS $\mathscr{S}_{h}$ baseada em círculos. Em (b), apresentamos os gráficos de convergência de $d\left(\Sigma, \mathscr{S}_{h}\right)$ (denotado por erro geométrico), de $E_{N}\left(\Sigma, \mathscr{S}_{h}\right)$ (denotado por erro das normais) e $E_{C}\left(\Sigma, \mathscr{S}_{h}\right)$ (denotado por erro de curvatura). 
em que $\mathbf{n}\left(\mathbf{y}_{\mathbf{x}}\right)$ é o vetor normal exato à $\Sigma$ em $\mathbf{y}_{\mathbf{x}}$. Já a curvatura dada pelo AMLS é simplesmente o inverso do raio do melhor círculo que aproxima localmente e, dessa forma, é dado por:

$$
\kappa_{\alpha}(\mathbf{x})=\left(\frac{\alpha_{2}^{2}+\alpha_{3}^{2}}{4 \alpha_{4}^{2}}-\frac{\alpha_{1}}{\alpha_{4}}\right)^{-\frac{1}{2}}
$$

Portanto, o erro de curvatura é definido por:

$$
E_{C}\left(\Sigma, \mathscr{S}_{h}\right)=\max _{\mathbf{x} \in \mathscr{S}_{h}}\left\|\kappa_{\alpha}(\mathbf{x})-\kappa\left(\mathbf{y}_{\mathbf{x}}\right)\right\|
$$

em que $\kappa\left(\mathbf{y}_{\mathbf{x}}\right)$, da mesma forma que o vetor normal, é a curvatura exata da superfície $\Sigma$ em $\mathbf{y}_{\mathbf{x}}[92]$.

Os gráficos de $E_{N}$ e $E_{C}$, ambos em função de $h$, são apresentados na Figura 5.4(b). É importante destacarmos que $\mathbf{n}_{\alpha}(\mathbf{x})$ e $\kappa_{\alpha}(\mathbf{x})$ não são o vetor normal e a curvatura correspondente à $\mathscr{S}_{h}$, mas sim correspondentes do círculo que aproxima a curva para x. Maiores detalhes a respeito da aproximação exata do vetor normal de $F$ podem ser encontrados nos trabalhos [7, 97].

Na verdade, o vetor normal e a curvatura que utilizamos são correspondentes ao círculo AMLS em x. No entanto, a convergência de $E_{N}$ é de ordem quadrática $\left(h^{2}\right)$ e $E_{C}$ é de ordem linear $(h)$, que são os resultados esperados, caso tenhamos os cálculos exatos para o vetor normal e para a curvatura de $F$.

No exemplo anterior, apresentamos a eficiência do método AMLS baseado em círculos. Também é interessante considerar a sua eficiência utilizando retas, isto é, desconsiderando o termo quadrático da base de polinômios. Nesse caso, o cálculo é mais simples que o caso anterior, pois apenas os coeficientes $\alpha_{1}, \alpha_{2}$ e $\alpha_{3}$ não são nulos.

Logo, a matriz $\mathbf{C}_{3 \times 3}$ contém como elementos não-nulos $\mathbf{C}_{22}=\mathbf{C}_{33}=1$ e segue que função implícita é a mesma proposta por Adamson e Alexa [3] (ver Equação 2.15).

Utilizando os mesmos conjuntos de pontos da análise anterior, a superfície $\mathscr{S}_{h}$ resultante é apresentada na Figura 5.5-(a). Os gráficos de $d\left(\Sigma, \mathscr{S}_{h}\right)$ e de $E_{N}\left(\Sigma, \mathscr{S}_{h}\right)$ em função de $h$ são 
mostrados na Figura 5.5-(b). Nesse caso, como esperávamos, o erro geométrico $d\left(\Sigma, \mathscr{S}_{h}\right)$ se manteve na ordem quadrática $\left(h^{2}\right)$, enquanto o erro dos vetores normais se manteve na ordem linear $(h)$. No caso de aproximações por planos, a curvatura pelo AMLS não é possível de ser determinada.

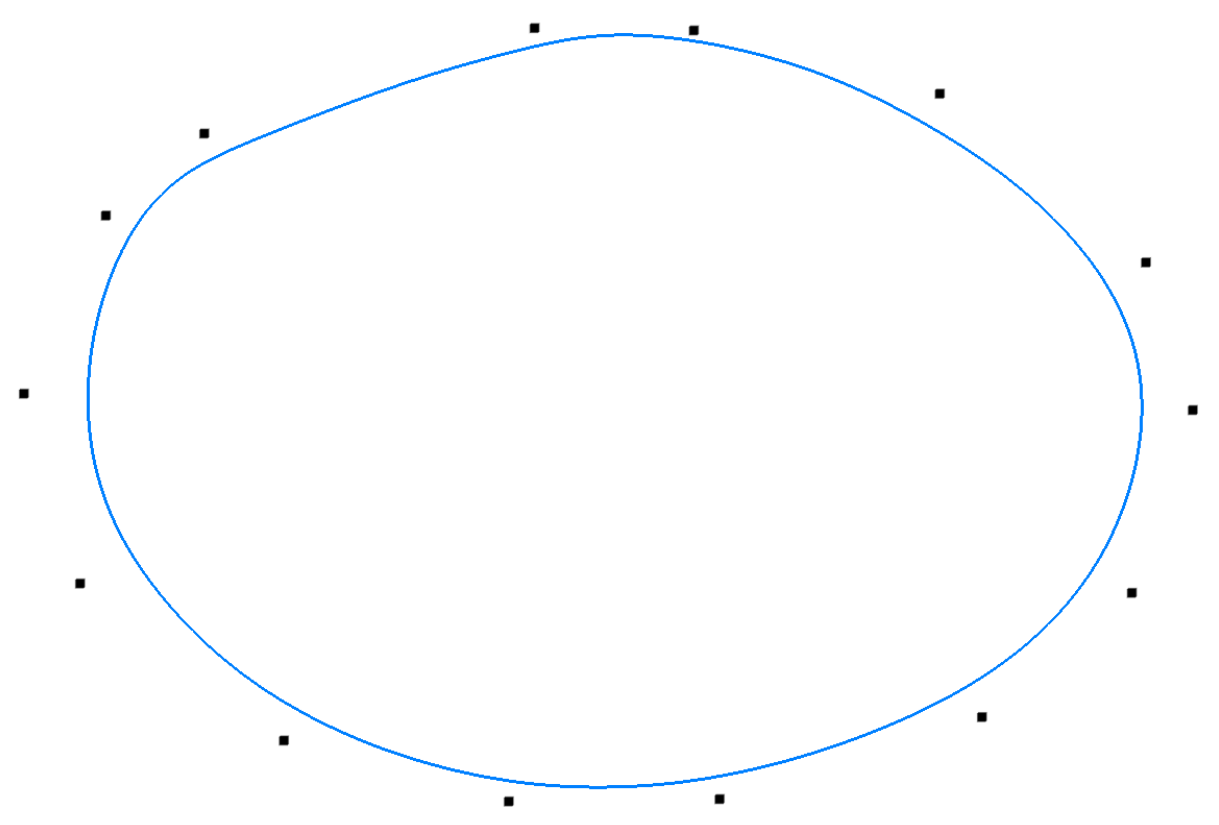

(a)

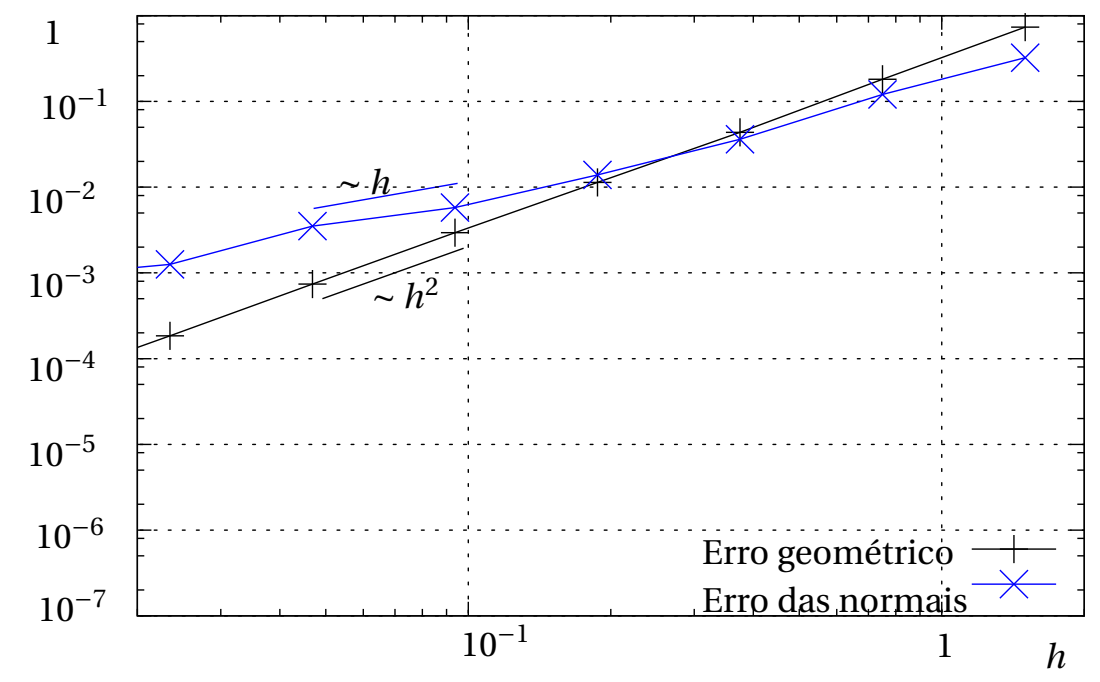

(b)

Figura 5.5: Em (a), apresentamos o conjunto de pontos $\mathscr{P}_{h}$, correspondente a $h=1.5$ no caso da elipse e a curva AMLS $\mathscr{S}_{h}$ baseada em retas. Em (b), apresentamos os gráficos de $d\left(\Sigma, \mathscr{S}_{h}\right)$ (denotado por erro geométrico) e $E_{N}\left(\Sigma, \mathscr{S}_{h}\right)$ (denotado por erro das normais). 


\section{Elipsóide (Caso Tridimensional)}

De forma análoga ao caso bidimensional, também analisamos a convergência do método para o caso tridimensional, utilizando um elipsóide $\Sigma$ [207], dado por:

$$
\frac{x_{1}^{2}}{16}+\frac{x_{2}^{2}}{9}+\frac{x_{3}^{2}}{4}=1
$$

O conjunto de pontos $\mathscr{P}_{h}$, nesse caso, teve espaçamento médio:

$$
h=0.75,0.375, \ldots, 2.34 \times 10^{-2}
$$

que corresponde a

$$
N_{h}=265,1085,4369, \ldots, 276414
$$

pontos, respectivamente.

No caso tridimensional, os vetores normais do AMLS e a curvatura são dados por:

$$
\mathbf{n}_{\alpha}(\mathbf{x})=\left(\alpha_{2}(\mathbf{x})+2 \alpha_{5}(\mathbf{x}) x_{1}, \alpha_{3}(\mathbf{x})+2 \alpha_{5}(\mathbf{x}) x_{2}, \alpha_{4}(\mathbf{x})+2 \alpha_{5}(\mathbf{x}) x_{3}\right)
$$

$\mathrm{e}$

$$
\kappa_{\alpha}(\mathbf{x})=\left(\frac{\alpha_{2}^{2}+\alpha_{3}^{2}+\alpha_{4}^{2}}{4 \alpha_{5}^{2}}-\frac{\alpha_{1}}{\alpha_{5}}\right)^{-\frac{1}{2}} .
$$

Os gráficos de convergência são apresentados na Figura 5.6-(b). Primeiramente podemos concluir que, ao contrário do caso bidimensional, a taxa de convergência em três dimensões do erro geométrico atinge ordem quadrática. Tal fato é devido claramente às bases polinomiais aplicadas, que contêm apenas um termo quadrático, que é insuficiente para obter uma convergência de terceira ordem. No entanto, a aproximação é satisfatória. Basta tomar o caso em que a nuvem de pontos contém 4369 pontos a uma distância média de $h=0.375$, e a distância entre a superfície $\Sigma$ e $\mathscr{S}_{h}$ é menor que $2.3 \times 10^{-3}$, isto é, duas ordens de magnitude menor que a distância entre os pontos. 
Já o erro $E_{N}$ dos vetores normais se comporta com ordem $\mathscr{O}(h)$ e a curvatura falha na convergência $\left(E_{C}=\mathscr{O}(1)\right)$. Esse é o principal problema a ser resolvido para ser aplicável diretamente em questões envolvendo forças capilares (superficiais) [24], por exemplo. Por isso, o estudo de uma aproximação adequada de curvatura será deixado como um trabalho futuro.

Para os mesmos conjuntos de pontos, como mencionamos anteriormente, também realizamos os testes para superfícies AMLS baseadas em planos. Apresentamos os gráficos de convergência na Figura 5.7-(b). As taxas de convergências são as mesmas para as aproximações por esferas, tanto em relação ao erro geométrico, quanto em relação ao erro das normais $E_{N}\left(\Sigma, \mathscr{S}_{h}\right)$. Além disso, os erros das normais em ambos os casos, além de serem de mesma ordem, também são similares. Entretanto, o erro geométrico $d\left(\Sigma, \mathscr{S}_{h}\right)$ para o caso de aproximações por planos é maior por um fator de 10, indicando que o termo quadrático, de fato, melhora a aproximação.

Finalmente, nas Figuras 5.6-(a) e 5.7-(a), apresentamos as aproximações correspondentes a superfícies AMLS baseadas em esferas e planos, respectivamente. É possível notar que a convexidade do elipsóide faz com que a superfície AMLS aproximada por planos deixe os pontos fora dela, enquanto que aquela baseada em esferas mostra o potencial do ajuste, mesmo para um conjunto pequeno de pontos.

\subsubsection{A Questão das Características Afiadas}

Em aplicações de dinâmica dos fluidos, é comum a existência de interfaces (que evoluem com o tempo) que apresentam características afiadas ou mesmo alterações topológicas. A capacidade do método em lidar com dados não-suaves tem grande importância sobre a robustez de todo o mecanismo de simulação. Por tal motivo, métodos menos precisos, tais como o LS, são freqüentemente preferidos em simulações tecnológicas, devido à robustez oriunda dessas abordagens.

É importante mencionar que, até o momento, a superfície $\Sigma$ ainda está fixa no espaço. 


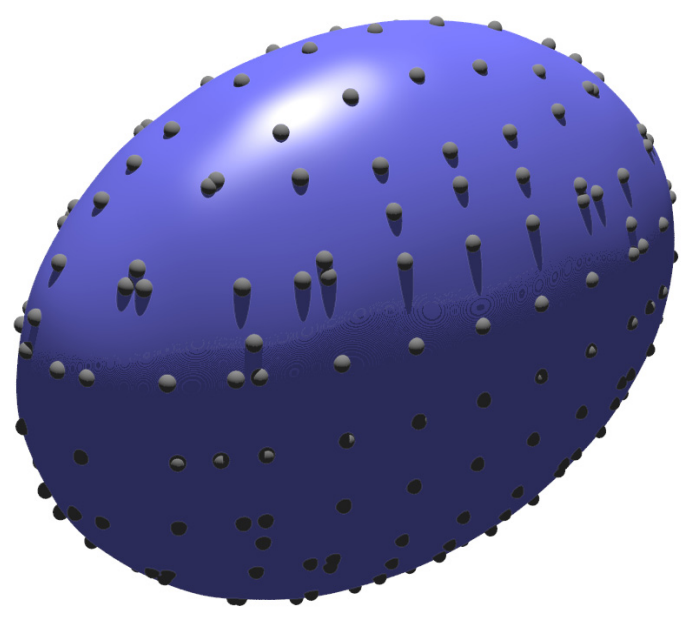

(a)

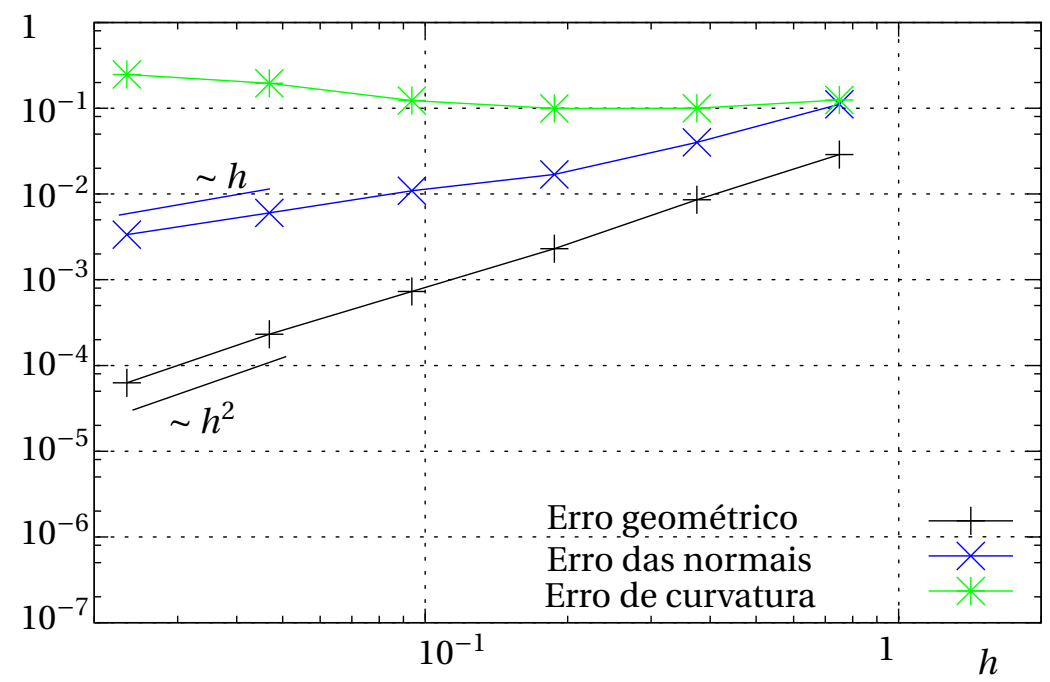

(b)

Figura 5.6: Em (a), temos o elipsóide gerado pela superfície AMLS, baseada em esferas para um conjunto de 265 pontos a uma distância média de $h=0.75$. Em (b), temos os gráficos de convergência de $d\left(\Sigma, \mathscr{S}_{h}\right)$ (denotado por erro geométrico), de $E_{N}\left(\Sigma, \mathscr{S}_{h}\right.$ ) (denotado por erro das normais) e de $E_{C}\left(\Sigma, \mathscr{S}_{h}\right)$ (denotado por erro de curvatura). 


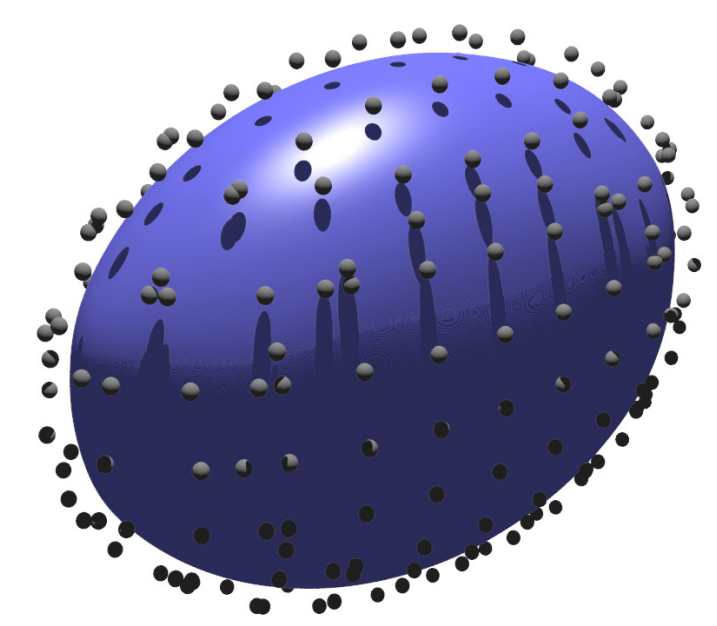

(a)

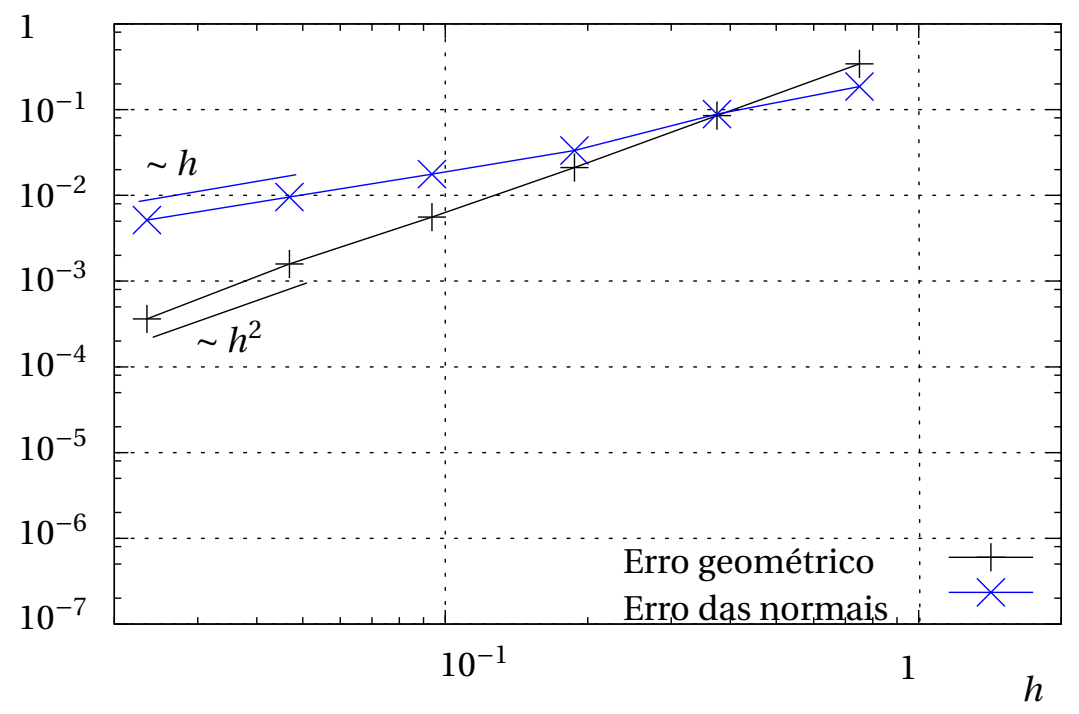

(b)

Figura 5.7: Em (a), temos o elipsóide gerado pela superfície AMLS, baseada em planos para um conjunto de 265 pontos a uma distância média de $h=0.75$. Em (b), temos os gráficos de convergência de $d\left(\Sigma, \mathscr{S}_{h}\right)$ (denotado por erro geométrico) e de $E_{N}\left(\Sigma, \mathscr{S}_{h}\right)$ (denotado por erro das normais). 
Simplesmente realizamos toda a análise por meio da superfície AMLS $\mathscr{S}_{h}$, reconstruída a partir dos conjuntos de pontos $\mathscr{P}_{h}$, na qual os pontos estão a uma distância média entre eles de $h$, os quais foram amostrados a partir de uma superfície $\Sigma$.

Como caso de análise, definimos uma superfície $\Sigma$ gerada pela remoção de um quarto de uma esfera de raio unitário. Denotamos esse teste como o "caso do 3/4-esfera”. Geramos conjuntos de pontos não-organizados $\mathscr{P}_{h}$ a partir do 3/4-esfera com espaçamento médio entre os pontos de $h \simeq 0.12$ (1030 pontos), $h \simeq 0.08$ (2031 pontos) e $h \simeq 0.05$ (4748 pontos). Na Figura 5.8, apresentamos as superfícies AMLS (utilizando a abordagem por esferas para todas as próximas análises), obtidas a partir desses conjuntos de pontos. Fica claro que as vizinhanças nas quinas, onde duas superfícies planas e um setor esférico se encontram, desafiam a capacidade do método AMLS em aproximar corretamente a superfície.

De fato, pudemos notar que artefatos em tais cantos são devidos à incapacidade do método em lidar com tal situação, e o algoritmo de traçado-de-raios não foi capaz de encontrar o conjunto zero corretamente. Portanto, esses artefatos são produzidos pela falta de robustez do método, podendo gerar resultados fisicamente inválidos e instabilidades na solução, quando acoplado a algum mecanismo de solução numérica de simulação de escoamento de fluidos.

Assim, dado tal problema de robustez, isso certamente comprometerá a definição das interfaces em mecanismos de simulação numérica (solvers). Portanto, na seção seguinte, apresentamos uma solução estável e eficiente para lidar com tal questão, que denominaremos de superfícies RAMLS.

\subsection{Superfícies AMLS Robustas}

Guennebaud e Gross [97] propuseram um mecanismo que soluciona o problema das características afiadas da metodologia do AMLS, proposta previamente. Os autores apresentaram uma modificação do mecanismo de minimização descrito nas Seções 5.3.2 e 5.3.3, que detalhamos a seguir: 


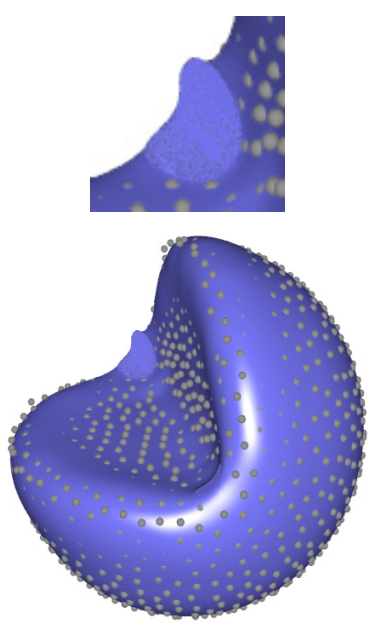

(a)

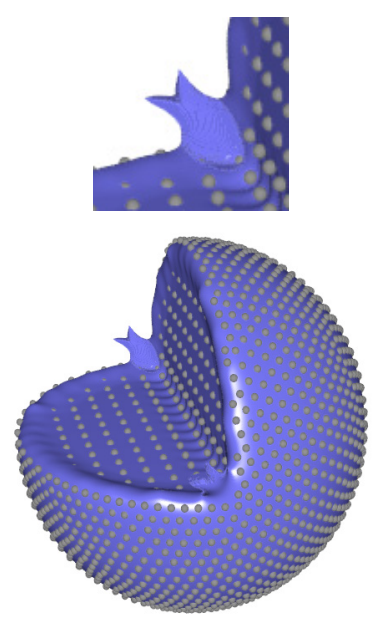

(b)

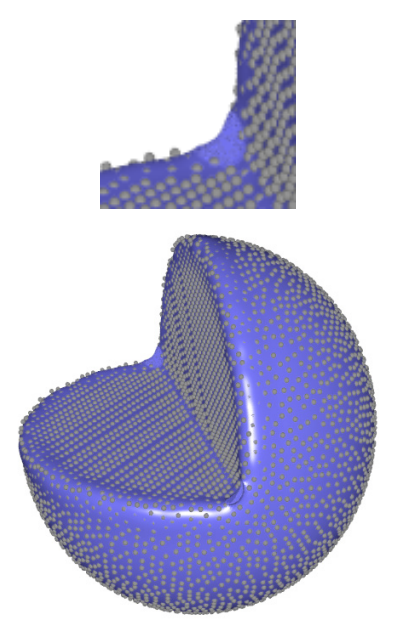

(c)

Figura 5.8: Aproximações do caso 3/4-esfera com a superfície AMLS baseada em conjuntos com (a) 1030, (b) 2031 e (c) 4748 pontos, respectivamente. Os artefatos no topo mostram que a função implícita falhou no momento de reconstruir, mesmo para conjuntos de dados refinados.

Passo A Para cada ponto $\mathbf{p}_{i} \in \mathscr{P}_{h}$, calcule o vetor normal pelo método AMLS: Note que essa etapa calcula $\alpha$ (pela Equação 5.14) apenas para os pontos $\mathbf{p}_{i}$ no conjunto $\mathscr{P}_{h}$. Os vetores normais $\mathbf{N}_{i}=\mathbf{n}_{\alpha}\left(\mathbf{p}_{i}\right) /\left\|\mathbf{n}_{\alpha}\left(\mathbf{p}_{i}\right)\right\|, i=1, \ldots, m$ são, então, obtidos a partir de (5.30) para o caso tridimensional e a partir de (5.25) para o caso bidimensional. O problema de orientação nessa abordagem é baseado em uma estrutura de propagação de orientação das normais em que se utilizam árvores BSP [97, 59].

Passo B Defina a função implícita $F(\mathbf{x})$ para $\mathbf{x} \in U$ : Para esse propósito, os coeficientes não são mais determinados pela minimização de $\tilde{J}$, definida em (5.5)-(5.6), entretanto o vetor de coeficientes $\alpha(\mathbf{x})$ é obtido por:

$$
\alpha(\mathbf{x})=\arg \min _{\beta \in \mathbb{R}^{N}} G(\beta)
$$

com

$$
G(\beta)=\sum_{i=1}^{m} \omega_{i}\left|F_{\beta}\left(\mathbf{p}_{i}\right)\right|^{2}+K \sum_{i=1}^{m}\left\|\mathbf{n}_{\beta}\left(\mathbf{p}_{i}\right)-\mathbf{N}_{i}\right\|^{2} \omega_{i}
$$


Tal esquema de minimização, que leva em conta também os vetores normais e um fator de penalidade, já foi aplicado em outros métodos de representação por nuvens de pontos $[147,158]$.

Quando comparada com a Formulação (5.5)-(5.6), observamos que a minimização presente em (5.32) é irrestrita. A condição $\left\|\nabla F_{\beta}\right\| \simeq 1$ em $\mathscr{S}_{\beta}$, que faz $F_{\beta}$ aproximar a função distância com sinal, é, de fato, forçada pelo segundo termo em $G(\beta)$ (Equação 5.33). Esse termo penaliza a diferença na distribuição dos vetores normais nos pontos calculados no Passo A do algoritmo. Como o segundo passo consiste simplesmente em uma minimização irrestrita, seu custo computacional é ditado pela solução de um sistema linear, que é um esforço menor que o problema de autovetor para uma matriz não-simétrica (5.14).

Como em qualquer método de penalidade, a escolha da constante $K$, da Equação 5.33, não é óbvia e pode afetar a precisão e a estabilidade numérica do método, requerendo a priori, métodos numéricos estáveis e, portanto, computacionalmente custosos para a solução do problema. Guennebaud e Gross propuseram o uso de $K=10^{6} h^{2}$, mas sem explicações significantes. Sugerimos aqui uma variante que é livre do parâmetro $K$. De fato, o que fizemos foi considerar a formulação acima no caso em que $K$ tende a infinito.

Uma observação primordial se deve ao fato de que o segundo termo em $G$ (Equação 5.33) não depende de $\alpha_{1}$ (devido às derivadas da minimização anularem $\alpha_{1}$ por ser o polinômio constante), então, quando $K$ é "muito grande", o primeiro termo de $G$ apenas tem "força" para determinar $\alpha_{1}$. Portanto, podemos dividir o problema de minimização em duas etapas, como mostraremos a seguir. Primeiro, vamos dividir o vetor de coeficientes em duas partes, separando o primeiro coeficiente dos demais:

$$
\beta \in \mathbb{R}^{N}, \quad \beta=\left(\beta_{1}, \hat{\beta}\right),
$$

em que $\hat{\beta}=\left(\beta_{2}, \ldots, \beta_{N}\right) \in \mathbb{R}^{N-1}$. Como o vetor normal em qualquer $\mathbf{x}$ definido por 5.30 também não depende de $\beta_{1}$, denotá-lo-emos por $\mathbf{n}_{\hat{\beta}}$.

A partir dessas definições, apresentamos o nosso método de superfície AMLS que calcula 
$\alpha(\mathbf{x})$ para um $\mathbf{x} \in U$ (usaremos o acrônimo RAMLS - Robust AMLS). Note que a nossa superfície implícita continuou sendo dada por:

$$
F(\mathbf{x})=\sum_{k=1}^{N} \alpha_{k}(\mathbf{x}) q_{k}(\mathbf{x})
$$

e, portanto, mantivemos a notação da função como $F(\mathbf{x})$, pois a única diferença entre o AMLS e RAMLS esteve na escolha dos coeficientes de $\alpha(\mathbf{x})$. Da mesma forma, a superfície RAMLS também continuou sendo denotada por $\mathscr{S}$ e também sendo definida pelo conjunto de nível zero de $F$.

\section{Reconstrução pelo método RAMLS:}

Passo A Para todo $\mathbf{p}_{i} \in \mathscr{P}_{h}$, calculam-se os vetores normais pelo método AMLS : Essa etapa é realizada pela determinação de $\alpha$ a partir de (5.14), mas apenas nos pontos $\mathbf{p}_{i}$. Então, os vetores $\mathbf{N}_{i}$ são obtidos a partir de (5.30), no caso 3D, e a partir de (5.25), para o caso 2D. Como em $\mathbf{p}_{i}$ assumimos que temos um vetor normal aproximado $\tilde{\mathbf{n}}_{i}$, a orientação $\mathbf{N}_{i}$ será a correta se o ângulo entre $\mathbf{N}_{i}$ e $\tilde{\mathbf{n}}_{i}$ for menor que $\pi / 2$, caso contrário invertemos a orientação de $\mathbf{N}_{i}$.

Passo B Definição da função implícita $F(\mathbf{x})$ para $\mathbf{x} \in U$ : O cálculo dos coeficientes $\alpha(\mathbf{x})$ é dividido em dois subpassos:

Subpasso B.1 Determine $\hat{\alpha}(\mathbf{x})$ como:

$$
\hat{\alpha}(\mathbf{x})=\arg \min _{\hat{\beta} \in \mathbb{R}^{N-1}} \sum_{i=1}^{m}\left\|\mathbf{n}_{\hat{\beta}}\left(\mathbf{p}_{i}\right)-\mathbf{N}_{i}\right\|^{2} \omega_{i},
$$

em que $\hat{\alpha}(\mathbf{x})$ é a solução do sistema linear:

$$
\mathbf{A} \hat{\alpha}=\mathbf{b}
$$

em que

$$
\begin{aligned}
\mathbf{A}_{k \ell} & =\sum_{i=1}^{m} \omega_{i} \nabla q_{k}\left(\mathbf{p}_{i}\right) \cdot \nabla q_{\ell}\left(\mathbf{p}_{i}\right) \\
b_{k} & =\sum_{i=1}^{m} \omega_{i} \nabla q_{k}\left(\mathbf{p}_{i}\right) \cdot \mathbf{N}_{i}
\end{aligned}
$$


Em particular, para o método baseado em esferas (base definida na Equação 5.2), denotando por $\left(x_{i}, y_{i}, z_{i}\right)$ as coordenadas de $\mathbf{p}_{i}$ e por $\left(N_{i x}, N_{i y}, N_{i z}\right)$ as coordenadas de $\mathbf{N}_{i}$, temos que:

$$
\mathbf{A}=\left(\begin{array}{cccc}
\sum_{i=1}^{m} \omega_{i} & 0 & 0 & 2 \sum_{i=1}^{m} \omega_{i} x_{i} \\
0 & \sum_{i=1}^{m} \omega_{i} & 0 & 2 \sum_{i=1}^{m} \omega_{i} y_{i} \\
0 & 0 & \sum_{i=1}^{m} \omega_{i} & 2 \sum_{i=1}^{m} \omega_{i} z_{i} \\
2 \sum_{i=1}^{m} \omega_{i} x_{i} & 2 \sum_{i=1}^{m} \omega_{i} y_{i} & 2 \sum_{i=1}^{m} \omega_{i} z_{i} & 4 \sum_{i=1}^{m} \omega_{i}\left\|\mathbf{p}_{i}\right\|^{2}
\end{array}\right)
$$

$\mathrm{e}$

$$
\mathbf{b}=\left(\begin{array}{c}
\sum_{i=1}^{m} \omega_{i} n_{i x} \\
\sum_{i=1}^{m} \omega_{i} n_{i y} \\
\sum_{i=1}^{m} \omega_{i} n_{i z} \\
2 \sum_{i=1}^{m} \omega_{i} \mathbf{p}_{i} \cdot \mathbf{N}_{i}
\end{array}\right)
$$

É importante destacarmos a simplicidade da estrutura da matriz A que permite ser resolvida facilmente por meio de fórmulas fechadas.

Subpasso B.2 Agora que temos definido o vetor $\hat{\alpha}(\mathbf{x})=\left(\alpha_{2}(\mathbf{x}), \ldots, \alpha_{N}(\mathbf{x})\right)$, obtemos $\alpha_{1}(\mathbf{x})$ pela minimização da equação:

$$
\sum_{i=1}^{m}\left|F_{\beta}\left(\mathbf{p}_{i}\right)\right|^{2} \omega_{i}
$$

sobre todos os $\beta$ tais que $\hat{\beta}=\hat{\alpha}(\mathbf{x})$. Dessa forma, a solução é simplesmente:

$$
\alpha_{1}(\mathbf{x})=-\frac{\sum_{i=1}^{m} \omega_{i}\left(\sum_{k=2}^{N} \alpha_{k}(\mathbf{x}) q_{k}\left(\mathbf{p}_{i}\right)\right)}{\sum_{i=1}^{m} \omega_{i}}
$$

Note que o numerador do lado direito de (5.41) é a soma $\sum_{i=1}^{m} \omega_{i} F_{\beta}\left(\mathbf{p}_{i}\right)$ considerando $\beta=\left(0, \alpha_{2}(\mathbf{x}), \ldots, \alpha_{N}(\mathbf{x})\right)$. Para o caso específico do método baseado em esferas, a equação acima se escreve como:

$$
\alpha_{1}(\mathbf{x})=-\frac{\sum_{i=1}^{m} \omega_{i}\left[\alpha_{2}(\mathbf{x}) x_{i}+\alpha_{3}(\mathbf{x}) y_{i}+\alpha_{4}(\mathbf{x}) z_{i}+\alpha_{5}(\mathbf{x})\left\|\mathbf{p}_{i}\right\|^{2}\right]}{\sum_{i=1}^{m} \omega_{i}}
$$


Em síntese, temos que a superfície $\mathscr{S}$, dada pelo método RAMLS, é dada pelo conjunto de nível-zero de $F(\mathbf{x}) \operatorname{com} F(\mathbf{x})=\sum_{k=1}^{N} \alpha_{k}(\mathbf{x}) q_{k}(\mathbf{x})$ no qual os coeficientes $\left\{\alpha_{k}(\mathbf{x})\right\}(k=1, \ldots, N)$ são determinados pelo algoritmo descrito anteriormente. Novamente, a continuidade de $F$ não é óbvia, assim, consideremos como uma conjectura que $\mathscr{S}$ é uma variedade.

Além disso, notemos que a solução da Equação 5.34, que determina os coeficientes $\alpha_{2}, \ldots, \alpha_{N}$, é baseada apenas na aproximação dos vetores normais e não na minimização de uma distância algébrica. Portanto, a pergunta que nos surge é se tal fato afetaria nas taxas de convergência do método. Por isso, novamente realizamos experimentos numéricos, que apresentaremos na próxima seção.

É importante mencionarmos que o custo computacional do RAMLS é significativamente menor que a técnica AMLS, apresentada por Guennebaud e Gross [97], mostrado na Seção 5.3. De fato, para definir a superfície, o número de pontos $\mathbf{x}$ no qual a função $F$ é avaliada (não esquecendo que cada avaliação de $F$ é uma construção dos coeficientes, pois é um método MLS) é muito maior que o número de pontos no conjunto $\mathscr{P}$. No método AMLS, um auto-sistema é necessário para cada $\mathbf{x}$, enquanto que no RAMLS, auto-sistemas são necessários apenas para a definição dos vetores normais em cada ponto e, portanto, o cálculo de $F$ em cada ponto envolve apenas um sistema linear (5.38) cuja solução é trivialmente imediata.

Observação 9 O problema da orientação, discutido na Seção 5.3 .4 é aliviado no método RAMLS. Enfatizamos que, para cada avaliação da função pelo AMLS, deve-se realizar um teste de orientação, ao passo que no RAMLS o problema da orientação é resolvido de forma natural, pois a minimização envolvida é diretamente baseada nos vetores normais.

\section{Precisão da Superfície RAMLS}

Para estudarmos a precisão do método RAMLS, aplicamos os mesmos testes da Seção 5.3.5: elipse, elipsóide e o 3/4-esfera. Os gráficos de convergência para a elipse e para o elipsóide são apresentados nas Figuras 5.9-(b) e 5.10-(b), respectivamente. Portanto, 


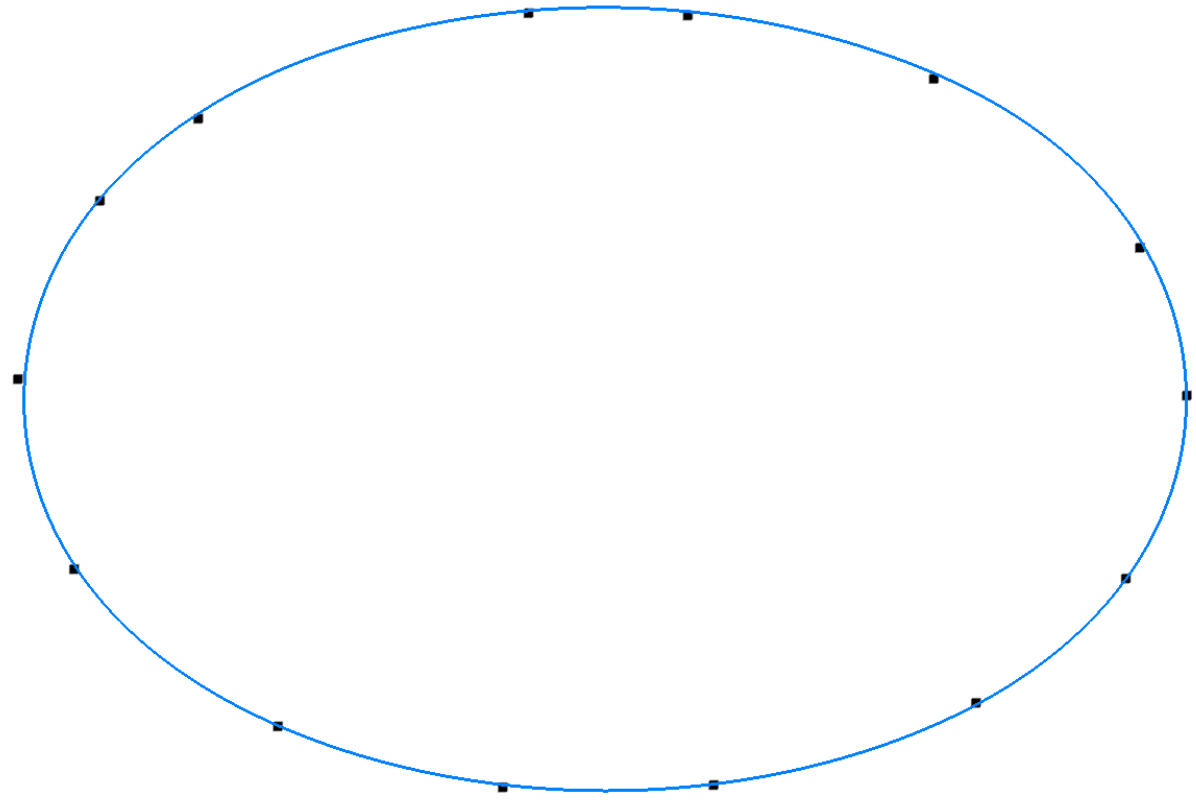

(a)

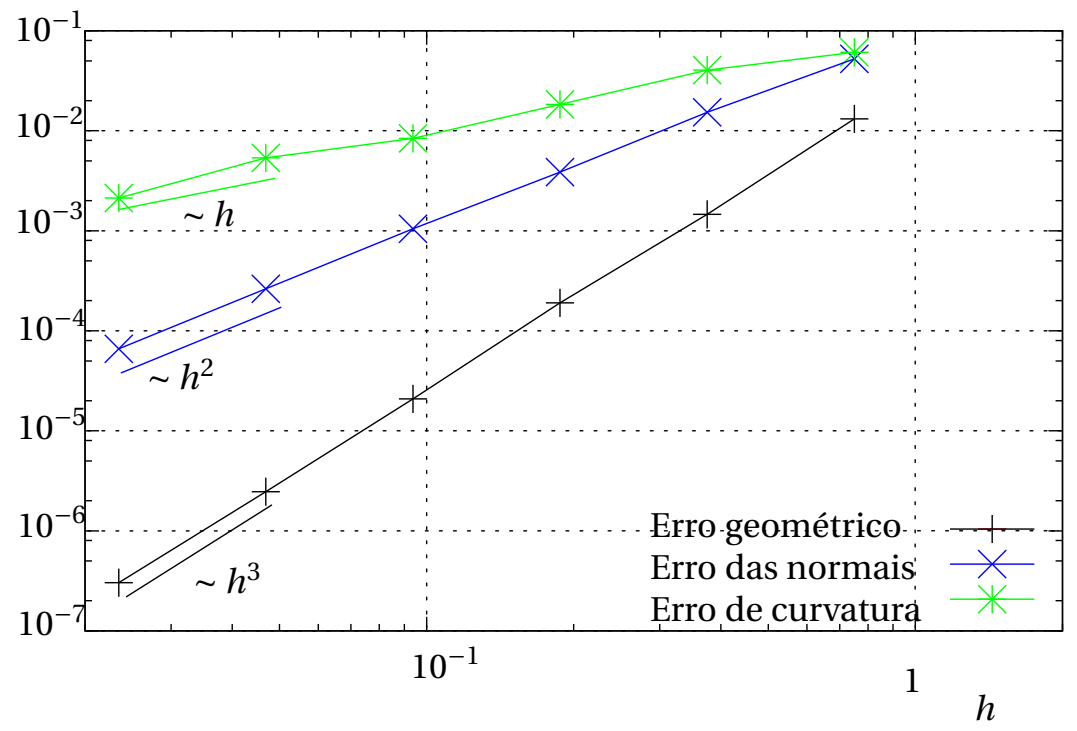

(b)

Figura 5.9: Aproximação da elipse pela curva RAMLS: (a) Conjunto de pontos $\mathscr{P}_{h}$ correspondente a $h=1.5$ junto com a curva resultante pelo RAMLS baseado em círculos; (b) Gráficos de convergência de $d\left(\Sigma, \mathscr{S}_{h}\right)$ (denotado por erro geométrico), $E_{N}\left(\Sigma, \mathscr{S}_{h}\right)$ (denotado por erro das normais), e $E_{C}\left(\Sigma, \mathscr{S}_{h}\right)$ (denotado por erro de curvatura). 
observamos que o comportamento do RAMLS é semelhante ao método AMLS, isto é, o erro geométrico se manteve com ordem $\mathscr{O}\left(h^{3}\right)$ para o caso bidimensional do RAMLS baseado em círculos, e também se manteve com ordem $\mathscr{O}\left(h^{2}\right)$ para o caso tridimensional do RAMLS baseado em esferas. Por outro lado, como buscávamos, o melhoramento na robustez foi significante, como mostrado na Figura 5.12 (compare com a Figura 5.8).

Para efeitos de análise qualitativa, na Figura 5.11, apresentamos como a curvatura aproximada pelo RAMLS se comporta para o elipsóide $(h=1 / 128)$.

Observação 10 Guennebaud e Gross [97] argumentam que a estimativa da curvatura pela inversão do raio da esfera calculada pela Equação 5.33 é razoável. Entretanto, mostramos que tal estimativa para ambos os AMLS e RAMLS (que é um caso particular da Equação 5.33 quando $K \rightarrow \infty$, proposta por Guennebaud e Gross [97]) converge apenas para o caso bidimensional.

Para finalizar, na Figura 5.13, apresentamos as soluções do RAMLS para o mesmo conjunto de dados presentes na Figura 5.2, no qual pudemos notar um comportamento menos oscilatório do RAMLS em relação ao AMLS.

\subsection{Acompanhamento de Fronteiras com RAMLS}

Até o momento, propusemos, descrevemos e analisamos os métodos AMLS e RAMLS no caso em que os pontos não se movem com o tempo. Nas seções seguintes, discorreremos o nosso algoritmo de acompanhamento de fronteiras com RAMLS, analisaremos e faremos comparações com trabalhos prévios.

\subsubsection{O Algoritmo}

Consideremos uma superfície inicial $\mathscr{S}(0) \subset \Omega$, em que $\Omega \subset \mathbb{R}^{3}$ é um domínio limitado. Também consideremos um campo de velocidades $\mathbf{v}(\mathbf{x}, t)$ de classe $\mathscr{C}^{1}$ para todo $\mathbf{x} \in \Omega$, e $t \in[0, T]$, em que $T$ é o tempo total de simulação. 


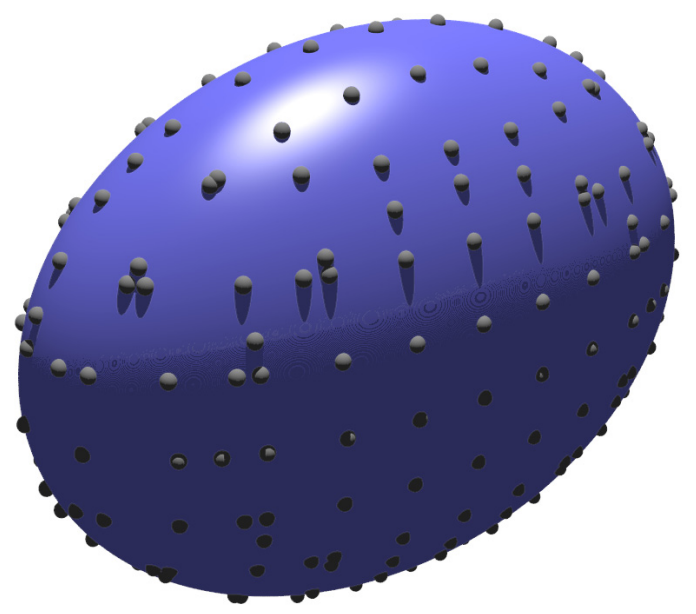

(a)

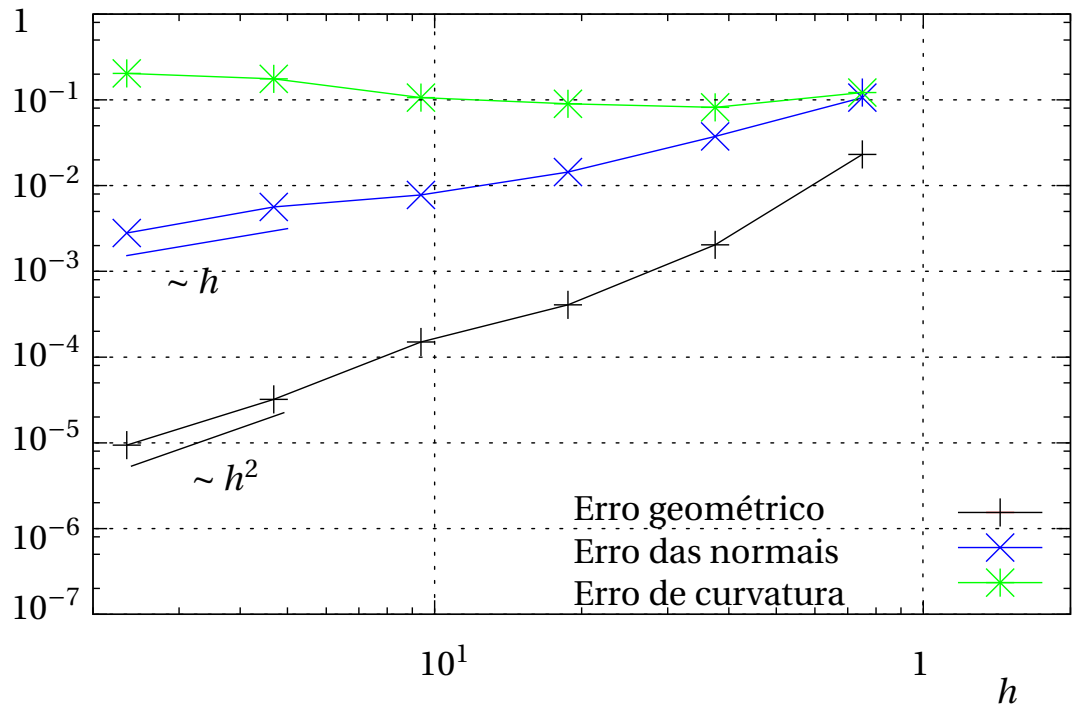

(b)

Figura 5.10: Aproximação do elipsóide 3D com a superfície RAMLS: (a) conjunto de pontos $\mathscr{P}_{h}$ correspondente a $h=0.75$, junto com a superfície RAMLS baseada em esferas; (b) gráficos de convergência de $d\left(\Sigma, \mathscr{S}_{h}\right)$ (denotado por erro geométrico), de $E_{N}\left(\Sigma, \mathscr{S}_{h}\right)$ (denotado por erro das normais), e de $E_{C}\left(\Sigma, \mathscr{S}_{h}\right)$ (denotado por erro de curvatura). 


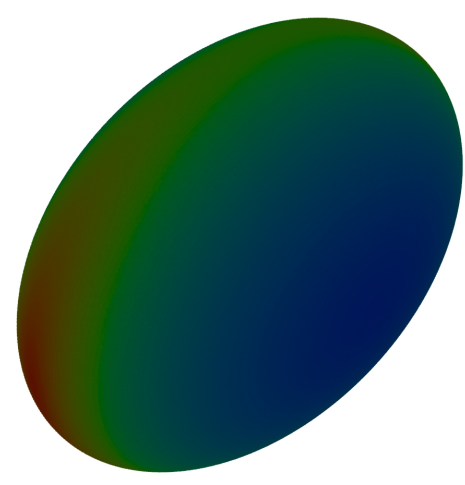

(a)

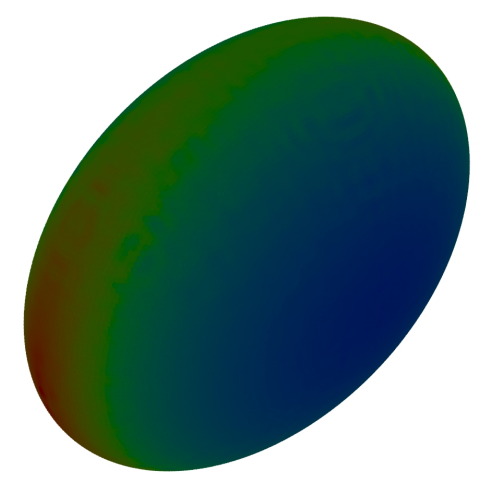

(b)

Figura 5.11: Exemplo do comportamento da curvatura exata (a) e dada pela aproximação por esferas (b) para o conjunto de pontos com $h=1 / 128$.

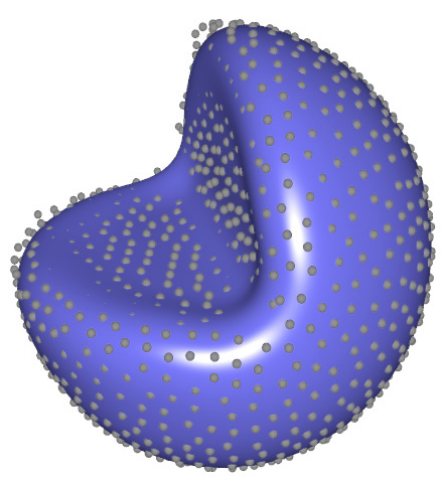

(a)

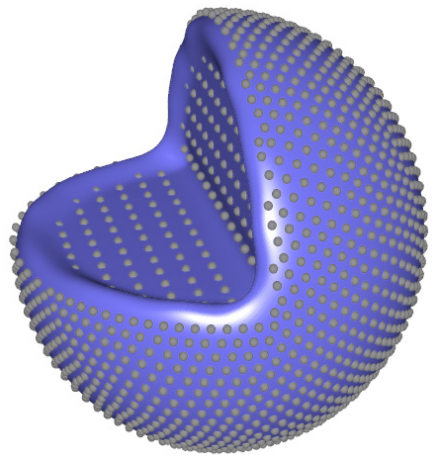

(b)

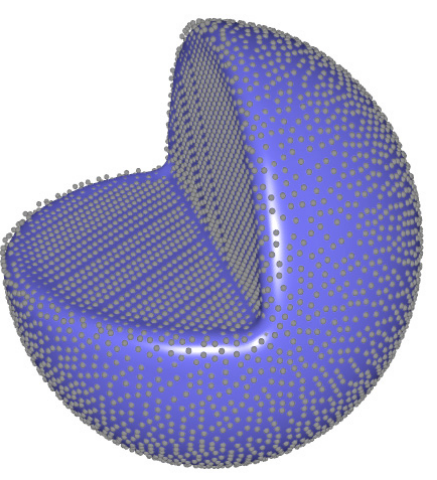

(c)

Figura 5.12: Aproximação do caso 3/4-esfera com a superfície RAMLS em conjuntos com (a) 1030, (b) 2031 e (c) 4748 pontos, respectivamente.

A trajetória Lagrangeana $\boldsymbol{\varphi}(\mathbf{x}, s, t)$ de uma partícula que está em $\mathbf{x}$ no tempo $s$ e se move com o campo de velocidade v é solução da equação diferencial:

$$
\frac{\partial \boldsymbol{\varphi}}{\partial t}(\mathbf{x}, s, t)=\mathbf{v}(\boldsymbol{\varphi}(\mathbf{x}, s, t), t) ; \quad \boldsymbol{\varphi}(\mathbf{x}, s, s)=\mathbf{x}
$$

Dessa forma, o problema a ser resolvido é a determinação da superfície $\mathscr{S}(t)$ definida por:

$$
\mathscr{S}(t)=\{\mathbf{y} \in \Omega, \mathbf{y}=\boldsymbol{\varphi}(\mathbf{x}, 0, t), \mathbf{x} \in \mathscr{S}(0)\}
$$




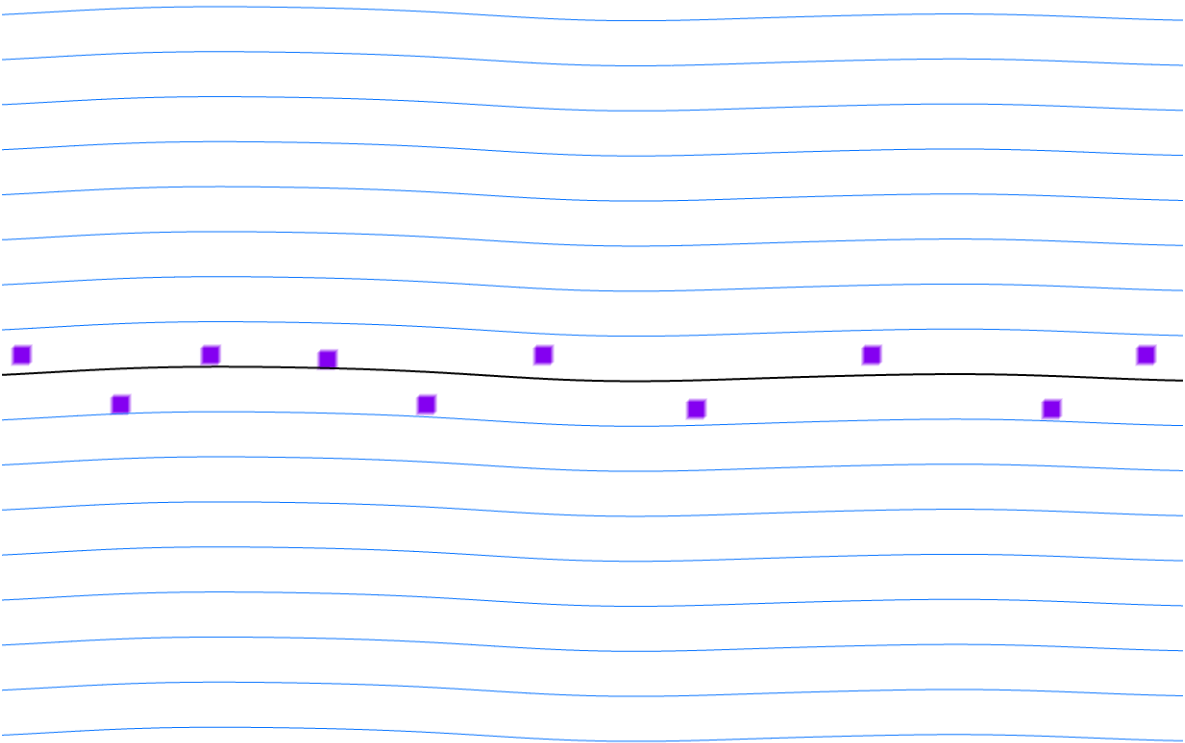

(a)

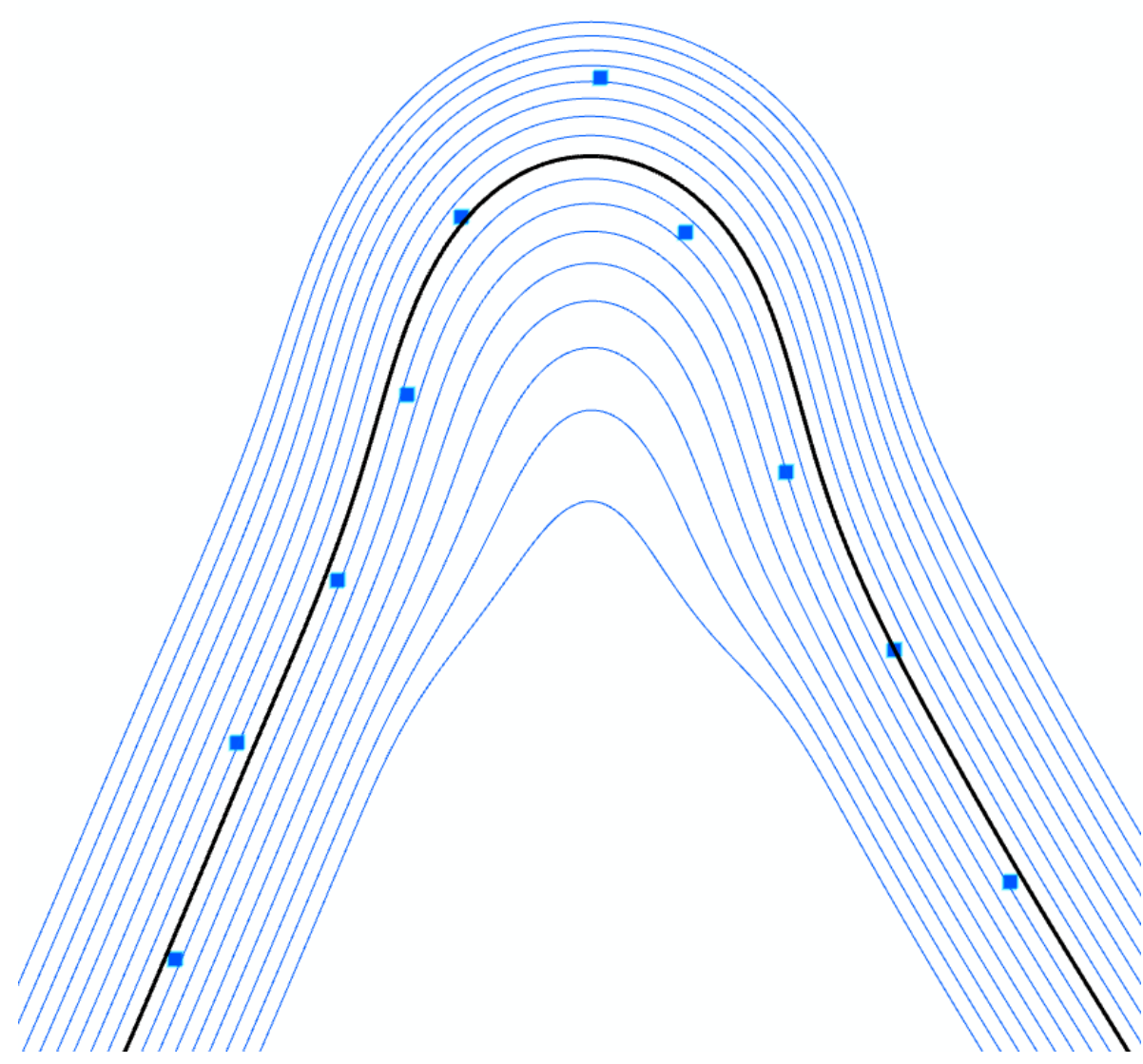

(b)

Figura 5.13: Reconstrução RAMLS de pontos perturbados a partir de (a), uma reta, e a partir de (b), uma quina: comparação com a Figura 5.2. 
Notemos que estamos assumindo que a superfície $\mathscr{S}(t) \subset \Omega$ durante todo o tempo $t \in[0, T]$ de simulação.

Para isso, definimos uma discretização do domínio $\Omega$ por meio de uma malha estruturada. Consideremos, então, uma malha cartesiana $\mathscr{T}_{h}$ com espaçamento uniforme $h$, embora pudéssemos naturalmente estender essa grade computacional para malhas nãouniformes, ou curvilineares. De fato, essa malha apenas define o conjunto $R_{h}$ de "raios" (pois nosso algoritmo é baseado no princípio de métodos de traçado-de-raios para superfícies MLS [3]):

$$
R_{h}=R_{1 h} \cup R_{2 h} \cup R_{3 h}
$$

onde construímos os conjuntos $R_{1 h}, R_{2 h}$ e $R_{3 h}$, alinhados com os eixos $x_{1^{-}}, x_{2^{-}}$, e $x_{3}$, respectivamente, por:

$$
\begin{array}{rlrl}
R_{1 h} & =\bigcup_{j, k \in \mathbb{Z}} r_{1 j k} ; & r_{1 j k}=\left\{\mathbf{x}=\left(x_{1}, x_{2}, x_{3}\right) \in \Omega, x_{2}=j h, x_{3}=k h\right\} \\
R_{2 h}=\bigcup_{i, k \in \mathbb{Z}} r_{2 i k} ; & r_{2 i k}=\left\{\mathbf{x}=\left(x_{1}, x_{2}, x_{3}\right) \in \Omega, x_{1}=i h, x_{3}=k h\right\} \\
R_{3 h}=\bigcup_{i, j \in \mathbb{Z}} r_{3 i j} ; & r_{3 i j}=\left\{\mathbf{x}=\left(x_{1}, x_{2}, x_{3}\right) \in \Omega, x_{1}=i h, x_{2}=j h\right\} .
\end{array}
$$

Assim, o conjunto de raios $R_{h}$ define o conjunto de pontos $\mathscr{Q}_{h}(0)$ pela interseção de $R_{h}$ $\operatorname{com} \mathscr{S}(0)$, isto é:

$$
\mathscr{Q}_{h}(0)=R_{h} \cap \mathscr{S}(0) .
$$

O conjunto de pontos $\mathscr{Q}_{h}(0)$ é, então, transportado no tempo de $t=0$ para $t=\Delta t$, em que $\Delta t$ é o passo no tempo da solução da Equação 5.43, que produz $\mathscr{P}_{h}(\Delta t)$ :

$$
\mathscr{P}_{h}(\Delta t)=\boldsymbol{\varphi}\left(\mathscr{Q}_{h}(0), 0, \Delta t\right)=\left\{\mathbf{y} \in \Omega, \mathbf{y}=\boldsymbol{\varphi}(\mathbf{x}, 0, \Delta t), \mathbf{x} \in \mathscr{Q}_{h}(0)\right\}
$$

em que a notação $\boldsymbol{\varphi}\left(\mathscr{Q}_{h}(s), s, s+\Delta t\right)$ representa o conjunto de pontos, obtido pelo transporte dos pontos em $\mathscr{Q}_{h}(s)$, pela trajetória induzida pelo campo de velocidades $\mathbf{v}$ do tempo $s$ para 
$s+\Delta t$

Observação 11 Voltando à discussão dos vetores normais, assumimos, nesse momento, que os vetores normais para todos os pontos $\mathbf{p}_{i} \in \mathscr{P}_{h}(\Delta t)$ são os mesmos calculados do passo anterior. Apesar de não serem precisos, são aqueles que utilizamos para estimar a orientação correta dos vetores, como discutido previamente. Portanto, para cada $\mathbf{p}_{i}$, os vetores normais são calculados por meio da superfície AMLS e as orientações corretas são obtidas pelo procedimento descrito no Passo A do Algoritmo de Representação por RAMLS.

O conjunto de pontos $\mathscr{P}_{h}(\Delta t)$ finalmente define a superfície atualizada $\mathscr{S}_{h}(\Delta t)$ por meio do método de RAMLS. Denotemos por $\mathbf{S}_{\mathrm{RAMLS}}$ o operador que associa ao conjunto de pontos a superfície RAMLS, reconstruída a partir dele:

$$
\mathscr{S}_{h}(\Delta t)=\mathbf{S}_{\mathrm{RAMLS}}\left(\mathscr{P}_{h}(\Delta t)\right)
$$

Nesse momento, a superfície atualizada está disponível e o procedimento é repetido para o outro passo no tempo. Logo, o algoritmo do método proposto é definido como:

Inicialização: Defina o conjunto de raios $R_{h}$, o passo no tempo $\Delta t$, e a superfície inicial $\mathscr{S}(0)$.

Passo 0: Determine o conjunto de pontos $\mathscr{Q}_{h}(0)=R_{h} \cap \mathscr{S}(0)$.

Passo 1: A partir de $\mathscr{Q}_{h}(t)$ conhecido, calcule as trajetórias de todos os pontos em $\mathscr{Q}_{h}(t)$ de $t$ para $t+\Delta t$ e então construa:

$$
\mathscr{P}_{h}(t+\Delta t)=\boldsymbol{\varphi}\left(\mathscr{Q}_{h}(t), t, t+\Delta t\right)
$$

Passo 2: Definida a superfície RAMLS $\mathscr{S}_{h}(t+\Delta t)$ associada ao conjunto de pontos $\mathscr{P}_{h}(t+\Delta t)$ (isto é, $\mathscr{S}_{h}(t+\Delta t)=\mathbf{S}_{\text {RAMLS }}\left(\mathscr{P}_{h}(t+\Delta t)\right)$ ), calcule $\mathscr{Q}_{h}(t+\Delta t)$ como a interseção de $R_{h}$ com $\mathscr{S}_{h}(t+\Delta t):$ 


$$
\mathscr{Q}_{h}(t+\Delta t)=R_{h} \cap \mathscr{S}_{h}(t+\Delta t) .
$$

Passo 3: Faça $t \leftarrow t+\Delta t$ e volte para o Passo 1 .

Portanto, um passo no tempo é sumarizado como $(i)$ o deslocamento de um conjunto de pontos não-organizados por meio das trajetórias, seguido pela ( $i$ i) interseção dos raios com a superfície definida pelos pontos transportados, a fim de gerar um novo conjunto de pontos.

A primeira dessas tarefas (Passo 1 no algoritmo) consiste em resolver a Equação Diferencial Ordinária 5.43 em relação ao tempo $t$, para o que utilizamos o esquema tradicional Runge-Kutta de quarta ordem [105]. A segunda tarefa (Passo 2), que é a essência do método proposto, não é freqüente em mecânica computacional, mas sim em computação gráfica.

Na próxima seção, descreveremos os principais detalhes do Passo 2, no qual fazemos uso dos mecanismos do método de traçado-de-raios para nuvem de pontos [3].

Ilustramos na Figura 5.14 um exemplo bidimensional do nosso algoritmo de acompanhamento de fronteiras com RAMLS.

\subsubsection{Interseção Raio-Superfície}

O esquema de interseção (Passo 2) que utilizamos, em linhas gerais, consiste em determinar um conjunto de pontos gerados pelas interseções de raios $R_{h}$ com a superfície $\mathscr{S}_{h}(t+\Delta t)$ definida pelas partículas transportadas $\mathscr{P}_{h}(t+\Delta t)$. Para tal tarefa, propusemos um método de traçado-de-raios, semelhante ao método de iluminação proposto por Adamson e Alexa [3]. No entanto, diferente do modelo físico que guia a trajetória de um raio, em nossa abordagem, a direção do raio manteve-se inalterada, pois precisamos determinar todas as interseções da superfície com o raio. Em termos da função implícita $F$, para cada raio $r \in R_{h}$, precisamos determinar todos os pontos $\mathbf{x} \in r$, tal que $F(\mathbf{x})=0$.

Existem dois aspectos que devemos destacar em relação ao algoritmo de interseção: primeiro, como em qualquer função MLS, $F$ é definida apenas em uma vizinhança $U$ de 


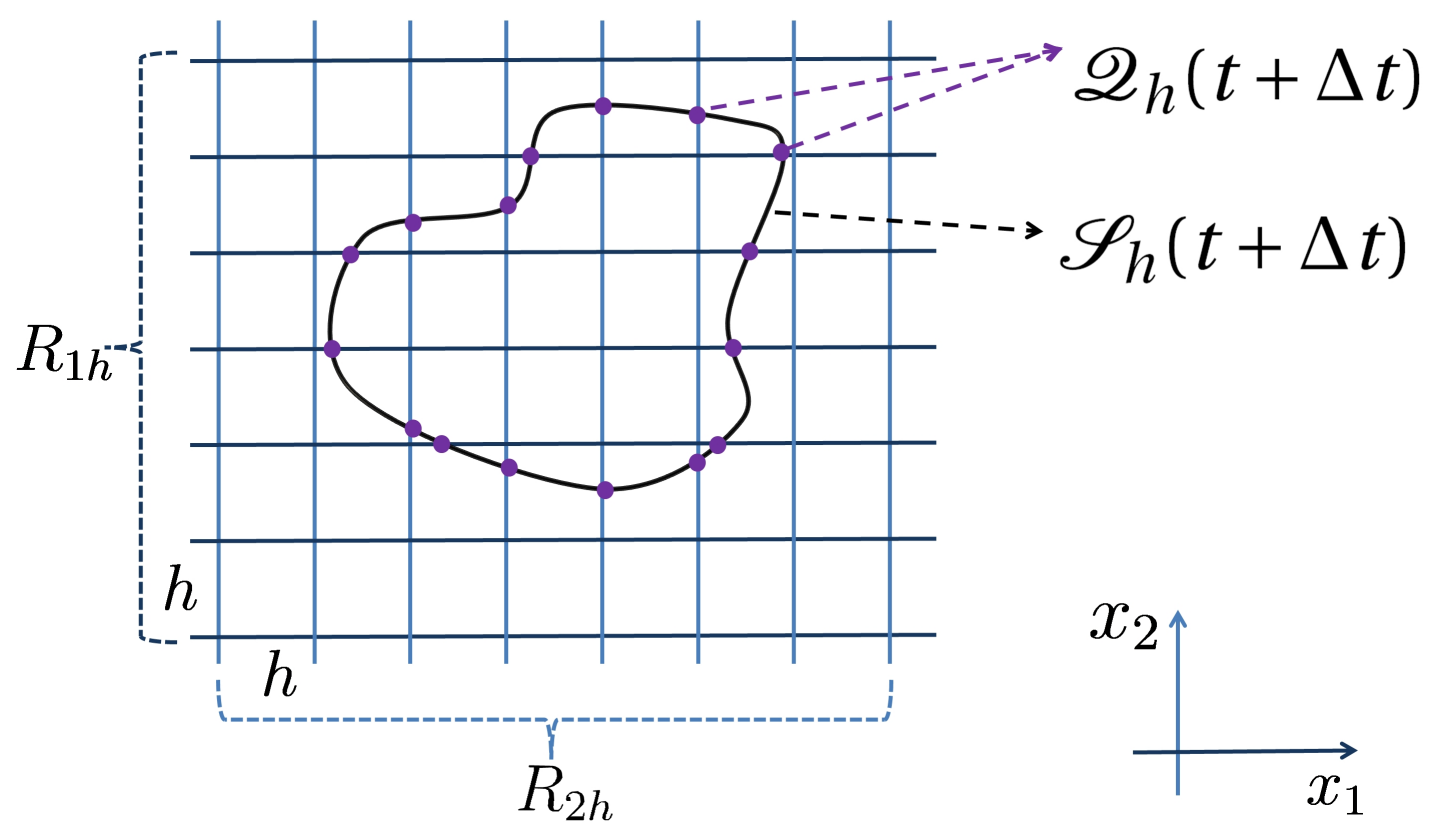

Figura 5.14: Conjunto de raios $\left(R_{1 h}, R_{2 h}\right)$ que quando intersectados com a superfície atualizada RAMLS $\mathscr{S}_{h}(t+\Delta t)$, definem o novo conjunto de pontos $\mathscr{Q}_{h}(t+\Delta t)$.

$\mathscr{S}_{h}(t+\Delta t$ ); segundo, o cálculo de $F$ em um ponto é custoso (cerca de 1000 operações de ponto flutuante (FLOPS) para a versão tridimensional).

Como no método de Adansom e Alexa [3], definimos, inicialmente, um conjunto $\mathscr{B}$ de esferas de raio $h$ ao redor dos pontos $\mathbf{p}_{i} \in \mathscr{P}_{h}(t+\Delta t)$, que ameniza as duas dificuldades anteriores: garante que a avaliação da função ocorra em $U$ e que a busca por um $\mathbf{x}$ tal que $F(\mathbf{x})=0$ se inicie próximo à superfície. Formalmente:

$$
\mathscr{B}=\left\{\mathbf{b}_{i}: \mathbf{x} \in \mathbf{b}_{i} \Rightarrow\left\|\mathbf{x}-\mathbf{p}_{i}\right\| \leq h, \mathbf{p}_{i} \in \mathscr{P}_{h}(t+\Delta t), i \in 1, \cdots, m\right\} .
$$

Também definimos $V$ como sendo a união dessas bolas $\left(V=\bigcup_{i=1}^{m} \mathbf{b}_{i}\right)$.

É importante evidenciarmos que, para cada ponto $\mathbf{q} \in \mathscr{Q}_{h}(t)$, sempre garantimos a existência de outro ponto $\mathbf{p} \in \mathscr{Q}_{h}(t)$ tal que $\|\mathbf{q}-\mathbf{p}\|<\sqrt{3} h$ (em que $\sqrt{3}$ é a diagonal de cada cubo da grade computacional, definido por 12 raios). Então, para $\Delta t$, suficientemente pequeno, assumimos que os pontos da superfície transportada estarão contidos completamente na união das bolas, isto é: $\mathscr{S}_{h}(t+\Delta t) \subset V \subset U$.

A seguir, apresentaremos o algoritmo para execução do Passo 2 do algoritmo previa- 
mente descrito (Página 158):

\section{Passo 2:}

2.0: Pré-processamento: Para cada $\mathbf{p}_{i} \in \mathscr{P}_{h}(t+\Delta t)$, calcule o vetor normal $\mathbf{N}_{i}$, como descrito no Passo A do algoritmo de Reconstrução RAMLS.

2.1: Para cada raio $r \in R_{h}$

2.1.1: Encontre o conjunto de esferas $\mathscr{W} \subset \mathscr{B}$, satisfazendo $\mathbf{b}_{i} \cap r \neq \varnothing$

2.1.2: Para cada $\mathbf{b}_{i} \in \mathbb{W}$,

2.1.2.1: Calcule os dois pontos de interseção $\mathbf{p}_{\text {in }}$ e $\mathbf{p}_{\text {out }}$ entre $r$ e $\mathbf{b}_{i}$. Avalie $F$ em $\mathbf{p}_{\text {in }}$ e $\mathbf{p}_{\text {out }}$, definindo $F\left(\mathbf{p}_{\text {in }}\right)$ e $F\left(\mathbf{p}_{\text {out }}\right)$, utilizando o algoritmo de reconstrução RAMLS;

2.1.2.2: Se $F\left(\mathbf{p}_{\text {in }}\right) F\left(\mathbf{p}_{\text {out }}\right)<0$, encontre pelo método regula-falsi $\left.s^{*} \in\right] 0,1[$ tal que $F\left(\mathbf{p}_{\text {in }}+s^{*}\left(\mathbf{p}_{\text {out }}-\mathbf{p}_{\text {in }}\right)\right)=0$.

2.1.2.3: Adicione $\mathbf{p}=\mathbf{p}_{\text {in }}+s^{*}\left(\mathbf{p}_{\text {out }}-\mathbf{p}_{\text {in }}\right)$ a $\mathscr{Q}_{h}(t+\Delta t)$, se não foi previamente adicionado por uma outra bola $\mathbf{b}_{i}$.

2.2: Remova pontos de $\mathscr{Q}_{h}(t+\Delta t)$, de forma que dois pontos não estejam a uma distância inferior a $\frac{h}{2}$.

Uma questão importante, que define a qualidade das superfícies MLS, é a distribuição de pontos. O Passo 2.1.2.3 evita a possibilidade de que vários pontos sejam gerados como o mesmo ponto de interseção (ver Figura 5.15). Evitamos tal fato, verificando se, na esfera $\mathbf{b}_{i}$ que estamos processando, existe um ponto definido em seu interior, que é a interserção entre um raio $r_{i}$ e uma esfera $\mathbf{b}_{j}$ previamente processada. Nesse caso, simplesmente não executamos o algoritmo de regula-falsi e processamos a próxima esfera.

O procedimento previamente descrito, aliado ao Passo 2.1.2.2, permite gerar apenas um ponto por esfera por raio. Dessa forma, se dentro da uma esfera existirem duas regiões da superfície a uma distância menor que $h$, a interseção não será calculada e parte da superfície será automaticamente removida. 


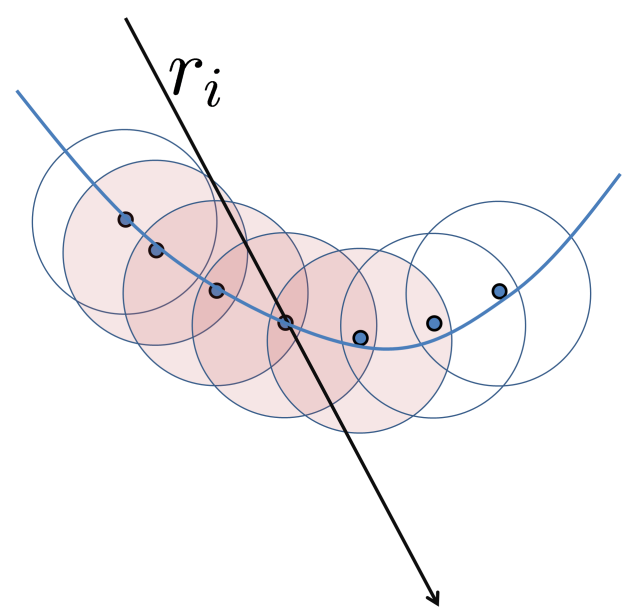

(a)

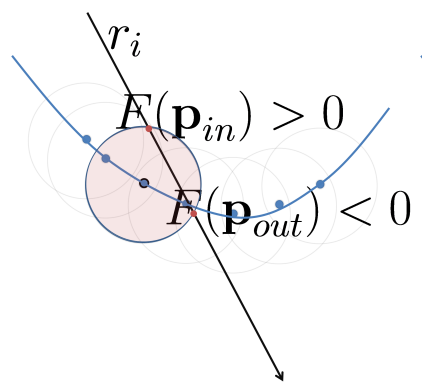

(c)

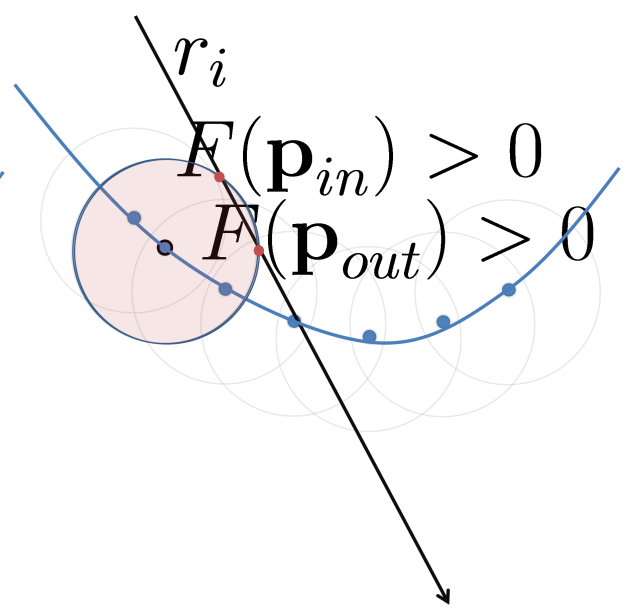

(b)

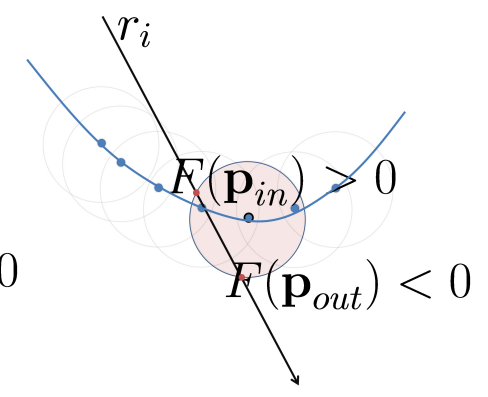

(e)

Figura 5.15: Interseções raio-esferas: observemos que três interseções produzem o mesmo zero sobre a superfície. Nesse caso, consideramos apenas a busca pelo zero da função na primeira esfera.

A última situação que pode gerar pontos próximos ou duplicados acontece pelo fato de que dois ou três raios (cada um em uma direção) podem gerar pontos muito próximos. No Passo 2.2 removemos esses pontos de $\mathscr{Q}_{h}(t+\Delta t)$ para evitar tal situação (Figura 5.16). Para finalizar, note que o Passo 2.1 pode ser implementado em paralelo, pois cada raio é independente, implicando a escalabilidade do método.

\subsection{Resultados Numéricos}




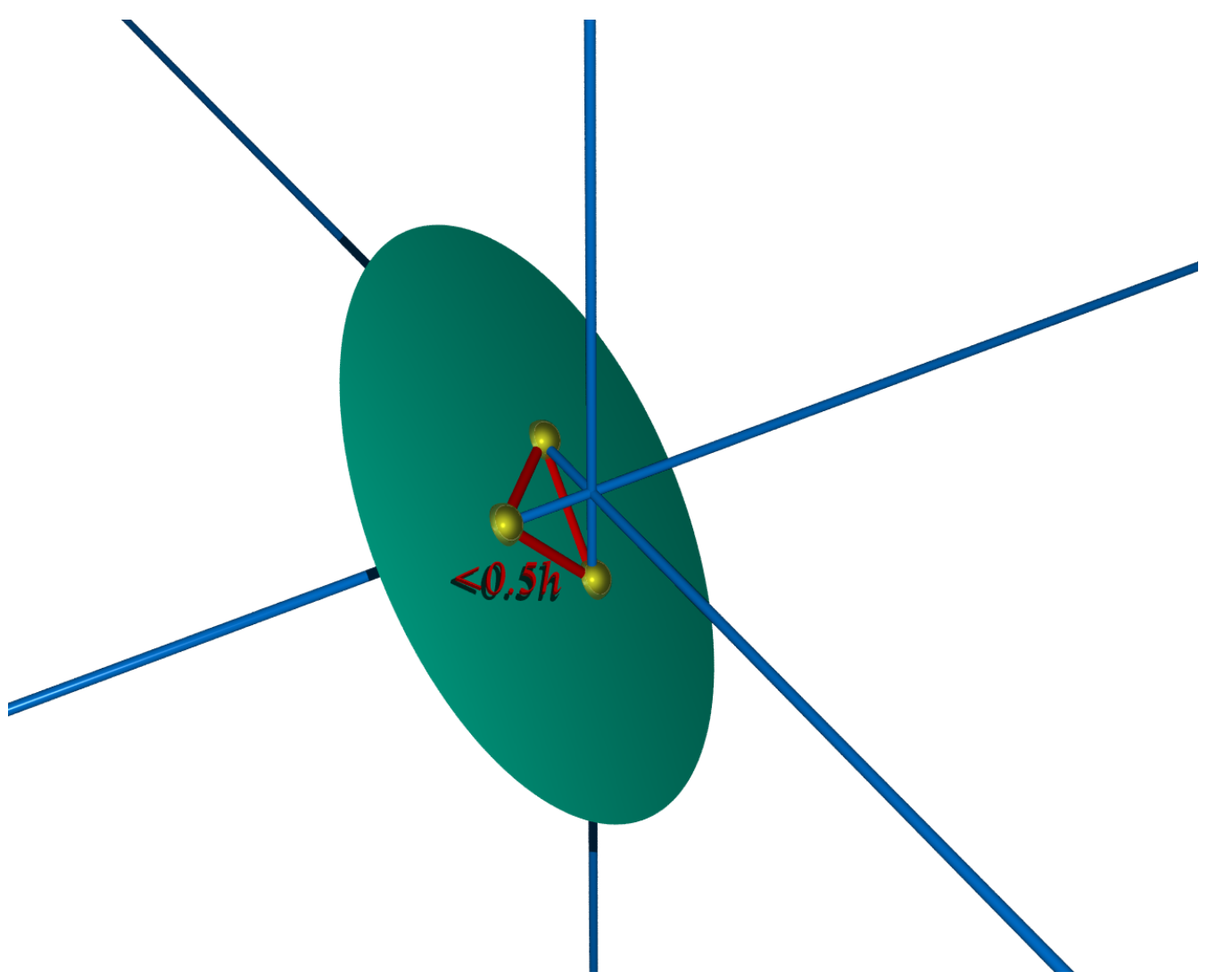

Figura 5.16: Pontos muito próximos: quando pontos (amarelo) são gerados por interseções de raios (verde) com a superfície a uma distância menor $0.5 h$, consideramos apenas um deles.

\subsubsection{Teste de Convergência}

Nesta seção, analisaremos o erro do nosso método de acompanhamento de fronteira em termos do erro da reconstrução RAMLS, presente na Seção 5.4. Iniciemos considerando a desigualdade triangular:

$$
\begin{aligned}
d\left(\mathscr{S}(t+\Delta t), \mathscr{S}_{h}(t+\Delta t)\right)= & d\left(\varphi(\mathscr{S}(t)), \mathbf{S}_{\mathrm{RAMLS}}\left(\mathscr{P}_{h}(t+\Delta t)\right)\right) \\
= & d\left(\mathbf{S}_{\mathrm{RAMLS}}\left(\varphi\left(\mathscr{Q}_{h}(t)\right)\right), \varphi(\mathscr{S}(t))\right) \\
\leq & d\left(\mathbf{S}_{\mathrm{RAMLS}}\left(\varphi\left(\mathscr{Q}_{h}(t)\right)\right), \varphi\left(\mathscr{S}_{h}(t)\right)\right)+ \\
& +d\left(\varphi\left(\mathscr{S}_{h}(t)\right), \varphi(\mathscr{S}(t))\right),
\end{aligned}
$$

em que, para simplificar, omitimos os últimos dois $\operatorname{argumentos}$ em $\varphi$, que tomamos iguais a 
$t$ e $t+\Delta t$, respectivamente, isto é, $\varphi(\cdot)=\varphi(\cdot, t, t+\Delta t)$.

Agora, notemos que o primeiro termo do lado direito da desigualdade é o erro da reconstrução da superfície $\varphi\left(\mathscr{S}_{h}(t)\right)$, porque os pontos em $\mathscr{Q}_{h}(t)$ pertencem a $\mathscr{S}_{h}(t)$ (de fato, $\mathscr{Q}_{h}(t)=R_{h} \cap \mathscr{S}_{h}(t)$ e a operação de transporte, nesse momento, é considerada exata). Se o passo no tempo é pequeno suficiente, a continuidade de $\varphi$ implica que $\varphi\left(\mathscr{Q}_{h}(t)\right)$ é a nuvem de pontos amostrada em $\varphi\left(\mathscr{S}_{h}(t)\right)$ com espaçamento médio $\simeq h$, tal que:

$$
d\left(\mathbf{S}_{\mathrm{RAMLS}}\left(\varphi\left(\mathscr{Q}_{h}(t)\right)\right), \varphi\left(\mathscr{S}_{h}(t)\right)\right) \leq C_{1} h^{r}
$$

em que $r$ é a taxa de convergência estudada nas seções anteriores. De forma análoga, temos que o segundo termo da desigualdade representa a distância entre a superfície aproximada $\mathscr{S}_{h}(t)$ e a superfície exata $\mathscr{S}(t)$, ambas transportadas, e dessa forma:

$$
d\left(\varphi\left(\mathscr{S}_{h}(t)\right), \varphi(\mathscr{S}(t))\right) \leq\left(1+C_{2} \Delta t\right) d\left(\mathscr{S}_{h}(t), \mathscr{S}(t)\right)
$$

em que $C_{2}$ depende do campo de velocidades, mas não de $h$ e de $\Delta t$. Assim, temos que:

$$
d\left(\mathscr{S}(t+\Delta t), \mathscr{S}_{h}(t+\Delta t)\right) \leq C_{1} h^{r}+\left(1+C_{2} \Delta t\right) d\left(\mathscr{S}(t), \mathscr{S}_{h}(t)\right)
$$

portanto:

$$
d\left(\mathscr{S}(t), \mathscr{S}_{h}(t)\right) \leq C_{3} \frac{h^{r}}{\Delta t}+e^{C_{2} t} d\left(\mathscr{S}(0), \mathscr{S}_{h}(0)\right),
$$

implicando que o erro geométrico é dado por $\mathscr{O}\left(h^{r} / \Delta t\right)$, que é típico dos métodos semiLagrangeanos. Se nas análises anteriores também levarmos em consideração o erro no cálculo das trajetórias, o erro total será:

$$
\mathscr{O}\left(h^{r} / \Delta t\right)+\mathscr{O}\left(\Delta t^{s}\right)
$$

em que $s$ é a ordem da integração do tempo para a Equação 5.43. Na Tabela 5.1, apresentamos o erro do método proposto para várias grades computacionais e passos no tempo. Consideramos, nesse caso, o problema de uma rotação rígida completa (rotação de $2 \pi$ ) de 
um elipsóide (o mesmo que utilizamos anteriormente) em torno do eixo $x_{3}$, com velocidade angular igual a $2 \pi$, isto é, uma unidade de tempo para dar uma volta completa.

Tabela 5.1: Erro na rotação de corpo rígido do elipsóide em torno do eixo $x_{3}$ - uma volta completa.

\begin{tabular}{lccc}
\hline & $h=\frac{12}{32}$ & $h=\frac{12}{64}$ & $h=\frac{12}{128}$ \\
\hline$\Delta t=\frac{1}{16}$ & 0.06261 & 0.00494 & 0.00065 \\
$\Delta t=\frac{1}{64}$ & 0.14635 & 0.01007 & 0.00246 \\
$\Delta t=\frac{1}{256}$ & 0.34056 & 0.02561 & 0.00756 \\
$\Delta t=\frac{1}{1024}$ & 0.76286 & 0.07314 & 0.02352 \\
$\Delta t=\frac{1}{4096}$ & 1.00345 & 0.16459 & 0.06322 \\
\hline
\end{tabular}

\subsubsection{Disco e Esfera de Zalesak}

Dois testes bem documentados para transporte de interfaces consistem na rotação de corpo rígido de um disco com uma fenda retangular, para o caso bidimensional (Figura 5.18-(a)) ou uma esfera com uma fenda em forma de um paralelepípedo (Figura 5.19-(a)), denominados por disco de Zalesak e esfera de Zalesak, respectivamente.

Para o caso bidimensional, o centro do disco está em $(0.5,0.75)$, com raio igual a 0.15 e uma fenda de largura 0.05 e comprimento 0.25 (Figura 5.18-(a)). O campo de velocidades é dado por:

$$
\mathbf{v}\left(x_{1}, x_{2}\right)=\frac{\pi}{314}\left(0.5-x_{2}, x_{1}-0.5\right)
$$

de forma que uma completa revolução leve 628 unidades de tempo. O passo no tempo é de $\Delta t=1$ e testamos o método para diferentes valores de $h$, como apresentado na Figura 5.18. É importante enfatizarmos que, para uma grade computacional com $h=512$, o método numérico não calcula $512^{2}=262144$ valores para cada vértice da grade computacional em cada passo do tempo. Porém, a técnica calcula as interseções de $2 \times 512=1024$ raios com a superfície RAMLS. A precisão desse cálculo é notada na Figura 5.18-(e) que, em média, para cada passo de tempo, possuía 700 partículas, cujo resultado é equivalente ao método PLS [72] (Figura 5.17-(b)), que foi simulado em uma grade $100 \times 100$, com cerca de 12864 
partículas (estimativa dada por Hieber e Koumoutsakos [104], a partir da sugestão de Enright et al de distribuir 16 partículas para cada célula próxima ao contorno no caso 2D, Figura $5.17-(a))$

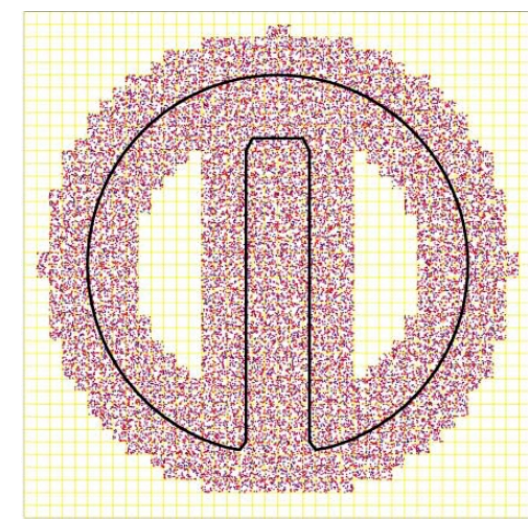

(a)

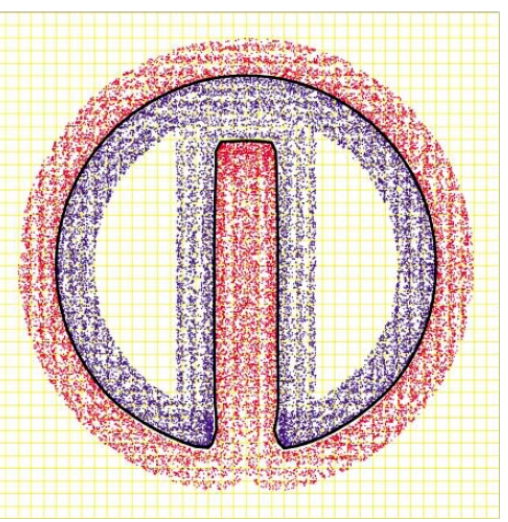

(b)

Figura 5.17: Resultados do método PLS [72]: em (a), temos a distribuição de pontos próximos ao contorno, e em (b), a solução obtida (em preto) após uma volta completa.

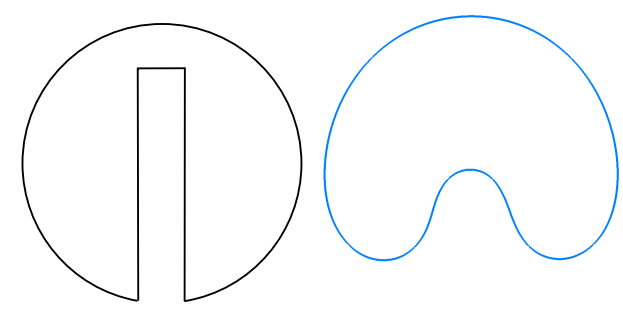

(a)

(b)

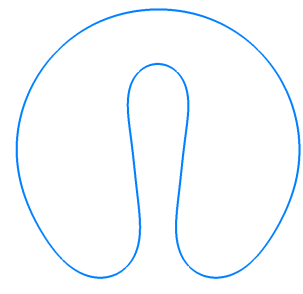

(c)

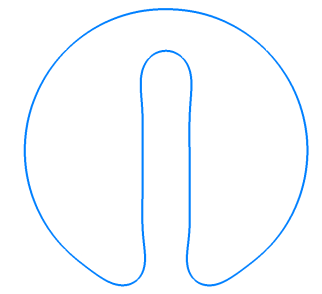

(d)

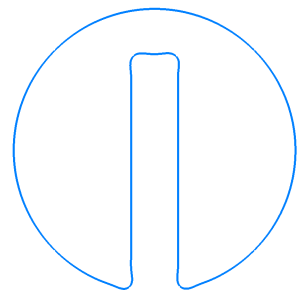

(e)

Figura 5.18: Rotação do disco de Zalesak: resultados após uma volta: (a) modelo original, (b) $\mathrm{h}=1 / 64$, (c) $h=1 / 128$, (d) $h=1 / 256$, e (e) $h=1 / 512$.

$\mathrm{Na}$ Tabela 5.2, apresentamos os resultados quantitativos de uma e de duas voltas completas do disco de Zalesak. Em comparação com outros métodos, o nosso método de acompanhamento de fronteiras também foi capaz de preservar bem a área. Por exemplo, 
considerando uma volta do trabalho de Enright et al. [72] na grade computacional Euleriana $100 \times 100$, o erro da área foi $0.31 \%$. Já no trabalho de Hieber e Koumoutsakos [104], o erro foi $0.30 \%$.

Tabela 5.2: Disco de Zalesak: Método RAMLS.

\begin{tabular}{cccccc}
\hline & $h$ & Área & \% Perda de área & Erro máximo (Hausdorff) & Ordem \\
\hline \multirow{3}{*}{ Uma volta } & Exata & 0.05821 & - & - & - \\
& $1 / 64$ & 0.05880 & -1.00272 & 0.03485 & N/A \\
& $1 / 128$ & 0.05810 & 0.19839 & 0.01409 & 1.30 \\
& $1 / 256$ & 0.05812 & 0.16307 & 0.00628 & 1.16 \\
& $1 / 512$ & 0.05811 & 0.17118 & 0.00335 & 0.90 \\
Duas voltas & $1 / 64$ & 0.05859 & -0.64552 & 0.04470 & N/A \\
& $1 / 128$ & 0.05813 & 0.133343 & 0.02052 & 1.12 \\
& $1 / 256$ & 0.05812 & 0.166363 & 0.00833 & 1.29 \\
& $1 / 512$ & 0.05812 & 0.156388 & 0.00415 & 1.00 \\
\hline
\end{tabular}

Para realizarmos o teste para o caso tridimensional - esfera de Zalesak - definimos uma esfera de raio 0.15 , centrada inicialmente em $(0.5,0.75,0.75)$, em um domínio unitário, com uma fenda de largura 0.10 e comprimento 0.20 . A rotação é dada pelo campo de velocidades:

$$
\mathbf{v}\left(x_{1}, x_{2}, x_{3}\right)=\frac{\pi}{314}\left(0.5-x_{2}, x_{1}-0.5,0\right) .
$$

O passo no tempo novamente foi tomado como $\Delta t=1$ e para uma volta completa foram necessários 628 passos. Apresentamos a geometria do modelo nos tempos $t=0,79,157,236$, 314, 393, 471, 550 e 628 na Figura 5.19. Para esse teste, adotamos uma malha com $h=1 / 256$, e o número de partículas para essa simulação foi em média 19000 para cada passo de tempo. Podemos observar que as características afiadas se tornaram suaves com o tempo, contudo a forma e o volume se mantiveram preservados.

Observação 12 Nesses testes, o método de acompanhamento de fronteiras baseado em RAMLS re-gerou um novo conjunto de partículas para cada passo no tempo. Isso é certamente desnecessário no caso da rotação rígida, pois a distância entre as partículas se mantém preservada. Se as partículas fossem simplesmente advectadas, como no método Lagrangeano de Hieber e Koumoutsakos [104], a forma final coincidiria com a solução inicial. 


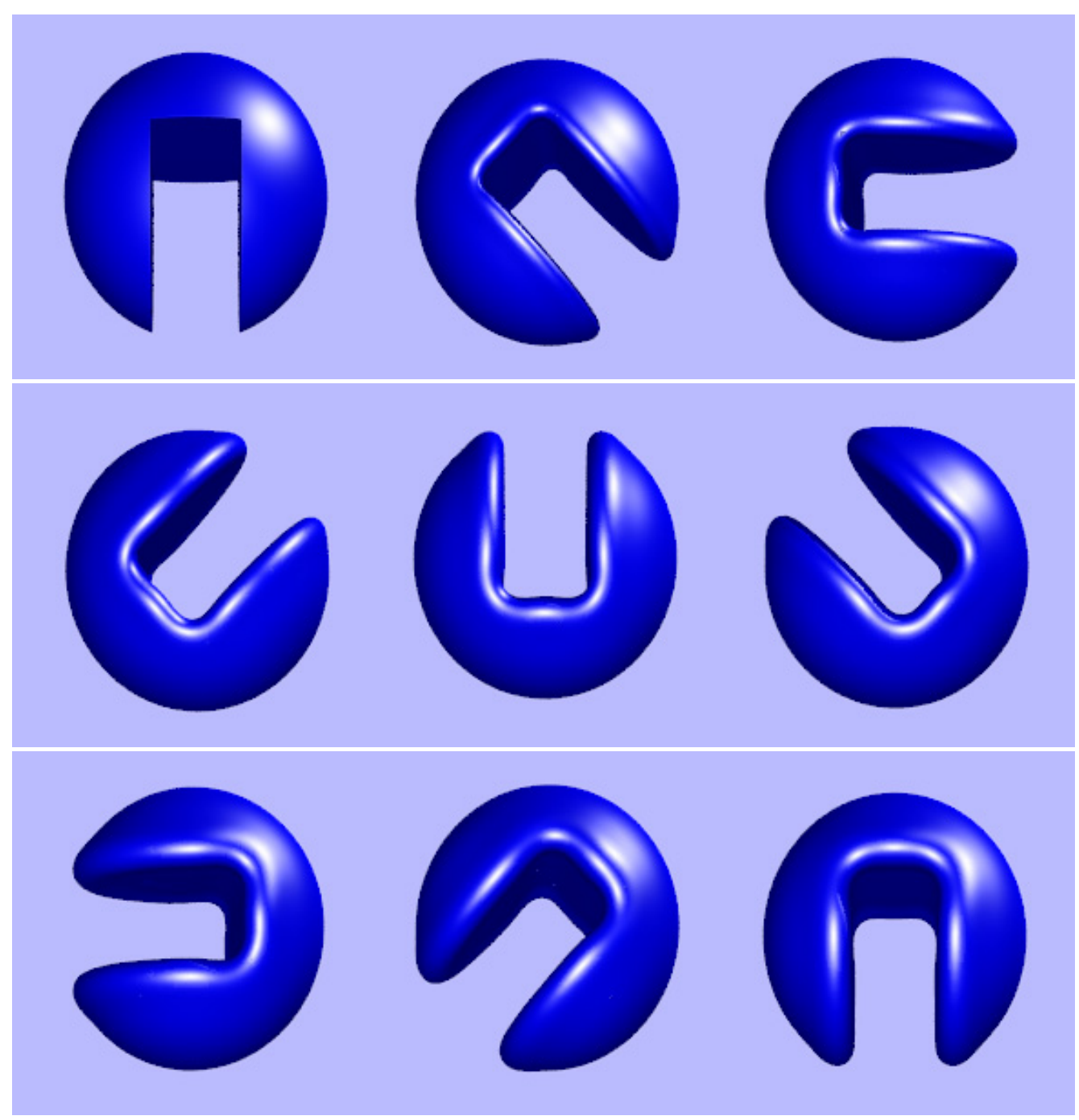

Figura 5.19: Rotação da esfera de Zalesak com $h=1 / 256$ (19000 pontos em média) e nos passos de tempo $t=0,79,157,236,314,393,471,550$ e 628 unidades de tempo (da esquerda para a direita e de cima para baixo).

\subsubsection{Escoamento em um Unico Vórtice}

Nosso próximo caso-teste constitui em medir a capacidade do método em preservar massa, geometria e topologia sujeito a severas deformações da interface. Esse teste é denominado escoamento em um único vórtice [25] (teste conhecido na literatura como single vortex flow). A geometria inicial consiste de um círculo, centrado em $(0.5,0.75)$, com raio igual a 0.15 , em um domínio quadrado unitário. O campo de velocidades é dado por: 


$$
\mathbf{v}\left(x_{1}, x_{2}\right)=2\left(-\operatorname{sen}^{2}\left(\pi x_{1}\right) \operatorname{sen}\left(\pi x_{2}\right),-\operatorname{sen}^{2}\left(\pi x_{2}\right) \operatorname{sen}\left(\pi x_{1}\right)\right) .
$$

Tomamos $\Delta t=0.01, h$ igual a 1/256 e 1/512 e consideramos os tempos de simulação de $t=1$, 3 e 5 unidades de tempo. Os estados iniciais contiveram 233 e 469 partículas, respectivamente. Esse último número foi mais favorável que as 4000 partículas usadas pelo método LSL [104] e que as 59000 partículas utilizadas pelo método PLS [72], ambos para uma grade computacional com espaçamento 1/256.

Podemos observar na Figura 5.20 que os resultados do RAMLS (curvas em azul) ficaram muito próximos da solução exata (curvas pretas), mesmo quando a curva é muito fina. Esses resultados são comparáveis aos métodos mais eficientes apresentados na literatura. Note, entretanto, que quando a solução exata é muito fina, o método tende a eliminar as regiões com espaçamento menor que $h$. Para efeito de comparação, se utilizássemos retas ao invés de círculos, na "cauda da interface" ocorreriam indeterminações no sinal da função, e portanto, a solução seria comprometida (Figura 5.21). Esse problema é inerente a qualquer superfície MLS baseada em retas [119, 16, 3], presente na literatura.

Na Figura 5.22, apresentamos resultados do método LSL [104] em (a) e do método PLS [72] em (b). Ambos os resultados foram simulados em uma grade computacional com espaçamento 1/128. No entanto, o número inicial de partículas para cada simulação foi 1160 para o LSL e 15040 para o PLS. Além disso, para o LSL, no tempo $t=3$, exemplo apresentado na mesma figura, o número de partículas foi de 55914.

Também simulamos o problema do vórtice com campo de velocidade modulado no tempo por $\cos (\pi t / T)$, para que, quando o tempo atingisse $t=T / 2$, o campo de velocidade se revertesse de forma que a interface exata retornasse para a configuração inicial em $t=T$. Em nossos testes, consideramos $T=8$ e 800 passos de tempo. Na Figura 5.23, apresentamos as formas da interface geradas pelo nosso método em $t=T$ para as grades computacionais com resoluções de $64^{2}, 128^{2}, 256^{2}$ e $512^{2}$ (a forma exata coincide com o círculo inicial).

Na Tabela 5.3, comparamos os resultados em termos da perda de área e a distância 


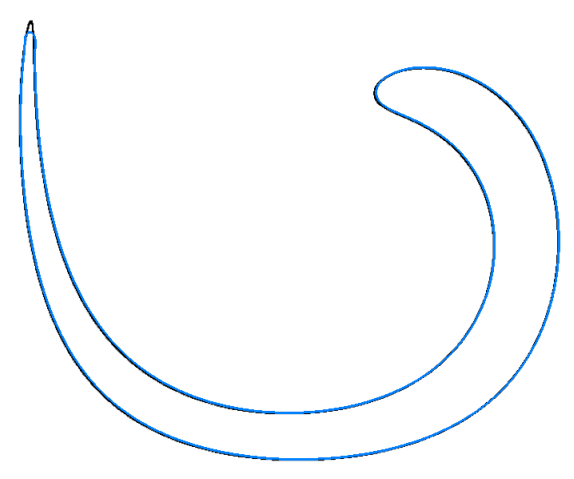

(a)

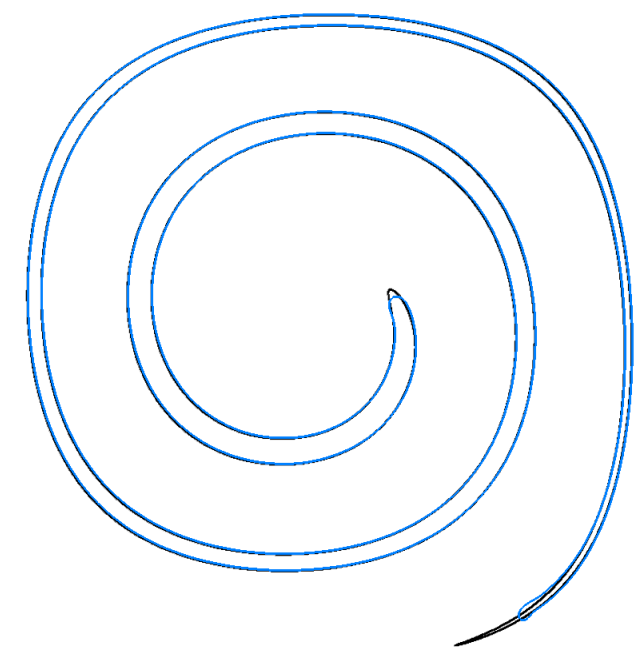

(c)

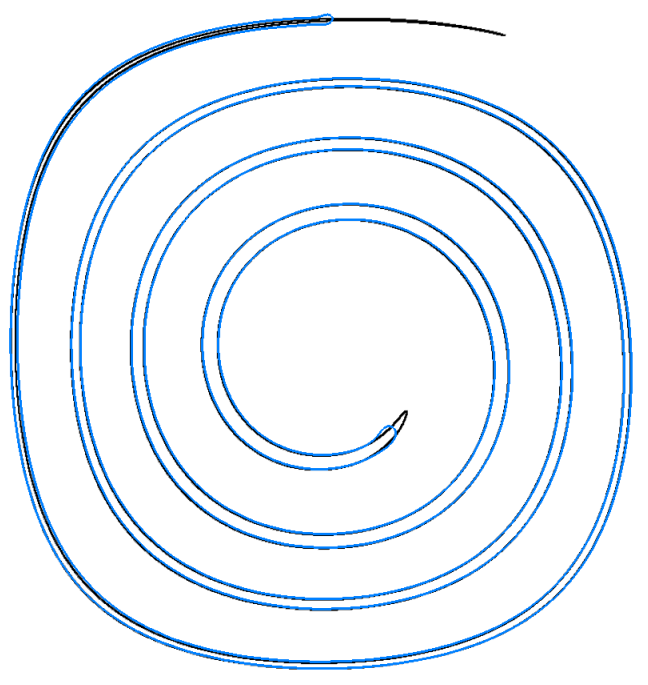

(e)

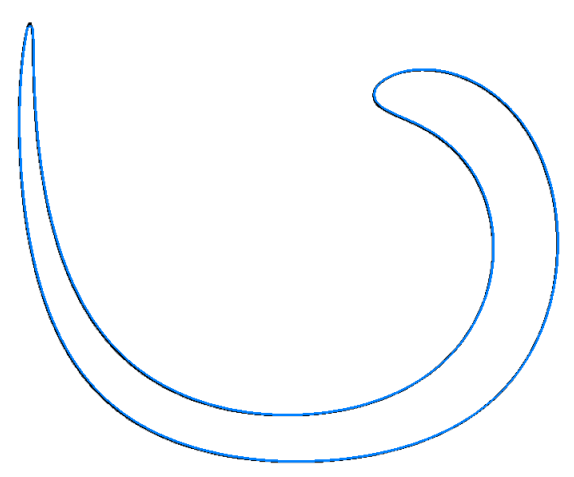

(b)

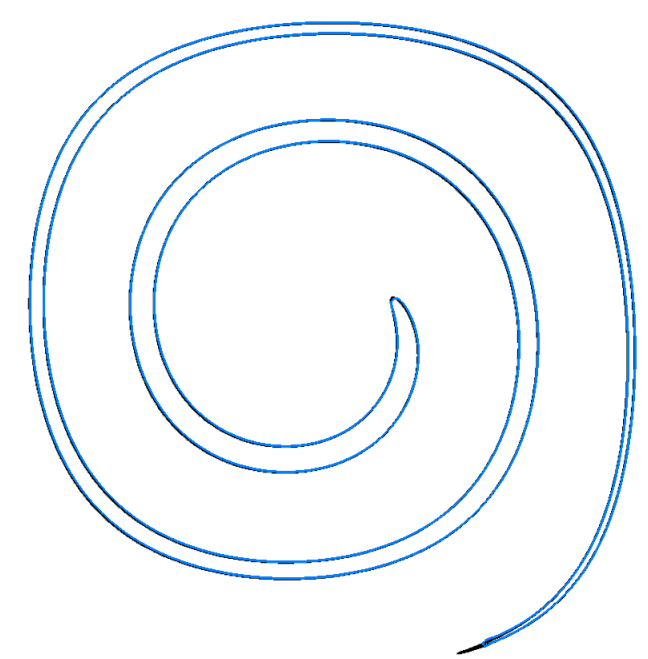

(d)

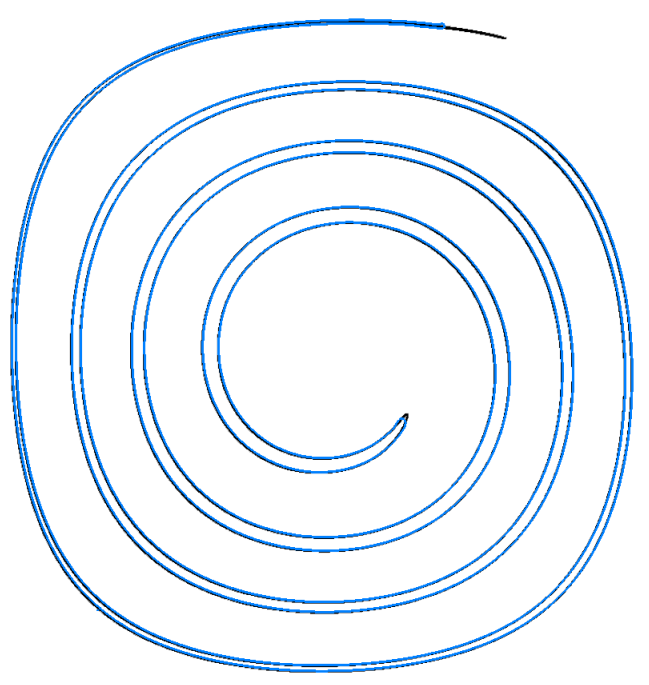

(f)

Figura 5.20: Solução exata (preto) e RAMLS (azul), $h=1 / 256$ (esquerda) e $h=1 / 512$ (direita) com $\Delta t=0.01$, em que (a) e (b) estão em 1, (c) e (d) estão em 3, e (e) e (f) estão em 5 unidades de tempo, respectivamente. 


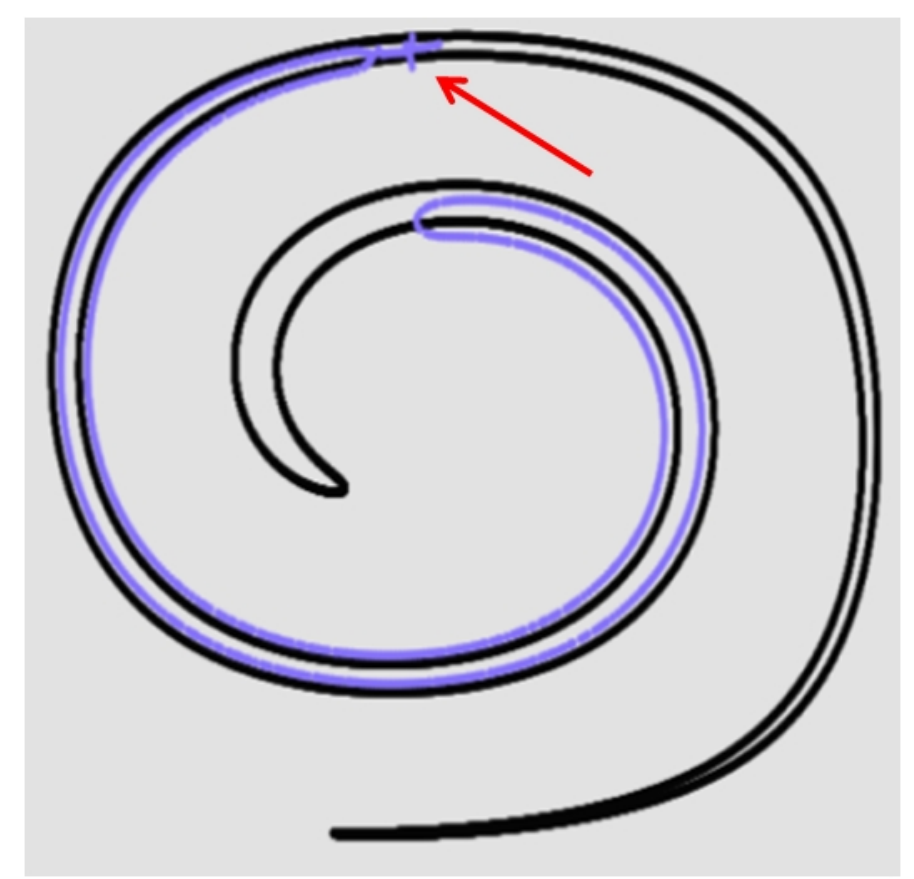

Figura 5.21: Solução exata (preto) e AMLS utilizando aproximações por retas (azul): é possível notarmos que, ao contrário do método baseado em círculos, o baseado em retas não é capaz de lidar naturalmente com duas regiões próximas da curva. Veja que a "cauda da interface" foi mal calculada, comprometendo a qualidade da interface.

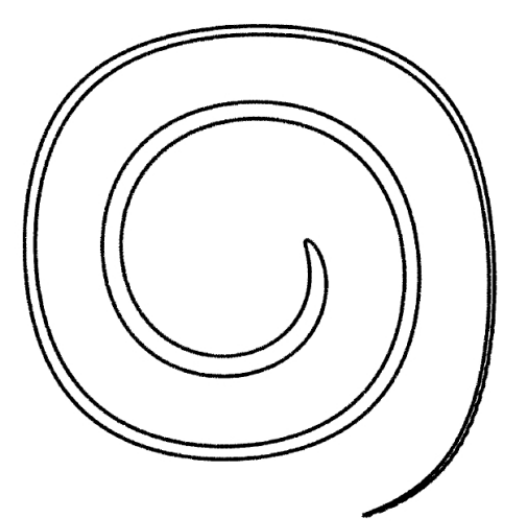

(a)

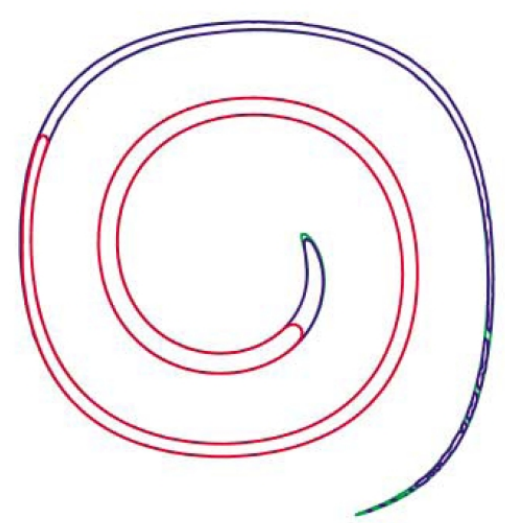

(b)

Figura 5.22: Grade computacional com espaçamento 1/128 e $t=3$ unidades de tempo: em (a), temos o método LSL [104], com 1160 partículas no seu estado inicial e, em (b), [72] temos o PLS com 15040 partículas em seu estado inicial, no qual, em vermelho, temos a solução por LS, em verde, a solução exata, e em azul, a solução por PLS. No primeiro caso, o número de partículas necessárias em $t=3$ foi de 55914 . 


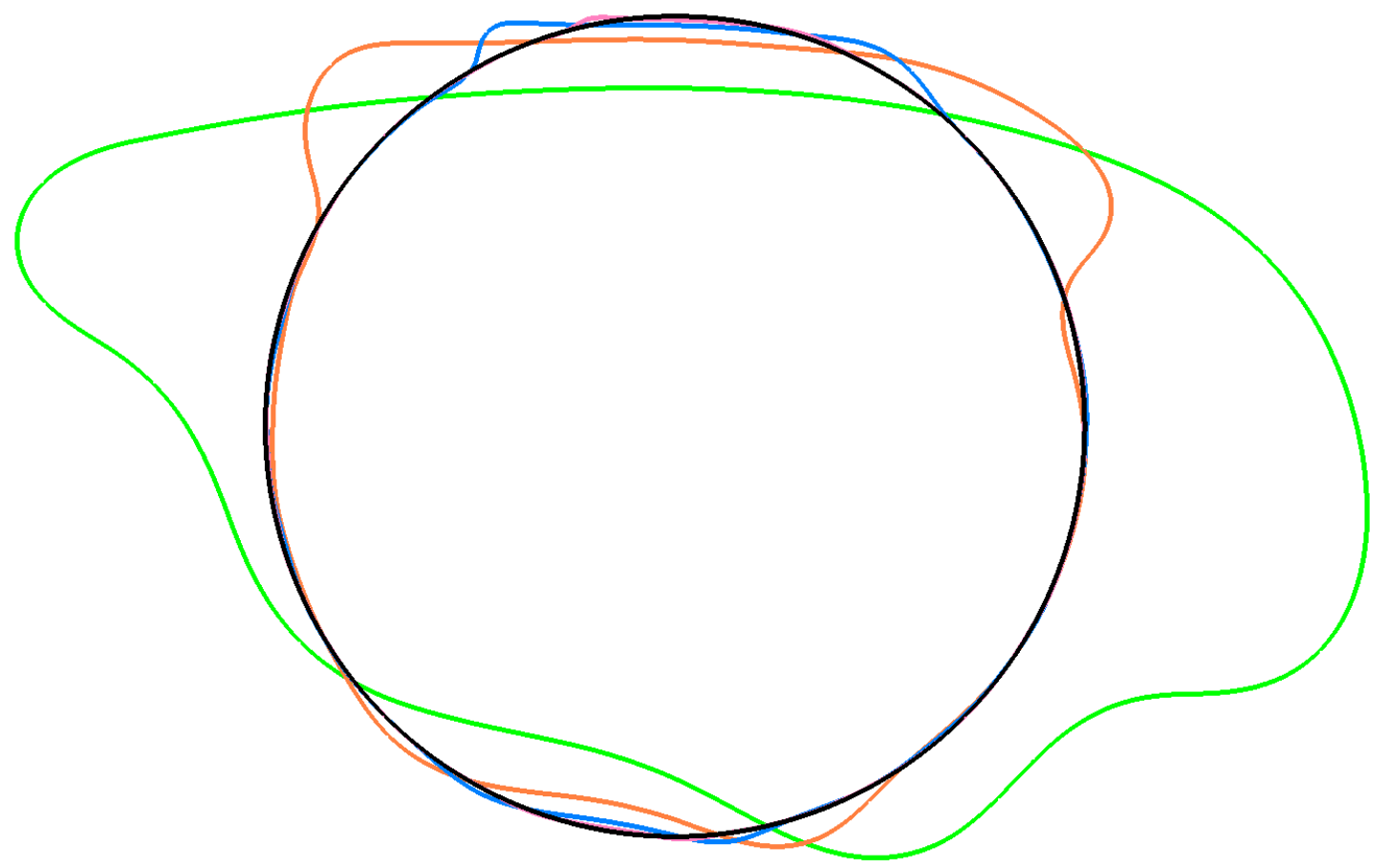

Figura 5.23: Solução exata (preto) e as obtidas numericamente a partir de grades computacionais com resoluções $h=1 / 64$ (verde), $h=1 / 128$ (laranja), $h=1 / 256$, (azul) $h=1 / 512$ (rosa).

entre a interface calculada e a exata. A perda de área obtida para $h=1 / 256$, que é aproximadamente $0.36 \%$, é similar às obtidas pelos métodos LSL, que foi (na melhor das configurações) de $0.8 \%$, e para o PLS, que foi de $0.4 \%$, ambos com grades computacionais com espaçamento de 1/256.

Na Figura 5.24, apresentamos o gráfico do número de pontos em função do tempo. Como pode ser visto, para $h=1 / 256$, que já possui uma boa precisão, foram necessários apenas 1500 pontos quando o objeto "esteve enrolado ao máximo" ( $T=4$ unidades de tempo). Além disso, podemos notar que a curva era simétrica e contínua. O conjunto de pontos foi aumentado e diminuído conforme a interface estica e contrai. No cálculo com $h=1 / 128$, por exemplo, o conjunto de pontos se inicia com 118 pontos e termina com 128. De fato, isso foi um melhoramento, quando comparamos com o LSL [104], que inicia com 1200 e termina com 2800 (Figura 5.25).

Para finalizar, apresentamos, na Figura 5.26, os resultados finais do teste do único vórtice modulado com o tempo para o método LSL e para o PLS. 


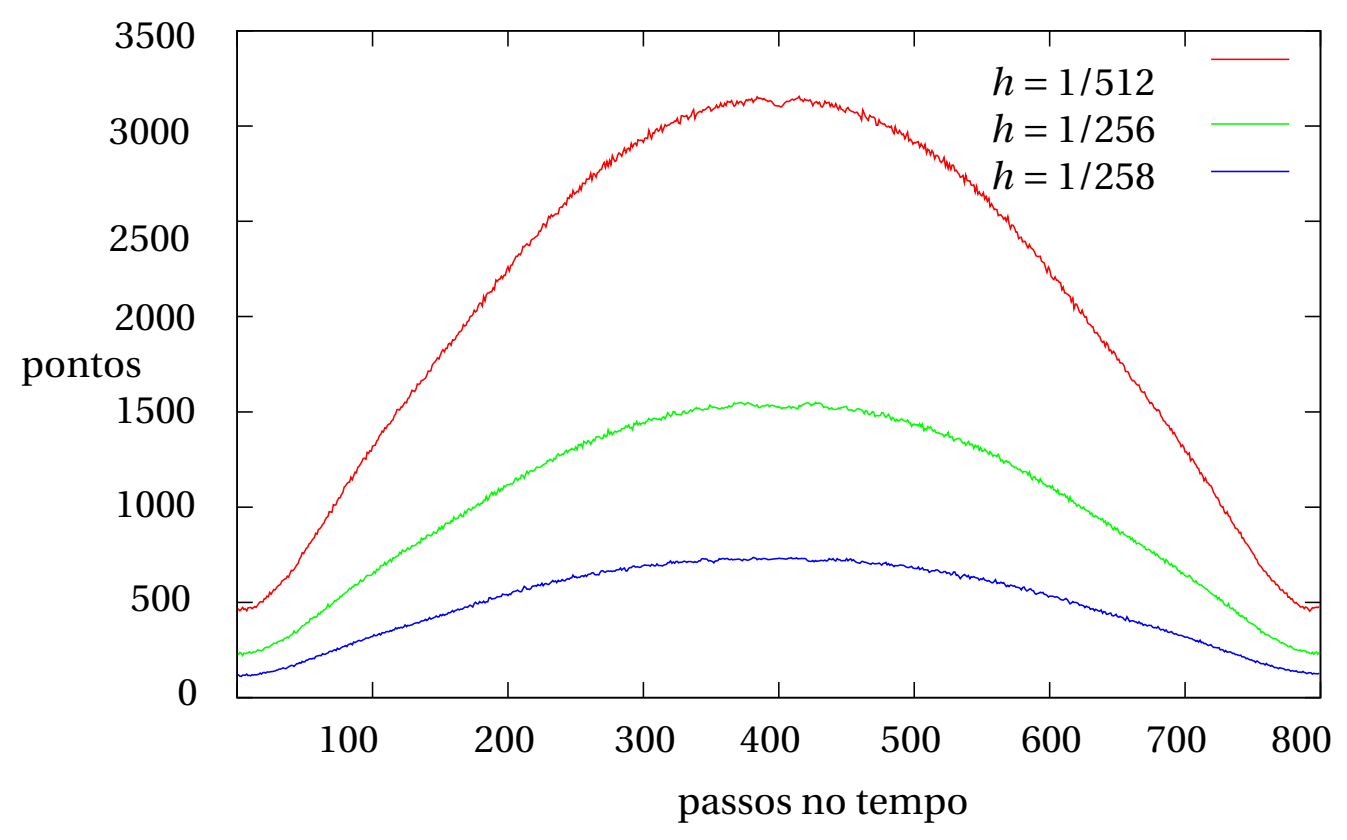

Figura 5.24: Evolução do número de pontos em $\mathscr{Q}_{h}(t)$ ao longo dos passos no tempo, na simulação do único vórtice modulado no tempo.

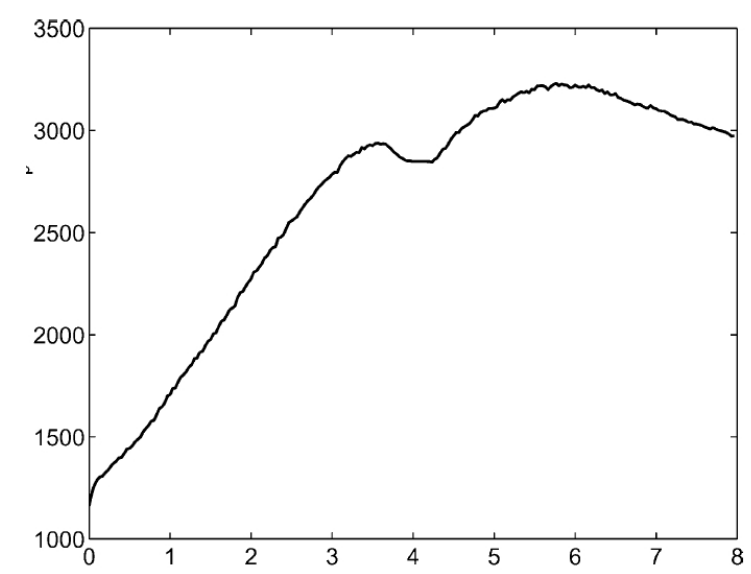

Figura 5.25: Simulação do único vórtice modulado no tempo: número de partículas geradas pelo LSL [104] no tempo para uma grade computacional com espaçamento 1/128.

Tabela 5.3: Testes numéricos do único vórtice modulado com o tempo pelo RAMLS: $T=8$ unidades de tempo.

\begin{tabular}{ccccc}
\hline Grade & Área & Perda de massa & Erro máximo(Hausdorff) & Ordem \\
\hline exata & 0.0706858347 & - & - & - \\
64 & 0.0972437082476 & $-37.5717054 \%$ & 0.106489841920 & N/A \\
128 & 0.073988917376 & $4.6729061 \%$ & 0.032472829711 & 1.713410805 \\
256 & 0.0709436344459 & $-0.364712 \%$ & 0.010440674216 & 1.63701823 \\
512 & 0.0706768662762 & $0.012687724 \%$ & 0.002361795476 & 2.144258936 \\
\hline
\end{tabular}




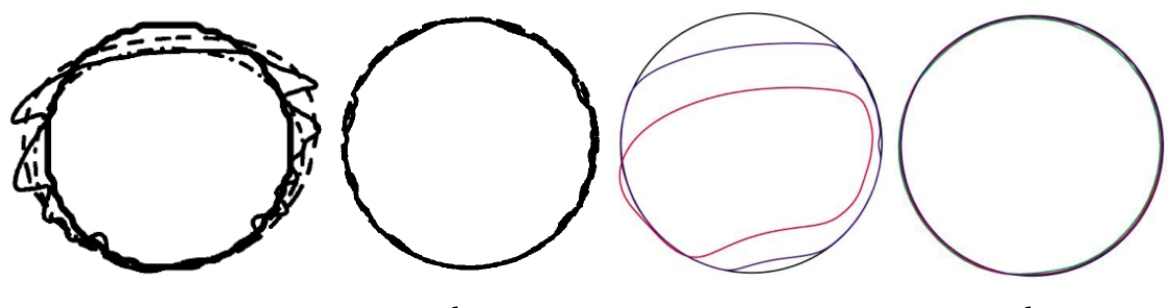

(a)

(b)

(c)

(d)

Figura 5.26: Em (a) e (b), temos os resultados de LSL [104] para grades computacionais com espaçamento de 1/128 e 1/1000 para diversas configurações do método; em (c), apresentamos soluções por LS [72] para grades computacionais com espaçamento de 1/64 (desapareceu), 1/128 (vermelho) e 1/256 (azul),e a solução exata (preto); em (d), apresentamos os resultados para o PLS (as cores para as soluções são as mesmas definidas na Figura 5.22-(b)), em que o número de partículas no estado inicial corresponde a 3376, 15040 e 59072 para as grades computacionais com espaçamentos 1/64, 1/128 e 1/256, respectivamente.

\subsubsection{Deformação de Esfera no Espaço Tridimensional}

O último caso-teste que realizamos foi a deformação de uma esfera em três dimensões. O estado inicial da interface $\mathscr{S}(0)$ foi uma esfera de raio 0.15 , centrada em $(0.35,0.35,0.35)$. O domínio computacional foi o cubo unitário. O campo de velocidades foi dado por:

$$
\mathbf{v}\left(x_{1}, x_{2}, x_{3}\right)=\left(\begin{array}{l}
2 \operatorname{sen}^{2}\left(\pi x_{1}\right) \operatorname{sen}\left(2 \pi x_{2}\right) \operatorname{sen}\left(2 \pi x_{3}\right) \\
-\operatorname{sen}\left(2 \pi x_{1}\right) \operatorname{sen}^{2}\left(\pi x_{2}\right) \operatorname{sen}\left(2 \pi x_{3}\right) \\
-\operatorname{sen}\left(2 \pi x_{1}\right) \operatorname{sen}\left(2 \pi x_{2}\right) \operatorname{sen}^{2}\left(\pi x_{3}\right)
\end{array}\right) .
$$

Em $t=T / 2=2$ unidades de tempo, invertemos o sentido do campo de velocidades com o intuito de verificar a capacidade do método em preservar topologia e geometria. A Figura 5.27 apresenta tal simulação, utilizando $h=1 / 512, \Delta t=0.0064$ e 628 unidades de tempo.

Os métodos de Enright et al. [72] e Hieber e Koumoutsakos [104] apresentam resultados similares (Figura 5.29). O método proposto aparenta preservar melhor a topologia do que os métodos anteriores, quando o tempo computacional está em $t=2$. A geometria final é muito próxima da esfera original, embora um pequeno artefato apareça (veja Figura 5.28).

É importante mencionarmos que a simulação da torção 3D para uma grade computacional $h=1 / 256$ falha já durante a "ida" da interface. A superfície, em determinado 


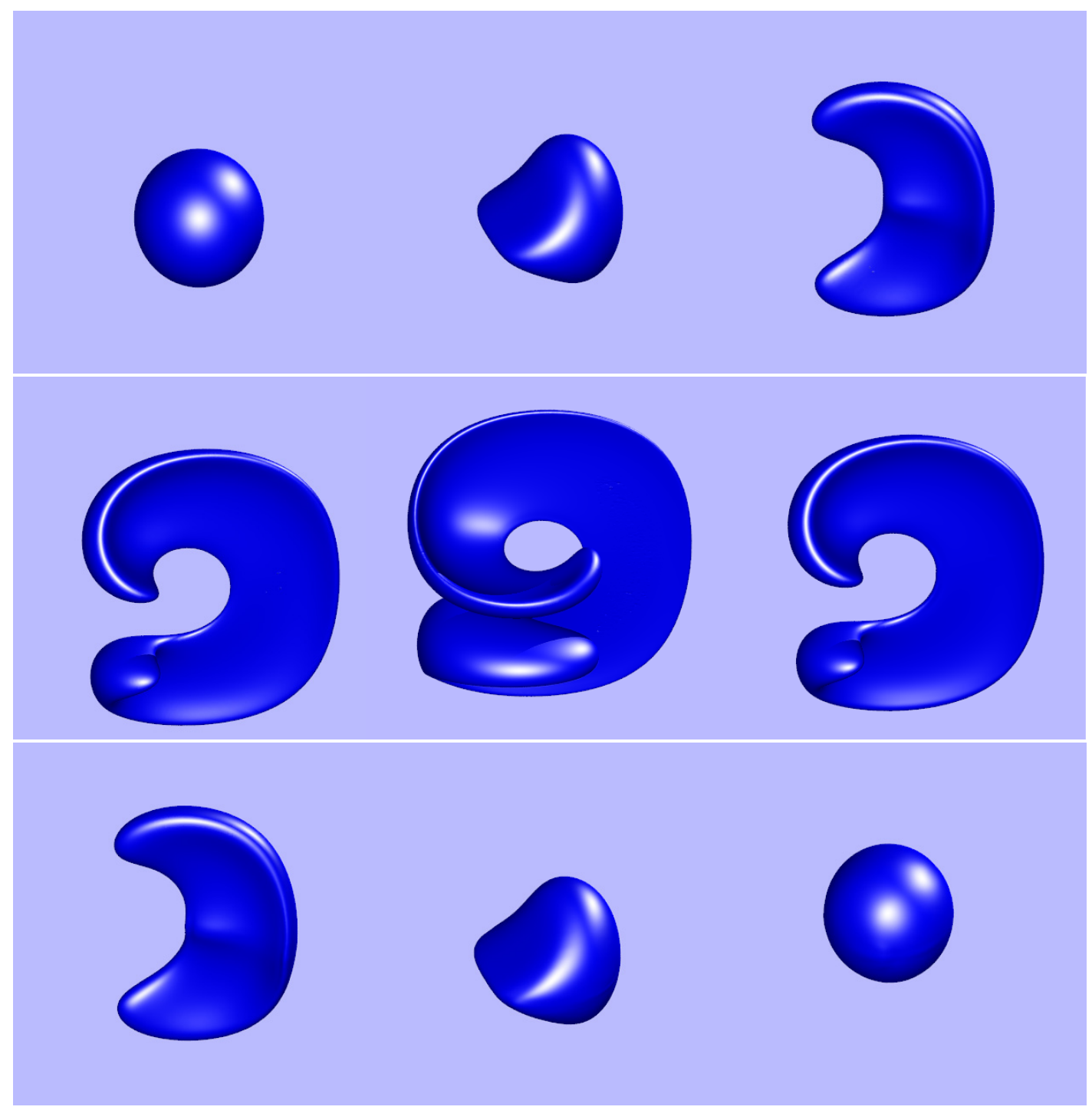

Figura 5.27: Torção tridimensional ( $h=1 / 512)$ obtida numericamente em diferentes instantes: o número de pontos em cada um dos conjuntos era (da esquerda para direita, de cima para baixo): 65000, 69314, 109728, 187571, 277021, 193238, 114898, 72774, 68031. 


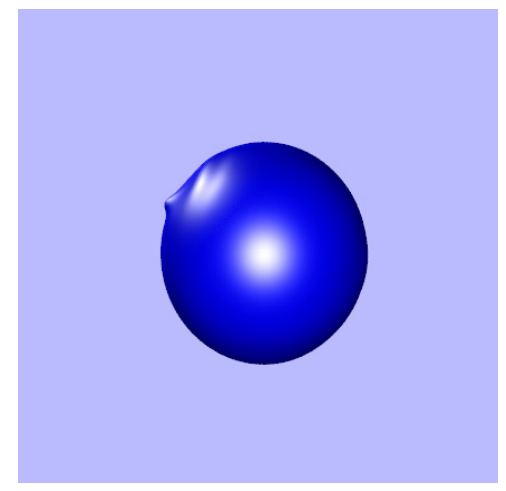

Figura 5.28: A interface à direita da parte de baixo na Figura 5.27 em outro ponto de vista. Pode ser visto um pequeno artefato na solução.

momento da simulação, gera um pequeno artefato que, quando propagado, compromete a solução. Pretendemos investigar esse problema inerente a superfícies MLS, que apesar de muito aliviado pelo nosso método, ainda persiste: pequenos erros podem ser ampliados durante o transporte da superfície, de forma que a qualidade da solução se comprometa.

\subsection{Conclusão}

Neste capítulo, apresentamos um mecanismo poderoso e promissor para a representação de superfícies a partir de superfícies AMLS. Até onde sabemos, essa técnica não havia sido aplicada para a representação de interfaces móveis. Como vimos, ela pode representar de forma precisa objetos tridimensionais por um número consideravelmente pequeno de pontos.

Além do método de acompanhamento de fronteiras baseado em AMLS, também apresentamos uma variante da superfície AMLS de Guennebaud e Gross [97], que denominamos por superfície RAMLS. As suas vantagens são o fato de o método ser livre de parâmetros, o baixo custo computacional e o fato de manter solução precisa durante o processo de simulação.

Apresentamos uma grande quantidade de testes, que nos permitiram argumentar que o nosso método é competitivo com trabalhos anteriores, apresentados na literatura, em termos de precisão e robustez. 

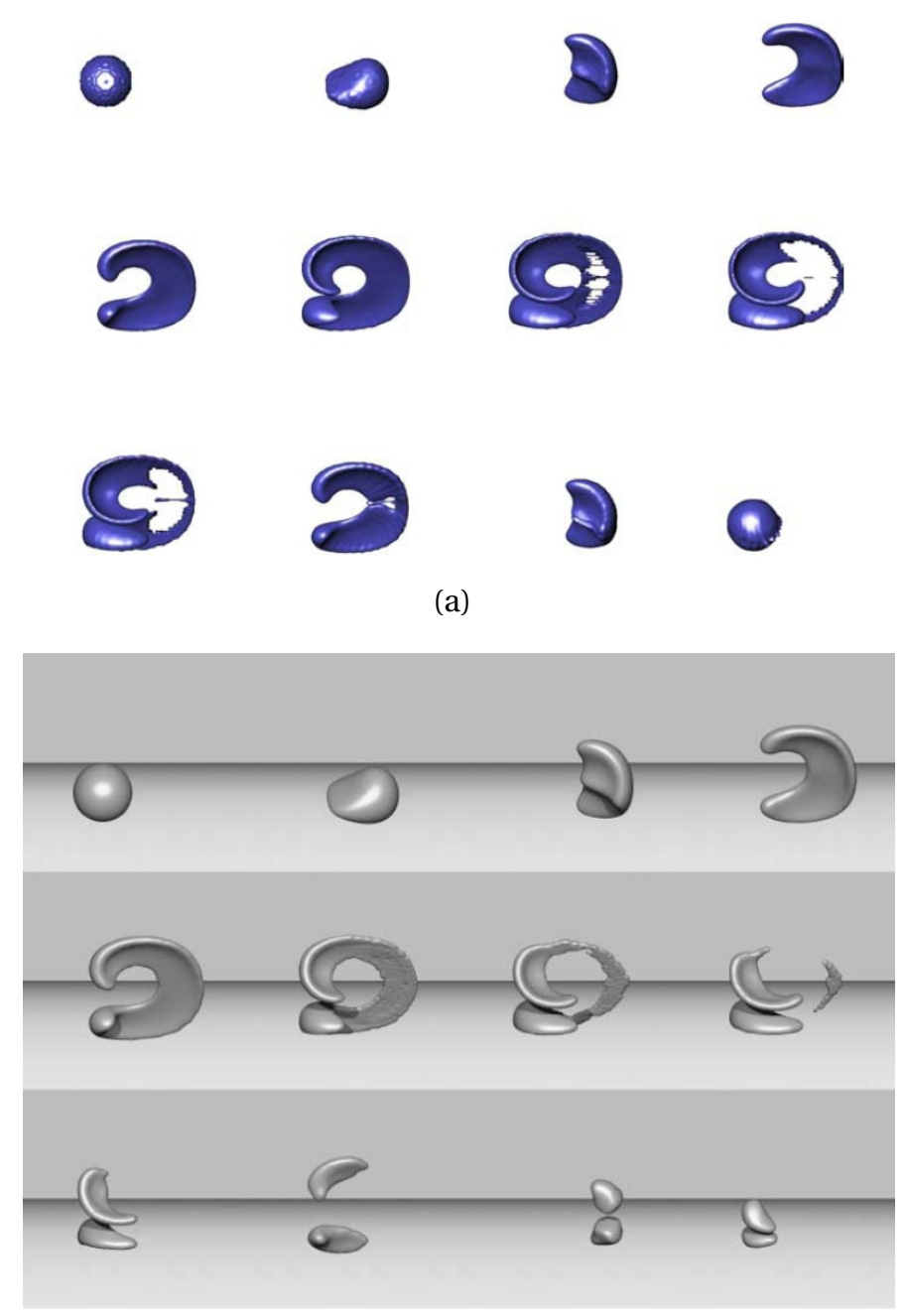

(b)

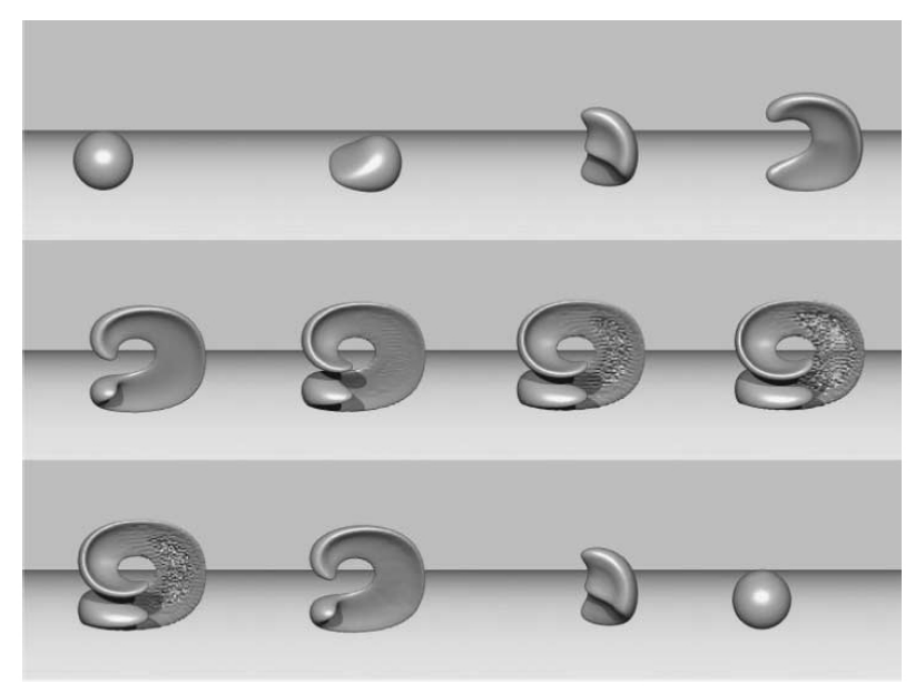

(c)

Figura 5.29: Torção 3D do método LSL [104] e PLS [72]: temos, em (a) LSL, grade computacional com espaçamento de 1/100 (número de partículas mínimo é de 14054 e máximo de 30739); em (b), a solução pelo LS (espaçamento da grade 1/100), e, em (c), a solução pelo PLS, também com espaçamento da grade 1/100. 
Existem diversas extensões de nossa abordagem. No âmbito de mudanças topológicas, o problema é, de fato, desafiador: quando se têm duas interfaces desconectadas (por exemplo, duas bolhas) e o problema físico deve realizar a união delas. Trabalhos nesse sentido já foram desenvolvidos e podem sem aplicados eficientemente, entre eles as técnicas de modelagem presentes no PointShop3D [224], desde que essas superfícies sejam tratadas de forma independente. No entanto, o problema de mudanças topológicas é mais delicado quando a própria interface faz interseção com ela mesma (Figura 5.1). Por isso, mecanismos eficientes ainda devem ser desenvolvidos.

Também pretendemos desenvolver mecanismos para amenizar a propagação de erros na interface. Refinar a grade computacional, como fizemos para realizar a simulação da torção 3D, é a solução trivial que de fato funciona. No entanto, o custo computacional é significativamente aumentado. O problema de remoção de pontos duplicados apenas baseada na distância entre pontos também é uma questão que pode ser melhorada. Uma solução que julgamos mais robusta para tal fato é a utilização não apenas da distância geométrica para decidir se dois pontos estão próximos, mas também do ângulo entre seus vetores normais. Dessa forma, evitaríamos a remoção de pontos duplicados que pertençam a diferentes regiões da interface.

Outro aspecto de suma importância para nossa técnica é a definição de um esquema eficiente para o cálculo da curvatura para o caso tridimensional, pois simulações com superfície livre, que apresentam tensões superficiais, necessitam da estimativa da curvatura na interface.

Ainda no sentido de aliviar o custo computacional, uma extensão seria propor uma técnica de criação e redistribuição de pontos, como o método de Lipman et al. [138], de forma a satisfazer as ordens obtidas pelo método RAMLS.

No estado atual do trabalho, o método foi desenvolvido de forma que o conjunto de pontos é re-gerado a cada passo de tempo, nas interseções de um conjunto predefinido de raios $R_{h}$ com a interface. Isso automaticamente mantém a boa distribuição de pontos (aliada com a remoção de duplicados). De fato, os raios $R_{h}$ podem ser substituídos pela 
grade Euleriana que é utilizada para o solver de simulação do escoamento. Nesse caso, as interseções das arestas da grade com a interface não dependeriam dos raios $R_{h}$. Além disso, a distribuição de partículas seria automaticamente consistente com a grade do solver.

Além dessa situação, também pretenderemos estudar mecanismos para realizar a regeração de pontos menos vezes (como no método de Hieber e Koumoutsakos [104]), o que, além de aliviar o custo computacional, ainda abrandaria o efeito difusivo causado na solução (como ocorrido no caso do Zalesak 3D). 


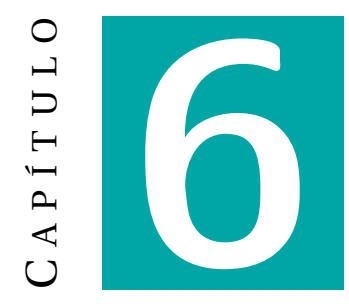

\section{Representação de Dados Volumétricos Não-Organizados}

Apresentaremos dois métodos de reconstrução de função para serem aplicados ao rendering de dados volumétricos não-organizados, originados da simulação de fenômenos físicos. O nosso objetivo na elaboração desses métodos é definir abordagens capazes de produzir rendering de dados originados de malhas arbitrárias. Para isso, o primeiro método que apresentaremos faz uso de uma aproximação robusta que utiliza filtros bilaterais e o método dos mínimos-quadrados-móveis. Nesse contexto, utilizamos a base de polinômios ortogonais segundo o produto interno induzido pelas equações normais. No segundo método, utilizamos novamente o iaMLS, contudo, definido em um domínio anisotrópico para tornar o método eficiente na representação de dados originados de malhas que possuem células com comprimentos discrepantes em cada uma de suas direções.

\subsection{Rendering de Dados Volumétricos}

A simulação numérica de fenômenos físicos tridimensionais se dá, tradicionalmente, em domínios discretizados por malhas poliedrais. Como resultado das simulações, são gerados valores de natureza escalar ou vetorial que ficam depositados nas malhas (em geral, nos vértices das malhas), definindo dados volumétricos. Com isso, métodos de visualização 
científica são propostos para codificar os resultados da simulação para uma representação gráfica, tornando possível realizar uma análise qualitativa da simulação. Entre os métodos mais tradicionais de visualização científica, está o rendering volumétrico e a extração de isosuperfícies [100]. Para a realização de tais processos, uma etapa fundamental é a definição de uma função reconstruída a partir dos dados armazenados na malha.

Embora a aproximação seja abordada de forma diferente a cada tipo de malha, também existem métodos que buscam realizar aproximações em malhas mais gerais $[165,214,112$, 111, 54]. Tais trabalhos, que focam aplicações de visualização, apresentam soluções para problemas específicos de alguns tipos de malhas. Por exemplo, malhas com refinamento adaptativo, em que os dados são armazenados no centro de células de diferentes tamanhos, e malhas multiblocos que possuirem submalhas com múltiplas sobreposições, são casos em que a interpolação dos dados não é trivial (veja Figura 6.1). Por exemplo, descontinuidades e artefatos são freqüentemente gerados durante a geração das iso-superfícies a partir de malhas multiblocos, que são, em geral, tratadas com estratégias geométricas $[54,127,190$, 218]. Outros tipos de malhas, em que o mecanismo de interpolação e, conseqüentemente, o rendering é desafiador, são aquelas definidas por células de diferentes tipos.

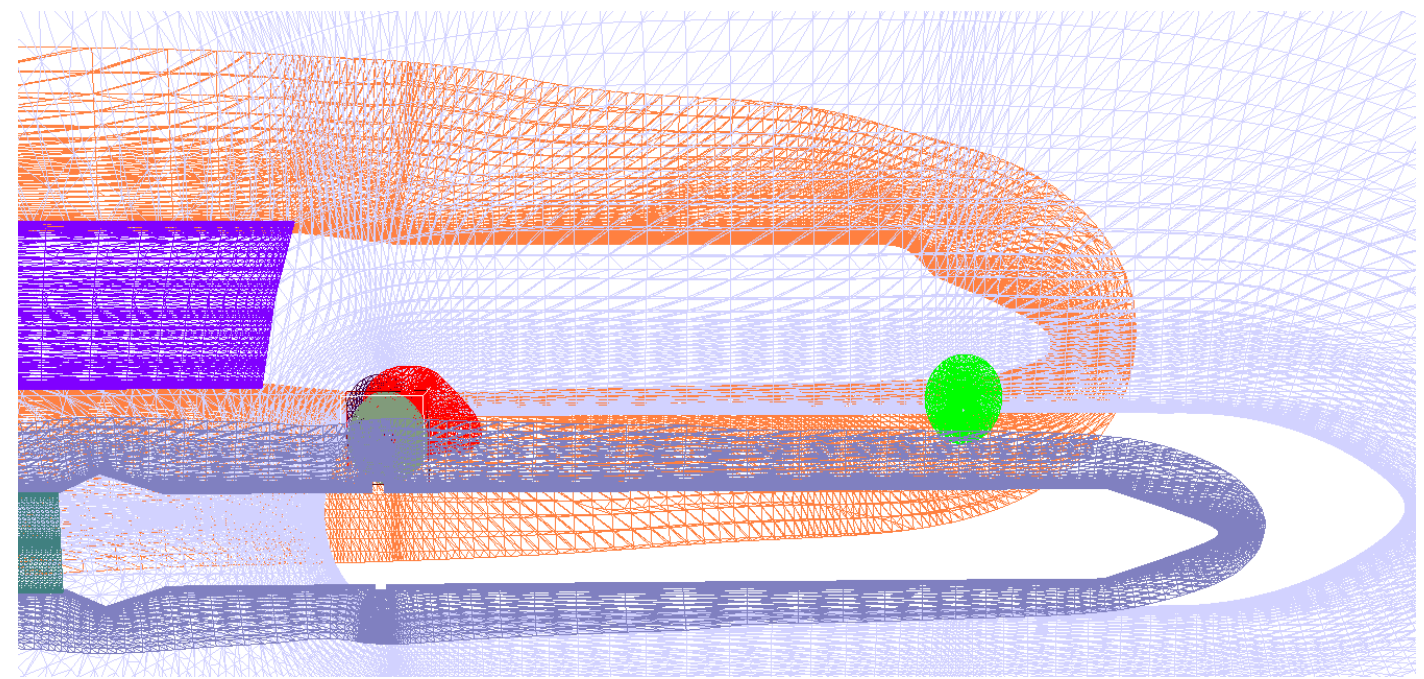

Figura 6.1: Wireframe do Space Shuttle Launch Vehicle definido por uma malha multibloco. A aproximação dos dados volumétricos armazenados em malhas desse tipo não é trivial para a tarefa de rendering. 
Dessa forma, a obtenção de mecanismos de aproximação de dados armazenados em malhas com células arbitrárias é um problema que merece a atenção e o foco do presente capítulo. A metodologia direta para esse tipo de problema seria desconsiderar a malha e tratá-la como um problema de aproximação. Entretanto, as informações providas pela conectividade da malha são importantes, pois $i$ ) definem as buscas por vizinhos de forma natural e eficiente, e $i$ i) definem uma relação de ordem espacial, que é necessária em diversos métodos de aproximação. Portanto, a conectividade não pode ser substituída simplesmente por buscas espaciais (utilizando $k d$-trees, por exemplo), usualmente realizadas por aproximações em dados não-organizados.

Isso significa que a eficiência de um método de aproximação livre-de-malhas a partir de pontos não-organizados depende do método de aproximação. Seguindo o mesmo sentido dos capítulos anteriores, investigamos variantes do método de mínimos-quadrados-móveis para desenvolver os nossos mecanismos de aproximação. Nesse sentido, apresentamos dois métodos de aproximação de dados volumétricos para serem aplicados ao contexto de rendering a partir de dados oriundos de malhas arbitrárias.

No primeiro, estendemos para o espaço tridimensional a aproximação robusta de Fenn et al. [79] que é baseada em filtros bilaterais e mínimos-quadrados-móveis. Embora a extensão para o espaço 3D seja direta, em termos computacionais, problemas de mal condicionamento de matrizes surgem. Entretanto, utilizamos os polinômios ortogonais de Bartels e Jezioranski no contexto dos mínimos-quadrados [23] para amenizar o problema de sistemas mal condicionados e aumentar o desempenho computacional. Fornecemos comparações qualitativas e de tempo de processamento em relação a outros métodos para solução do problema de mínimos-quadrados [30]. Além das comparações, também apresentamos resultados do nosso método em grades cartesianas, malhas não-estruturadas, grades curvilineares, malhas com refinamento adaptativo e malhas multiblocos com sobreposições.

Já no segundo método que propusemos, novamente fizemos uso do iAMLS. Com o intuito de adequar o método a qualquer tipo de malha, utilizamos funções-peso com 
suportes anisotrópicos para a realização das aproximações locais, pois a posição dos dados pode não seguir uma forma radial. Fornecemos comparações por meio de testes qualitativos e quantitativos. Pelo fato de utilizarmos o iaMLS, fomos capazes de propor mecanismos para pré-calcular os resultados do processo iterativo nos vértices da malha com o objetivo de aumentar o desempenho do método.

O uso de domínios anisotrópicos foi utilizado com grande sucesso em diversas aplicações, por exemplo, em geração de malhas [188], em codificação de dados escalares [111] e em reconstrução de superfícies [111]. Entretanto, o uso de espaços anisotrópicos para iaMLS e no contexto de rendering foi, pela primeira vez, aplicado por nós.

É importante mencionar que, ao contrário do trabalho original de Fasshauer e Zhang [77] que provaram a convergência da seqüência de soluções aproximadas para funções de bases radiais, não fomos capazes, até o momento, de provar sobre quais situações nossa abordagem também é convergente para uma solução ótima. No entanto, os resultados numéricos mostram a eficiência do iaMLS anisotrópico.

A importância do iaMLS aplicado aos espaços anisotrópicos se deve ao fato de que ele pode gerar reconstruções razoáveis de informação volumétrica, sem a necessidade de resolução de sistemas lineares e sem a necessidade de estruturas de dados auxiliares, como nas abordagens baseadas em wavelets [95] e B-splines [129]. Isso nos permitiu a definição de uma abordagem simples com potencial para ser implementada em placas gráficas modernas.

Ambos os métodos que aqui propusemos possuem, em comum, a qualidade de serem livres da solução de sistemas lineares e não exigirem a criação de malhas auxiliares como em métodos de aproximação.

Antes de detalharmos as duas abordagens, apresentaremos um breve levantamento bibliográfico dos métodos de aproximação de dados volumétricos não-organizados. 


\subsection{Aproximação de Funções a partir de Dados Volumétricos}

O problema de rendering de dados volumétricos armazenados em malhas estruturadas e não-estruturadas tem sido abordado por diferentes métodos para cada tipo de malha em específico. Mecanismos eficientes e interativos de rendering para malhas cartesianas têm sido amplamente estudados e estão bem documentados. Embora os mecanismos de rendering para outros tipos de malhas não tenham recebido a mesma atenção pela comunidade de visualização, vários métodos para grades curvilineares, malhas tetraedrais, malhas com refinamento adaptativo e malhas multiblocos [128] foram propostos, usualmente utilizando parametrizações dentro das células com o intuito de realizar uma interpolação linear. Floater et al. [81] introduziram as parametrizações de mean value coordinates, que permitem eficientemente lidar com diversos tipos de poliedros. Essa parametrização assegura uma função de classe $C^{0}$ ao longo dos bordos da célula, mas também requer que as faces dos poliedros sejam triangulares, o que, embora seja uma tarefa trivial, torna a qualidade da aproximação dependente da triangulação.

Contudo, também fazem parte do contexto de rendering os métodos de aproximação de dados volumétricos que não são desenvolvidos para tipos de malhas específicas. A literatura sobre o tópico é abundante e diversas coletâneas foram propostas [84, 155, 10].

Em geral, existem duas abordagens básicas para a aproximação de dados. A primeira é baseada simplesmente na posição dos pontos, e a segunda utiliza alguma estrutura de dados espacial para auxiliar no processo de interpolação. Um dos métodos mais conhecidos de interpolação, que é devido a Shepard [187], produz uma interpolação de Classe $C^{0}$. Frank e Nielson [83] propuseram um método de Shepard modificado que é capaz de produzir interpolações de Classe $C^{1}$ pelos cálculos de polinômios por mínimos-quadrados em cada amostra dos pontos combinados continuamente por uma partição da unidade. No entanto, como de costume, para os métodos baseados em partição da unidade, a decomposição ótima e a escolha de boas aproximações locais são o principal desafio dessa abordagem [155]. 
Outra abordagem que produz interpolações de Classe $C^{1}$ é a de Sibson [10]. Tradicionalmente, a interpolação de Sibson faz uso do Diagrama de Voronoi, que torna o processo custoso. Com o objetivo de superar tal dificuldade, Park et al. [165] propuseram uma versão baseada em grades da interpolação de Sibson para ser implementada em GPU. Lee et al. [129] utilizaram B-splines que foram capazes de produzir bons resultados. Porém, a necessidade de uma grade regular para os pontos de controle pode ser vista como uma desvantagem. O mesmo fato ocorre nos métodos baseados em wavelets [95].

Splines mais flexíveis em relação aos domínios também foram propostas, mas problemas numéricos e o custo computacional aumentaram significativamente. Além disso, a conectividade das malhas ainda é necessária. Rösssl et al. [176] também apresentaram um mecanismo de interpolação de dados não-organizados, baseado em splines e em mínimos-quadrados locais definidos por bases de Bernstein-Beziér e uma decomposição tetraedral. Um dos principais fatores que elevam o custo computacional dessa abordagem está relacionado à decomposição por valores singulares, que é realizada diversas vezes, a partir de um grau alto de polinômio para graus menores, buscando aproximações locais que sejam satisfatórias, porém, com o menor número possível de coeficientes.

Funções de bases radiais (RBF) também foram utilizadas no contexto de interpolação de dados não-organizados. Jang et al. [112] e Weiler et al. [214] usaram RBF para codificar informações escalares e vetoriais em malhas estruturadas e não-estruturadas. Co et al. [54] apresentaram um método híbrido de extração de iso-superfícies a partir de dados multiblocos. A conectividade original é desconsiderada e uma grade regular, no qual funções de bases radiais são definidas, é criada para definir uma malha a partir de um poligonalizador. Tejada et al. [204] realizam o rendering de point-based surfaces a partir de dados volumétricos (grades cartesianas), utilizando superfícies MLS, que geram as isosuperfícies nas localizações de alto gradiente de magnitude.

Hong et al. [106] evidenciam um mecanismo de rendering por splatting, por meio do qual também é definido um elipsóide para cada vértice da malha por mínimos-quadradosponderado. Jang et al. [111] apresentaram uma técnica para codificar dados escalares, a 
partir de malhas arbitrárias, utilizando funções de bases elipsoidais e um mecanismo de minimização não-linear para a determinação das formas dos elipsóides e seus respectivos centros.

\subsection{Aproximação Robusta para Dados Volumétricos}

Nesta seção, apresentamos nosso método de aproximação robusta de dados volumétricos. Para preservar detalhes nos dados, estendemos para 3D a aproximação robusta de Fenn et al. [79], baseada em filtros bilaterais [71] e mínimos-quadrados-móveis. Embora a extensão desse método para o espaço tridimensional seja definitivamente direta, problemas de instabilidade numérica podem aparecer tornando o custo computacional significativamente alto para o contexto de rendering.

Para contornar o primeiro dos problemas previamente citados, poderíamos utilizar métodos, tais como a decomposição QR através da fatoração de Householder ou a decomposição em valores singulares para resolver o problema de mínimos-quadrados-móveis [30]. No entanto, o custo computacional é alto em comparação com outros métodos, tais como o método de Gauss com pivotamento e o método dos gradientes conjugados, cujo número de condição da matriz é o quadrado do número de condição dos métodos baseados na decomposição QR e SVD. Uma última opção é a utilização de bases de polinômios que são ortogonais segundo o produto interno induzido pelas equações normais. Nessa abordagem, segundo os autores que a propuseram [23, 22], o custo computacional é aliviado e a estabilidade numérica também é melhorada.

\subsubsection{MLS e Polinômios Ortogonais de Várias Variáveis}

Nesta seção, apresentamos a construção dos polinômios que são ortogonais, segundo o produto interno induzido pelas equações normais. Consideremos um conjunto de pontos $\mathscr{P}=\left\{\mathbf{x}_{1}, \ldots, \mathbf{x}_{n}\right\} \subsetneq \mathbb{R}^{3}$ e a função $f: \mathbb{R}^{3} \rightarrow \mathbb{R}$, avaliada em $\mathscr{P}$, gerando o conjunto $\mathscr{F}=\left\{f\left(\mathbf{x}_{1}\right), \ldots, f\left(\mathbf{x}_{n}\right)\right\} \subsetneq \mathbb{R}$. Para o conjunto de funções-base (polinômios, em nosso caso) 
$\mathscr{M}=\left\{\psi_{1}, \ldots, \psi_{m}\right\}$, o objetivo do método dos mínimos-quadrados-móveis é definir uma combinação linear de $\mathscr{M}$ que aproxima $\mathscr{F}$. Para isso, consideremos os vetores $\Psi_{i}=$ $\left(\psi_{i}\left(\mathbf{x}_{1}\right), \ldots, \psi_{i}\left(\mathbf{x}_{n}\right)\right)$ e $\Gamma=\left(f\left(\mathbf{x}_{1}\right), \ldots, f\left(\mathbf{x}_{n}\right)\right)$. A Função $u$ minimiza:

$$
\sum_{i=1}^{n}\left(f\left(\mathbf{x}_{i}\right)-u\left(\mathbf{p}, \mathbf{x}_{i}\right)\right)^{2} \omega_{i}(\mathbf{p})
$$

em que $u(\mathbf{p})=\sum_{j=1}^{m} c_{j}(\mathbf{p}) \psi_{j}(\mathbf{p})$ é a solução pelo mínimos-quadrados-móveis em $\mathbf{p}$. Assim, dado o produto interno $<,>_{\omega}: \mathbb{R}^{n} \times \mathbb{R}^{n} \rightarrow \mathbb{R}^{+}:$

$$
<\xi, \eta>_{\omega}(\mathbf{p})=\sum_{i=1}^{n} \xi_{i} \eta_{i} \omega_{i}(\mathbf{p})
$$

em que $\omega: \mathbb{R} \rightarrow \mathbb{R}_{+}$é uma função-peso que depende do ponto p. Como descrito nos Capítulo 2 e 5, sabemos que $u$ é determinada pelas equações normais [57]:

$$
\left[\begin{array}{ccc}
<\Psi_{1}, \Psi_{1}>_{\omega} & \ldots & <\Psi_{1}, \Psi_{m}>_{\omega} \\
\vdots & \ddots & \vdots \\
<\Psi_{m}, \Psi_{1}>_{\omega} & \ldots & <\Psi_{m}, \Psi_{m}>_{\omega}
\end{array}\right]\left[\begin{array}{c}
c_{1} \\
\vdots \\
c_{m}
\end{array}\right]=\left[\begin{array}{c}
<\Gamma, \Psi_{1}>_{\omega} \\
\vdots \\
<\Gamma, \Psi_{m}>_{\omega}
\end{array}\right] .
$$

Reescrevendo o sistema anterior em uma forma compacta temos:

$$
\left\{\sum_{j=1}^{m}<\Psi_{i}, \Psi_{j}>_{\omega} c_{j}=<\Gamma, \Psi_{i}>_{\omega} ; i=1, \ldots, m .\right.
$$

Se definirmos o conjunto $\mathscr{M}$ de forma que o produto interno satisfaça:

$$
<\Psi_{i}, \Psi_{j}>_{\omega}=\kappa_{i j} \delta_{i j}
$$

em que $\delta_{i j}$ é o delta de Kronecker, a Equação (6.3) se torna um sistema linear em que a matriz dos coeficientes apresentará elementos não-nulos apenas na diagonal. Isso significa que $\mathscr{M}$ é definido por um conjunto de polinômios que são ortogonais, segundo o produto interno induzido pelas equações normais. Dessa forma, a aproximação é dada simplesmente por:

$$
u(\mathbf{p})=\sum_{i=1}^{m} \psi_{i}(\mathbf{p}) \frac{<\Gamma, \Psi_{i}>_{\omega}}{<\Psi_{i}, \Psi_{i}>_{\omega}}
$$


O conjunto $\mathscr{M}$ que satisfaz tal propriedade pode ser obtido utilizando o processo de ortogonalização de Gramm-Schmidt para polinômios de várias variáveis. Entretanto, Forysthe [82] e Weisfeld [215] mostraram que o processo de Gramm-Schmidt revisado é mais eficiente. Weisfeld apresentou uma generalização da recorrência de três termos [41] dos polinômios ortogonais de várias variáveis, tornando o método mais eficiente.

Bartels e Jezioranski [23] enriqueceram os resultados de Weisfeld [215], apresentando um método ainda mais eficiente em termos computacionais, pois possuem propriedades que permitem reduzir ainda mais o custo computacional. Assim, optamos, no presente método, pelo uso dos polinômios ortogonais de Bartels e Jezioranski, no âmbito de mínimosquadrados-móveis.

Existem outros mecanismos para a construção de polinômios ortogonais de várias variáveis [195, 169], já que a construção não é única, pois não existe uma relação de ordem total para espaços multidimensionais [23]. Contudo, a construção dos polinômios pelo método de Bartels e Jezioranski, além de apresentar resultados satisfatórios, é de fácil compreensão e sua generalização para qualquer dimensão é computacionalmente viável.

\section{Indexação dos polinômios ortogonais}

Para definirmos uma base ortogonal por um processo do tipo Gramm-Schmidt, primeiramente é necessário estabelecermos um mapeamento dos monômios para números inteiros. Consideremos um ponto $\mathbf{x}=\left(x_{1}, x_{2}, x_{3}\right) \in \mathbb{R}^{3}$. O esquema de Bartels e Jezioranski para a construção de um conjunto de polinômios ortogonais $\mathscr{M}$ é baseado em uma ordenação espacial do conjunto:

$$
\left\{x_{1}^{s_{1}} x_{2}^{s_{2}} x_{3}^{s_{3}}: s_{i} \in I \subsetneq \mathbb{N}, i=1,2,3\right\}
$$

de monômios de três variáveis (em nosso caso) e uma aplicação de tais monômios para números inteiros que induz à redução do número de operações computacionais necessárias.

Organizemos os monômios de três variáveis em um padrão triangular em que a $r$-ésima linha contenha todos os monômios de grau $(r-1)$, e cada linha, com exceção da primeira, 
seja separada em 3 intervalos:

1. A linha 1 contém o monômio 1 ;

2. A linha 2 contém 3 intervalos com apenas um monômio em cada, isto é: $x_{1}, x_{2}, x_{3}$;

3. A linha $r$ tem como seu $1^{\circ}, 2^{\circ}$ e $3^{\circ}$ intervalos os monômios definidos pela multiplicação de $x_{1}, x_{2}$ e $x_{3}$ por cada um de seus membros, na ordem dos intervalos $1,2,3 ; 2,3$, e 3, que estão na linha $r-1$.

Por exemplo, as quatro primeiras linhas da construção anterior são:

1. 1

2. $\begin{array}{lll}x_{1} & x_{2} & x_{3}\end{array}$

3. $\begin{array}{lllllll}x_{1}^{2} & x_{1} x_{2} & x_{1} & x_{3} & x_{2}^{2} & x_{2} x_{3} & x_{3}^{2}\end{array}$

4. $\begin{array}{llllllllllllll}x_{1}^{3} & x_{1}^{2} x_{2} & x_{1}^{2} x_{3} & x_{1} x_{2}^{2} & x_{1} x_{2} x_{3} & x_{1} x_{3}^{2} & x_{2}^{3} & x_{2}^{2} x_{3} & x_{2} x_{3}^{2} & x_{3}^{3}\end{array}$

cujo símbolo indica um intervalo.

O conjunto das posições nessa tabela é dado por:

$$
\{i\}=\{1,2,3,4,5,6,7,8,9, \ldots\}
$$

Por exemplo, o monômio na posição 6 é $x_{1} x_{2}$. Já o conjunto de monômios é dado por:

$$
\{\beta(i)\}=\left\{1, x_{1}, x_{2}, x_{3}, x_{1}^{2}, x_{1} x_{2}, x_{1} x_{3}, x_{2}^{2}, x_{2} x_{3}, \ldots\right\}
$$

e o conjunto de vetores de expoentes associado aos monômios $\beta(i)$ é dado por:

$$
\{\gamma(i)\}=\{(0,0,0),(1,0,0),(0,1,0),(0,0,1),(2,0,0),(1,1,0),(1,0,1), \ldots\}
$$

Durante a construção dos polinômios ortogonais, é importante armazenar as informações dos polinômios previamente calculados. O predecessor $j^{\prime}$ da posição $j$ na construção triangular é definido por: para o primeiro intervalo, $\gamma(j)=\left(j_{1}, j_{2}, j_{3}\right)$, que está 
na linha $j_{1}+j_{2}+j_{3}+1$. A posição do predecessor $j^{\prime}$ de $j$ está na posição definida por $\gamma\left(j^{\prime}\right)=\left(j_{1}-1, j_{2}, j_{3}\right)$. Dessa forma, considerando $\gamma\left(j^{\prime}\right)$ no conjunto $\{\gamma(i)\}$, somos capazes de identificar a posição $j^{\prime}$ (que está na linha $\left(j_{1}-1\right)+j_{2}+j_{3}+1$ ). Por exemplo, se considerarmos $j=6$, que está no primeiro intervalo, $\beta(6)=x_{1} x_{2}$, que tem $\gamma(6)=(1,1,0)$ e $\gamma\left(j^{\prime}\right)=(0,1,0)$, acarretando em $j^{\prime}=3$.

Para o segundo intervalo, temos argumentos similares: $\gamma(j)=\left(0, j_{2}, j_{3}\right)$ que está na linha $j_{2}+j_{3}+1$. A posição de $j^{\prime}$ é definida por $\gamma\left(j^{\prime}\right)=\left(0, j_{2}-1, j_{3}\right)$. O predecessor $j^{\prime}$ está, nesse caso, na linha $\left(j_{2}-1\right)+j_{3}+1$.

Finalmente, para o terceiro intervalo temos $\gamma(j)=\left(0,0, j_{3}\right)$, que está na linha $j_{3}+1$. Dessa forma, $j^{\prime}$ é definido por $\gamma\left(j^{\prime}\right)=\left(0,0, j_{3}-1\right)$, que está na linha $\left(j_{3}-1\right)+1$.

Portanto, baseada nessa relação de ordem com predecessores, a construção do polinômio ortogonal $\psi_{i}$ dar-se-á a partir da posição das informações de predecessores da posição $i$ da mesma relação triangular previamente descrita.

\section{Construção dos polinômios ortogonais}

O processo de Gramm-Schmidt, proposto por Bartels e Jezioranski, é dado pela seguinte relação de recorrência:

$$
\begin{aligned}
& \psi_{1}=1 ; \\
& \psi_{j}=x_{k_{j}} \psi_{j^{\prime}}-\sum_{l=1}^{j-1} \alpha_{j, l} \psi_{l} ; j=2,3, \ldots,
\end{aligned}
$$

em que $x_{k_{j}}=x_{1}$ quando o predecessor $j^{\prime}$ está no primeiro intervalo, $x_{k_{j}}=x_{2}$, quando $j^{\prime}$ está no segundo intervalo e $x_{k_{j}}=x_{3}$ quando $j^{\prime}$ está no terceiro intervalo, e:

$$
\alpha_{j, l}=\frac{<x_{k_{j}} \Psi_{j^{\prime}}, \Psi_{l}>_{\omega}}{<\Psi_{l}, \Psi_{l}>_{\omega}}
$$

em que

$$
<x_{k_{j}} \Psi_{j^{\prime}}, \Psi_{l}>_{\omega}=\sum_{i=1}^{n} x_{k_{j}}^{[i]} \psi_{j^{\prime}}{ }^{[i]} \psi_{l}^{[i]} \omega^{[i]}
$$


Utilizamos o índice superior [i] para denotar os valores das funções nos pontos $\mathbf{x}_{i}$ e $\psi_{j^{\prime}}$ é o j'-ésimo polinômio ortogonal previamente construído.

O método, então, define os polinômios ortogonais $\psi_{i}$ a partir do percurso na tabela de monômios: quando $j$ percorre a linha $r$ pelo intervalo $k_{j}(1,2$, ou 3$), j^{\prime}$ percorre os intervalos $k_{j}$ nos três intervalos na linha $r-1$ (note que em ambos percursos de $j$ e $j^{\prime}$ na linha $r$ e $r-1$ respectivamente, "passam" o mesmo número de monômios).

Quando $j$ pula do intervalo $k_{j}$ para $k_{j}+1, j^{\prime}$ é colocado novamente no início do intervalo $k_{j}+1$ na linha $r-1$. Também definimos um processo similar para o predecessor de $j^{\prime \prime}$, que utilizaremos no contexto de redução dos cálculos (Página 193).

Observação 13 Bartels e Jezioranski provaram que os polinômios $\psi_{i}$ são linearmente independentes [23], definindo então uma base.

$$
\begin{gathered}
\psi_{1}(\mathbf{x})=1, \\
\psi_{2}(\mathbf{x})=x_{1}-\frac{\sum_{i=1}^{n} x_{1}^{[i]} \omega^{[i]}}{\sum_{i=1}^{n} \omega^{[i]}}, \\
\psi_{3}(\mathbf{x})=x_{2}-\sum_{l=1}^{2} \frac{\sum_{i=1}^{n} x_{2}^{[i]} \psi_{l}^{[i]} \omega^{[i]}}{\sum_{i=1}^{n} \psi_{l}^{[i]} \psi_{l}^{[i]} \omega^{[i]}} \psi_{l}(\mathbf{x}), \\
\psi_{4}(\mathbf{x})=x_{3}-\sum_{l=1}^{3} \frac{\sum_{i=1}^{n} x_{3}^{[i]} \psi_{l}^{[i]} \omega^{[i]}}{\sum_{i=1}^{n} \psi_{l}^{[i]} \psi_{l}^{[i]} \omega^{[i]}} \psi_{l}(\mathbf{x}), \\
\psi_{5}(\mathbf{x})=x_{1} \psi_{2}(\mathbf{x})-\sum_{l=1}^{4} \frac{\sum_{i=1}^{n} x_{1}^{[i]} \psi_{2}^{[i]} \psi_{l}^{[i]} \omega^{[i]}}{\sum_{i=1}^{n} \psi_{l}^{[i]} \psi_{l}^{[i]} \omega^{[i]}} \psi_{l}(\mathbf{x}), \\
\psi_{6}(\mathbf{x})=x_{1} \psi_{3}(\mathbf{x})-\sum_{l=1}^{5} \frac{\sum_{i=1}^{n} x_{1}^{[i]} \psi_{3}^{[i]} \psi_{l}^{[i]} \omega^{[i]}}{\sum_{i=1}^{n} \psi_{l}^{[i]} \psi_{l}^{[i]} \omega^{[i]}} \psi_{l}(\mathbf{x}), \\
\psi_{7}(\mathbf{x})=x_{1} \psi_{4}(\mathbf{x})-\sum_{l=1}^{6} \frac{\sum_{i=1}^{n} x_{1}^{[i]} \psi_{4}^{[i]} \psi_{l}^{[i]} \omega^{[i]}}{\sum_{i=1}^{n} \psi_{l}^{[i]} \psi_{l}^{[i]} \omega^{[i]}} \psi_{l}(\mathbf{x}),
\end{gathered}
$$




$$
\begin{aligned}
& \psi_{8}(\mathbf{x})=x_{2} \psi_{3}(\mathbf{x})-\sum_{l=1}^{7} \frac{\sum_{i=1}^{n} x_{2}^{[i]} \psi_{3}^{[i]} \psi_{l}^{[i]} \omega^{[i]}}{\sum_{i=1}^{n} \psi_{l}^{[i]} \psi_{l}^{[i]} \omega^{[i]}} \psi_{l}(\mathbf{x}), \\
& \psi_{9}(\mathbf{x})=x_{2} \psi_{4}(\mathbf{x})-\sum_{l=1}^{8} \frac{\sum_{i=1}^{n} x_{2}^{[i]} \psi_{4}^{[i]} \psi_{l}^{[i]} \omega^{[i]}}{\sum_{i=1}^{n} \psi_{l}^{[i]} \psi_{l}^{[i]} \omega^{[i]}} \psi_{l}(\mathbf{x}), \\
& \psi_{10}(\mathbf{x})=x_{3} \psi_{4}(\mathbf{x})-\sum_{l=1}^{9} \frac{\sum_{i=1}^{n} x_{3}^{[i]} \psi_{4}^{[i]} \psi_{l}^{[i]} \omega^{[i]}}{\sum_{i=1}^{n} \psi_{l}^{[i]} \psi_{l}^{[i]} \omega^{[i]}} \psi_{l}(\mathbf{x}) .
\end{aligned}
$$

Como pode ser observado pela Equação 6.5, para a definição do $k$-ésimo polinômio, são necessários os $(k-1)$-ésimos polinômios previamente construídos. No entanto, Bartels e Jezioranski apresentam resultados que mostram que não são necessários todos os polinômios previamente calculados para o cálculo do próximo. Apresentamos, a seguir, os principais resultados.

\section{Evitando cálculos repetitivos}

A forma com que Bartels e Jezioranski dispõem os monômios para a construção dos polinômios ortogonais permitiu provar resultados que garantem a eficiência computacional da abordagem. Os dois primeiros resultados que enunciamos definem a generalização da recorrência de três termos, para polinômios de uma variável, em que pode-se definir o $k$ ésimo polinômio utilizando apenas o $(k-1)$ - e o $(k-2)$-ésimos polinômios previamente calculados. Dessa forma, Bartels e Jezioranski provaram que:

Teorema 3 ([23]) Se $x_{k_{j}} \beta(l) \prec \beta\left(j^{\prime}\right)$, então $\alpha_{j, l}=0$, em que $\prec$ significa que $x_{k_{j}} \beta(l)$ é definido antes de $\beta\left(j^{\prime}\right)$ no conjunto dos $\{\beta()$.$\} .$

\section{Teorema 4 ([23])}

$$
\forall i>j^{\prime \prime} \Rightarrow \alpha_{j, i}=0
$$

em que j" é o predecessor de j'.

Esses resultados definem a generalização da recorrência de três termos, pois garantem que alguns valores de $\alpha$ serão iguais a zero na construção dos polinômios. 
Além desses, outro resultado que alivia o custo computacional por relacionar produtos internos já calculados foi proposto:

Teorema 5 ([23]) Se j, l, p e m são tais que

$$
<x_{k_{j}} \psi_{j^{\prime}}, \psi_{l}>_{\omega}=<x_{k_{p}} \psi_{p^{\prime}}, \psi_{m}>_{\omega},
$$

então

$$
\alpha_{j, l}=\alpha_{p, m} \frac{<\Psi_{m}, \Psi_{m}>_{\omega}}{<\Psi_{l}, \Psi_{l}>_{\omega}} .
$$

\subsubsection{Definição da Aproximação Robusta Utilizando Polinômios Ortogonais}

No contexto do presente capítulo, uma aproximação robusta é aquela que considera não apenas as distâncias do ponto em avaliação $\mathbf{p}$ e dos pontos $\mathbf{x}_{i}$, mas também a diferença entre $f\left(\mathbf{x}_{i}\right)$ e $u\left(\mathbf{p}, \mathbf{x}_{i}\right)$, que pondera a influência dos valores da função nas amostras $\mathbf{x}_{i}$ sobre o resultado. Tal condição permite que o método seja capaz de preservar detalhes do objeto e também de evitar que ruídos de baixa freqüência exerçam grandes influências nos cálculos. Assim, realizamos a minimização robusta por meio da equação:

$$
\mathbf{R}(\mathbf{p})=\sum_{i=1}^{n} \Upsilon\left(\left(f\left(\mathbf{x}_{i}\right)-u\left(\mathbf{p}, \mathbf{x}_{i}\right)\right)^{2}\right) \omega_{i}(\mathbf{p}),
$$

em que

$$
\Upsilon(t)=1-\exp \left(-\frac{t}{2 \sigma_{\rho}}\right)
$$

e $\sigma_{\rho}$ é um parâmetro que determina a sensibilidade da variação dos valores da função. Esse tipo de minimização robusta também foi aplicada por Mederos et al. para a remoção de ruídos em nuvens de pontos [150]. Outras funções $\Upsilon$ que definem a aproximação robusta podem ser encontradas na literatura $[79,211]$.

Nesse caso, segundo Fenn et al. [79], o sistema de equações que minimiza $\mathbf{R}(\mathbf{p})$ é dado por: 


$$
\left\{\sum_{j=1}^{m}<\Psi_{i}, \Psi_{j}>_{\omega \Upsilon^{\prime}} c_{j}=<\Gamma, \Psi_{i}>_{\omega \Upsilon^{\prime}} ; i=1, \ldots, m\right.
$$

em que $\Upsilon^{\prime}$ é a primeira derivada de $\Upsilon \mathrm{e}$

$$
<\Psi_{j}, \Psi_{k}>_{\omega \Upsilon^{\prime}}=\sum_{i=1}^{n} \psi_{j_{i}} \psi_{k_{i}} \omega_{i}(\mathbf{p}) \Upsilon^{\prime}\left(\left(f\left(\mathbf{x}_{i}\right)-u\left(\mathbf{p}, \mathbf{x}_{i}\right)\right)^{2}\right)
$$

Note que a Minimização 6.7 é não-linear, pois o Produto Interno 6.8 também depende dos coeficientes de $u$. Dessa forma, ela é resolvida pelo método iteração do ponto-fixo [41].

Consideremos:

$$
u^{(t)}\left(\mathbf{p}, \mathbf{x}_{i}\right)=\sum_{j=1}^{m} c_{j}^{(t)}(\mathbf{p}) \psi_{j}\left(\mathbf{x}_{i}\right)
$$

como a solução da iteração $t$ e $\left(c_{1}^{(0)}(\mathbf{p}), \ldots, c_{m}^{(0)}(\mathbf{p})\right)$ como a estimativa inicial obtida pela solução da Equação 6.3, isto é, a solução inicial é dada pelo método de MLS. Dessa forma, os produtos internos são fixos para a iteração $t$, pois:

$$
<\Psi_{j}, \Psi_{k}>_{\omega \Upsilon^{\prime}}^{(t)}=\sum_{i=1}^{n} \psi_{j_{i}} \psi_{k_{i}} \omega\left(\left\|\mathbf{p}-\mathbf{x}_{i}\right\|\right) \Upsilon^{\prime}\left(\left(f\left(\mathbf{x}_{i}\right)-u^{(t-1)}\left(\mathbf{p}, \mathbf{x}_{i}\right)\right)^{2}\right),
$$

e a solução para a iteração $t+1$ é obtida pela solução do sistema:

$$
\left\{\sum_{j=1}^{m}<\Psi_{i}, \Psi_{j}>_{\omega \Upsilon^{\prime}}^{(t)} c_{j}^{(t)}=<\Gamma, \Psi_{i}>_{\omega \Upsilon^{\prime}}^{(t)} ; i=1, \ldots, m .\right.
$$

Portanto, para cada iteração, realizamos uma aproximação por MLS para encontrar o novo vetor $\left(c_{1}^{(t+1)}(\mathbf{p}), \ldots, c_{m}^{(t+1)}(\mathbf{p})\right)$. Embora a garantia de convergência não fosse, até o momento, estudada para o nosso método, em nossos testes cinco iterações foram suficientes para apresentarmos resultados satisfatórios, assumindo uma solução inicial oriunda do MLS. Notemos também que as funções $\Upsilon^{\prime}, \omega>0$, e monotonicamente decrescentes, as quais asseguram que $<,>\underset{\omega \Upsilon^{\prime}}{(t)}$ continuam definindo um produto interno. Conseqüentemente, podemos aplicar a ortogonalização proposta por Bartels e Jezioranski [23] para cada iteração.

Algoritmicamente, então, temos que a primeira aproximação da solução é dada por: 


$$
u^{(1)}(\mathbf{p})=\sum_{i=1}^{m} \psi_{i}(\mathbf{p}) \frac{<\Gamma, \Psi_{i}>_{\omega}}{<\Psi_{i}, \Psi_{i}>_{\omega}}
$$

A partir desse resultado, o processo iterativo é iniciado, onde em cada iteração $t$, um novo conjunto de polinômios ortogonais deve ser construído, utilizando o produto interno $<,>_{\omega \Upsilon^{\prime}}^{(t)}$. Portanto, uma nova aproximação é obtida por:

$$
u^{(t)}(\mathbf{p})=\sum_{i=1}^{m} \psi_{i}(\mathbf{p}) \frac{<\Gamma, \Psi_{i}>_{\omega \Upsilon^{\prime}}^{(t)}}{\left\langle\Psi_{i}, \Psi_{i}>_{\omega \Upsilon^{\prime}}^{(t)}\right.} .
$$

\subsubsection{Resultados e Discussões}

A implementação do método foi testada com grades cartesianas, grades curvilineares, malhas tetraedrais, malhas com refinamento adaptativo e malhas definidas por multiblocos. A partir dos testes realizados, notamos que a aproximação robusta é capaz de preservar detalhes e de filtrar dados ruidosos de baixa freqüência. Podemos notar tal fato na Figura 6.2 na qual apresentamos uma comparação com o método de Shepard [187], MLS e a nossa aproximação robusta. O método de Shepard é significativamente o mais rápido entre os comparados. No entanto, falha em termos de precisão ao passo que o método de MLS suaviza os dados.

Como mencionado anteriormente, comparamos o custo computacional e os métodos de solução dos mínimos-quadrados por meio de um resultado qualitativo. Utilizamos a decomposição QR com fatoração de Householder e a decomposição por valores singulares [172]. Ambos os métodos são aplicados diretamente no sistema de equações incompatíveis (como apresentado na Seção 3.1, Página 47), que evita a construção das equações normais que possuirem a desvantagem de elevar ao quadrado o número de condição da matriz [93, 30]. Também comparamos com o método de Gauss com pivotamento e com o método dos gradientes conjugados [189], ambos sobre as equações normais.

Apresentamos resultados qualitativos de uma fatia da grade curvilinear do Combustion Chamber (Figura 6.3). Para análise comparativa, também realizamos uma interpolação 

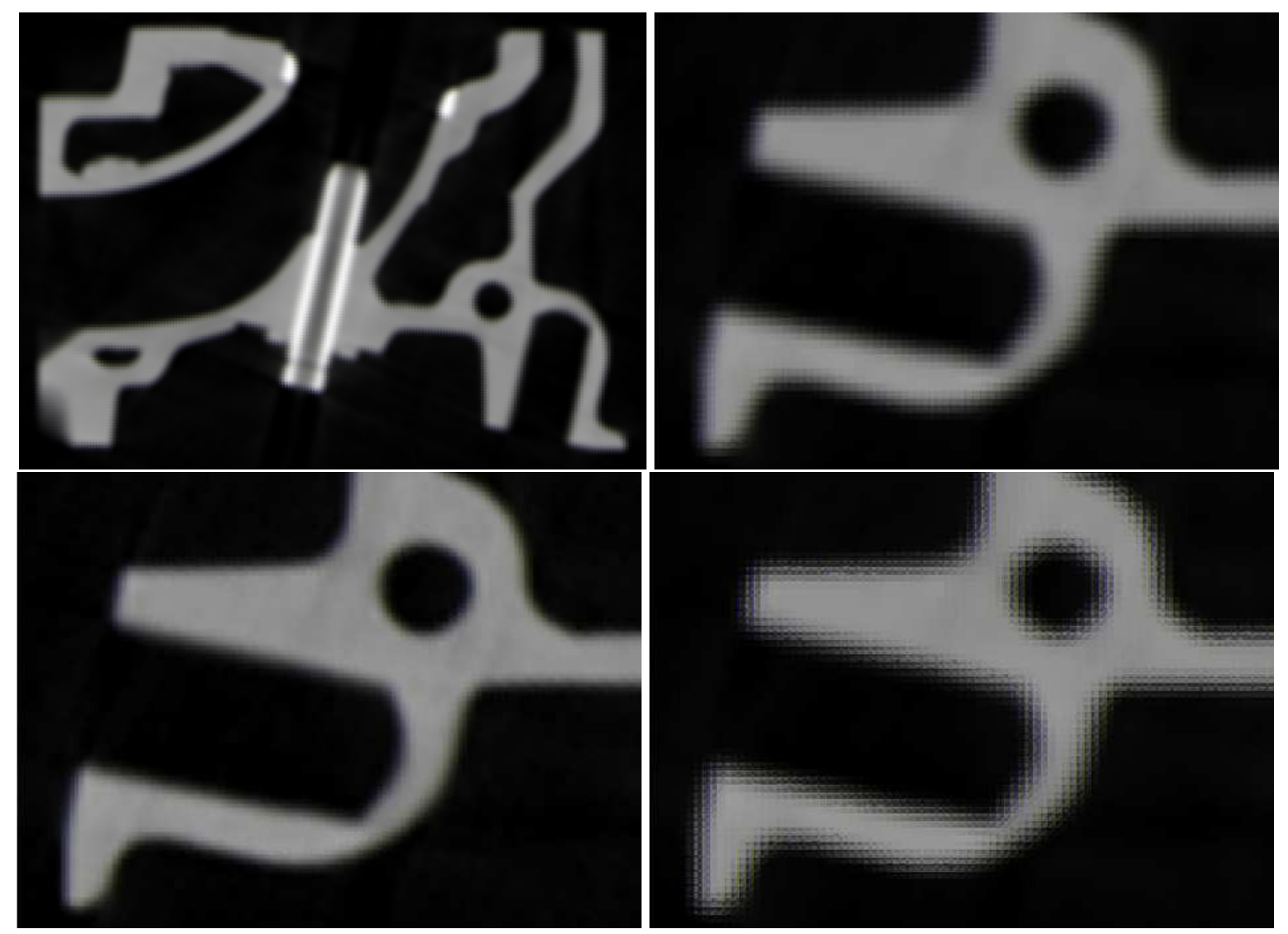

Figura 6.2: Fatia 82 do volume de dados Engine (topo-esquerda). Enquanto a aproximação por mínimos-quadrados-móveis suaviza a solução (topo-direita), a aproximação robusta preserva detalhes (base-esquerda). A aproximação de Sheperad (base-direita) também é apresentada para fins comparativos.

linear sobre a malha curvilinear original, decompondo as células em tetraedros, utilizando coordenadas baricêntricas. O tipo de dados utilizados para todos os testes foi float. É importante mencionarmos que, apesar de termos apresentado uma única fatia, a função foi aproximada no espaço tridimensional. É possível notar nas imagens que o método dos gradientes conjugados e de Gauss com pivotamento não foram capazes de apresentar bons resultados.

A decomposição por valores singulares e o método QR foram, como esperado, mais estáveis que a nossa escolha pelos polinômios ortogonais, embora consideravelmente mais lentos. Apresentamos, na Tabela 6.1, o desempenho do método em comparação com os demais. O desempenho foi medido em um PC Athlon com processador de $3.4 \mathrm{GHz}$ e $2 \mathrm{~GB}$ de 


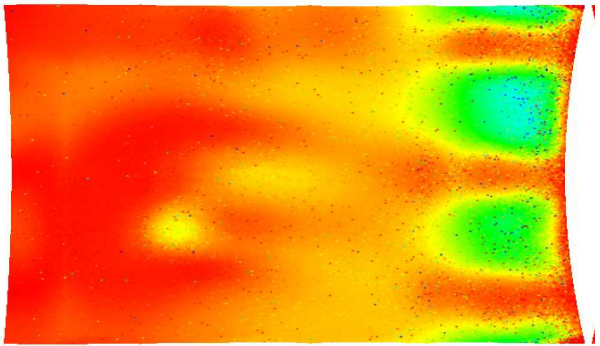

(a)

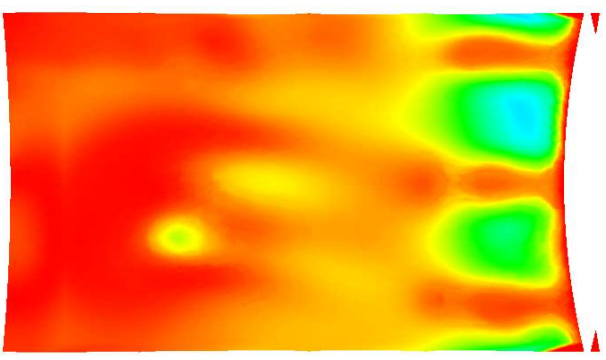

(c)

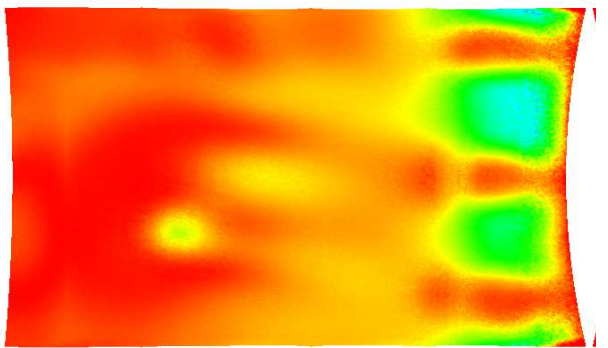

(e)

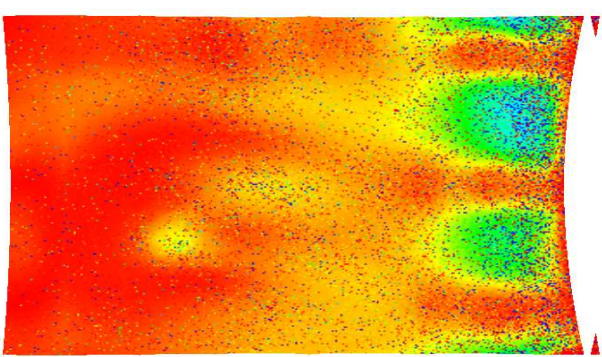

(b)

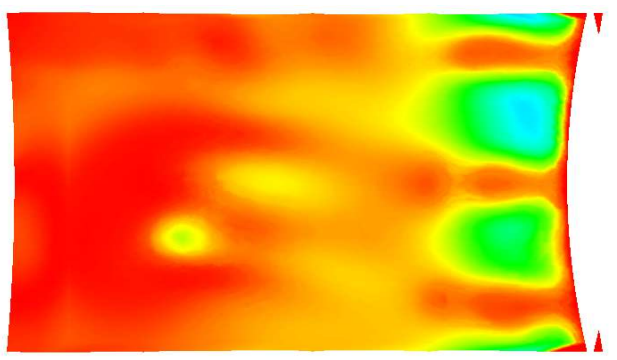

(d)

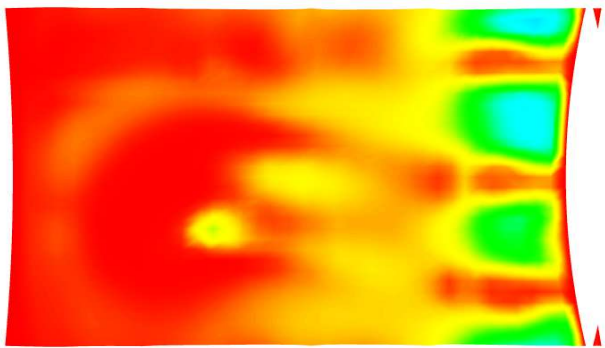

(f)

Figura 6.3: Aproximação (polinômio de grau 2) de dados volumétricos para uma fatia da malha curvilinear do Combustion Chamber: (a) Gauss com pivotamento, (b) gradientes conjugados, (c) QR, (d) SVD e (e) polinômios ortogonais. O ruído representa os pontos de avaliação da função onde ocorreram instabilidades, acarretarando uma aproximação pobre. Em (f) temos o resultado da interpolação linear sobre a malha original. 
memória RAM. Na tabela, apresentamos aproximações para polinômios de grau 2 a 4 .

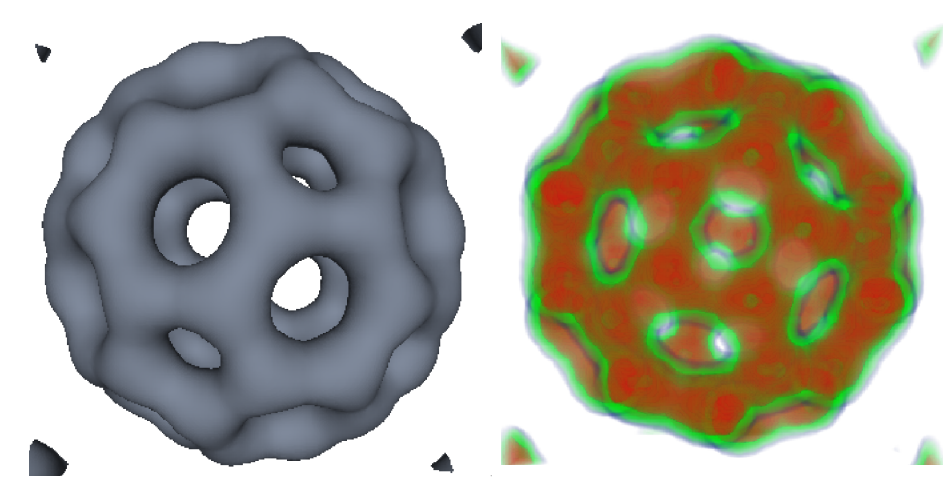

(a)
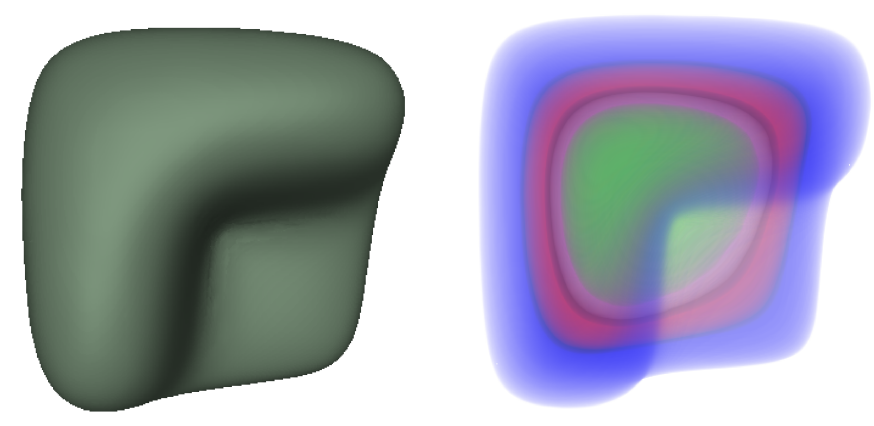

(b)
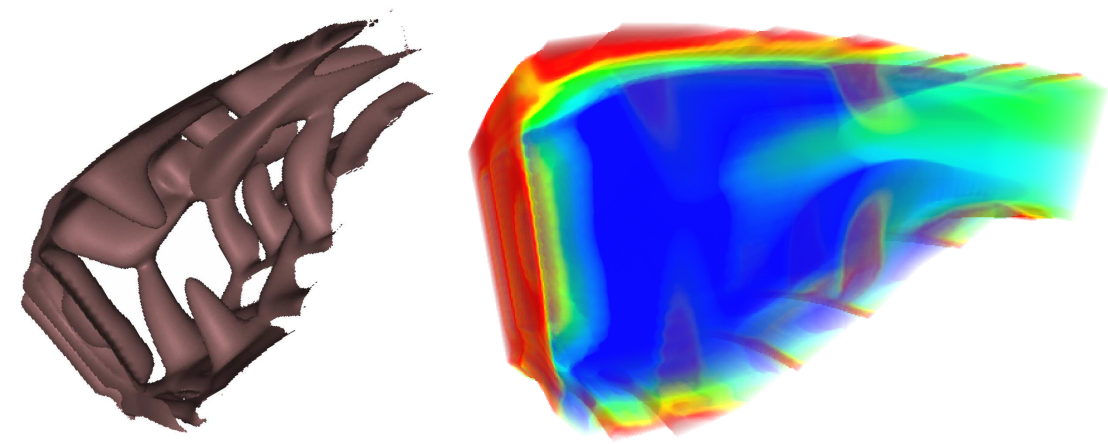

(c)

Figura 6.4: Rendering volumétrico e de iso-superfícies de diferentes volumes de dados: (a) Bucky Ball, grade cartesiana com $32^{3}$ voxels; (b) Heat Sink, malha não-estruturada com 121668 tetraedros; (c) Combustion Chamber (grade curvilinear) $27 \times 33 \times 25$.

Os resultados de rendering volumétrico e de iso-superfícies são apresentados nas Figuras 6.4 e 6.5, para diferentes tipos de dados. Note que as iso-superfícies são suaves, mesmo para as malhas com refinamento adaptativo e malhas definidas por multiblocos. Para esses testes, utilizamos polinômios de segundo grau e consideramos uma média de quarenta vizinhos. 

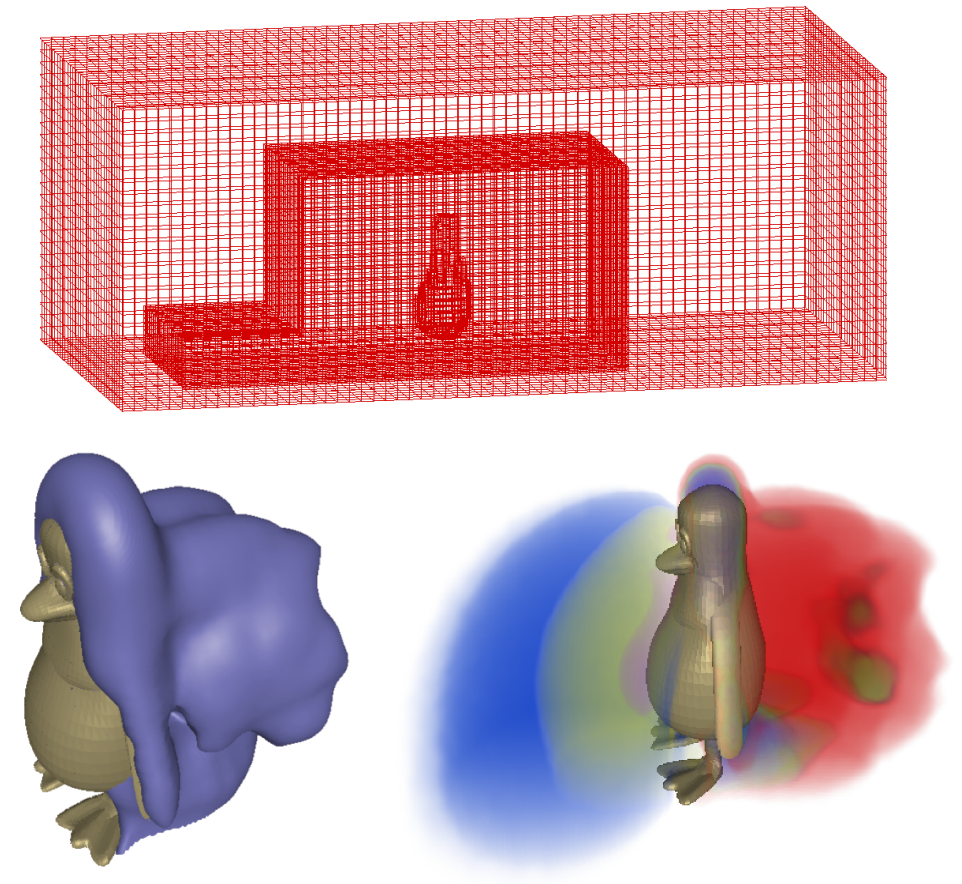

(a)

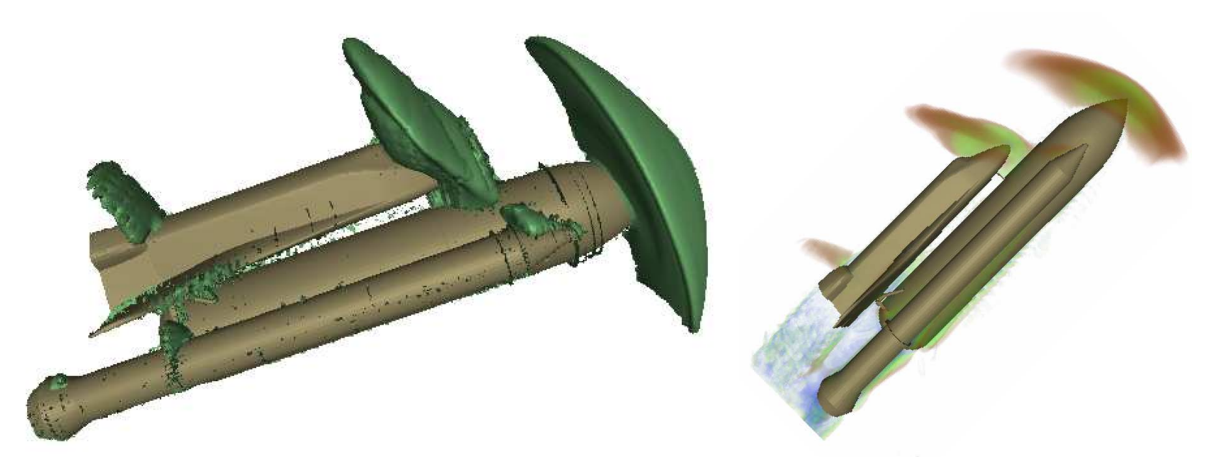

(b)

Figura 6.5: Rendering volumétrico e de iso-superfícies de diferentes volumes de dados: (a) Pingüim, malha com refinamento adaptativo contendo 115378 vértices e 106348 células (no topo apresentamos o wireframe da malha); (b) Ônibus Espacial com foguetes, malha por multiblocos com sobreposição de grades curvilinear, 9 malhas com 172139, 130060, 338653, 16951, 21846,15137, 36756, 8700 e 56206 vértices. 
Tabela 6.1: Tempo de processamento (em milissegundos) para uma única avaliação da aproximação da função com Polinômios ortogonais (PO), gradientes conjugados (GC), Gauss com pivotamento (GP), QR e SVD.

\begin{tabular}{c|ccccc} 
Grau do & \multicolumn{5}{|c}{ Método } \\
Polinômio & PO & GC & GP & QR & SVD \\
\hline 2 & 0.19 & 0.43 & 0.76 & 0.46 & 0.87 \\
3 & 0.47 & 0.61 & 0.93 & 1.15 & 2.84 \\
4 & 0.76 & 0.82 & 1.83 & 2.19 & 8.35
\end{tabular}

Os parâmetros $h$ e $\sigma_{p}$ foram escolhidos após alguns testes para cada modelo.

Também realizamos uma extensão do nosso método para acomodar pesos cujos suportes são elipsóides alinhados aos eixos coordenados. Isso permite lidar com malhas cujas células são bem esticadas nas direções dos eixos principais, para os quais um peso esférico pode falhar. Para cada ponto da avaliação, era procurado um conjunto de vizinhos até encontrarmos uma quantidade mínima em cada direção $x, y$ e $z$. A partir disso, tomávamos a distância ao vizinho mais próximo a cada direção para, então, definirmos um peso elíptico por meio de escalas.

A Figura 6.6 apresenta uma comparação entre o peso gaussiano e o peso elíptico, por meio do qual podemos notar que, para o presente modelo, o resultado obtido com os pesos elípticos é melhor. A principal limitação desse tipo de peso se deve ao fato de os suportes serem alinhados aos eixos coordenados, o que não permite lidar com qualquer tipo de distribuição de pontos de forma eficiente.

\subsection{Reconstrução de Dados Volumétricos por iaMLS Anisotrópico}

Na seção anterior, apresentamos o nosso método de reconstrução de dados volumétricos que utiliza filtros bilaterais com MLS. Nessa seção, apresentamos nosso outro método de reconstrução de dados volumétricos que faz uso do iaMLS. Ao contrário do método tradicional de iaMLS, que utiliza pesos com suportes esféricos para definir as aproximações, no presente método utilizamos pesos elipsoidais para realizar as aproximações, com o intuito de definir um método que, como no caso anterior, fosse independente do tipo de 

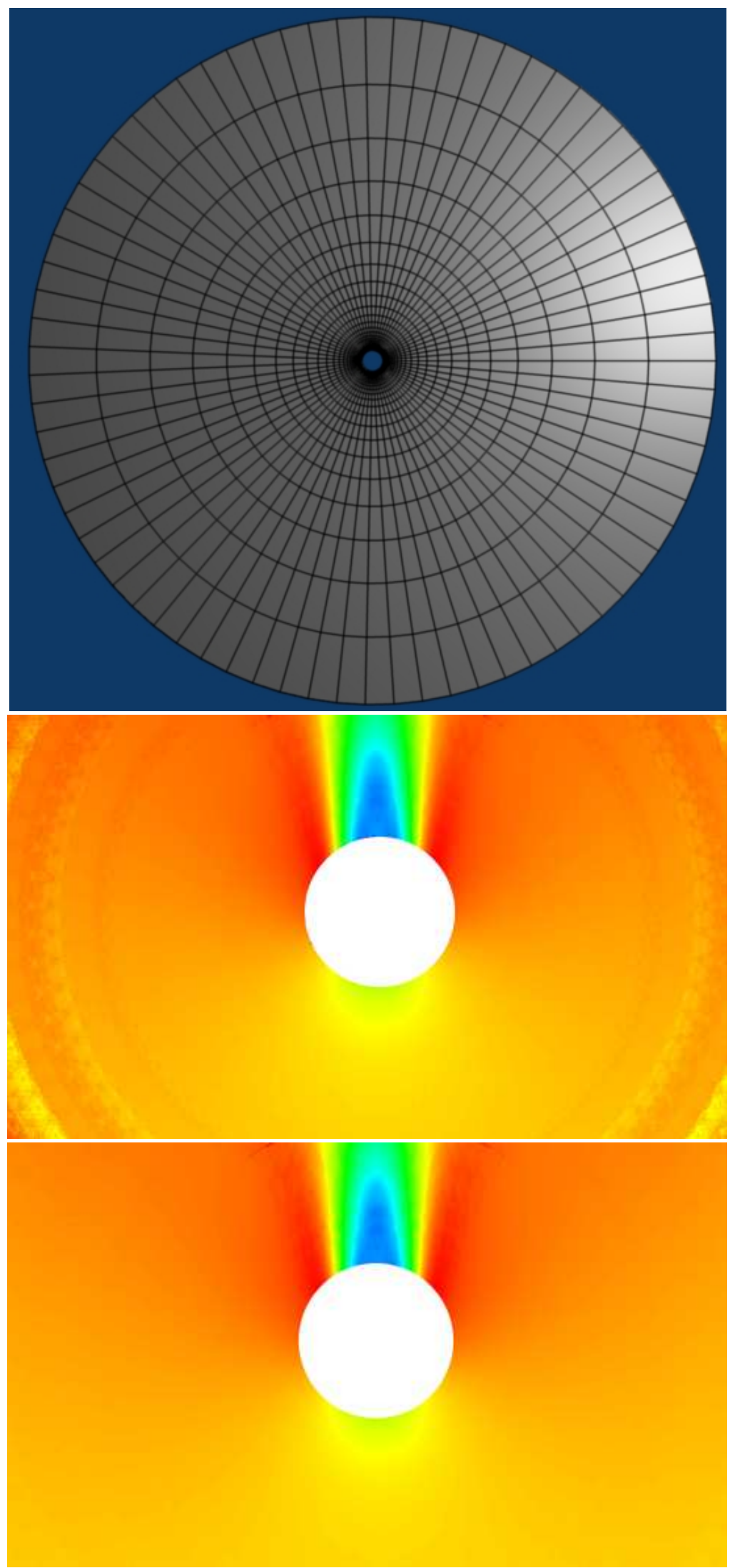

Figura 6.6: Conjunto de dados Oxygen Post: wireframe (topo) e o rendering resultante utilizando pesos esféricos (meio) e elipsoidais (base). 
malha.

\section{Espaço Anisotrópico}

Para cada vértice $\mathbf{x}_{i}$ da malha, calculamos o conjunto de vértices:

$$
\mathbb{V}_{i}=\left\{\mathbf{x}_{j} \in \mathbb{X}: \mathbf{x}_{j} \in \operatorname{star}\left(\mathbf{x}_{i}\right)\right\}
$$

que compartilham uma aresta da malha com $\mathbf{x}_{i}$ (estrela do vértice). Então, calculamos a co-variância dos pontos em $\mathbb{V}_{i}$. Com isso, os autovetores $\mathbf{e}_{1}, \mathbf{e}_{2}$ e $\mathbf{e}_{3}$ determinam as direções dos eixos de um elipsóide (ou suporte $\mathrm{em} \mathbf{x}_{i}$ ), que define a anisotropia localmente. Determinamos o comprimento dos eixos do elipsóide pela distância máxima em cada direção do domínio entre $\mathbf{x} \in \mathbb{V}_{i}$ e $\mathbf{x}_{i}$; isto é, $\delta_{k}=\max _{\mathbf{x} \in \mathbb{V}_{i}}\left|<\mathbf{x}-\mathbf{x}_{i}, \mathbf{e}_{k}>\right|$, em que $2 \delta_{k}$ determina o comprimento do eixo do elipsóide na direção $\mathbf{e}_{k}$. Dessa forma, a matriz $\mathbf{M}_{\mathbf{i}}$, para cada $\mathbf{x}_{i}$, é dada por:

$$
\mathbf{M}_{\mathbf{i}}=\operatorname{diag}\left(\delta_{1}, \delta_{2}, \delta_{3}\right)\left[\begin{array}{l}
\mathbf{e}_{1} \\
\mathbf{e}_{2} \\
\mathbf{e}_{3}
\end{array}\right],
$$

em que a matriz diagonal é uma matriz de escala $\mathbf{S}$ e a matriz definida pelos autovetores é uma matriz de rotação $\mathbf{R}$.

Portanto, para aplicar o nosso problema de reconstrução da função em um domínio anisotrópico, precisamos definir a matriz simétrica e definida positiva, como no trabalho de Jang et al. [111]:

$$
\mathbf{A}_{i}=\mathbf{R S}^{-1} \mathbf{S}^{-1} \mathbf{R}^{t}
$$

sendo $\mathbf{R}^{-1}=\mathbf{R}^{t}$.

Assim, ao contrário do método iaMLS original, que foi definido pelo produto interno canônico, isto é, em um espaço isotrópico, utilizamos o produto interno induzido pela matriz positiva definida A: 


$$
<\mathbf{x}, \mathbf{y}>_{\mathbf{A}}=\mathbf{x}^{t} \mathbf{A y}
$$

Portanto, aplicando a anisotropia à função Laguerre-Gaussiana de segunda ordem, sugerida por Fazzhauer e Zhang [77], temos:

$$
\Psi_{i}(\mathbf{x})=\frac{\epsilon^{3}}{\pi^{3 / 2}} \exp \left(-\hat{r}_{i}(\mathbf{x})\right)
$$

que é a função geradora para a amostra $\mathbf{x}_{i}$, em que

$$
\hat{r}_{i}(\mathbf{x})=\frac{\epsilon^{2} \hat{\mathbf{x}}_{i} \mathbf{A}_{i} \hat{\mathbf{x}}_{i}^{T}}{h^{2}}
$$

$\mathrm{e} \hat{\mathbf{x}}_{i}=\mathbf{x}-\mathbf{x}_{i}$

Notemos que poderíamos utilizar funções geradoras definidas positivas de alta ordem [77], como sugerido por Fasshauer. Além disso, também é importante observarmos que fazemos uso do mesmo valor de $h$ para cada ponto.

\section{Estimativa do Vetor Gradiente}

Estimamos o vetor gradiente em um ponto arbitrário do interior da malha também pelo uso do iaMLS. Para isso, precisamos definir, para cada vértice da malha, uma estimativa do vetor gradiente, no qual obtemos por meio de mínimos-quadrados, estendendo o trabalho de Dimitri [143] para o espaço tridimensional. A vantagem desse procedimento se deve ao fato de nosso método continuar independente de malha.

Consideremos um ponto $\mathbf{x}_{i}$ em que desejamos avaliar o gradiente da função e seus vizinhos $\mathbf{x}_{k}=\left(x_{k}, y_{k}, z_{k}\right) \in \mathbb{V}\left(\mathbf{x}_{i}\right)$. Para isso, realizamos a minimização da seguinte expressão em relação à $\nabla f\left(\mathbf{x}_{i}\right)=\left(\left(f_{x}\right)_{i},\left(f_{y}\right)_{i},\left(f_{z}\right)_{i}\right)$ :

$$
\sum_{\mathbf{x}_{k} \in \mathbb{V}_{i}} \exp \left(-<\mathbf{x}_{k}-\mathbf{x}_{i}, \mathbf{x}_{k}-\mathbf{x}_{i}>\right)\left(E_{i k}\right)^{2}
$$

em que:

$$
E_{i k}=\left(\left(f_{x}\right)_{i} \cdot d x_{i k}+\left(f_{y}\right)_{i} \cdot d y_{i k}+\left(f_{z}\right)_{i} \cdot d z_{i k}-d f_{i k}\right)
$$


em $d f_{i k}=f\left(\mathbf{x}_{k}\right)-f\left(\mathbf{x}_{i}\right)$ e analogamente $d x_{i k}=x_{k}-x_{i}, d y_{i k}=y_{k}-y_{i}, d z_{i k}=z_{k}-z_{i}$.

Notemos que o número de pontos na estrela [88] de $\mathbf{x}_{i}$ é, em geral, pequeno, influenciando no baixo custo da solução. Além disso, pontos podem estar posicionados arbitrariamente, podendo gerar um sistema mal condicionado. Dessa forma, resolvemos tal problema de minimização utilizando a decomposição em valores singulares [172].

Com isso, da mesma forma que aproximamos a função volumétrica, utilizando o método iaMLS (Equações 3.32-3.33, Página 69), aproximamos o vetor gradiente para um ponto $\mathbf{x}$ no interior da malha pelo processo iterativo:

$$
\begin{gathered}
\mathscr{Q}_{\nabla f}(\mathbf{x})^{(0)}=\sum_{\mathbf{x}_{i} \in \mathbb{X}} \nabla f\left(\mathbf{x}_{i}\right) \Psi_{i}(\mathbf{x}), \\
\mathscr{Q}_{\nabla f}^{(n+1)}(\mathbf{x})=\mathscr{Q}_{\nabla f}^{(n)}(\mathbf{x})+\sum_{\mathbf{x}_{i} \in \mathbb{X}}\left[\nabla f\left(\mathbf{x}_{i}\right)-\mathscr{Q}_{\nabla f}^{(n)}\left(\mathbf{x}_{i}\right)\right] \Psi_{i}(\mathbf{x}) .
\end{gathered}
$$

\section{Implementação em GPU}

Como mencionado anteriormente, fazemos uso de GPU para acelerar o processo de rendering. A implementação em GPU foi feita em OpenGl 2.0 e completamente idealizada e implementada por nossos colaboradores da Universidade de Stuttgart ${ }^{1}$. Dessa forma, dedicamos esta seção apenas aos aspectos computacionais relacionados ao método numérico de aproximação em GPU. Na abordagem, foi proposto um conjunto de précálculos, realizados em CPU para serem armazenados em texturas, com o intuito de otimizar o processo. Dois conjuntos de pré-cálculos foram possíveis devido à natureza do iaMLS, que são relacionados à aproximação da função e do vetor gradiente. É importante mencionarmos que também pré-calculamos as matrizes $\mathbf{A}_{i}$ de cada vértice.

Os seguintes pré-cálculos são significativamente importantes para acelerar o processo de rendering e só foram possíveis devido à forma em que o método iaMLS foi concebido. Isto é, reescrevendo a Equação 3.33 (Página 69), da seguinte forma:

\footnotetext{
${ }^{1}$ http://www.vis.uni-stuttgart.de/eng/
} 


$$
\mathscr{Q}_{f}^{(n+1)}(\mathbf{x})=\sum_{\mathbf{x}_{i} \in \mathbb{X}}\left[f\left(\mathbf{x}_{i}\right)+\sum_{\mathbf{x}_{i} \in \mathbb{X}}\left(f\left(\mathbf{x}_{i}\right)-\mathscr{Q}_{f}^{(j)}\left(\mathbf{x}_{i}\right)\right)\right] \Psi_{i}(\mathbf{x}),
$$

pudemos acumular os resultados do processo iterativo em cada vértice como:

$$
g\left(\mathbf{x}_{i}\right)=f\left(\mathbf{x}_{i}\right)+\sum_{\mathbf{x}_{i} \in \mathbb{X}}\left(f\left(\mathbf{x}_{i}\right)-\mathscr{Q}_{f}^{(j)}\left(\mathbf{x}_{i}\right)\right)
$$

e armazená-los na textura que contém o dado volumétrico. Dessa maneira, durante o rendering, o valor reconstruído da função é simplesmente dado por:

$$
\mathscr{Q} f^{(n+1)}(\mathbf{x})=\sum_{\mathbf{x}_{i} \in \mathbb{X}} g\left(\mathbf{x}_{i}\right) \Psi_{i}(\mathbf{x})
$$

Além do pré-cálculo do valor das funções $g\left(\mathbf{x}_{i}\right)$, seguindo o mesmo princípio, os gradientes nos vértices da malha também são pré-calculados.

\subsubsection{Resultados}

Em nossos testes, aplicamos funções Laguerre-Gaussianas de ordem $O\left(h^{2}\right)$ esperando alcançar resultados semelhantes aos de interpolação linear em coordenadas baricêntricas nos tetraedros da malha. Assim, para efeito comparativo, nas malhas onde as células eram simplesmente cubos, aplicamos uma decomposição em tetraedros. Também destacamos que a atual implementação em GPU está limitada a malhas convexas. Dessa forma, todos os resultados foram gerados assumindo tal restrição nas malhas. Os resultados numéricos das malhas não-estruturadas estão apresentados na Tabela 6.2, apresentamos o erro médio e máximo para as seguintes funções-testes: 
Tabela 6.2: Erro médio e máximo para funções-testes em malhas tetraedrais.

$$
\begin{aligned}
& \text { Função iaMLS Interpolação Linear } \\
& f_{1} \quad 1 \mathrm{e}-3 / 8 \mathrm{e}-2 \quad 1 \mathrm{e}-3 / 6 \mathrm{e}-2 \\
& f_{2} \quad 8 \mathrm{e}-4 / 5 \mathrm{e}-2 \quad 9 \mathrm{e}-4 / 4 \mathrm{e}-2 \\
& f_{3} \quad 2 \mathrm{e}-3 / 4 \mathrm{e}-2 \quad 1 \mathrm{e}-3 / 3 \mathrm{e}-2 \\
& f_{1}(x, y, z)=0.75 \exp \left[-\frac{(9 x-2)^{2}+(9 y-2)^{2}+(9 z-2)^{2}}{4}\right] \\
& +\quad 0.75 \exp \left[-\frac{(9 x+1)^{2}}{49}-\frac{(9 y+1)^{2}}{10}-\frac{(9 z+1)^{2}}{10}\right] \\
& +0.5 \exp \left[-\frac{(9 x-7)^{2}+(9 y-3)^{2}+(9 z-5)^{2}}{4}\right] \\
& -0.2 \exp \left[-(9 x-4)^{2}-(9 y-7)^{2}-(9 z-5)^{2}\right] \text {, } \\
& f_{2}(x, y, z)=\frac{(\tanh (9 z-9 x-9 y)+1)}{9} \text {, } \\
& f_{3}(x, y, z)=\frac{(1.25+\cos (5.4 y)(\cos (6 z)))}{\left(6+6(3 x-1)^{2}\right)},
\end{aligned}
$$

amostradas nos vértices dos tetraedros. O domínio das funções era $C=[0,1] \times[0,1] \times[0,1]$ e suas imagens eram $[-0,1,1.1],[0.0,0.22]$ e $[-0.37,0.37]$, respectivamente.

É importante notarmos que, em todos os testes, o método atingiu um estado estacionário, porém de forma extremamente lenta. Como argumentado por Fasshauer e Zhang [77], outros valores de $\epsilon$ podem fazer com que o método atingia o estado estacionário mais rápido, no entanto, a técnica fica sujeita a instabilidades.

Na Figura 6.7, mostramos a qualidade da reconstrução para a função-teste de MarschnerLobb [142] (Figura 6.7-(a)), dada pela Equação:

$$
\rho(x, y, z)=\frac{1-\operatorname{sen}(\pi z / 2)+\alpha\left(1+\cos \left(2 \pi \varphi \cos \left(\pi\left(\sqrt{x^{2}+y^{2}}\right) / 2\right)\right)\right)}{2(1+\alpha)}
$$

no qual tomamos $\alpha=0.25, \varphi=0.6$ e isovalor $\rho(x, y, z)=0.5$.

Novamente, nosso método (Figura 6.7-(d)) realizou uma melhoria modesta em relação a interpolação linear (Figura 6.7-(c)). E, como esperado, a spline cúbica de Catmull-Rom [50] (Figura 6.7-(b)) apresentou resultado superior. 


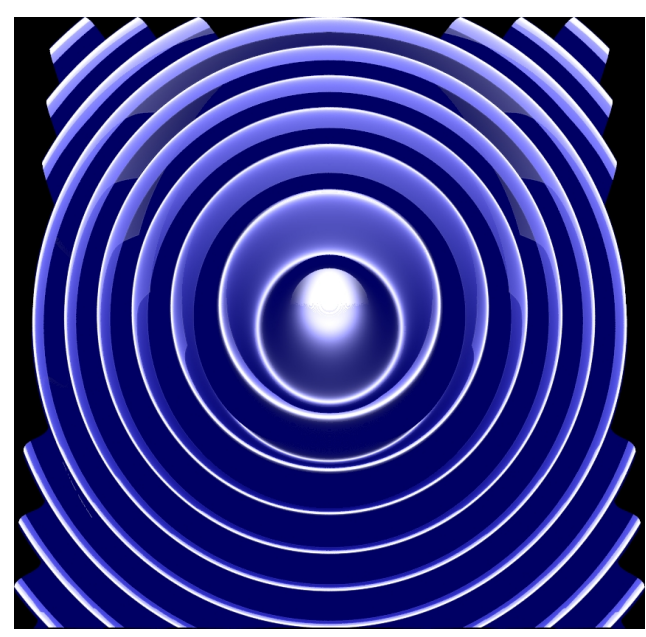

(a)

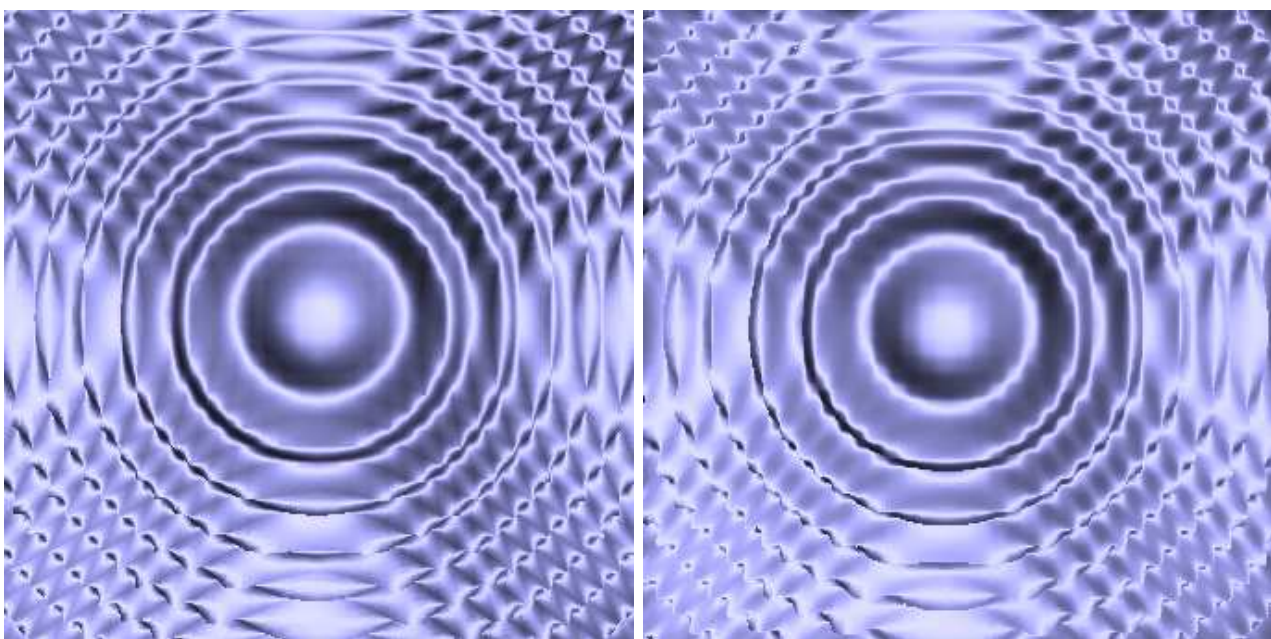

(c)

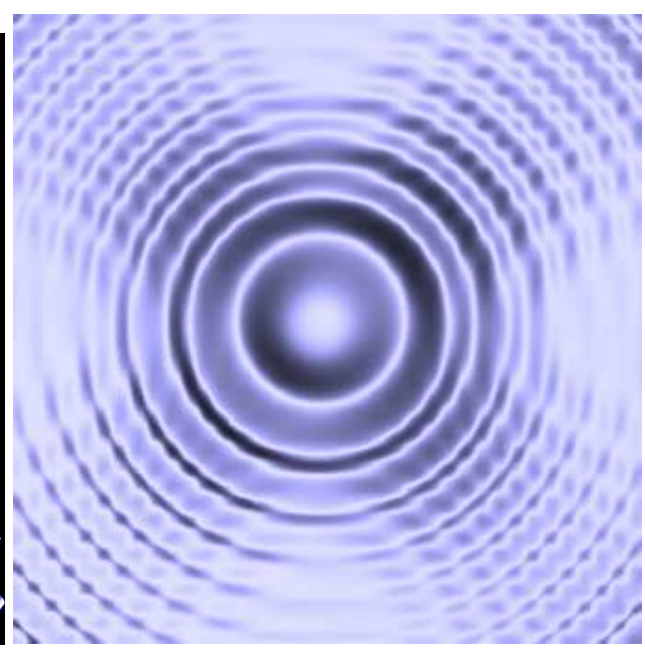

(b)

(d)

Figura 6.7: Comparação visual do rendering da iso-superfície (ray-casting) da Função 6.18, em (a): em (b), aproximação pela spline cúbica de Catmull-Rom; em (c), interpolação linear e; em (d), iaMLS. 
Tabela 6.3: Tempo de rendering da imagem (em segundos).

\begin{tabular}{cc} 
& Tempo \\
\hline Heat Sink & 11.64 \\
Oxygen Post & 4.45 \\
Fighter (70215 tetraedros) & 2.95 \\
Blunt Fin & 2.97 \\
Bucky Ball & 8.63 \\
Combustion Chamber & 10.09
\end{tabular}

Considerando tempo de desempenho, todos os testes foram realizados utilizando uma placa de vídeo Nvidia GeForce 8800 Ultra. A principal dificuldade na implementação do método para GPU foi encontrar uma técnica eficiente para lidar com buscas por vizinhos. Foi utilizada uma $k d$-tree que permitiu limitar o número de vértices visitados para reconstrução da função num ponto dado, mas o desempenho diminuiu drasticamente devido ao número de passagens pelo render. Programar o método em um único passo de rendering é um desafio futuro a ser investigado. Demonstramos o tempo utilizado para gerar a imagem dos conjuntos de dados na Tabela 6.3.

Os resultados de rendering são apresentados nas Figuras 6.8, 6.9 e 6.10 com diferentes malhas estruturadas e não-estruturadas. Em todos os casos, inclusive para os testes numéricos anteriores, utilizamos $h=0.25$ e parâmetro $\epsilon=0.9$. A utilização desses valores gerou resultados visuais satisfatórios. Obviamente, precisamos definir de forma mais rigorosa as estimativas para os parâmetros $h$ e $\epsilon$.

\subsection{Conclusão}

Neste capítulo, apresentamos nossas abordagens para a reconstrução de função a partir de dados volumétricos não-organizados, originados de malhas arbitrárias.

O primeiro método que apresentamos fez o uso de uma aproximação robusta de dados volumétricos, utilizando bases de polinômios ortogonais para o produto interno induzido pelas equações normais. Os resultados apresentados se mostraram satisfatórios. Contudo, as duas principais dificuldades computacionais do método são a definição das 


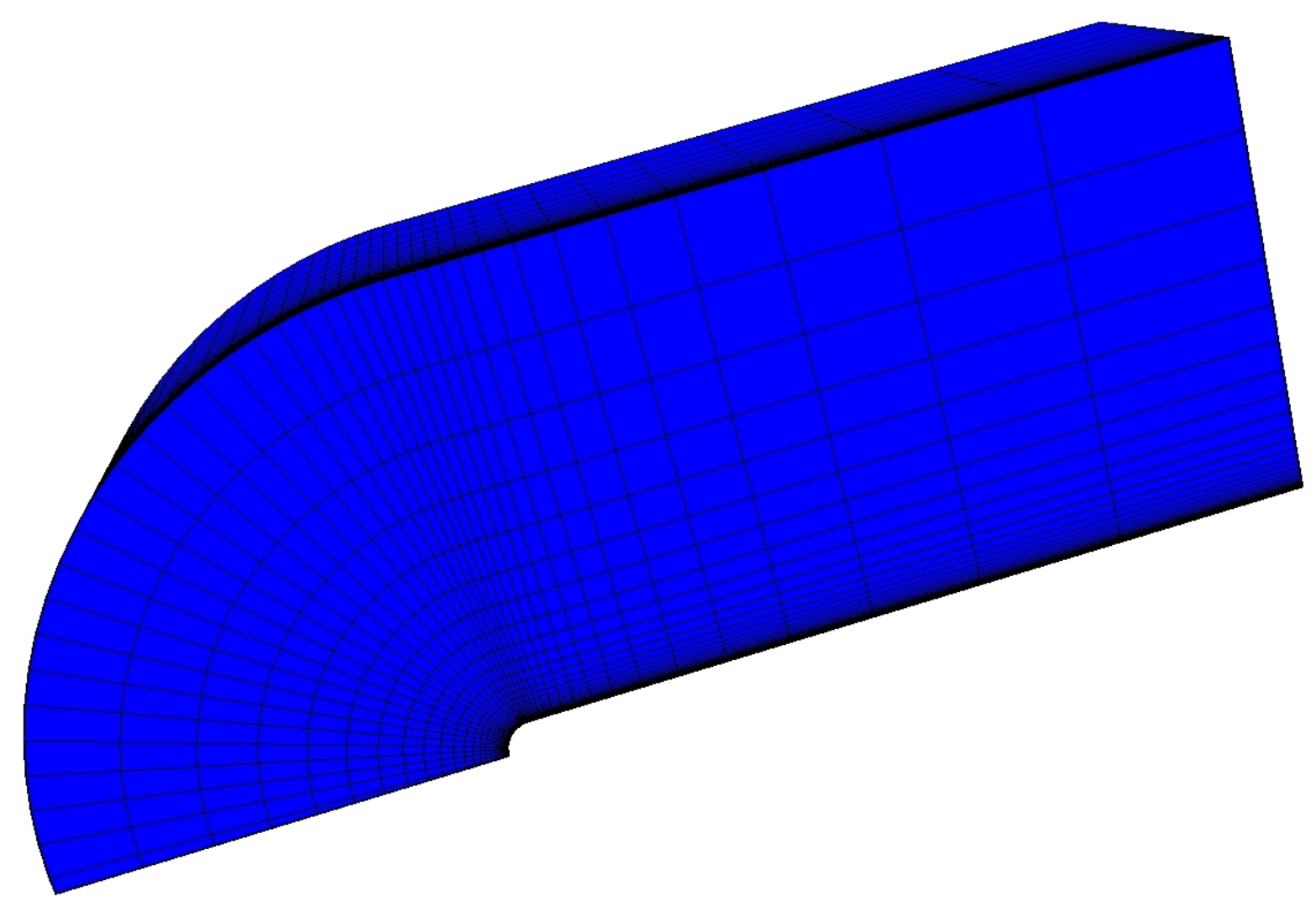

(a)

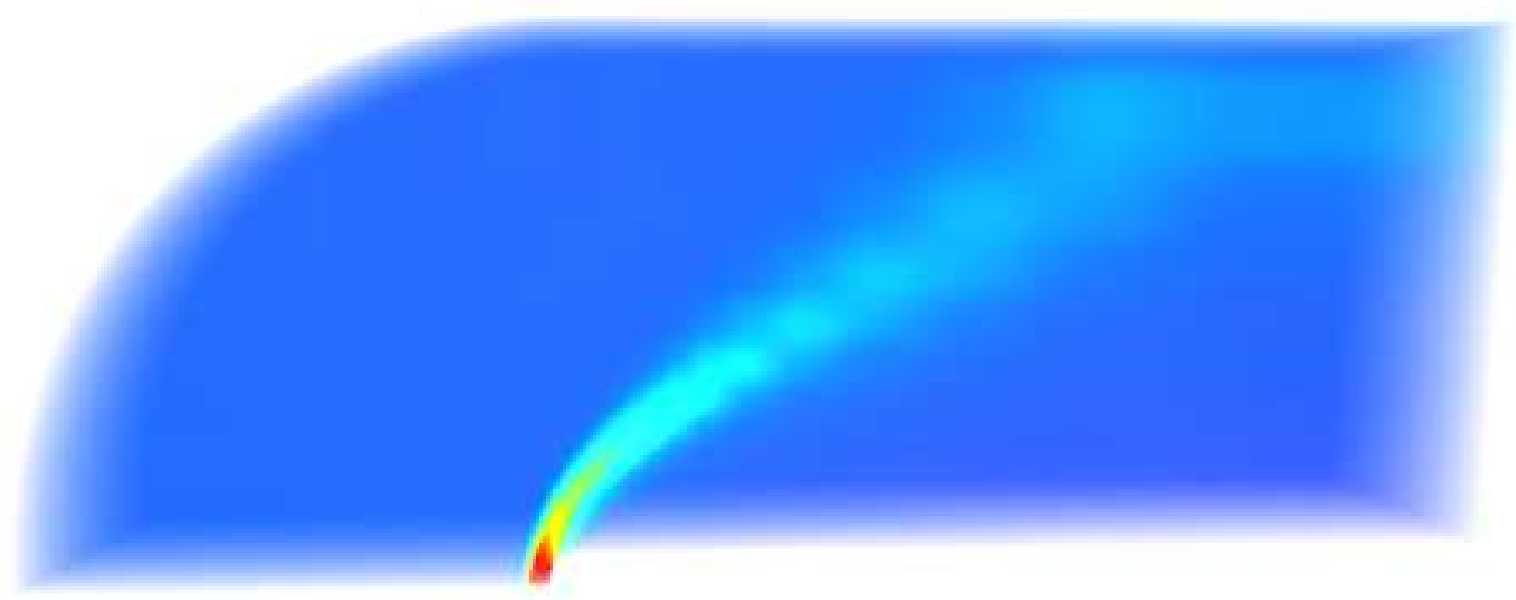

(b)

Figura 6.8: Conjunto de dados Blunt Fin $(40 \times 32 \times 32$ células): (a) wireframe do modelo; (b) rendering volumétrico. 

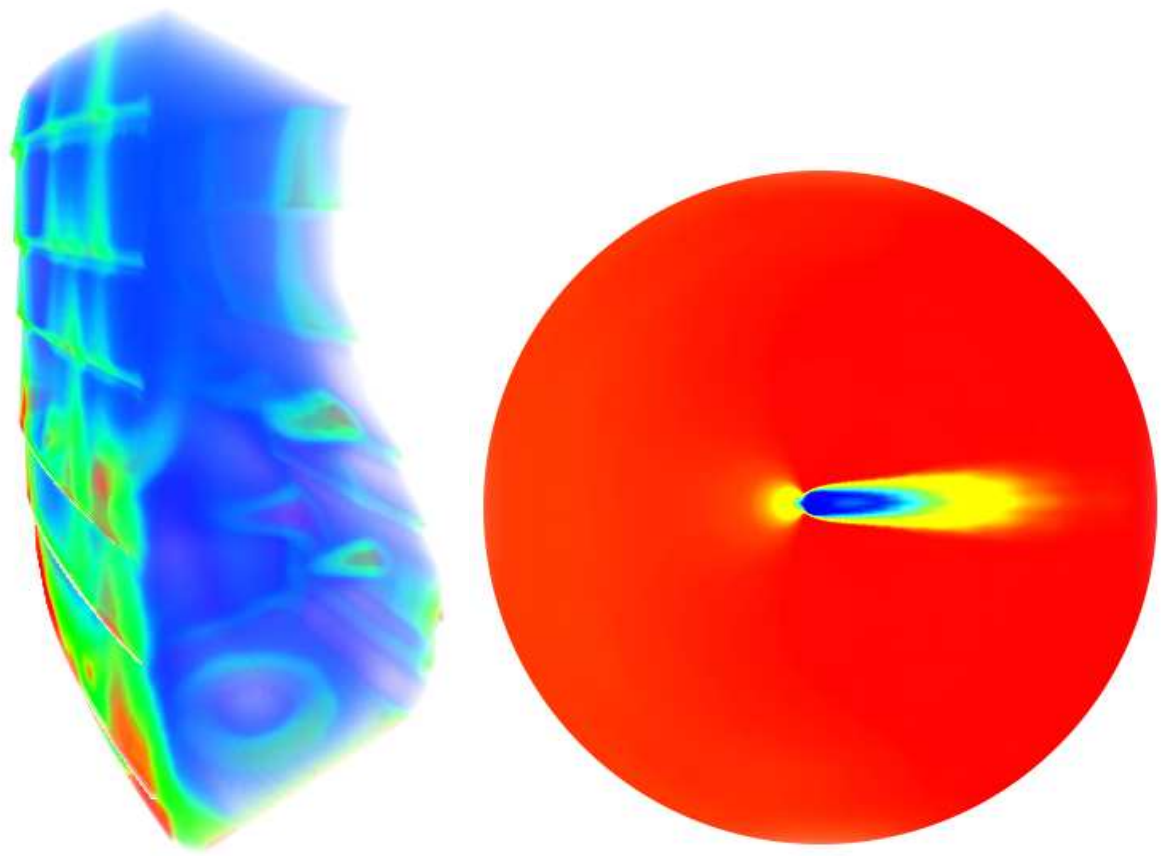

Figura 6.9: Rendering volumétrico dos conjuntos de dados: à esquerda, Combustion Chamber $(57 \times 33 \times 25$ células) e, a direita, Oxygen Post $(38 \times 76 \times 38$ células) .

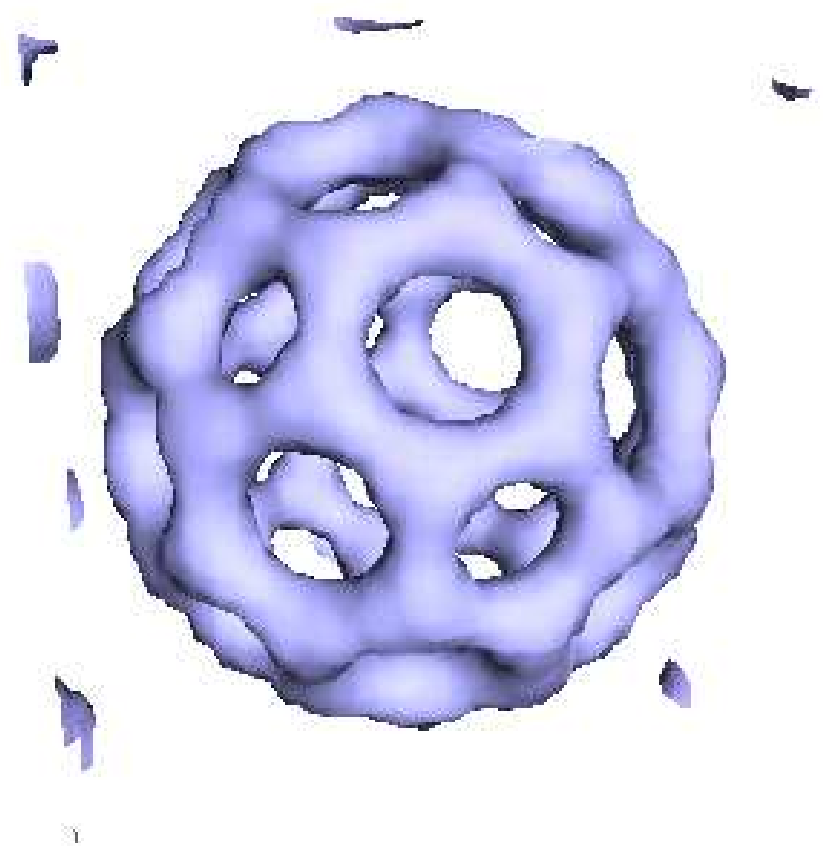

Figura 6.10: Rendering de iso-superfície do conjunto Bucky Ball ( $32^{3}$ células). 
aproximações locais e o processo de busca espacial por vizinhos, que torna o processo custoso.

Apresentamos algumas comparações que pretendemos estender, entre elas, análises quantitativas entre os métodos de minimização (QR, SVD, Gauss com pivotamento e gradientes conjugados), e também, a relação entre a aproximação robusta e a aproximação simplesmente por MLS. Pelo fato de a abordagem ser livre de sistemas, acreditamos que existe um potencial nessa metodologia para uma implementação dos polinômios ortogonais em GPU.

Já o segundo método que propusemos é computacionalmente mais eficiente que o anterior. Nesse, também objetivando apresentar um esquema para rendering de malhas definidas por geometrias e topologias arbitrárias, fizemos uso de um resultado recente da teoria de aproximação denominado o iaMLS. Entretanto, ao contrário do método original, desenvolvemos nossa aplicação para espaços anisotrópicos. A implementação foi realizada em GPU, demonstrando que o custo computacional dessa abordagem não é tão elevado, porém que ainda está longe dos métodos desenvolvidos para cada tipo de malha em específico, os quais são capazes de realizar visualizações em tempo real.

Apresentamos resultados e comparações numéricas em relação aos métodos clássicos. Como discutido previamente, não presenciamos instabilidades, mas o método necessitava de muitas iterações para alcançar um estado estacionário. Logo, o trabalho futuro mais imediato será focado na análise do desempenho e no estudo dos parâmetros, de forma similar à conduzida por Fasshauer e Zhang [77]. Buscaremos com isso, a capacidade de definir parâmetros ótimos para nossas aplicações. Também pretendemos estudar e implementar o filtro anisotrópico de Dihn et al. [64], que seleciona um subconjunto de elipsóide, podendo diminuir o custo computacional do método.

Como pudemos verificar, esse trabalho abre margem para diversos trabalhos futuros. A utilização de funções geradoras de alta ordem e o estudo da ordem de convergência do método também estão entre eles. Além desses, na versão atual do código implementado para GPU, existe a limitação de que as malhas devem ser convexas. Pretendemos desen- 
volver mecanismos para estender esse resultado para malhas não-convexas e de geometrias arbitrárias. 


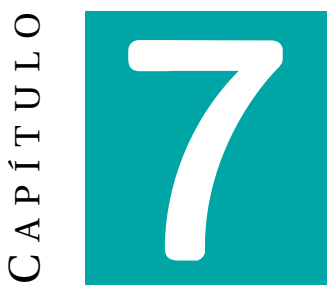

\section{Conclusão}

Modelos tridimensionais estão presentes em diversas áreas científicas, tecnológicas e de entretenimento. Por conseguinte, tarefas de definição, manipulação e visualização desses modelos impulsionam pesquisas e investimentos em computação gráfica, em modelagem geométrica, em engenharias, entre outras.

Uma vertente de modelagem geométrica consiste na definição de métodos de representação automática ou semi-automática a partir de pontos não-organizados, extraídos de superfícies arbitrárias. Segundo Hoppe et al. [107], tais métodos podem ser vistos como "metodologias unificantes", pois assumem como entrada a forma mais simples de dados pontos não-organizados e sem qualquer informação de conectividade - podendo, assim, ser aplicados a qualquer problema cujos dados permitam ser reduzidos a pontos, por exemplo, seqüências de imagens [156].

Apesar de o problema de representação de superfícies a partir de pontos não-organizados com topologia e geometria arbitrárias não ser recente, os aprimoramentos desses métodos continuam sendo necessários. Principalmente partindo dos requisitos de áreas que deles fazem uso, por exemplo, em simulação numérica de escoamentos de fluidos com superfície livre, na qual existe a necessidade de que a normal e a curvatura sejam eficientemente calculadas sobre a superfície.

No presente projeto, desenvolvemos métodos de representação por nuvens de pontos, 
motivados pela proposta de elaborar abordagens que utilizassem métodos numéricos de aproximação superficial computacionalmente interessantes, tanto para a computação gráfica quanto para a mecânica dos fluidos computacional.

A nossa primeira proposta foi uma técnica de partição da unidade implícita adaptativa em duas vias, pois $i$ ) fazemos uso da triangulação algébrico-adaptativa $J_{1}^{a}$ para a decomposição espacial e para a poligonalização, e $i$ i) também de uma base de polinômios para o método dos mínimos-quadrados, que permite aumentar o grau da aproximação polinomial, a partir de cálculos previamente executados. Tais fatos produzem um método capaz de refinar localmente a solução, aumentando o grau da aproximação local, antes de realizar um refinamento na triangulação $J_{1}^{a}$. Propusemos também três extensões: modelagem de características afiadas, melhoramento da malha triangular superficial do modelo e edição interativa da função implícita. Os resultados alcançados foram mais robustos que o método original [158], sem aumentar significativamente o custo computacional.

Outras duas abordagens de representação por nuvens de pontos foram propostas. Por meio delas, buscamos desenvolver mecanismos que fossem capazes de representar fielmente os objetos originais, porém diminuindo o custo computacional, principalmente os cálculos matriciais relacionados com o método dos mínimos-quadrados. Apresentamos diversos exemplos e algumas comparações, contudo diversas questões em aberto precisam ser investigadas em relação a esses métodos, principalmente questões pertinentes à validação matemática dessas abordagens.

A segunda contribuição da tese refere-se a um método Lagrangeano de acompanhamento de fronteiras livre de malhas que utiliza mínimos-quadrados-móveis-algébricos [97]. Diferente de outras abordagens Lagrangeanas [210, 208, 209, 194], que geram a preocupação da consistência topológica da malha ao ser transportada, nosso método foi capaz de representar interfaces por um conjunto de pontos não-organizados que são transportados sem levar em consideração essa preocupação. Além desse fato, também propusemos uma formulação algébrica dos mínimos-quadrados-móveis, que faz uso dos vetores normais, livres de parâmetros de penalidade, capaz de aumentar a robustez do 
método e reduzir o custo computacional. Para a realização do acompanhamento da fronteira, utilizamos princípios do algoritmo de traçado-de-raios, popular em computação gráfica para simulação de iluminação. Em cada passo de tempo, os pontos eram regerados, mantendo um espaçamento médio entre eles, que permitiu assegurar a qualidade da reconstrução realizada. Apresentamos diversos testes e análises que demonstram a capacidade do nosso método para a representação, tanto de superfícies estáticas, quanto em movimento.

As últimas contribuições da presente tese estão relacionadas com a reconstrução de funções a partir de dados volumétricos não-organizados, contidos em malhas de simulação computacional de fenômenos físicos. Definimos métodos para realizar o rendering de dados originados de malhas com diferente topologia e geometria. O primeiro método que sugerimos faz uso de filtros bilaterais via aproximação robusta e o método dos mínimosquadrados-móveis. Para a solução dos mínimos-quadrados-móveis, novamente optamos pela base de polinômios ortogonais, segundo o produto interno induzido pelas equações normais. No entanto, nesse método, apesar dos resultados satisfatórios, o custo computacional foi proibitivo. Com o intuito de contornar essa restrição, propusemos outra abordagem, na qual utilizamos os mínimos-quadrados-móveis-aproximado iterado, definidos sobre domínios anisotrópicos. Devido à simplicidade do método numérico dessa abordagem, foi possível realizar uma implementação eficiente para GPU e os resultados apresentados foram satisfatórios.

\subsection{Desafios Futuros}

Em relação ao nosso método de partição da unidade implícita, fizemos o uso da triangulação $J_{1}^{a}$ para realizar a decomposição espacial e para a poligonalização. Existem outras estruturas propostas na literatura com potencial para substituir a triangulação $J_{1}^{a}[116,135$, 212, 53]. Para isso, precisamos, inicialmente, pesquisar as propriedades intrínsecas de cada abordagem a fim de, então, realizar implementações e análises comparativas entre esses métodos. Queremos verificar seus impactos mediante a nossa abordagem de partição da 
unidade implícita, tanto ao método de reconstrução quanto às extensões propostas. Tal trabalho, apesar de exaustivo, aparenta ser promissor.

Também a edição interativa via partição da unidade implícita merece uma atenção, pois permite remodelar localmente o objeto pela substituição das aproximações locais. O primeiro investimento consistirá em melhorar a interface gráfica e adicionar outros tipos de aproximações locais, por exemplo, splines, funções trigonométricas e formas geométricas predefinidas (por exemplo, cubos, prismas, esferas). A interatividade da seleção de blocos também pode ser aprimorada para permitir a seleção de mais de um bloco por vez e, conseqüentemente, aprimorar a navegação pela triangulação $J_{1}^{a}$. Queremos tornar essa ferramenta útil para outras áreas.

Sobre os aspectos teóricos, nossa abordagem faz uso de parâmetros para a definição dos limites de recobrimento, cujos valores padrões foram escolhidos empiricamente. Almejamos derivar limites teóricos a respeito dos critérios de recobrimento do domínio. Também pretendemos utilizar suportes que sejam definidos conforme a decomposição do domínio, por exemplo, suportes que respeitem formas de cubos ou de tetraedros [193]. Além dessas contribuições, um aspecto que não foi estudado em todos os métodos de partição da unidade implícita e, certamente, merece atenção é o estudo da convergência dos métodos e a verificação da capacidade dos métodos em fornecer informações "matematicamente enriquecidas".

Com respeito à geração de malhas volumétricas com qualidade, queremos investigar a possibilidade de adaptação do método de Labelle \& Shewchuk [122], para a geração de malhas tetraedrais com garantia de qualidade, para a triangulação $J_{1}^{a}$ e a partição da unidade implícita que propusemos.

Até o presente momento, não investimos na análise numérica do nosso método de aproximação de superfícies guiada por curvaturas, no qual apresentamos apenas resultados de ordem qualitativa. Contudo, realizaremos a mesma análise de convergência conduzida pelo nosso método RAMLS. Para isso, pretendemos gerar as normais para cada ponto da nuvem, utilizando o AMLS, e, então, comparar a presente técnica com o RAMLS. 
Pretendemos também reformular a abordagem para eliminar a equação do calor. Para isso, a nossa intenção é partir do princípio de um método de penalidade em relação a uma aproximação local polinomial utilizando, em vez de vetores normais, as curvaturas principais. Finalmente, como as curvaturas produzem uma informação local sobre o objeto, elas podem ser utilizadas para auxiliar a identificação de características afiadas, como feito por Lipman et al. [137] e também podem ser utilizadas em métodos de rendering que fazem uso de informações diferenciais, por exemplo os differential points [113].

Em relação ao nosso método de representação a partir de nuvens de pontos, baseado em iaMLS, tentaremos validá-lo e propor mecanismos de garantir aproximações de alta ordem. Nessas duas abordagens preliminares não fomos capazes de explorar minuciosamente as propriedades e também não realizamos comparações quantitativas e análises numéricas. Dessa maneira, como os resultados foram promissores, seria interessante, como trabalho futuro, investigar as propriedades matemáticas desses métodos.

O nosso método de acompanhamento de fronteiras sugeriu diversas direções futuras. A primeira que analizaremos é a capacidade de mudança topológica, que gera dois tipos de problemas: o primeiro, e que já possui algumas soluções adequadas, ocorre quando dois objetos distintos se unem, e, nesse caso, o tratamento já é bem documentado na literatura; o segundo, acontece quando um objeto ou se rompe ou realiza uma interseção com ele mesmo (caso de ondas do mar). Tal problema é mais complexo, principalmente quando se pretende manter a qualidade da solução numérica.

Outro assunto que devemos investigar é a elaboração de uma metodologia que seja convergente para o cálculo da curvatura no caso tridimensional, tarefa de suma importância em simulações com superfícies livres. A opção mais imediata para esse tipo de abordagem é considerar bases com mais termos que a da esfera algébrica e também fazer o parâmetro $\beta$ tender ao infinito.

Testes futuros consistirão em elaborar mecanismos para a geração e re-geração de pontos no domínio utilizando a malha em que está se realizando a simulação numérica, em vez da criação da "grade de raios". Além disso, pretendemos acoplar a abordagem de 
Lipman et al. para redistribuir pontos sobre a superfície [138] por meio de um esquema previsor-corretor, já que esse método é garantidamente de ordem $O\left(h^{2}\right)$. Por fim, também buscaremos não realizar a re-geração de pontos a todo passo de tempo, como no método de Hieber e Koumoutsakos [104], pois, além de estarmos diminuindo o custo computacional, também evitaríamos o problema de difusão da solução, como ocorrido no teste do Zalesak 3D.

Cabe também estudar a inclusão de anisotropia no RAMLS para evitar que os pontos sejam definidos de forma a manterem um espaçamento médio constante. Uma estrutura candidata para auxiliar nessa tarefa é a triangulação $J_{1}^{a}$, que, nesse caso, seria a responsável pelo refinamento e engrossamento local do objeto.

Estamos estendendo o trabalho de Cohen-Steiner et al. [55], que é aplicado em modelos definidos por malhas, para agrupamento de nuvens de pontos (Figura 7.1). Acreditamos que a utilização desses agrupamentos pode ser útil tanto para nosso método de partição da unidade implícita, quanto para o método de acompanhamento de fronteiras, pois, com esse mecanismo, podemos identificar se estamos utilizando pontos de duas partes da superfície. Dessa forma, no caso de partição da unidade implícita, a ferramenta auxiliaria no critério de refinamento e na escolha da função local. Já no caso do método de acompanhamento de fronteiras, acreditamos que esse mecanismo pode auxiliar na detecção de alterações topológicas.

Para os métodos de representação de dados volumétricos que apresentamos, primeiramente precisamos realizar mais estudos com respeito a comparações quantitativas. Já em relação a nosso método de representação utilizando iaMLS, o investimento futuro imediato será a análise de desempenho e o estudo do conjunto de parâmetros ótimos para o método, de forma similar à conduzida por Fasshauer e Zhang [77]. Além desse trabalho, o uso de funções geradoras de alta ordem e a análise de convergência do método também serão realizados. A princípio, mesmo que a análise não seja conduzida de forma analítica, realizaremos esses estudos por meio de testes numéricos. Em relação à implementação, atualmente existe como limitação o fato de as malhas serem convexas devido à implementação realizada na 
GPU.

Em um âmbito menos relacionado às técnicas propostas, é interessante definir uma taxonomia e conjuntos de casos-testes para a análise dos métodos de representação por nuvens de pontos. Como vimos no Capítulo 5, em mecânica dos fluidos é comum análises comparativas, tanto qualitativas quanto quantitativas. Conseqüentemente, existem diversos casos-testes que são utilizados para a verificação da eficiência de um método. Pretendemos definir um conjunto de casos-testes que sejam capazes de inferir os seguintes aspectos de um método de representação por nuvens de pontos (a princípio):

- Ordem de convergência do método;

- Ordem de complexidade - tempo de processamento;

- Ordem de complexidade - memória requerida;

- Estabilidade numérica e robustez do método;

- Capacidade de lidar de forma eficiente com dados ruidosos;

- Capacidade de lidar com dados massivos;

- Garantias de reconstrução e quais as condições de amostragem;

- Necessidade de vetores normais;

- Processamento de características afiadas;

- Capacidade de identificar múltiplas componentes conexas;

- Capacidade representação de superfícies não-orientadas;

- Método automático ou semi-automático (número de parâmetros).

Ainda há muito que se pesquisar sobre as questões aqui levantadas. Esperamos, portanto, que nossas contribuições, além de terem sido relevantes para as áreas interessadas, 
tenham aberto novos caminhos de pesquisa, como o intuito de enriquecer o universo dos métodos de representação por nuvens de pontos e áreas afins da computação gráfica.

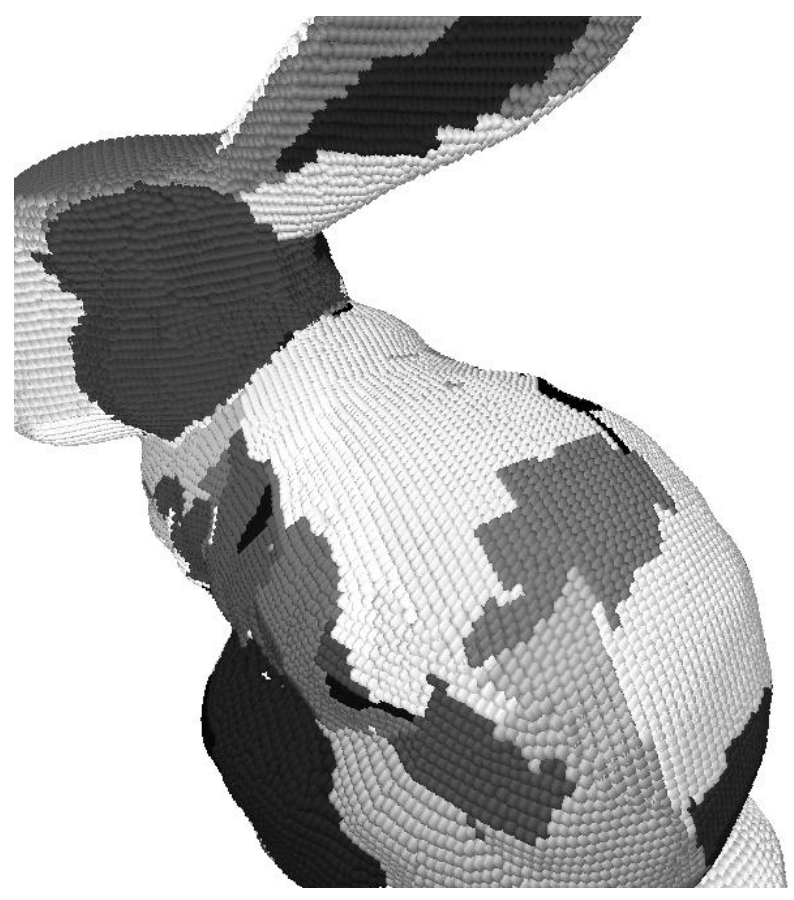

Figura 7.1: Resultado preliminar do agrupamento de pontos baseado no trabalho de CohenSteiner et al. [55]. 


\section{REFERÊNCIAS BIBLIOGRÁFICAS}

[1] B. Adams e P. Dutré. Interactive boolean operations on surfel-bounded solids. ACM Trans. Graph., 22(3):651-656, 2003.

[2] A. Adamson e M. Alexa. Approximating and intersecting surfaces from points. Em Proc. of Eurographics/ACM Symposium on Geometry Processing, páginas 230-239. Eurographics Assoc., 2003.

[3] A. Adamson e M. Alexa. Ray-tracing point set surfaces. Em Proceedings of the Shape Modeling International, páginas 272-279, 2003.

[4] A. Adamson e M. Alexa. Anisotropic point set surfaces. Em Afrigraph '06: Proceedings of the 4th international conference on virtual reality, computer graphics, visualisation e interaction in Africa, páginas 7-13, USA, 2006. ACM Press.

[5] U. Adamy, J. Giesen, e M. John. Surface reconstruction using umbrella filters. Computational Geometry Theory and Applications, 21:63-86, 2002.

[6] G. Agam eX. Tang. A sampling framework for accurate curvature estimation in discrete surfaces. IEEE Transactions on Visualization and Computer Graphics, 11(5):573-583, 2005.

[7] M. Alexa e A. Adamson. On normals and projection operators for surfaces defined by point sets. Em Proceeding of Eurographics Symposium on Point-Based Graphics, páginas 149-155, 2004.

[8] M. Alexa, J. Behr, D. Cohen-Or, S. Fleishman, D. Levin, e C. T. Silva. Point set surfaces. Em VIS '01: Proceedings of the conference on Visualization '01, páginas 21-28, USA, 2001. IEEE Computer Society.

[9] M. Alexa, J. Behr, D. Cohen-Or, S. Fleishman, D. Levin, e C. T. Silva. Computing and rendering point set surfaces. IEEE Transactions on Visualization and Computer Graphics, 9(1):3-15, 2003.

[10] P. Alfeld. Scattered data interpolation in three or more variables. In T. Lyche e L. Schumaker, editores, Mathematical Methods in Computer Aided Geometric Design, páginas 1-34. 1989. 
[11] N. Amenta e M. Bern. Surface reconstruction by voronoi filtering. Discrete and Computational Geometry, 22:481-504, 1999.

[12] N. Amenta, M. Bern, e M. Kamvysselis. A new voronoi-based surface reconstruction algorithm. Em SIGGRAPH '98: Proceedings of the 25th annual conference on Computer graphics and interactive techniques, páginas 415-421, USA, 1998. ACM Press.

[13] N. Amenta, S. Choi, T. K. Dey e N. Leekha. A simple algorithm for homeomorphic surface reconstruction. Em SCG '00: Proceedings of the sixteenth annual symposium on Computational geometry, páginas 213-222, USA, 2000. ACM Press.

[14] N. Amenta, S. Choi e R. Kolluri. The power crust. Em 6th ACM Symposium on Solid Modeling, 249-260, 2001.

[15] N. Amenta, S. Choi e R. Kolluri. The power crust, unions of balls and the medial axis transform. Computational Geometry: Theory and Applications, 19(2-3):127-153, 2001.

[16] N. Amenta and Y. J. Kil. Defining point-set surfaces. ACM Trans. Graph., 23(3):264-270, 2004.

[17] N. Amenta and Y. J. Kil. The domain of a point set surfaces. In M. Gross, H. Pfister, M. Alexa e S. Rusinkiewicz, editores, Eurographics Symposium on Pointbased Graphics, páginas 139-147, PO Box 16, CH-1288 Aire-laVille, Switzerland, 2004. Eurographics Association.

[18] D. Attali. r-regular shape reconstruction from unorganized points. Computational Geometry, 10(4):239-247, July 1998.

[19] M. Attene and M. Spagnuolo. Automatic surface reconstruction from point sets in space. Computer Graphics Forum, 19(3):9, 2000.

[20] I. Babuška, U. Banerjee e J. Osborn. Survey of meshless and generalized finite element methods: A unified approach. Acta Numerica, 12:1-125, 2003.

[21] C. L. Bajaj, F. Bernardini e G. Xu. Automatic reconstruction of surfaces and scalar fields from 3d scans. Em SIGGRAPH '95: Proceedings of the 22nd annual conference on Computer graphics and interactive techniques, páginas 109-118, USA, 1995. ACM Press.

[22] R. H. Bartels and J. J. Jezioranski. Algorithm 634: Constr and eval: routines for fitting multinomials in a least-squares sense. ACM Trans. Math. Softw., 11(3):218-228, 1985. 
[23] R. H. Bartels and J. J. Jezioranski. Least-squares fitting using orthogonal multinomials. ACM Transactions on Mathematical Software, 11(3):201-217, 1985.

[24] G. K. Batchelor and G. K. Batchelor. An Introduction to Fluid Dynamics. Cambridge University Press, February 2000.

[25] J. Bell, P. Colella e H. Glaz. A 2nd-order projection method for the incompressible navier-stokes equations. Journal of Computational Physics, 2(85):257-283, 1989.

[26] T. Belytschko, Y. Guo, W. K. Liu e S. Xiao. A unified stability analysis of meshless particle methods. Int. J. Numer. Meth. Engng., 48:1359-1400, 2000.

[27] F. Bernardini and C. Bajaj. Sampling and reconstructing manifolds using alpha-shapes. Em Proc. 9th Canad. Conf. Comput. Geom, páginas 193-198, 1997.

[28] F. Bernardini, C. L. Bajaj, J. Chen e D. Schikore. Automatic reconstruction of 3d cad models from digital scans. International Journal of Computational Geometry and Applications, 9(4/5):327-369, 1999.

[29] F. Bernardini, J. Mittleman, H. Rushmeier, C. Silva e G. Taubin. The ball-pivoting algorithm for surface reconstruction. IEEE Transactions on Visualization and Computer Graphics, 5(4):349-359, 1999.

[30] Å. Björck. Numerical Methods for Least Squares Problems. SIAM, Philadelphia, 1996.

[31] M. M. Blane, Z. Lei, H. Çivi e D. B. Cooper. The $3 \ell$ algorithm for fitting implicit polynomial curves and surfaces to data. IEEE Trans. Pattern Anal. Mach. Intell., 22(3):298-313, 2000.

[32] J. Bloomenthal. Polygonization of implicit surfaces. Comput. Aided Geom. Des., 5(4):341-355, 1988.

[33] J. Bloomenthal. An implicit surface polygonizer. In P. Heckbert, editor, Graphics Gems $I V$, páginas 324-349. Academic Press, Boston, 1994.

[34] J.-D. Boissonnat. Geometric structures for three-dimensional shape representation. ACM Transactions on Graphics, 3(4):266-286, 1984.

[35] J.-D. Boissonnat and F. Cazals. Smooth surface reconstruction via natural neighbour interpolation of distance functions. Computational Geometry, 22(1-3):185-203, May 2002. 
[36] M. Bolitho, M. Kazhdan, R. Burns e H. Hoppe. Multilevel streaming for out-of-core surface reconstruction. Em SGP '07: Proceedings of the fifth Eurographics symposium on Geometry processing, páginas 69-78, Aire-la-Ville, Switzerland, Switzerland, 2007. Eurographics Association.

[37] A. Bordignon, T. Lewiner, H. Lopes, G. Tavares e R. Pereira. Point set compression through BSP quantization. Em 19th Brazilian Symposium on Computer Graphics and Image Processing, páginas 229-236, Manaus, AM, october 2006.

[38] I. Braude, J. Marker, K. Museth, J. Nissanov e D. Breen. Communicated by hans-peter seidel: Contour-based surface reconstruction using mpu implicit models. Graph. Models, 69(2):139-157, 2007.

[39] A. Brito. Blender 3d - Guia do Usuário. Novatec, segunda edição, 2007.

[40] H. Bíscaro, A. Castelo, L. Nonato e M. Oliveira. A topological approach for surface reconstruction from sample points. The Visual Computer, 23(9-11):793-801, 2007.

[41] R. L. Burden and J. D. Faires. Numerical Analysis. PWS Publishing Co., USA, quarta edição, 1989.

[42] R. Caiden, R. P. Fedkiw e C. Anderson. A Numerical Method for Two-Phase Flow Consisting of Separate Compressible and Incompressible Regions. J. Comput. Phys., 166:1-27, 2001.

[43] M. P. D. Carmo. Differential Geometry of Curves and Surfaces. Prentice-Hall, 1976.

[44] J. C. Carr, R. K. Beatson, J. B. Cherrie, T. J. Mitchell, W. R. Fright, B. C. McCallum e T. R. Evans. Reconstruction and representation of $3 \mathrm{~d}$ objects with radial basis functions. Em SIGGRAPH '01, páginas 67-76, 2001.

[45] P. Carrica, R. Wilson e F. Stern. Unsteady RANS simulation for the forward speed diffraction problem. Computers and Fluids, 35:545-570, 2006.

[46] P. Carrica, R. Wilson e F. Stern. An unsteady single-phase level set method for viscous free surface flows. Int. J. Numer. Meth. Fluids, 53:229-256, 2007.

[47] A. Castelo. Aproximação adaptativa de variedades implícitas com aplicações na modelagem implícita e em equações algébrico-diferenciais. Tese de Doutorado, Departamento de Matemática, Pontifícia Universidade Católica, Rio de Janeiro, Brasil, 1992. 
[48] A. Castelo, L. G. Nonato, M. Siqueira, R. Minghim e G. Tavares. The jla triangulation: An adaptive triangulation in any dimension. Computer \& Graphics, 30(5):737-753, 2006.

[49] A. Castelo, M. Tomé, C. César, S. McKee e J. Cuminato. Freeflow: an integrated simulation system for three-dimensional free surface flows. Computing Visualization in Science, 2:199-210, 2000.

[50] E. Catmull and R. Rom. A class of local interpolating splines. Computer Aided Geometric Design, 21(1):317-326, 1974.

[51] Y.-L. Chen and S.-H. Lai. A partition-of-unity based algorithm for implicit surface reconstruction using belief propagation. Em IEEE International Conference on Shape Modeling and Applications, páginas 147-155, 2007.

[52] S. Choi and N. Amenta. Delaunay triangulation programs on surface data. Em The 13th ACM-SIAM Symposium on Discrete Algorithms, páginas 135-136, 2002.

[53] P. Cignoni, F. Ganovelli, E. Gobbetti, F. Marton, F. Ponchio e R. Scopigno. Adaptive tetrapuzzles: efficient out-of-core construction and visualization of gigantic multiresolution polygonal models. ACM Trans. Graph., 23(3):796-803, 2004.

[54] C. S. Co, S. D. Porumbescu e K. I. Joy. Meshless isosurface generation from multiblock data. Em Proceedings of Eurographics/IEEE TCVG Symposium on Visualization VisSym, páginas 273-281, 2004.

[55] D. Cohen-Steiner, P. Alliez e M. Desbrun. Variational shape approximation. Em SIGGRAPH '04: ACM SIGGRAPH 2004 Papers, páginas 905-914, USA, 2004. ACM.

[56] B. Curless and M. Levoy. A volumetric method for building complex models from range images. Em SIGGRAPH '96: Proceedings of the 23rd annual conference on Computer graphics and interactive techniques, páginas 303-312, USA, 1996. ACM Press.

[57] P. J. Davis. Interpolation and Approximation. Blaisdell, primeira edição, 1963.

[58] L. H. de Figueiredo, J. M. Gomes, D. Terzopoulos e L. Velho. Physically-based methods for polygonization of implicit surfaces. Em Proc. of the conference on Graphics interface '92, páginas 250-257, 1992.

[59] M. deBerg, M. van Kreveld, M. Overmars e O. Schwarzkopf. Computational Geometry: Algorithms and Applications. Springer-Verlag, 1997. 
[60] T. K. Dey. Curve and Surface Reconstruction: Algorithms with Mathematical Analysis. Cambridge University Press, primeira edição, 2006.

[61] T. K. Dey and S. Goswami. Tight cocone : A water-tight surface reconstruction. Relatório Técnico, The Ohio State University, 2002.

[62] T. K. Dey and S. Goswami. Provable surface reconstruction from noisy samples. Em Proceedings of the twentieth annual symposium on Computational Geometry, páginas 330-339. ACM Press, 2004.

[63] T. K. Dey and J. Sun. An adaptive mls surface for reconstruction with guarantees. Em SGP '05: Proceedings of the third Eurographics symposium on Geometry processing, page 43, Aire-la-Ville, Switzerland, Switzerland, 2005. Eurographics Association.

[64] H. Q. Dinh, G. Turk e G. Slabaugh. Reconstructing surfaces using anisotropic basis functions. Em International Conference on Computer Vision (ICCV), páginas 606-613, 2001.

[65] Y. Dobashi, T. Yamamoto e T. Nishita. Radiosity for point-sampled geometry. Em PG '04: Proceedings of the Computer Graphics and Applications, 12th Pacific Conference on (PG’04), páginas 152-159, USA, 2004. IEEE Computer Society.

[66] H. Edelsbrunner. Shape reconstruction with delaunay complex. In A. V. M. C.L. Lucchesi, editor, LATIN'98: Theoretical Informatics, LNCS 1380, 1998.

[67] H. Edelsbrunner. Geometry and Topology for Mesh Generation. Cambridge Monographs on Applied and Computational Mathematics. Cambridge, 2001.

[68] H. Edelsbrunner. Surface reconstruction by wrapping finite sets in space. Relatório Técnico, Raindrop Geomagic, 2002.

[69] H. Edelsbrunner and J. Harer. Jacobi sets of multiple morse functions. Foundations of Computational Mathematics, Minneapolis, eds. F. Cucker, R. DeVore, P. Olver and E. Sueli, Cambridge Univ. Press, England,, páginas 37-57, 2002.

[70] H. Edelsbrunner and E. P. Mücke. Three-dimensional alpha-shapes. ACM Transaction on Graphics, 13(1):43-72, 1994.

[71] M. Elad. On the origin of the bilateral filter and ways to improve it. IEEE Transactions on Image Processing, 11(10):1141-1151, 2002.

[72] D. Enright, R. Fedkiw, J. Ferziger e I. Mitchell. A Hybrid Particle Level Set Method for Improved Interface Capturing. J. Comput. Phys., 183:83-116, 2002. 
[73] D. Enright, F. Losasso e R. Fedkiw. A fast and accurate semi-Lagrangian particle level set method. Computers and Structures, 83:479-490, 2005.

[74] G. Fasshauer. Approximate moving least-squares approximation: A fast and accurate multivariate approximation method. Em Curve and Surface Fitting, páginas 139-148. Nashboro Press, 2002.

[75] G. Fasshauer. Matrix-free multilevel moving least-squares methods. In C. K. C. L. L. Schumaker and J. Stöckler, editores, Approximation Theory X: Wavelets, Splines, and Applications, páginas 271-281, 2002.

[76] G. Fasshauer. Toward approximate moving least squares approximation with irregularly spaced centers. Computer Methods in Applied Mechanics \& Engineering, 193:1231-1243, 2004.

[77] G. Fasshauer and J. Zhang. Iterated approximate moving least squares approximation. In C. A. V. M. A. Leitao and C. A. Duarte, editores, Advances in Meshfree Techniques, page to appear. Springer, 2007.

[78] G. Fasshauer and J. Zhang. Scattered data approximation of noisy data via iterated moving least squares. In T. Lyche, J. L. Merrien e L. L. Schumaker, editores, Curve and Surface Fitting, páginas 150-159. Eurographics Association, 2007.

[79] M. Fenn and G. Steidl. Robust local approximation of scattered data, volume 31 of Computational Imaging and Vision, páginas 317-334. Springer-Verlag, 2005.

[80] S. Fleishman, D. Cohen-Or e C. T. Silva. Robust moving least-squares fitting with sharp features. ACM Trans. Graph., 24(3):544-552, 2005.

[81] M. S. Floater, G. K'os e M. Reimers. Mean value coordinates in 3d. Computer Aided Geometric Design, 22(7):623-631, 2005.

[82] G. Forsythe. Geration an use of orthogonal polynomials for data-fitting with a digital computer. J. Soc. Indust. Appl. Math., 5:74-88, 1957.

[83] R. Franke and G. M. Nielson. Smooth interpolation of large sets of scattered data. International Journal for Numerical Methods in Engineering, 15(11):1691-1704, 1980.

[84] R. Franke and G. M. Nielson. Focus on Scientific Visualization, chapter Scattered data interpolation and applications: A tutorial and survey, páginas 131-159. SpringerVerlag, 1995. 
[85] W. Gander, G. H. Golub e R. Strebel. Least-squares fitting of circles and ellipses. In editorial board Bulletin Belgian Mathematical Society, editor, Numerical analysis (in honour of Jean Meinguet), páginas 63-84, 1996.

[86] J. Giesen and M. John. Surface reconstruction based on a dynamical system. Computer Graphics Forum, 21(3):363, September 2002.

[87] O. Gloth, D. Hänel, L. Tran e R. Vilsmeier. A front tracking method on unstructured grids. Computers \& Fluids, 32:547-570, 2003.

[88] J. P. Gois. Reconstrução de superfícies a partir de nuvens de pontos. Dissertação de Mestrado, Instituto de Ciências Matemáticas e de Computação, Universidade de São Paulo, 2004.

[89] J. P. Gois, A. C. Filho, L. G. Nonato e H. H. Bíscaro. Surface reconstruction: Classification, comparisons and applications. Em Proceedings of XXV CILAMCE Iberian Latin American Congress on Computational Methods, 2004.

[90] J. P. Gois, V. Polizelli-Junior, T. Etiene, E. Tejada, A. Castelo, T. Ertl e L. G. Nonato. Robust and adaptive surface reconstruction using partition of unity implicits. Em Brazilian Symposium on Computer Graphics and Image Processing, páginas 95-102, 2007.

[91] J. P. Gois, E. Tejada, T. Etiene, L. G. Nonato, A. Castelo e T. Ertl. Curvature-driven modeling and rendering of point-based surfaces. Em Brazilian Symposium on Computer Graphics and Image Processing, páginas 27-36. IEEE CS, 2006.

[92] R. Goldman. Curvature formulas for implicit curves and surfaces. Computer Aided Geometric Design, 22(7):632-658, 2005.

[93] G. Golub and C. V. Loan. Matrix Computations. Johns Hopkins Press, segunda edição, 1989.

[94] D. González, E. Cueto, F. Chinesta e M. Doblaré. A natural element updated lagrangian strategy for free-surface fluid dynamics. J. Comput. Phys., 223(1):127-150, 2007.

[95] M. H. Gross, L. Lippert, R. Dittrich e S. Häring. Two methods for wavelet-based volume rendering. Computers and Graphics, 21(2):237-252, 1997.

[96] GSL. Gsl - gnu scientific library - http://www.gnu.org/software/gsl/. novembro/2007.

[97] G. Guennebaud and M. Gross. Algebraic point set surfaces. Em SIGGRAPH '07: ACM SIGGRAPH 2007 papers, artigo 23, USA, 2007. ACM. 
[98] X. Guo, J. Hua e H. Qin. Touch-based haptics for interactive editing on point set surfaces. IEEE Comput. Graph. Appl., 24(6):31-39, 2004.

[99] M. Hall and J. Warren. Adaptive polygonalization of implicitly defined surfaces. Computer Graphics and Applications, IEEE, 10(6):33-42, Nov. 1990.

[100] B. C. D. Hansen and C. R. Johnson. The Visualization Handbook. Elsevier, 2005.

[101] J. C. Hart. Distance to an ellipsoid, páginas 113-119. Academic Press Professional, Inc., USA, 1994.

[102] J. C. Hart. Sphere tracing: A geometric method for the antialiased ray tracing of implicit surfaces. The Visual Computer, 12(10):527-545, 1996.

[103] T. Hastie, R. Tibshirani e J. H. Friedman. The Elements of Statistical Learning. Springer, August 2001.

[104] S. Hieber and P. Koumoutsakos. A Lagrangian particle level set method. J. Comput. Phys., 210:342-367, 2005.

[105] C. Hirsch. Numerical Computational of Internal and External Flows, volume 1. A Wiley-Interscience Publication, 1989.

[106] W. Hong, N. Neophytou, K. Mueller e A. Kaufman. Constructing 3d elliptical gaussians for irregular data. Em Mathematical Foundations of Scientific Visualization, Computer Graphics, and Massive Data Exploration. Springer, 2006.

[107] H. Hoppe, T. DeRose, T. Duchampy, J. McDonaldz e W. Stuetzlez. Surface reconstruction from unorganized points. Computer Graphics, 26(2):71-78, 1992.

[108] J. Huang and C. H. Menq. Combinatorial manifold mesh reconstruction and optimization from unorganized points with arbitrary topology. Computer-Aided Design, 34:149-165, February 2002.

[109] A. Huerta, T. Belytschko, S. Fernandez-Mendez e S. Rabczuk. Meshfree methods, volume 1, páginas 279-309. Wiley, 2004. in Encyclopedia of Computational Mechanics, Stein, E., de Borst, R. and Hughes T. J. R. (eds.).

[110] E. Isaacson and H. B. Keller. Analysis of Numerical Methods. John Wiley \& Sons, 1966.

[111] Y. Jang, R. P. Botchen, A. Lauser, D. S. Ebert, K. P. Gaither e T. Ertl. Enhancing the Interactive Visualization of Procedurally Encoded Multifield Data with Ellipsoidal Basis Functions. Em Proceedings of Eurographics, page 587. Eurographics Association, 2006. 
[112] Y. Jang, M. Weiler, M. Hopf, J. Huang, D. S. Ebert, K. P. Gaither e T. Ertl. Interactively Visualizing Procedurally Encoded Scalar Fields. Em Proceedings of VisSym, páginas 35-44, 2004.

[113] A. Kalaiah and A. Varshney. Differential point rendering. Em Proceedings of the 12th Eurographics Workshop on Rendering Techniques, páginas 139-150. Springer-Verlag, 2001.

[114] M. Kazhdan. Reconstruction of solid models from oriented point sets. Eurographics Symposium on Geometry Processing, 2005:73-82, 2005.

[115] M. Kazhdan, M. Bolitho e H. Hoppe. Poisson surface reconstruction. Em Proceedings of Eurographics Symposium on Geometry Processing, 2006.

[116] M. Kazhdan, A. Klein, K. Dalal e H. Hoppe. Unconstrained isosurface extraction on arbitrary octrees. Em Eurographics Symposium on Geometry processing, páginas 125133, 2007.

[117] L. Kobbelt and M. Botsch. A survey of point-based techniques in computer graphics. Computers and graphics, 28(6):801-814, 2004.

[118] L. P. Kobbelt, M. Botsch, U. Schwanecke e H.-P. Seidel. Feature sensitive surface extraction from volume data. Em SIGGRAPH'01, páginas 57-66, USA, 2001. ACM Press.

[119] R. Kolluri. Provably good moving least squares. Em SODA '05: Proc. of the 16th annual ACM-SIAM symposium on Discrete algorithms, páginas 1008-1017, 2005.

[120] R. K. Kolluri, J. R. Shewchuk e J. F. OB́rien. Spectral watertight surface reconstruction. Em Proceedings of the SIGGRAPH 2003 conference on Sketches \& applications, 2003.

[121] P. Koumoutsakos. Multiscale flow simulations using particles. Annu. Rev. Fluid Mech., 37:457-487, 2005.

[122] F. Labelle and J. R. Shewchuk. Isosurface stuffing: fast tetrahedral meshes with good dihedral angles. Em SIGGRAPH '07: ACM SIGGRAPH 2007 papers, artigo 57, USA, 2007. ACM.

[123] B. Lafaurie, C. Nardone, R. Scardovelli, S. Zaleski e G. Zanetti. Modelling Merging and Fragmentation in Multiphase Flows with SURFER. J. Comput. Phys., 113:134-147, 1994. 
[124] D. Lakehal, M. Meier e M. Fulgosi. Interface tracking towards the direct simulation of heat and mass transfer in multiphase flows. International Journal of Heat and Fluid Flow, 23:242-257, 2002.

[125] P. Lancaster and K. Salkauskas. Surfaces generated by moving least squares methods. Mathematics of Computation, 37(155):141-158, 1981.

[126] C. Lange and K. Polthier. Anisotropic smoothing of point sets. Comput. Aided Geom. Des., 22(7):680-692, 2005.

[127] R. Laramee and R. Bergeron. An isosurface continuity algorithm for super adaptive resolution data. Em Proceedings of Computer Graphics International, páginas 215-237, 2002.

[128] J. Lee, L. C. Burton, R. Machiraju e D. S. Reese. Efficient rendering of multiblock curvilinear grids with complex boundaries: Research articles. Comput. Animat. Virtual Worlds, 16(1):53-68, 2005.

[129] S. Lee, G. Wolberg e S. Y. Shin. Scattered data interpolation with multilevel b-splines. IEEE Transactions on Visualization and Computer Graphics, 3(3):228-244, 1997.

[130] D. Levin. The approximation power of moving least-squares. Mathematics of Computation, 67(224):1517-1531, October 1998.

[131] D. Levin. Mesh-independent surface interpolation. Advances in Computational Mathematics, 2:37-49, 2001.

[132] M. Levoy. Exploring david: Diagnostic tests and state of conservation, 2004.

[133] M. Levoy, K. Pulli, B. Curless, S. Rusinkiewicz, D. Koller, L. Pereira, M. Ginzton, S. Anderson, J. Davis, J. Ginsberg, J. Shade e D. Fulk. The digital michelangelo project: 3d scanning of large statues. Em SIGGRAPH '00: Proceedings of the 27th annual conference on Computer graphics and interactive techniques, páginas 131-144, USA, 2000. ACM Press/Addison-Wesley Publishing Co.

[134] M. Levoy and T. Whitted. The use of points as display primitives. Relatório Técnico, Computer Science Department, University of North Carolina at Chapel Hill, 1985.

[135] T. Lewiner, L. Velho, H. Lopes e V. Mello. Simplicial isosurface compression. Em Vision, Modelling and Visualization, 2004. 
[136] Y. Lipman, D. Cohen-Or e D. Levin. Error bounds and optimal neighborhoods for mls approximation. Em SGP '06: Proceedings of the fourth Eurographics symposium on Geometry processing, páginas 71-80, Aire-la-Ville, Switzerland, Switzerland, 2006. Eurographics Association.

[137] Y. Lipman, D. Cohen-Or e D. Levin. Data-dependent mls for faithful surface approximation. Em SGP '07: Proceedings of the fifth Eurographics symposium on Geometry processing, páginas 59-67, Aire-la-Ville, Switzerland, Switzerland, 2007. Eurographics Association.

[138] Y. Lipman, D. Cohen-Or, D. Levin e H. Tal-Ezer. Parameterization-free projection for geometry reconstruction. ACM Trans. Graph., 26(3):22, 2007.

[139] W. E. Lorensen and H. E. Cline. Marching cubes: A high resolution 3d surface construction algorithm. Em SIGGRAPH '87, páginas 163-169. ACM Press, 1987.

[140] F. Losasso, R. Fedkiw e S. Osher. Spatially adaptive techniques for level set methods and incompressible flow. Computers and Fluids, 35:995-1010, 2006.

[141] J.-L. Maltret and M. Daniel. Discrete curvatures and applications : a survey. Relatório Técnico LSIS.RR.2002.002, Laboratoire des Sciences de l'Information et des Systèmes, 2002.

[142] S. R. Marschner and R. J. Lobb. An evaluation of reconstruction filters for volume rendering. Em VIS '94: Proceedings of the conference on Visualization '94, páginas 100107, USA, 1994. IEEE Computer Society Press.

[143] D. J. Mavriplis. Revisiting the least-squares procedure for gradient reconstruction on unstructured meshes. Relatório Técnico CR-2003-212683, NASA, 2006.

[144] V. Maz'ya. A new approximation method and its applications to the calculation of volume potentia. boundary point method. Em 3. DFG-Koloqium des DFG-Forschungs schwerpunctes 'Randelementmethoden', page 18, 1991.

[145] V. Maz'ya. Approximate approximation in the mathematics of finite elements and applications. Highlights, 77, 1994.

[146] B. Mederos, N. Amenta, L. Velho e L. H. de Figueiredo. Surface reconstruction from noisy point clouds. In M. Desbrun and H. Pottmann, editores, Proceedings Eurographics Symposium on Geometry Processing, 2005.

[147] B. Mederos, S. Arouca, M. Lage, H. Lopes e L. Velho. Improved partition of unity implicit surface reconstruction. Relatório Técnico TR-0406, IMPA, Brazil, 2006. 
[148] B. Mederos, M. Lage, S. Arouca, F. Petronetto, L. Velho, T. Lewiner e H. Lopes. Regularized implicit surface reconstruction from points and normals. Journal of the Brazilian Computer Society, 2007.

[149] B. Mederos, L. Velho e L. H. de Figueiredo. Moving least squares multiresolution surface approximation. Em Proceedings SIBGRAPI 2003, 2003.

[150] B. Mederos, L. Velho e L. H. Figueiredo. Robust smoothing of noisy point clouds. Em Proc. SIAM Conference on Geometric Design and Computing, 2003.

[151] G. MEDIONI, M. LEE e C. TANG. A Computational Framework for Segmentation and Grouping. Elsevier, 2000.

[152] J. Monaghan. Simulating free surface flows with SPH. J. Comput. Phys., 110:399-406, 1994.

[153] B. S. Morse, T. S. Yoo, P. Rheingans, D. T. Chen e K. R. Subramanian. Interpolating implicit surfaces from scattered surface data using compactly supported radial basis functions. Em SIGGRAPH '05: ACM SIGGRAPH 2005 Courses, artigo 78, USA, 2005. ACM.

[154] M. Müller, R. Keiser, A. Nealen, M. Pauly, M. Gross e M. Alexa. Point based animation of elastic, plastic and melting objects. Em SCA '04: Proceedings of the 2004 ACM SIGGRAPH/Eurographics symposium on Computer animation, páginas 141-151, Airela-Ville, Switzerland, Switzerland, 2004. Eurographics Association.

[155] G. M. Nielson. Scattered data modeling. IEEE Computer Graphics and Applications, (1):60-70, 1993.

[156] L. G. Nonato, A. J. Cuadros-Vargas, R. Minghim e M. C. F. D. Oliveira. Beta-connection: Generating a family of models from planar cross sections. ACM Trans. Graph., 24(4):1239-1258, 2005.

[157] E. Oñate, S. Idelsohn, M. Celigueta e R. Rossi. Advances in the particle finite element method for the analysis of fluid-multibody interaction and bed erosion in free surface flows. Comput. Methods Appl. Mech. Engrg., in press, 2007.

[158] Y. Ohtake, A. Belyaev, M. Alexa, G. Turk e H.-P. Seidel. Multi-level partition of unity implicits. ACM Trans. Graph., 22(3):463-470, 2003.

[159] Y. Ohtake, A. Belyaev e H.-P. Seidel. 3d scattered data approximation with adaptive compactly supported radial basis functions. Em SMI '04: Proceedings of the Shape 
Modeling International 2004 (SMI'04), páginas 31-39, USA, 2004. IEEE Computer Society.

[160] Y. Ohtake, A. Belyaev e H.-P. Seidel. Sparse surface reconstruction with adaptive partition of unity and radial basis functions. Graph. Models, 68(1):15-24, 2006.

[161] S. Osher and R. Fedkiw. Level Set Methods and Dynamic Implicit Surfaces, volume 153 of Applied Mathematical Sciences. Springer, 2003.

[162] S. Osher and J. A. Sethian. Front Propagating with Curvature-Dependent Speed: Algorithms Based on Hamilton-Jacobi Formulations. J. Comput. Phys., 79:12-49, 1988.

[163] D. V. Ouellette. Schur complements and statistics. Linear Algebra and its Applications, (36):187-295, 1981.

[164] A. Paiva, H. Lopes, T. Lewiner e L. H. de Figueiredo. Robust adaptive meshes for implicit surfaces. Em Proceedings of SIBGRAPI, 2006.

[165] S. Park, L. Linsen, O. Kreylos, J. D. Owens e B. Hamann. Discrete sibson interpolation. IEEE Transactions on Visualization and Computer Graphics, páginas 243-253, 2006.

[166] M. Pauly, M. Gross e L. P. Kobbelt. Efficient simplification of point-sampled surfaces. Em VIS'02: Proceedings of the conference on Visualization, USA, 2002. IEEE Computer Society.

[167] M. Pauly, R. Keiser, L. P. Kobbelt e M. Gross. Shape modeling with point-sampled geometry. ACM Transactions on Graphics, 22(3):641-650, 2003.

[168] M. Pauly, L. P. Kobbelt e M. Gross. Point-based multiscale surface representation. ACM Trans. Graph., 25(2):177-193, 2006.

[169] W. Philips. Orthogonal base functions on a discrete two-dimensional region. Relatório Técnico DG 91-20, ELIS, RUG, Universiteit Gent, 1992.

[170] Persistence of vision - http://www.porvay.org. novembro/2007.

[171] V. Pratt. Direct least-squares fitting of algebraic surfaces. SIGGRAPH Comput. Graph., 21(4):145-152, 1987.

[172] W. H. Press, B. P. Flannery, S. A. Teukolsky e W. T. Vetterling. Numerical Recipes: The Art of Scientific Computing. Cambridge University Press, primeira edição, 1986. 
[173] P. Reuter, P. Joyot, J. Trunzler, T. Boubekuer e C. Schilick. Surface reconstruction with enriched reproducing kernel particle approximation. Em IEEE/Eurographics PointBased Graphics, 2005.

[174] P. Reuter, I. Tobor, C. Schlick e S. Dedieu. Point-based modelling and rendering using radial basis functions. Em GRAPHITE '03: Proceedings of the 1st international conference on Computer graphics and interactive techniques in Australasia and South East Asia, páginas 111-118, USA, 2003. ACM.

[175] A. Rodriguez, J. M. Espadero, D. Lopez e L. Pastor. Delaunay surface reconstruction from scattered points. Em Proceedings of Discrete Geometry for Computer Imagery 9th International Conference, DGCI, 1994.

[176] C. Rössl, F. Zeilfelder, G. Nürnberger e H.-P. Seidel. Spline approximation of general volumetric data. Em SM '04: Proceedings of the ninth ACM symposium on Solid modeling and applications, páginas 71-82, Aire-la-Ville, Switzerland, Switzerland, 2004. Eurographics Association.

[177] M. Sainz and R. Pajarola. Point-based rendering techniques. Computer \& Graphics, 28(6):869-879, December 2004.

[178] R. Scardovelli and S. Zaleski. Direct numerical simulation of free-surface and interfacial flow. Annu. Rev. Fluid Mech., 31:567-603, 1999.

[179] O. Schall, A. Belyaevand e H.-P. Seidel. Robust filtering of noisy scattered point data. In M. Pauly and M. Zwicker, editors, IEEE/Eurographics Symposium on Point-Based Graphics, páginas 71-77, Stony Brook, 2005. Eurographics Association.

[180] C. E. Scheidegger, S. Fleishman e C. T. Silva. Triangulating point set surfaces with bounded error. Em SGP '05: Proceedings of the third Eurographics symposium on Geometry processing, page 63, Aire-la-Ville, Switzerland, Switzerland, 2005. Eurographics Association.

[181] G. Schmidt. Operator Theory: Advances and Applications, volume 109 of The Maz'ya Anniversary Collection, v.1, chapter Approximate approximations and their applications, páginas 111-136. Birkhäuser, 1999.

[182] J. Schreiner, C. Scheidegger e C. Silva. High-quality extraction of isosurfaces from regular and irregular grids. IEEE Transactions on Visualization and Computer Graphics, 12(5):1205-1212, 2006. 
[183] J. A. Sethian. Fast Marching Methods and Level Set Methods for Propagationg Interfaces. Em von Karman Institute Lecture Series, Computational Fluid Mechanics. 1998.

[184] J. A. Sethian and P. Smereka. Level Set Methods for Fluids Interfaces. Annual Rev. Fluid Mech., 35:341-372, 2003.

[185] A. Sharf, T. Lewiner, A. Shamir, L. Kobbelt e D. Cohen-Or. Competing fronts for coarseto-fine surface reconstruction. Em Eurographics, páginas 389-398, Vienna, september 2006.

[186] C. Shen, J. F. O'Brien e J. R. Shewchuk. Interpolating and approximating implicit surfaces from polygon soup. ACM Transactions on Graphics, 23(3):896-904, 2004.

[187] D. Shepard. A two-dimensional interpolation function for irregularly-spaced data. Em Proceedings of the ACM national conference, páginas 517-524. ACM Press, 1968.

[188] J. R. Shewchuck. What is a good linear element? interpolation, conditioning, and quality measures. Em Eleventh International Meshing Roundtable, páginas 115-126, 2002.

[189] J. R. Shewchuk. An introduction to the conjugate gradient method without the agonizing pain. Relatório técnico, 1994.

[190] R. Shu, C. Zhou e M. S. Kankanhalli. Adaptive marching cubes. The Visual Computer, 11(4):202-217, 1995.

[191] Xix brazilian symposium on computer graphics and image processing-capa. http: / / ieeexplore.ieee.org/xpl/tocresult.jsp?isnumber=4027037\&isYear=2006.

[192] Xx brazilian symposium on computer graphics and image processing-capa. http: / / ieeexplore.ieee.org/xpl/tocresult.jsp?isnumber=4368154\&isYear=2007.

[193] M. Siqueira. Mesh Generation from Imaging Data. Tese de Doutorado, Universidade da Pensilvânia, 2006.

[194] F. Sousa, N. Mangiavacchi, L. Nonato, A. Castelo, M. Tomé, V. Ferreira, J. Cuminato e S. McKee. A front-tracking method for simulation of 3D multifluid flows with free surfaces. J. Comput. Phys., 198:469-499, 2004.

[195] J. V. Stokman, C. F. Dunkl e Y. Xu. Orthogonal polynomials of several variables. Approximation Theory, 112(2):318-319, 2001. 
[196] M. Sussman. A second order coupled level set and volume-of-fluid method for computing growth and collapse of vapor bubbles. J. Comput. Phys., 187:110-136, 2003.

[197] M. Sussman e E. Fatemi. An efficient, interface-preserving level set redistancing algorithm and its aplication to interfacial incompressible fluid flow. SIAM J. Sci Comput., 20(4):1165-1191, 1999.

[198] M. Sussman, E. Fatemi, P. Smereka e S. Osher. An improved level set method for incompressible two-phase flows. Computers \& Fluids, 27(5-6):663-680, 1998.

[199] M. Sussman e E. G. Puckett. A coupled level set and volume-of-fluid method for computing $3 \mathrm{~d}$ and axisymmetric incompressible two-phase flows. J. Comput. Phys., 162:301-337, 2000.

[200] M. Sussman, P. Smereka e S. Osher. A Level Set Approach for Computing Solutions to Incompressible Two-Phase Flow. J. Comput. Phys., 114:146-159, 1994.

[201] G. Taubin. An improved algorithm for algebraic curve and surface fitting. Em 4th Int. Conf. Computer Vision, páginas 658-665, Berlin, 1993.

[202] G. Taubin. Estimating the tensor of curvature of a surface from a polyhedral approximation. Em ICCV '95: Proceedings of the Fifth International Conference on Computer Vision, páginas 902-907, Washington, DC, USA, 1995. IEEE Computer Society.

[203] M. Teichmann e M. Capps. Surface reconstruction with anisotropic density-scaled alpha shapes. Em VIS '98: Proceedings of the conference on Visualization '98, páginas 67-72, USA, 1998. IEEE Computer Society Press.

[204] E. Tejada, J. P. Gois, A. Castelo, L. G. Nonato e T. Ertl. Hardware-accelerated extraction and rendering of point set surfaces. Em EUROGRAPHICS - IEEE VGTC Symposium on Visualization. IEEE \& EUROGRAPHICS, 2006.

[205] I. Tobor, P. Reuter e C. Schlick. Reconstructing multi-scale variational partition of unity implicit surfaces with attributes. Graph. Models, 68(1):25-41, 2006.

[206] W.-S. Tong e C.-K. Tang. Robust estimation of adaptive tensors of curvature by tensor voting. IEEE Trans. Pattern Anal. Mach. Intell., 27(3):434-449, 2005.

[207] D. Torres e J. Brackbill. The point-set method: Front-tracking without connectivity. J. Comput. Phys., 165:620-644, 2000. 
[208] G. Tryggvason, B. Bunner, A. Esmaeeli, D. Juric, N. Al-Rawahi, W. Tauber, J. Han, S. Nas e Y. J. Jan. A Front-Tracking Method for the Computations of Multiphase Flow. J. Comput. Phys., 169:708-759, 2001.

[209] G. Tryggvason, B. Bunner, A. Esmaeeli, D. Juric, N. Al-Rawahi, W. Tauber, J. Han, S. Nas e Y.-J. Jan. A front-tracking method for the computations of multiphase flow. $J$. Comput. Phys., 169:708-759, 2001.

[210] S. Unverdi e G. Tryggvason. A front-tracking method for viscous, incompressible, multi-fluid flows. J. Comput. Phys., 100:25-37, 1992.

[211] J. van de Weijer e R. van den Boomgaard. Least squares and robust estimation of local image structure. International Journal of Computer Vision, 64(2/3):143-155, 2005.

[212] L. Velho e J. Gomes. Variable resolution 4-k meshes. Em SIBGRAPI '00: Proceedings of the 13th Brazilian Symposium on Computer Graphics and Image Processing, páginas 123-130, USA, 2000. IEEE Computer Society.

[213] I. Wald e H. Seidel. Interactive ray tracing of point-based models. Em Eurographics Symposium on Point-Based Graphics, páginas 1-8, 2005.

[214] M. Weiler, R. P. Botchen, S. Stegmaier, J. Huang, Y. Jang, D. Ebert, K. Gaither e T. Ertl. Hardware-assisted Feature Analysis and Visualization of Procedurally Encoded Multifield Volumetric Data. Computer Graphics and Applications, páginas 72-81, 2005.

[215] M. Weisfeld. Orthogonal polynomials in several variables. Numerical Mathematics, 1:38-40, 1959.

[216] E. W. Weisstein. Laguerre polynomial. From MathWorld-A Wolfram Web Resource. http://mathworld.wolfram.com/LaguerrePolynomial.html, 2006.

[217] H. Wendland. Local polynomial reproduction and moving least squares approximation. IMA Journal of Numerical Analysis, 21(1):285-300, 2001.

[218] R. Westermann, L. Kobbelt e T. Ertl. Real-time exploration of regular volume data by adaptive reconstruction of isosurfaces. The Visual Computer, 15(2):100-111, 1999.

[219] M. Wicke, M. Teschner e M. Gross. Csg tree rendering for point-sampled objects. Em Proceedings of the Pacific Graphics, páginas 160-168. IEEE CS, 2004.

[220] R. Wilson, P. Carrica e F. Stern. Simulation of ship breaking bow waves and induced vortices and scars. Int. J. Numer. Meth. Fluids, in press. 
[221] Q. Xia, M. Y. Wang e X. Wu. Orthogonal least squares in partition of unity surface reconstruction with radial basis function. Em Conference on Geometric Modeling and Imaging, páginas 28-33, 2006.

[222] H.-K. Zhao, S. Osher e R. Fedkiw. Fast surface reconstruction using the level set method. Em Proceedings of IEEE Workshop on Variational and Level Set Methods in Computer Vision, 2001., páginas 194-201, 2001.

[223] H.-K. Zhao, S. Osher, B. Merriman e M. Kang. Implicit and nonparametric shape reconstruction from unorganized data using a variational level set method. Comput. Vis. Image Underst., 80(3):295-314, 2000.

[224] M. Zwicker, M. Pauly, O. Knoll e M. Gross. Pointshop 3d: an interactive system for point-based surface editing. ACM Trans. Graph., 21(3):322-329, 2002. 